\title{
Oral Health in New Zealand \\ Findings from the New Zealand Health Survey 2006/07
}

\author{
A thesis \\ submitted in fulfillment \\ of the requirements for the Degree \\ of \\ Master of Science in Applied Statistics \\ by \\ Lisa N Lankshear
}

School of Mathematics Statistics and Operations Research

Victoria University of Wellington

New Zealand

Victoria University of Wellington

2010 


\section{Abstract}

This thesis investigates oral health in New Zealand. This is carried out through an analysis of the New Zealand Health Survey (NZHS) which was undertaken by the Ministry of Health in 2006/07.

The World Health Organisation recognises oral health as an integral part of general health and a basic human right. The New Zealand government also recognises the importance of oral health and aims to be proactive in addressing the needs of those at greatest risk of poor oral health. This analysis identifies those who have poorer oral health and less regular oral health care. The New Zealand goverment also aims for high-quality oral health services that promote, improve, maintain and restore good oral health to all New Zealanders.

The results of the NZHS 2006/07 showed that the mean number of teeth lost due to tooth decay and gum disease in people aged 15 and over is $4.59(4.56,4.61)$. This is strongly associated with age, with younger people having lost fewer teeth. Alcohol as well as fruit and vegetable intake had no association with tooth loss in adults. Fizzy drink intake was not significantly associated with poor child oral health, however a higher number of take away meals eaten by children consistently led to poorer oral health for those children. Ethnicity and deprivation were associated with tooth loss, regularity of oral health care, time since last oral health care visit, unmet oral health care need in the past 12 months and urgent unmet need. Those from more deprived populations had lower rates of regular care and higher rates of need and tooth loss.

The final component of this thesis is a comparison of oral health outcomes over time, using NZHS 2006/07 and the New Zealand data from the WHO International Collaborative Study of Oral Health Outcomes 1988 (ICS II). It was found that in 2006/07 more 12-13 year olds are brushing their teeth 2 or more times a day than in 1998, and that the time since last visit to an oral health care worker for adults has reduced over time. 


\section{Acknowledgments}

I would like to thank my supervisor Richard Arnold for his help, advice, patience and motivation through out this thesis journey and for putting up with me constantly knocking on his door and complaining about how computers hated me.

I would like to thank Health and Disability Intelligence and the Ministry of Health, who supplied the data sets and funding for this thesis. With special thanks to Kylie Mason for being my go to girl within the Ministry of Health.

I would like to thank my partner Chris and my Mum and Dad for financially supporting me while I finished my thesis, and for the proof reading and editing done in the final stages of this thesis, even when they did not understand anything I had written.

I would also like to thank the people I shared an office with while finishing this thesis, especially Ray and Lisa, for keeping the tone light hearted and fun even while work was getting done. 


\section{Contents}

1 Introduction $\quad 11$

1.1 Overall purpose of research . . . . . . . . . . . . . . . . . . . . . . . . . . 11

1.2 Research questions . . . . . . . . . . . . . . . . . . . . . . . . . . . . . . . .

1.3 Research methodology . . . . . . . . . . . . . . . . . . . . . . . . . . . . . . . . . .

1.4 New Zealand Oral Health Survey 2009 . . . . . . . . . . . . . . . . . 13

1.5 Structure of this thesis . . . . . . . . . . . . . . . . . . . . . . . . . . . . . . . . . . .

1.6 Literature review . . . . . . . . . . . . . . . . . . . . . 14

1.6.1 Oral health in New Zealand . . . . . . . . . . . . . . . . 15

1.6.2 Previous international findings . . . . . . . . . . . . . . . . . . 16

1.6.3 Oral health risk factors . . . . . . . . . . . . . 18

2 NZHS Survey Design $\quad 21$

2.1 Survey background . . . . . . . . . . . . . . . . . . . . . . . 21

2.2 Population and frame . . . . . . . . . . . . . . . . . . . . 21

2.3 Sample design and strategy . . . . . . . . . . . . . . . . . . . . . . . . . . . . . . . . . . 22

2.3.1 Primary sampling units . . . . . . . . . . . . . . . . . . . 22

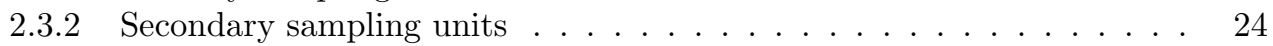

2.3.3 Respondent sampling . . . . . . . . . . . . . . . . 24

2.4 The questionnaire . . . . . . . . . . . . . . . . . . . . . . . . . . . . . . . . . . . . . . . .

2.5 Data collection and response rate . . . . . . . . . . . . . . . 26

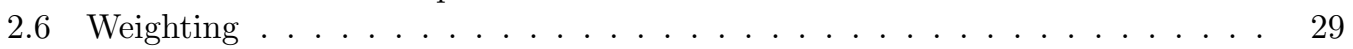

3 Statistical Methods $\quad 31$

3.1 General calculations and notation . . . . . . . . . . . . . . . 31

3.1.1 Descriptive analysis . . . . . . . . . . . . . . . . . . 31

3.1 .2 Single-factor analysis . . . . . . . . . . . . . . . . . . . . . . . . . . . . . . . . 32

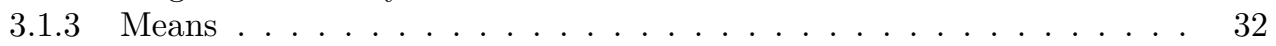

3.2 The jackknife method . . . . . . . . . . . . . . . . . . 32

3.2.1 Significance testing for differences . . . . . . . . . . . . . . . 33

3.3 Regression . . . . . . . . . . . . . . . . . . . . 34

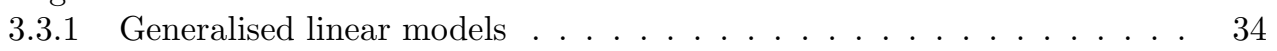

3.3.2 Forms of regression models . . . . . . . . . . . . . . . . . . . . . . . . . . . . . . 35

3.3.3 Logistic regression . . . . . . . . . . . . . . . . . . . . . . . . . . . . . . . . .

3.3 .4 Model interpretation . . . . . . . . . . . . . . . . . . . 36

3.3.5 Ordinal regression . . . . . . . . . . . . . . . . . . . . . 37

3.3.6 Ordinal regression model example . . . . . . . . . . . . . . . . . 38

3.3.7 Model selection and checking . . . . . . . . . . . . . 40

4 Demographic characteristics $\quad 43$

4.1 Adult New Zealand Health Survey 2006/07 . . . . . . . . . . . . . . . . . 43

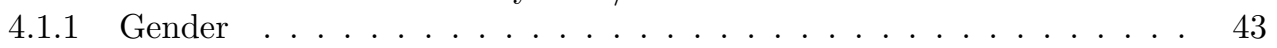

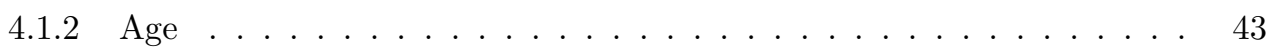

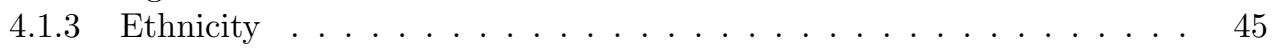


4.1 .4 Deprivation . . . . . . . . . . . . . . . . . 47

4.2 Child New Zealand Health Survey $2006 / 07 \ldots \ldots$. . . . . . . . . 48

5 Exploratory Data Analysis $\quad \mathbf{5 2}$

5.1 New Zealand Health Survey 2006/07 Adult Results . . . . . . . . . . . . . . . 52

5.1 .1 Removal of teeth due to tooth decay or gum disease . . . . . . . . 52

5.1 .2 Regularity of oral health care . . . . . . . . . . . . 57

5.1.3 Time since last visit to an oral health care worker . . . . . . . . . . 59

5.1.4 Unmet oral health care need in the past 12 months . . . . . . . . . . 60

5.1.5 Reasons for unmet oral health care need . . . . . . . . . . . . . . 64

5.1 .6 Urgent unmet oral health care need . . . . . . . . . . . . . . . 64

5.2 New Zealand Health Survey 2006/07 Child Results . . . . . . . . . . . . . 66

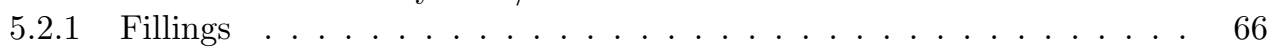

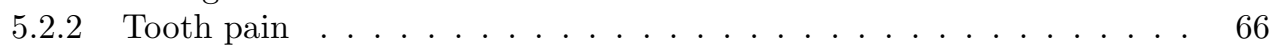

5.2 .3 Tooth removal . . . . . . . . . . . . . . . . . . . . . . . . . . . . 69

5.2 .4 Tooth brushing $\ldots \ldots \ldots \ldots \ldots \ldots \ldots \ldots \ldots \ldots \ldots \ldots \ldots$

5.2 .5 Fizzy drink . . . . . . . . . . . . . . . . . . . . . . . . . 74

5.2 .6 Take-away meals . . . . . . . . . . . . . . . . . . . 76

5.2 .7 Unmet need . . . . . . . . . . . . . . . . . . . . . . . . 80

5.2.8 Time since last visit to an oral health care worker . . . . . . . 80

6 Regression models for oral health outcomes $\quad \mathbf{8 4}$

6.1 Regularity of oral health care . . . . . . . . . . . . . . . . . . 85

6.1.1 Model 1 . . . . . . . . . . . . . . . . . . . . . . . . 85

$6.1 .2 \quad$ Model $2 \ldots \ldots \ldots \ldots$

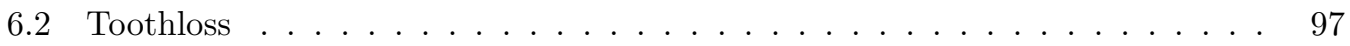

6.2.1 Model $3 \ldots \ldots \ldots$. . . . . . . . . . . . . . . . . . . . . 97

6.2 .2 Model 4 . . . . . . . . . . . . . . . . . . . . . . . . . . . . . . . . . . 101

6.2 .3 Model $5 \ldots \ldots \ldots$. . . . . . . . . . . . . . . . . . . . . . 110

6.2 .4 Model $6 \ldots \ldots \ldots$. . . . . . . . . . . . . . . . . . . 111

$\begin{array}{llr}7 & \text { Survey Comparison } & 117\end{array}$

7.1 ICS II Survey Design . . . . . . . . . . . . . . . . . . . . . . . 117

7.1 .1 Survey Background . . . . . . . . . . . . . . . . . . . . 117

7.1 .2 Population and frame . . . . . . . . . . . . . . . 118

7.1 .3 Sample design and strategy . . . . . . . . . . . . . . . . . 118

7.1.4 Data Collection and response rate . . . . . . . . . . . . . . . . . . . . 119

7.1 .5 The questionnaire . . . . . . . . . . . . . . . . . . . . . . 119

7.1 .6 Weighting . . . . . . . . . . . . . . . . . . . . 120

$7.2 \quad$ ICS II Demographics . . . . . . . . . . . . . . . . . . . . . . . 120

7.2 .1 Adults . . . . . . . . . . . . . . . . . . . . . . . 120

7.2 .2 Students . . . . . . . . . . . . . . . . . . . . . . . . 121

7.3 Data Exploration . . . . . . . . . . . . . . . . . . . . . . 121

7.3 .1 Adults . . . . . . . . . . . . . . . . . . . . . . 121

$7.3 .2 \quad$ Students . . . . . . . . . . . . . . . . . . . . . . . . 123

7.4 Comparison with NZHS $2006 / 07 \ldots \ldots \ldots \ldots$

8 Discussion $\quad 128$

8.1 Methods . . . . . . . . . . . . . . . . . . . . . . . . . . . 128

8.1 .1 Survey Limitations . . . . . . . . . . . . . . . . . . . . . . . . . 128

8.1 .2 Statistical Analysis . . . . . . . . . . . . . . . . . . . . . . 130

8.2 Main findings . . . . . . . . . . . . . . . . . . . 130

8.2 .1 Adults . . . . . . . . . . . . . . . . . . . . . 130

8.2 .2 Children . . . . . . . . . . . . . . . . . . . . . . . . . . . . . 132

8.2 .3 Regression . . . . . . . . . . . . . . . . . . . . . 133 
8.2.4 Comparison of NZHS 2006/07 with ICS II $1988 \ldots \ldots \ldots \ldots \ldots$

8.2 .5 Conclusions and future work . . . . . . . . . . . . . . . . . . . 134

$\begin{array}{ll}\text { A Definitions } & 139\end{array}$

$\begin{array}{lr}\text { B Derived Variables } & 141\end{array}$ 


\section{List of Tables}

2.1 Projected sample allocation, by District Health Board, based on 2001 Census

2.2 Summarised content of the NZHS 2006/07 adult questionnaire. Source: Methodology Report for the 2006/07 New Zealand Health Survey (Ministry of Health,

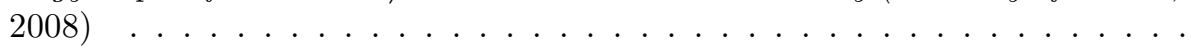

2.3 Summarised content of the NZHS 2006/07 child questionnaire. Source: Methodology Report for the 2006/07 New Zealand Health Survey (Ministry of Health, 2008) . . . . . . . . . . . . . . . . . . .

2.4 Final adult weighted response rates (percentage), by ethnic group and gender

2.5 Final child weighted response rates (percentage) . . . . . . . . . . . . 29

2.6 Representativeness of the NZHS 2006/07 Adult Sample . . . . . . . . . . 30

3.1 Arthritis Data . . . . . . . . . . . . . . 38

4.1 Demographics of the NZHS 2006/07 Adult Sample . . . . . . . . . . . . 44

4.2 Final adult weighted response rates (percentage), by ethnic group and gender

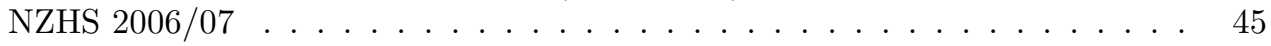

4.3 Ethnicity by Age for the Adult New Zealand Population based on the NZHS

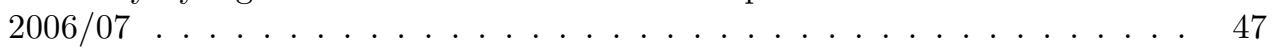

4.4 Ethnicity by Deprivation for the New Zealand Adult Population based on the

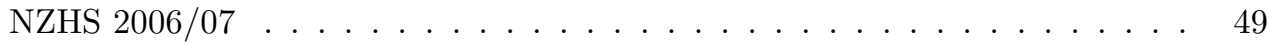

4.5 Demographic Characteristics of the NZHS 2006/07 Child Sample . . . . . 51

5.1 Mean Number of teeth removed due to tooth decay and gum disease for the Adult NZHS 2006/07 . . . . . . . . . . . . . . . .

5.2 Regularity of consultation with an oral health care worker for the Adult NZHS

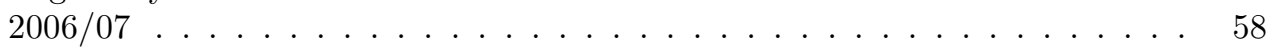

5.3 Time since last visit to oral health care worker for Adult NZHS 2006/07 . . 61

5.4 Prevalence of unmet oral health care needs in the past 12 months for Adults in the NZHS 2006/07 . . . . . . . . . . . . . . 63

5.5 Reasons for unmet oral health care needs in the past 12 months for Adult

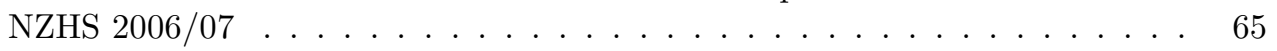

5.6 Urgent unmet oral health care needs in the past 12 months for Adult NZHS

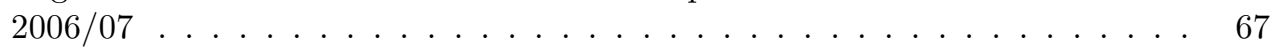

5.7 Rates of children with specific oral health characteristics NZHS 2006/07 . . 68

5.8 Frequency of tooth brushing by children, based on the NZHS 2006/07 . . . . 72

5.9 Frequency of tooth brushing and relationship with oral health outcomes, Child

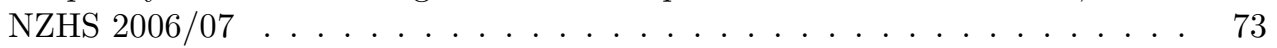

5.10 Child fizzy drink intake for the previous week, NZHS 2006/07 . . . . . . 75

5.11 Fizzy drink consumption and relationships to Fillings, Pain and Tooth Removal amoungst Children, from the NZHS 2006/07 . . . . . . . . . . . 77

5.12 Mean number of take away meals eaten in the previous week, for children, NZHS 2006/07 . . . . . . . . . . . . . . . . . 78

5.13 Take away meal intake and relationships to Fillngs, Pain and Tooth Removal amoungst Children, from the NZHS 2006/07 . . . . . . . . . . . . 79 
5.14 Child unmet need in previous 12 months, from the NZHS 2006/07 . . . . . 81

5.15 Child time since last oral health care worker visitation, from the NZHS 2006/07 82

6.1 Model 1: Regularity of oral health care, main effects including unmet need and toothloss, from the NZHS . . . . . . . . . . . . . 86

6.2 Model 1: Regularity of oral health care, including unmet need and toothloss, interaction terms, from the NZHS . . . . . . . . . . . . . . . 87

6.3 Model 2: Regularity of oral health care, excluding unmet need and toothloss, main effect terms . . . . . . . . . . . . . . . . . . . . . . . 92

6.4 Model 2: Regularity of oral health care, excluding unmet need and toothloss, interaction terms . . . . . . . . . . . . . . . . . . . . . 94

6.5 Model 3: Tooth loss, excluding regularity of care and unmet need, main effects 98

6.6 Model 3: Tooth loss, excluding regularity of care and unmet need, interaction terms . . . . . . . . . . . . . . . . . . . . . . . . . 99

6.7 Model 4: Tooth loss, including regularity of care and unmet need, main effects 105

6.8 Model 4: Tooth loss, including regularity of care and unmet need, interaction terms . . . . . . . . . . . . . . . . . . . . . 106

6.9 Model 6: Tooth loss, including regularity of care and unmet need, main effects 112

6.10 Model 6: Tooth loss, including regularity of care and unmet need, interaction terms . . . . . . . . . . . . . . . . . . . . . 113

7.1 Demographics of the ICS II Adult Sample . . . . . . . . . . . . . . . 122

7.2 Time since last visit to oral health care worker for Adult ICS II . . . . . . 122

7.3 Tooth brushing frequency for children aged $12-13 \ldots \ldots$. . . . . . . . 124

7.4 Time since last visit to an oral health care worker (for people aged 20-24,

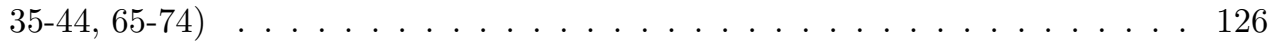

8.1 Item non response for oral health questions f . . . . . . . . . . . . 129 


\section{List of Figures}

1.1 The common risk factor approach (adapted from Petersen, 2003) . . . . . . 19

2.1 Procedure for selection of and participation rates for respondents in the NZHS

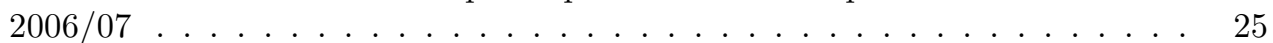

4.1 Sex distribution of sample and population for the Adult NZHS 2006/07 . . 45

4.2 Age Group distribution of Sample and Population for the Adult NZHS 2006/07 46

4.3 Ethnicity distribution of Sample and Population for the Adult NZHS 2006/07 46

4.4 Ethnicity by Age for the New Zealand Population, based on the weighted adult NZHS 2006/07 . . . . . . . . . . . . . . . . . 47

4.5 Deprivation Quintile distribution of Sample and Population, based on the

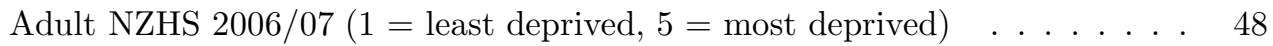

4.6 Ethnicity by Deprivation Quintile of NZ Population, based on the weighted Adult NZHS 2006/07 ( $1=$ least deprived, $5=$ most deprived $) \ldots . . . .49$

5.1 Tooth Loss due to Tooth Decay or Gum Disease for the Adult NZHS 2006/07

5.2 Mean Number of Teeth Lost due to Tooth Decay or Gum Disease by Age for the Adult NZHS 2006/07 . . . . . . . . . . . . . . . .

5.3 Mean Number of Teeth Lost due to Tooth Decay or Gum Disease by Ethnicity for the Adult NZHS 2006/07 . . . . . . . . . . . . . . 55

5.4 Regularity of consultations with an Oral Health care worker by Ethnicity for the Adult NZHS 2006/07 . . . . . . . . . . . . . . . . . 59

5.5 Regularity of consultations with an Oral Health care worker by Age for the Adult NZHS 2006/07 . . . . . . . . . . . . . .

5.6 Time since last visit to an oral health care worker by age for the Adult NZHS

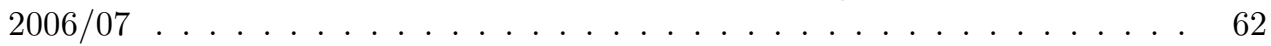

5.7 Time since last visit to an oral health care worker by ethnicity for the Adult NZHS 2006/07 .............................. 62

5.8 Rates of Children with Fillings by ethnicity for the Child NZHS 2006/07 . . 69

5.9 Rates of Children who are kept awake at night due to tooth or mouth pain, by ethnicity, for the Child NZHS 2006/07 . . . . . . . . . . . 70

5.10 Rates of Children who have had at least one tooth removed due to tooth decay, abscess or infection by ethnicity, for the Child NZHS 2006/07 . . . . . . 71

5.11 Rates of daily tooth brushing by ethnicity for the Child NZHS 2006/07 . . 73

5.12 Fizzy drink intake for the previous week for the Child NZHS 2006/07 . . . . 74

5.13 Fizzy drink intake for the previous week, by ethnicity for the Child NZHS

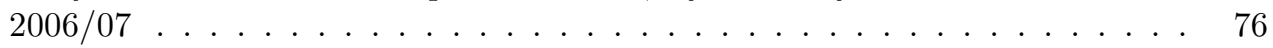

5.14 Take away meal intake for the previous week for the Child NZHS 2006/07 $\quad$ • 77

5.15 Take away meal intake for the previous week, by ethnicity for the Child NZHS

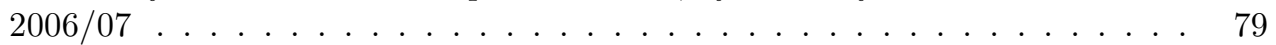

5.16 Time since last visit to an oral health care worker for children, NZHS 2006/07 83

6.1 Model 1 = Regularity of care (including oral health outcomes as predictors), residuals for level 1 (Check ups $<2$ years apart) . . . . . . . . . . 
6.2 Model $1=$ Regularity of care (including oral health outcomes as predictors), residuals for level 2 (Check ups 2-5 years apart) . . . . . . . . . . . . . .

6.3 Model 1 = Regularity of care (including oral health outcomes as predictors), residuals for level 3 (Visiting only when care is needed) . . . . . . . . . 90

6.4 Model 1 = Regularity of care (including oral health outcomes as predictors), residuals for level 4 (Never visiting and oral health care worker) . . . . . . .

6.5 Model $2=$ Regularity of care (excluding oral health outcomes as predictors), residuals for level 1 (Check ups $<2$ years apart) $\ldots \ldots \ldots \ldots$. . . . .

6.6 Model 2 = Regularity of care (excluding oral health outcomes as predictors), residuals for level 2 (Check ups 2-5 years apart) . . . . . . . . . . 95

6.7 Model 2 = Regularity of care (excluding oral health outcomes as predictors), residuals for level 3 (Visiting only when care is needed) . . . . . . . . . 96

6.8 Model 2 = Regularity of care (excluding oral health outcomes as predictors), residuals for level 4 (Never visiting and oral health care worker) . . . . . . 96

6.9 Model $3=$ Tooth loss (excluding regularity of care and unmet need as predictors), Residuals for level 1 (11 or more teeth lost) . . . . . . . . . . . . 102

6.10 Model $3=$ Tooth loss (excluding regularity of care and unmet need as predictors), Residuals for level 2 (1-10 teeth lost) _ . . . . . . . . . . . 102

6.11 Model 3 = Tooth loss (excluding regularity of care and unmet need as predictors), Residuals for level 3 (No teeth lost) . . . . . . . . . . . . . . . 103

6.12 Model $4=$ Tooth loss (including regularity of care and unmet need as predictors), Residuals for level 1 (11 or more teeth lost) . . . . . . . . . . . . . . 109

6.13 Model $4=$ Tooth loss (including regularity of care and unmet need as predictors), Residuals for level 2 (1-10 teeth lost) . . . . . . . . . . . . . 109

6.14 Model $4=$ Tooth loss (including regularity of care and unmet need as predictors), Residuals for level 3 (No teeth lost) . . . . . . . . . . . . . . . . 110

6.15 Model 6 Residual $1 \ldots \ldots$. . . . . . . . . . . . . . 115

6.16 Model 6 Residual 0 . . . . . . . . . . . . . . . . . . . . . . . . . . . 115

7.1 Time since last visit to an oral health worker for adults aged 20-24, 35-44 and $65-74$ ICS II 1988 . . . . . . . . . . . . . . . . . . . . .

7.2 Comparison of tooth brushing frequency for children aged 12-13, ICS II 1988 and NZHS $2006 / 07 \ldots \ldots \ldots \ldots \ldots \ldots \ldots$

7.3 Comparison of time since last visit to an oral health worker for adults aged 20-24, 35-44 and 65-74 ICS II 1988 and NZHS 2006/07 . . . . . . . . . 126

A.1 Adult teeth. source: http://www.colgate.com . . . . . . . . . . . . . . 140 


\section{Chapter 1}

\section{Introduction}

Good oral health is a hard concept to define. The World Health Organisation (WHO) uses a definition for good oral health that includes an individual having an acceptable dentition that does not stop that individual from carrying out regular functions such as eating and socialising without discomfort or embarassment due to their own oral health. This WHO definition of oral health links social functioning as well as physical and psychological aspects of life with oral health, and serves to highlight how important good oral health is in the scheme of health in general (Ministry of Health 2006).

\subsection{Overall purpose of research}

This research primarily uses the results of the New Zealand Health Survey 2006/07 (NZHS), conducted by the Ministry of Health, to describe the oral health of New Zealanders and determine the rates of access to oral health care professionals. It also helps to identify the risk factors for poor oral health and inadequate access to oral health professionals. Comparisons over time are carried out using the New Zealand data from the WHO International Collaborative Study of Oral Health Outcomes 1988 (ICS II).

\subsection{Research questions}

This research has the following objectives and questions:

To describe the Oral health of New Zealanders in 2006/07

- How many New Zealanders have had teeth removed due to tooth decay or gum disease?

- What proportion of children under the age of 15 , have fillings in their teeth?

- How often are people seeing oral health professionals?

To identify and quantify the demographic and behavioural risk factors for poor oral health

- What are the characteristics of people who have had teeth pulled out due to tooth decay and gum disease?

- Are tobacco or alcohol associated with adult tooth removal?

- What are the characteristics of children who have had fillings? 
- Are fizzy drink intake rates and tooth brushing associated with child tooth removal?

- Are fizzy drink intake rates and tooth brushing associated with the number of children with fillings?

To assess and describe the correlations between general health and oral health

- Do certain chronic illnesses (such as diabetes) have any association with oral health?

\section{To assess access to Oral Health Services in New Zealand}

- Do people have adequate access to oral health professionals when needed?

- What is stopping people from accessing oral health professionals?

- What are the characteristics of people who do not have the required access to oral health professionals?

To assess changes over time in New Zealanders' Oral Health using the New Zealand Health Survey 2006/07 and the 1988 New Zealand Oral Health Outcomes Survey

- How has the overall oral health of New Zealanders changed from 1988 to 2006 ?

- How have the characteristics of New Zealanders with certain oral health issues, such as people who have had teeth removed, changed over time?

\subsection{Research methodology}

This research involves analysis of the data from the oral health section of the New Zealand Health Survey, a nationwide probabilistic survey conducted by the Ministry of Health in 2006-2007, as well as the 1988 Oral Health Outcomes study of New Zealanders as part of the World Health Organisation International Collaborative Study of Oral Health Outcomes.

The target population of the NZHS 2006/07 was the New Zealand usually resident civilian population of all ages. Stratified cluster sampling was used based on area meshblocks, with a slightly higher rate of selection used for obtaining a higher proportion of Māori, Pacific Peoples and Asians. Weightings were assigned to each individual surveyed based on population benchmarks. These weightings were used along with the jackknife variance estimation method for the analysis of the data.

This research was carried out in several stages. Firstly, the NZHS 2006/07 data was explored at a basic level with descriptive statistics. Analysis of each related oral health question was carried out to create estimated total numbers, rates, averages and confidence intervals where necessary. General cross-tabulations was done for the oral health outcomes by demographic characteristics sex, age and ethnicity. Risk factors for oral health behaviours and oral health outcomes were identified and analysed. Variance estimation was done by jackknife estimation using the jackknife replicate weights supplied with the dataset.

Following the exploratory analysis, two particular outcomes were analysed in more detail. These were regularity of oral health care and tooth loss due to tooth decay and gum disease. For these variables multiple regression analysis was carried out, using the NZHS 2006/07, to see which explanatory variables (behavioural and demographic) could be used as predictors. Selected health outcomes were also used as predictors for these outcomes. The two outcomes of interest were analysed and models for ordinal data were created. All regression models 
were carried out using the weighted data and the SAS statistical computer package.

Lastly, a comparison of descriptive statistics and cross-tabulations of oral health outcomes was carried out between the 1988 Study of Oral Health Outcomes and the 2006/07 New Zealand Health Survey, with the selected age categories used in the 1988 Study of Oral Health Outcomes to test for changes over time.

\subsection{New Zealand Oral Health Survey 2009}

From February 2009 to December 2009 the Ministry of Health, Defence Dental of the New Zealand Armed Forces and the New Zealand Dental Association carried out the New Zealand Oral Health Survey 2009, which collected information on the oral health status, beliefs, attitudes, knowledge and practices of the New Zealand population.

The New Zealand Oral Health Survey 2009(NZOHS) was a follow up to the New Zealand Health Survey 2006/07, in which almost 5000 New Zealanders took part in a face to face interview survey and a simple dental examination which was carried out by registered dental practisioners. This survey aimed to 'describe the oral health of New Zealand children and adults, and the prevalence and severity of selected oral conditions, including dental injury' along with the following objectives:

- estimate the prevalence of risk and protective factors associated with these oral health conditions;

- examine the relationship between general health and oral health;

- examine the relationship between adult oral health and child oral health within households;

- describe the use of oral health services, including the nature of barriers to accessing oral health services, and the extent of any unmet need;

- examine inequalitites between population subgroups (as defined by age, gender, ethnicity, rurality and socio-economic position;

- examine changes which have occured in the oral health of New Zealanders, since previous national surveys;

- provide policy makers with information that can be used to improve oral health and the oral health care system.

Key results from this survey are due to be published in December 2010 by the Ministry of Health.

\subsection{Structure of this thesis}

The remainder of this chapter is a review of the literature relating to oral health in New Zealand and around the world, with specific emphasis on the specific oral health outcomes for which this research analysis.

Chapter Two describes the NZHS 2006/07, detailing the sample design and strategy used as well as the objectives for the survey.

Chapter Three is a review of the statistical methods used in this research. This includes a section on the jackknife method, as well as a section on regression modelling and model 
selection techniques used.

Chapter Four presents the demographic characteristics of the NZHS 2006/07 sample and the highlights the differences between the sample and the New Zealand population, due to the survey sampling strategy.

Chapter Five presents the exploratory data analysis for oral health outcomes for New Zealand adults and children. Results are presented with respect to population benchmark variables of sex, age and ethnicity. These are simple analyses showing the relationships between a single outcome and a single explanatory variable.

Chapter Six examines the risk factors for regularity of oral health care and tooth loss due to tooth decay and gum disease through the use of ordinal regression models. This chapter applies a more powerful set of analysis tools than in the exploratory analysis, and determines which variables are most strongly associated with, and predictive of our chosen principle outcomes (regularity of care and tooth loss due to tooth decay and gum disease). Explanatory variables are selected from the available data collected in the survey and in light of the risk factors identified in the literature review.

Chapter Seven describes the World Health Organisation (WHO) International Collaborative Study II (ICS II) from 1988. This is followed by demographic and oral health outcome analysis. Lastly a comparison is done between the ICS II from 1988 and the NZHS 2006/07 for oral health outcomes.

Chapter Eight is a discussion on the findings of this research, the survey and statistical limitations and a final conclusion of the results.

\subsection{Literature review}

ion

The World Health Organisation recognises oral health as an integral part of general health and a basic human right (Ministry of Health 2006). Dental decay, periodontal disease, missing or damaged teeth, or pain and embarrassment that limits an individual's eating, speaking or socialising without discomfort are some of the many things the Ministry of Health states could be used to define Oral Health (Ministry of Health 2006). In this chapter we review particular aspects of oral health that have been analysed in previous studies in New Zealand and elsewhere.

For the reader unfamiliar with oral health, there are some specific terms which we now define.

Dental Decay/Caries - Dental decay is a process in which the hard mineral structure of teeth is dissolved by acids produced by bacteria.

Dentate - The state of having one or more natural teeth.

Dentition - The set of teeth. A complete dentition comprises 32 adult teeth.

Fluoride - A naturally occuring mineral that helps reduce tooth decay.

Gum disease - Gingivitis or periodontitis.

Inadequate natural dentition - Fewer than 21 teeth.

Periodontitis - inflammations or infection of the gums and the surrounding bone.

Further definitions can be found in Appendix A. 


\subsubsection{Oral health in New Zealand}

Because oral health is so important in many aspects of an individual's life, such as social functioning, as well as physically and psychologically, it is important that oral health in New Zealand remains an ongoing health focus. The Ministry of Health released Good Oral Health for All, for Life: The Strategic Vision for Oral Health in New Zealand (Ministry of Health 2006). This document is New Zealand's vision for Oral health policy in the next 10 years. 'The vision is for high-quality oral health services that promote, improve, maintain and restore good oral health, and that are proactive in addressing the needs of those at greatest risk of poor oral health' (Ministry of Health 2006). The Ministry of Health recognises that this will take time and effort in reviewing the way publicly funded oral health services are delivered to New Zealanders.

Risk factors, behavioural and demographic, have been identified by oral health professionals. Oral health statistics collected from 2002 for children already show a significant difference between ethnicities, particularly Māori and Non-Māori Oral Health. Fluoride was introduced into toothpaste and some regional water supplies in the 1970s and, along with technology, has improved oral health over the last 30 years (Ministry of Health 2006). However, many other behavioural and environmental factors, such as region and water fluoridation status, are still linked to rates of dental decay among children in New Zealand, with rates of dental caries beginning to increase again after a period of stability in the mid-1990s (Ministry of Health 2006).

The Colgate Oral Health Survey coincided with Oral Health month in August 2006, which was sponsored by Colgate, in association with the New Zealand Dental Association. This survey compared results from 29 European and Australasian countries. It found that only $58 \%$ of New Zealanders brushed their teeth twice a day. Fewer than $40 \%$ of New Zealanders visit a dentist on a regular annual basis, compared to an average of $62 \%$ of people for all 29 countries. For those New Zealanders who had not seen a dentist in the last year, $55 \%$ cited expense as the main reason for not seeing a dentist, $29 \%$ of people believed they did not need to see a dentist and $8 \%$ of New Zealanders cited fear as a reason for not seeing a dentist in the last year (Colgate 2006).

Child oral health inequalities in New Zealand have also been identified by District Health Board (DHB) region, with 5 year old children in Wellington, Waitemata and Otago having the lowest rates of tooth decay, while Northland, Tairawhiti and the West Coast have the highest rates of tooth decay. Those in the regions with the higher rates of dental caries generally have lower socio-economic and ethnic differences in oral health (National Advisory Committee on Health and Disability 2003).

New Zealand provides a school dental service for school aged children which provides basic preventive and restorative care to preschoolers and primary and intermediate aged children. This School Dental Service aims to see children annually or on a six-month basis for at risk children who are identified based on past dental disease experience (Thomson et al. 2003). More than $95 \%$ of school aged children are estimated to be in the School Dental Service system, however people from lower socio-economic status groups (as well as Māori and Pacific children) have lower rates of preschool uptake for this service (Thomson et al. 2003). After year 8 , children are eligible to receive dental care until the age of 18 through the General Dental Benefit system which is now known as the Adolescent Oral Health Scheme(Thomson et al. 2003).

In 1988, New Zealand, along with 8 other countries and regions, participated in the World Health Organisation (WHO) Second International Collaborative Study (ICS II). The New Zealand objectives of the study included assessing oral health and oral disease for specific age groups and to examine the socio-demographic characteristics, oral health beliefs, attitudes, 
knowledge and self-care practices of the general public (Hunter et al. 1992). Blum's model of the determinants of health status states that four major factors, environment, lifestyle, the health care system and human biology, determine an individual's health status, and was used in the ICS II Blum (1973).

Chen \& Hunter (1996) used the New Zealand data from the World Health Organisation International Collaborative Study of Oral Health Outcomes (ICSII) to 'examine the social dimensions of oral health by analysing the relationships between socioeconomic status, oral health behaviour, biological measures of oral health ond oral quality of life' (Chen \& Hunter 1996). Their model hypothesised that socioeconomic status (education, occupation, income, and residence), as well as Health and Gender variables, was associated with oral health behaviour (brushing, flossing and dental visits) which in turn was associated with oral health status (decayed, filled and missing teeth and periodontal status) finally linking this to oral quality of life (symptoms, well-being and functioning). This hypothesis was supported by their results. For dentate adults aged 35-44 'The multiple regression results revealed 3 significant predictors of dental symptoms: perceived general health, making of symptomatic visits (i.e. visiting for pain reasons, as opposed to a visit for a check up) and the number of decayed teeth'. They found that brushing and flossing was not a significant predictor of oral well-being. It was found that oral health status variables were strong predictors of an adult's perceived oral well-being.

\subsubsection{Previous international findings}

The 2004-06 National Survey of Adult Oral Health was conducted in Australia with the main aims of the survey to 'describe levels of oral disease, perceptions of oral health and patterns of dental care' across Australia. This survey involved 14,123 interviews and 5,505 dental examinations. This survey also made comparisons to the first Australian oral health examination survey carried out 17 years earlier in 1987-88 (Slade et al. 2007).

The 1998 Adult Dental Health Survey was carried out in the United Kingdom by the four United Kingdom Health Departments. This survey has been carried out every 10 years since 1968 in England and Wales, and since 1978 for the whole of the United Kingdom. In 1998, 6204 adults were surveyed and 3817 dental examinations were carried out (Government Statistical Service 1999).

In 1989, the National Health Interview Survey (NHIS) was carried out in the United States, using a cross sectional household survey conducted by the National Center for Health Statistics (NCHS). This survey contained national estimates for oral health care outcomes and was designed to help direct 16 American oral health strategies until the year 2000 and provide baseline estimates for further analysis (Bloom et al. 1992).

We now summarise some of the findings from these three studies.

\section{Tooth loss and fillings}

Orthodontic treatment, trauma and removal of the third molars (wisdom teeth) are some of the reasons for tooth loss; however, the majority of teeth are lost or removed due to peridontal disease and or dental caries (Phipps \& Stevens 1995). Rates of edentulism are decreasing over time. Dental decay/caries is a process in which the hard mineral structure of teeth is dissolved by acids produced by bacteria. The process produces a cavity in the crown of the tooth or a softening of the root surface, which can lead to tooth removal and is affected by age, race, ethnicity and poverty level. However, rates of dental caries have been reported to be declining over time (The National Institute of Dental and Craniofacial Research (NIDCR) 
2007).

The Australian National Survey of Adult Oral Health found that 1 in 20 Australians (6.4\%) had lost all of their natural teeth. Of those who were dentate an average of 4.5 teeth per person had been extracted because of dental decay or gum disease. They found that the proportion of Australians with no natural teeth more than halved over the 17 year period, from $14.4 \%$ in $1987-88$ to $6.4 \%$ in $2004-06$ (Slade et al. 2007).

In the United Kingdom the proportion of people who had lost all of their teeth had decreased from $30 \%$ in 1978 to $13 \%$ in 1998 and the number of dentate people who had an adequate dentition had increased from $73 \%$ in 1978 to $83 \%$ in 1998, with people having an average of 24.8 teeth present, and an average of 7.2 teeth missing. The Adult Dental Health Survey was carried out in the United Kingdom and concluded that 'the retention of natural teeth (and their condition) is strongly associated with age' (Government Statistical Service 1999).

In the USA 7.3\% of children have lost at least one permanent tooth because of dental caries, with adult Americans having lost an average of 12.1 teeth by age 50 (including their wisdom teeth) (The National Institute of Dental and Craniofacial Research (NIDCR) 2007). 9.7\% of Americans over the age of 18 are edentulous. Rates increase as age increases, with $33.1 \%$ of Americans aged over 65 being edentulous (The National Institute of Dental and Craniofacial Research (NIDCR) 2007).

In the United States the proportion of teeth a person has is associated with their ethnicity/race, with Mexican American children having the highest rates of dental caries as well as untreated dental caries, compared to non Hispanic black or white Americans (The National Institute of Dental and Craniofacial Research (NIDCR) 2007). 'Individuals living below the poverty level experience more dental decay than those who are economically better off' in the United States. These same people are also more likely to leave their dental caries untreated, in themselves and in their children, with $36.8 \%$ of American children living below the poverty line having one or more untreated caries, compared to only $17.3 \%$ or non-poor American children having at least one untreated carie (The National Institute of Dental and Craniofacial Research (NIDCR) 2007).

In 2004-06 83.9\% of Australians had one or more filled teeth (Slade et al. 2007). In the United States it is reported that ' 6 out of 10 children have one or more decayed or filled primary teeth by age 5' (The National Institute of Dental and Craniofacial Research (NIDCR) 2007).

\section{Oral health service utilisation}

The Australian Adult Oral Health Survey found that almost $60 \%$ of Australians had visited a dentist in the previous 2 months (between 2004 and 2006), with $53.1 \%$ of adults visiting a dentist at least once a year. $30 \%$ of Australians reported avoiding dental care due to cost, with financial barriers to dental care being more likely to be reported by Indigenous Australians and those who were uninsured. Rates of yearly dental visits had increasing from $53 \%$ to $62 \%$ over the 17 year period from 1987-88 to 2004-06 (Slade et al. 2007).

According to the 1996 Medical Expenditures Panel Survey (MEPS) 42\% of the U.S. population over the age of 2 years old had at least one dental visit in the year 1996 (The National Institute of Dental and Craniofacial Research (NIDCR) 2007). Dentate people were 4 times more likely to report a dental visit within the past years than edentulous people, with $55.2 \%$ of edentulous people not having had a dental visit in the previous 5 years (Bloom et al. 1992).

There are many different reasons reported for nonutilisation of oral health care services, such as cost, time and fear of dental treatment. In the 1989 American National Health Interview Survey $46.8 \%$ of Americans said they had not visited a dentist in the past year because they 
had no dental problem, while $14.3 \%$ of people reported having no teeth as the reason for not visiting a dentist and $13.7 \%$ reported cost of care as their reason for nonutilisation of dental services in the past year, with Black people being more likely to cite cost as their reason for non use of oral health care services (Bloom et al. 1992).

In 1994 the National Access to Care Survey carried out in the United States found that $8.5 \%$ of the U.S. population was unable to obtain dental care when they wanted/needed it, compared to only $5.6 \%$ of medical and surgical needs being unmet (The National Institute of Dental and Craniofacial Research (NIDCR) 2007).

Using a sample of African Americans and non-Hispanic white people from the Florida Dental Care Study, Gilbert, Duncan and Shelton concluded that race and socio-economic status are strong determinants of tooth loss but 'because almost all tooth loss occurs by means of extraction' meaning that the total effects of race and socio-economic status on tooth loss are artificially minimized, unless dental care use is taken into account (Gilbert et al. 2003).

\section{General health}

'The recognition of well known and established signs and symptoms of oral diseases may assist in the early diagnosis and prompt treatment of some systemic diseases and disorders' (The National Institute of Dental and Craniofacial Research (NIDCR) 2007).

'Animal and populatation based studies have demonstrated an association between periodontal diseases and diabetes, cardiovascular disease, stroke and adverse pregnancy outcomes. Further research is needed to determine the extent to which these associations are causal or coincidental' (The National Institute of Dental and Craniofacial Research (NIDCR) 2007).

Diabetes is often linked with periodontitis, with many studies showing that people with Diabetes (type I and type II) have a greater prevalence, severity or manifestation of periodontal disease (The National Institute of Dental and Craniofacial Research (NIDCR) 2007).

General self-reported health has been associated with dental care and oral health (The National Institute of Dental and Craniofacial Research (NIDCR) 2007). In America 61.4\% of people who reported their own health to be 'excellent' or 'very good' had had a dental service visit in the previous year, while only $45.1 \%$ of those who reported their own health to be 'fair' or 'poor' had made a dentist visit in the past year (Bloom et al. 1992).

\subsubsection{Oral health risk factors}

Predisposing factors are factors that have an effect before a specific behaviour has occured, by influencing a person's or population's motivation to undertake that specific behaviour (Green \& Mercer 2002). In this case predisposing factors include demographic factors such as age and gender; social factors such as education, occupation, ethnicity and deprivation; and health belief factors such as attitudes and knowledge. 'High relative risk of oral disease relates to sociocultural determinants such as: poor living conditions; low education level; and lack of traditions, beliefs and culture in support of oral health' (Petersen 2003a).

The common risk factor approach model shown in Figure 1.1, 'emphasises the role of intermediate, modifiable risk behaviours, i.e. oral hygiene practices, sugars consumption (amount, frequency of intake, types) as well as tobacco use and excessive alcohol consumption. Such behaviours may not only affect oral health status negatively as expressed by clinical measures but also impact on quality of life' (Petersen 2003a). 


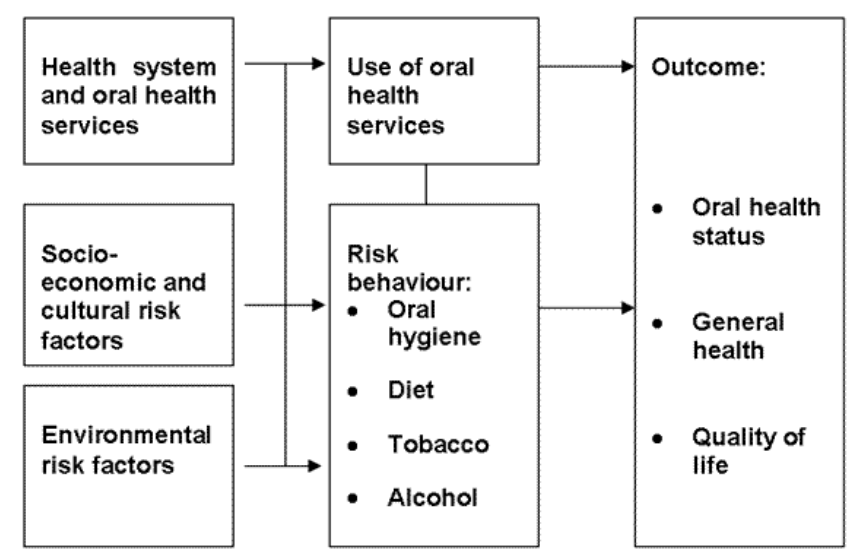

Figure 1.1: The common risk factor approach (adapted from Petersen, 2003)

\section{Tobacco}

Tobacco has been linked to oral cancer, periodontal diseases, and congenital defects in children whose mothers smoke during pregnancy, as well as non life-threatening issues such as tooth staining and discolouration, halitosis and loss of taste and smell (Reibel 2005). 'Tobacco use suppresses the immune system's response to oral infection, retards healing following surgical and accidental wounding, promotes peridontal degeneration in diabetics and adversely affects the cardiovascular system' (Petersen 2003b). In some industrialised countries studies have shown that smoking and tobacco use is responsible for more than half of the periodontitis cases in adults (Petersen 2003b). Smoking, heaviness of smoking and the number of years spent smoking has consistently been linked to higher prevalence, extent and severity of periodontal diseases, with upto 2 to 7 times greater risk of having periodontal diseases for those who smoke than those who do not (Albandar 2002).

\section{Diet and nutrition}

Nutrition influences rates of dental diseases such as dental caries and periodontal disease, with tooth loss then also influencing the ability to eat a nutritious diet (Moynihan 2005). So far no strong evidence has been produced to associate diet with periodontal (gum) disease (Moynihan 2005). Acidic foods and drinks have been associated with dental erosion, where dietary acids have eroded tooth enamel and dentine, as well as significant age related increases in dental erosion where large amounts of soft drink have been consumed (Moynihan 2005). Many studies in animals and humans have shown that sugar is the leading factor in tooth caries development, however there is no significant difference between the different types of sugars such as fructose and sucrose (Moynihan 2005). Dr Theresa Madden, previously a Colgate Senior Lecturer in Periodontology at Otago University advises 'limiting the consumption of sugary or acidic foods and drinks' and also states that tobacco products raise the risk of mouth cancer and gum disease (Colgate 2006)

While no strong evidence has been produced to link diet and nutrition with oral health, there has been research done that suggests the intake of fruit and vegetables is lower for those with inadequate dentition and lower incomes, for certain fruits and vegetables. Those missing 21 or more teeth have a more infrequent consumption of peaches, nectarines, plums and apricots as well as a range of vegetables including mushrooms, eggplant and capsicum (Brennan et al. 2010). 


\section{Fluoride}

Fluoride has long been acknowledged as having a beneficial effect on teeth. In the early 1930s researchers discovered less dental caries in people living in communities with naturally fluoridated water, than those who were not (The National Institute of Dental and Craniofacial Research (NIDCR) 2007). In the late 1940s they were able to start confirming this discovery with clinical trials and started to acknowledge that fluoride could be used to prevent dental caries and by the 1950's dental caries were in decline due to water fluoridation (The National Institute of Dental and Craniofacial Research (NIDCR) 2007). Low levels of fluoride have been associated with dental decay, whilst high levels of fluoride have been associated with fluorosis and enamel erosion (Fawell et al. 2006). 'Research has shown that fluoride is most effective in dental caries prevention when low level fluoride is constantly maintained in the oral cavity' (Petersen 2003a). 'Communities and countries with inappropriate exposure to fluorides imply higher risk of dental carries' (Petersen 2003a). Fluoride has been proven to reduce caries in children by up to 50\% (Moynihan 2005). Ingested fluoride becomes part of the tooth and makes it stronger, protecting it against tooth decay, while fluoride placed on teeth affects plaque directly and helps avoid tooth decay (Allukian 2002). Over 500 million people worldwide use fluoridated toothpaste. 210 million people worldwide have access to fluoridated water and 100 million people have access to fluoridated salt or other forms of fluoridation (Petersen 2003a).

\section{Oral hygiene practices}

Periodontal diseases are mainly caused by dental plaque (bacteria) build up, which is related to the level of oral hygiene. The National Health and Nutrition Examination Survey carried out in from 1971-1974 in the United States used an Oral Hygiene Index, which was based on the amount debris or calculus found on the surfaces of a specific 6 teeth for each person, to compare oral health hygiene status and periodontal status, and fond that oral hygiene was an important risk indicator for the level of periodontitis a person has. The survey also found that blacks and males had poorer oral hygiene than their white and female counterparts (Albandar 2002).

\section{Location}

Results from the Australian National Survey of Adult Oral Health 2004/06 (NSAOH) show that people residing outside of capital cities in Australia were more likely to have higher rates of dental caries, missing teeth, inadequate dentition and are more likely to suffer from complete tooth loss compared to those living inside capital cities (Roberts-Thomson \& Do 2007). Reasons for this rural/urban inequality have been suggested and include water fluoridation status, and a lower socio-economic status amoung rurally located Australians (Crocombe et al. 2010). No significant differences were found over a 17 year period from 1987/88 to 2004/06 between improvement rates in oral health status, with both rural and urban Australians reducing the rates of dental caries and tooth loss equally (Crocombe et al. 2010).

This chapter has summarised previous studies in Oral Health and helped to identify risk factors for poor oral health. Risk factors included age, ethnicity, income status, tabacco use, oral hygiene practices and diet and nutrition. 


\section{Chapter 2}

\section{NZHS Survey Design}

This chapter describes the New Zealand Health Survey 2006/07. Sample design and strategy are described as well as the properties of the questionnaire. A description of the sample weights used in the analysis is given, along with an overview of the survey response rates. Much of the material in this chapter is drawn from the Methodology Report for the 2006/07 New Zealand Health Survey (Ministry of Health 2008).

\subsection{Survey background}

The New Zealand Health Survey 2006/07 (NZHS) was the fourth national population-based health survey, following the 1992/93, 1996/97 and 2002/03 NZ Health Surveys. The Survey was conducted to measure self-reported physical and mental health status (including doctordiagnosed health conditions), risk and protective behaviours for health outcomes and the use of health care services among the usually resident New Zealand population living in private dwellings.

The objectives for the NZHS 2006/07 were designed by Public Health Intelligence Directorate (PHI) of the New Zealand Ministry of Health. The five objectives of the survey were to:

1. Measure the health status of New Zealanders, and the prevalence of selected health conditions;

2. Measure the prevalence of risk and protective factors associated with these health conditions;

3. Measure the use of health services, including barriers to accessing health services;

4. Examine differences between population groups (as defined by age, gender, ethnicity and socioeconomic posistion);

5. Examine changes in key NZ Health Survey data over time.

\subsection{Population and frame}

The target population was the usually resident civilian population of all ages living in permanent private dwellings in New Zealand. This is approximately 3.1 million adults (aged 15 years and over) and 854,000 children, based on figures from the 2006 New Zealand Census of Population and Dwellings. This target population excludes residents of New Zealand living in non-permanent private dwellings such as holiday accommodation and institutions. Based on the 2006 New Zealand Census, 30.6\% of people aged 75 and over are not covered by this 
target population. This is a significantly large proportion of elderly people as opposed to all other age groups, which all have less than $8 \%$ of people not covered by the target population.

Of the 1.4 million permanent private dwellings in New Zealand, $98.9 \%$ were eligible for participation in the NZ Health Survey. Those dwellings excluded were excluded due to location (ie not being on one of New Zealand's 3 main islands) or being in meshblocks too small. However the people residing in these excluded dwellings were accounted for in the final survey weights.

\subsection{Sample design and strategy}

The Centre for Statistical and Survey Methodology at the University of Wollongong, New South Wales, Australia developed the sample design for the 2006/07 NZ Health Survey. The sample design was based on the following objectives:

1. A range of population-level prevalences need to be estimated (eg asthma, diabetes, stroke, obesity, GP visitation, problem gambling) with sufficient accuracy.

2. Estimates for all ages were required, based on the following age groups: 0-4, 5-9, 10-14, $15-24,25-44,45-64,65+$ years.

3. Sufficient data was needed to allow for small area estimation at the level of the 21 different District Health Boards (DHB).

4. Estimates by ethnic group were required, with Māori estimates having approximately the same relative standard error as the non-Māori population estimates to the extent that this could be reasonably achieved.

5. The design should avoid large variation in estimation weights, in order to reduce standard errors of key estimates and to support anaylses of the survey data by multiple users.

6. The NZHS 2006/07 survey design should not vary too much from the design of the NZHS 2002/03, so that comparisons can be made between surveys.

Disproportionate sampling occurred where DHBs containing a higher proportion of Māori residents were sampled at a higher rate to achieve the 4th objective of creating more robust Māori estimates. However this disproportionate sampling was kept to a minimum so as not to create large variation of estimation weights as specified in objective 5 . The different selection probabilities are displayed in Table 2.1.

Following the other NZ Health Surveys, the NZHS 2006/07 used multi-stage, stratified, probability proportional to size (PPS) cluster sampling design to achieve the required sample sizes.

The following sampling method was selected to best meet the sample objectives and to limit the variation in the estimation weights and produce the lowest possible design effect. The clustering of the sample obtained through the use of meshblocks was done to limit travelling by interviews and make the survey more affordable. Figure 2.1 gives an overview of the selection process used.

\subsubsection{Primary sampling units}

The size of each meshblock was determined by the number of occupied dwellings in the meshblock based on the 2001 New Zealand Census. Therefore, the selection of meshblocks used 'probability proportional to size' sampling because of the variation of size among different 
Table 2.1: Projected sample allocation, by District Health Board, based on 2001 Census

\begin{tabular}{|l|r|r|r|r|r|r|}
\hline DHB & $\begin{array}{c}\text { Adult } \\
\text { popu- } \\
\text { lation } \\
(\text { 000s })\end{array}$ & $\begin{array}{l}\text { Percentage } \\
\text { of Māori }\end{array}$ & $\begin{array}{l}\text { Total } \\
\text { mesh- } \\
\text { blocks }\end{array}$ & $\begin{array}{l}\text { Meshblocks } \\
\text { in sample }\end{array}$ & $\begin{array}{l}\text { Adult sam- } \\
\text { ple } \\
\text { (core } \\
\text { screen }\end{array}$ & $\begin{array}{l}\text { Household prob- } \\
\text { and } \\
\text { ability of selec- } \\
\text { tion in core sam- } \\
\text { ple }\end{array}$ \\
\hline 01 Northland & 111.7 & 22.2 & 1342 & 78 & 727 & 0.0101 \\
02 Waitemata & 378.8 & 7.1 & 2909 & 130 & 1193 & 0.0057 \\
03 Auckland & 322.6 & 6.4 & 2792 & 108 & 1132 & 0.0054 \\
04 Counties Manukau & 322.4 & 12.7 & 2364 & 132 & 1469 & 0.0077 \\
05 Waikato & 259.3 & 15.6 & 3003 & 145 & 1306 & 0.0085 \\
06 Lakes & 72.6 & 24.6 & 802 & 55 & 544 & 0.0106 \\
07 Bay of Plenty & 149.7 & 18.3 & 1333 & 91 & 822 & 0.0092 \\
08 Tairawhiti & 32.0 & 35.5 & 390 & 29 & 320 & 0.0128 \\
09 Taranaki & 80.0 & 10.9 & 1154 & 41 & 320 & 0.0071 \\
10 Hawke's Bay & 112.1 & 17.5 & 1322 & 71 & 612 & 0.0090 \\
11 Whanganui & 47.2 & 17.0 & 748 & 32 & 265 & 0.0088 \\
12 Midcentral & 121.7 & 11.4 & 1489 & 632 & 513 & 0.0072 \\
13 Hutt & 104.7 & 11.5 & 1182 & 52 & 488 & 0.0073 \\
14 Capital and Coast & 211.9 & 7.6 & 2172 & 81 & 739 & 0.0059 \\
15 Wairarapa & 10.0 & 10.5 & 427 & 15 & 120 & 0.0070 \\
16 Nelson Marlborough & 101.6 & 6.2 & 1025 & 38 & 280 & 0.0053 \\
17 West Coast & 23.9 & 6.3 & 378 & 14 & 99 & 0.0075 \\
18 Canterbury & 371.1 & 5.1 & 3553 & 120 & 921 & 0.0049 \\
19 South Canterbury & 42.9 & 4.1 & 577 & 14 & 99 & 0.0044 \\
20 Otago & 141.9 & 4.6 & 1873 & 45 & 336 & 0.0046 \\
21 Southland & 82.6 & 8.1 & 1338 & 36 & 272 & 0.0061 \\
\hline Total & 3120.7 & 10.8 & 32173 & $1389^{*}$ & 12577 & 0.0072 \\
\hline
\end{tabular}

* A number of minor changes to the design resulted in this number being reduced to 1385.

Of these only 1378 meshblocks had eligible respondents. 
meshblocks. DHBs with larger proportions of Māori had slightly greater chances for meshblock selection. In total 1385 meshblocks were selected for surveying in the NZHS 2006/07.

\subsubsection{Secondary sampling units}

The second stage of sampling was the selection of households for the core and screened sample. The core sample was selected by selecting every $k$ th house in the meshblock based on a pre-allocated starting point. The screened sample used every $j$ th house. An average of 9.5 houses were selected for the core sample from each meshblock and 12 screened households in the 10 DHBs with higher concentrations of Māori, and 15 in the remaining DHBs. Each household in a DHB had the same chance of being selected in either the core or screened sample, creating a 'self-weighting sample', which helps reduce the variance in the estimation weights. However, this probability of selection varied among different DHBs and people of Māori, Pacific or Asian ethnicity.

\subsubsection{Respondent sampling}

Within each selected household all eligible people were recorded on a card in descending order of age, along with their ethnicity, on a sampling Kish grid. One adult and one child were selected based on whose name fell alongside the predetermined indicators on the Kish grid. The Kish selection table is a technique used in survey research, in which interviewers follow simple rules for selecting one person to interview from among household residents. 'The technique involves constructing a list of eligible individuals at a particular address, ordered by age, and then selecting according to the serial number of the address itself. The system is devised so that all individuals in a household have an equal chance of selection' (Marshall 1998). No interview was conducted for the screening sample if no household respondents were identified as Māori, Pacific or Asian. A total of 12,874 households participated in the NZHS 2006/07, with 12,488 adult interviews and 4,922 child interviews conducted through the use of primary caregivers.

\subsection{The questionnaire}

The NZHS 2006/07 remained similar to previous New Zealand Health Surveys to allow for comparisons over time. However the 2006/07 survey differed from previous NZ Health Surveys by adding additional questions on mental health conditions, new chronic pain questions and revised tobacco questions, as well as an expanded oral health care section. The NZHS 2006/07 was the first to ask comprehensive questions on child health, with the expanded child survey to be retained in future NZ Health Surveys.

The new topics and questions included in the NZHS 2006/07 had to meet the following criteria before they were added to the questionnaire:

- The NZ Health Survey is the most appropriate source for the information. The data cannot be collected more effectively and efficiently by any other means and the information should be required for monitoring purposes as opposed to a one-off research project.

- The data collected is needed to inform decisions made by the Ministry of Health and DHBs. The topic should be relevant to the New Zealand Health Strategy and current priority areas for the Ministry of Health.

- Quality information can be collected. The data collected by the questions must provide information of an acceptable quality. 


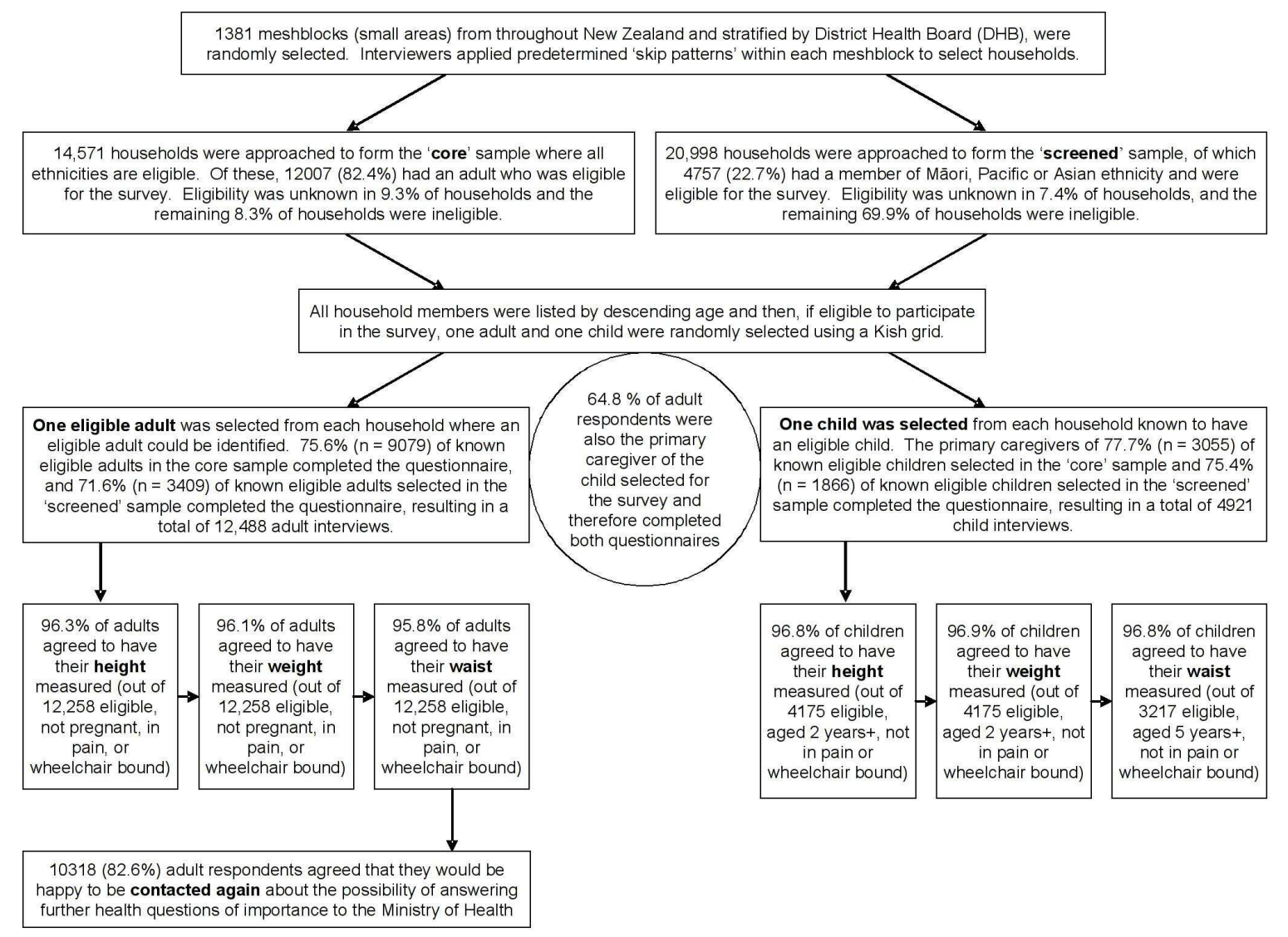

Figure 2.1: Procedure for selection of and participation rates for respondents in the NZHS 2006/07 
Content was also constrained by questionnaire limitations (i.e. closed questions with predetermined response categories), respondent burden and resistance (questions needed to be completed in a reasonable length of time and not offend anyone), continuity and relevance (questions needed to be able to be compared with previous NZHS) and the questions needed to be able to be combined with other surveys (e.g. collect ethnicity in the same standard way as is used in, for example, the Census).

Tables 2.2 and 2.3 display a summary of the content for the adult and child sections of the NZHS 2006/07.

\subsection{Data collection and response rate}

Participation in the NZHS 2006/07 was voluntary. The Ministry of Health sent invitation letters, consent forms and information to adults and primary caregivers of children selected for the survey.

Data collection for the NZHS 2006/07 was carried out between 6 October 2006 and 29 November 2007. A team of 200 National Research Bureau (NRB) professional social research interviewers were trained specifically for the NZHS 2006/07. Interviews were conducted faceto-face with respondents, in their homes, with the interviewer typing results straight into their computer using Blaise Computer Assisted Personal Interview (CAPI) software. Child interviews were conducted with the primary caregiver of the child.

Up to 10 calls were made to a selected dwelling before a dwelling was labelled as a noncontact. Calls were spaced over 3 months and conducted at different times of the week and day to try and capture all respondents. To minimize respondent burden and maximize response rates the following guidelines were used for the NZHS 2006/07:

- only one eligible adult and one eligible child were selected per dwelling;

- well-tested and largely well-proven questionnaires were used;

- professional trained interviewers conducted the interview;

- appointments were taken for interviews to be conducted at a time to suit the respondent and their family;

- language, culture and gender matching of eligible respondents and interviewer were undertaken where necessary;

- a proxy respondent could be used in case of severe ill health or cognitive disability;

- child care was provided if requested.

The final weighted response rate for adults was $67.9 \%$ as shown in Table 2.4. This reflects the probability of being selected into the sample and the rate of co-operation achieved by the target adult population. This response rate is the 'main measure used to assess the overall quality of a survey' (Ministry of Health 2008).

The response rate was calculated as follows:

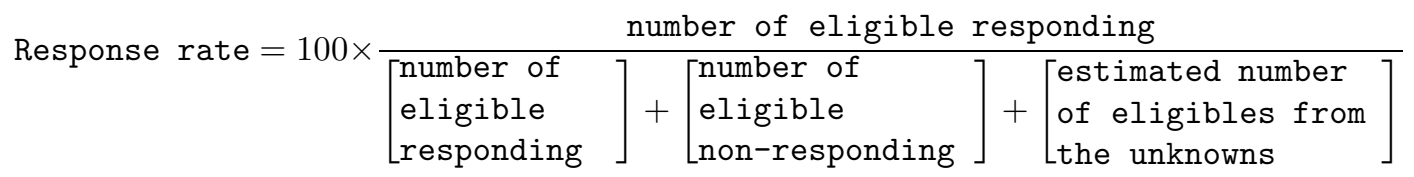


Table 2.2: Summarised content of the NZHS 2006/07 adult questionnaire. Source: Methodology Report for the 2006/07 New Zealand Health Survey (Ministry of Health, 2008)

\begin{tabular}{|c|c|c|}
\hline Module & Topics & Details \\
\hline $\begin{array}{l}\text { Chronic health } \\
\text { conditions }\end{array}$ & $\begin{array}{l}\text { Heart disease, stroke, diabetes, asthma, } \\
\text { chronic obstructive pulmonary disease, } \\
\text { arthritis, spinal disorders, osteoporosis, } \\
\text { cancer, mental health conditions, other } \\
\text { long-term conditions, chronic pain }\end{array}$ & $\begin{array}{l}\text { Prevalence of ever- } \\
\text { diagnosed condition, age } \\
\text { at diagnoses, treatments }\end{array}$ \\
\hline $\begin{array}{l}\text { Health service } \\
\text { utilisation }\end{array}$ & $\begin{array}{l}\text { Primary health care provider use, gen- } \\
\text { eral practitioners, nurses, oral health } \\
\text { care professionals, medical specialists, pre- } \\
\text { scriptions, complementary and alternative } \\
\text { health professionals, other health care pro- } \\
\text { fessionals, telephone health advice, hospi- } \\
\text { tal use }\end{array}$ & $\begin{array}{l}\text { Use in previous 12 } \\
\text { months, frequency of } \\
\text { contact, reasons for visit, } \\
\text { unmet need and barriers } \\
\text { to access, measures } \\
\text { of service for primary } \\
\text { health care }\end{array}$ \\
\hline $\begin{array}{l}\text { Health risk } \\
\text { and protective } \\
\text { factors }\end{array}$ & $\begin{array}{l}\text { High blood pressure, high blood choles- } \\
\text { terol, mammograms, cervical smears, } \\
\text { prostate specific antigen testing, physi- } \\
\text { cal activity, tobacco smoking, second-hand } \\
\text { smoke exposure, vegetable and fruit intake, } \\
\text { alcohol use and hazardous drinking, gam- } \\
\text { bling participation and problem gambling }\end{array}$ & $\begin{array}{l}\text { Prevalence of risk and } \\
\text { protective factors }\end{array}$ \\
\hline Health status & $\begin{array}{l}\text { General health in past four weeks (physical } \\
\text { and mental health), psychological distress }\end{array}$ & $\begin{array}{l}\text { SF-36 Health Status } \\
\text { Questionnaire and K10 } \\
\text { Psychological Distress } \\
\text { Scale }\end{array}$ \\
\hline $\begin{array}{l}\text { Socio- } \\
\text { demographic }\end{array}$ & $\begin{array}{l}\text { Gender, age, ethnicity, language, country } \\
\text { of birth, education, income support, labour } \\
\text { force status, income, racial discrimination, } \\
\text { medical insurance, household characteris- } \\
\text { tics, living standards and deprivation char- } \\
\text { acteristics }\end{array}$ & $\begin{array}{l}\text { Standard questions and } \\
\text { classifications }\end{array}$ \\
\hline Anthropometry & $\begin{array}{l}\text { Height, weight and waist circumference } \\
\text { measurements }\end{array}$ & $\begin{array}{ll}\text { Using } & \text { standardised } \\
\text { equipment } & \text { and proce- } \\
\text { dures } & \end{array}$ \\
\hline Re-contact & $\begin{array}{l}\text { Permission to re-contact within two-years, } \\
\text { contact details }\end{array}$ & \\
\hline
\end{tabular}


Table 2.3: Summarised content of the NZHS 2006/07 child questionnaire. Source: Methodology Report for the 2006/07 New Zealand Health Survey (Ministry of Health, 2008)

\begin{tabular}{|c|c|c|}
\hline Module & Topics & Details \\
\hline $\begin{array}{lr}\text { Health Status } \\
\text { and development }\end{array}$ & $\begin{array}{l}\text { Chronic conditions, general health in } \\
\text { past four weeks (physical and emo- } \\
\text { tional/behavioural), family cohesions, dis- } \\
\text { cipline }\end{array}$ & $\begin{array}{l}\text { Prevalence of ever- } \\
\text { diagnosed condition, age } \\
\text { at diagnosis, treatment, } \\
\text { CHQ-PF28 general } \\
\text { health questionnaire }\end{array}$ \\
\hline $\begin{array}{l}\text { Health service } \\
\text { utilisation }\end{array}$ & $\begin{array}{l}\text { Primary health care provider use, gen- } \\
\text { eral practitioners, nurses, oral health care } \\
\text { professionals, medical specialists, prescrip- } \\
\text { tions, other health care professionals, tele- } \\
\text { phone health advice, hospital use }\end{array}$ & $\begin{array}{l}\text { Use in previous } 12 \\
\text { months, frequency of } \\
\text { contact, reasons for visit, } \\
\text { unmet need and barriers } \\
\text { to access }\end{array}$ \\
\hline $\begin{array}{l}\text { Health risk } \\
\text { and protective } \\
\text { factors }\end{array}$ & $\begin{array}{l}\text { Breastfeeding, eating breakfast at home, } \\
\text { fizzy drink and fast food intake, active } \\
\text { transport to school, television watching, } \\
\text { exposure to second-hand smoke }\end{array}$ & $\begin{array}{l}\text { Prevalence of risk and } \\
\text { protective factors }\end{array}$ \\
\hline $\begin{array}{l}\text { Socio- } \\
\text { demographic }\end{array}$ & $\begin{array}{l}\text { Gender, age, ethnicity, language, country } \\
\text { of birth, early childhood care and educa- } \\
\text { tion, shared parenting arrangements, pri- } \\
\text { mary caregiver's relationship to child, age, } \\
\text { education, income support, labour status, } \\
\text { and household characteristics }\end{array}$ & $\begin{array}{l}\text { Standard questions and } \\
\text { classification }\end{array}$ \\
\hline Anthropometry & $\begin{array}{l}\text { Height and weight measurements (if two } \\
\text { years and over) and waist circumference } \\
\text { measurements (if five years and over) }\end{array}$ & $\begin{array}{ll}\text { Using } & \text { standardised } \\
\text { equipment } & \text { and proce- } \\
\text { dures } & \end{array}$ \\
\hline
\end{tabular}

Table 2.4: Final adult weighted response rates (percentage), by ethnic group and gender

\begin{tabular}{|l|c|c|c|c|c|}
\hline Ethnic group (total response) & \multicolumn{5}{|c|}{ Weighted Response rate (\%) } \\
\hline & Māori & Pacific & Asian & European/Other & Total \\
\hline Males & 62.6 & 65.5 & 79.5 & 66.4 & 66.1 \\
Females & 70.9 & 74.3 & 79.6 & 68.9 & 69.9 \\
\hline Total & 67.5 & 70.2 & 79.6 & 67.8 & 67.9 \\
\hline
\end{tabular}


The final weighted response rate for children was $71.2 \%$ as shown in Table 2.5. This was calculated using the same method as the adult response rate.

Table 2.5: Final child weighted response rates (percentage)

\begin{tabular}{|l|c|}
\hline Ethnic group (total response) & Weighted Response rate (\%) \\
\hline Māori & 74.9 \\
Pacific & 74.9 \\
Asian & 74.0 \\
European/Other & 75.0 \\
\hline Total & $71.2^{*}$ \\
\hline
\end{tabular}

* This lower overall response rate was due to children with unknown ethnicities treated as 'unknown eligibility' when non-response calculations were made.

Missing values of personal and household incomes were not imputed for this survey. The non-response was accounted for in the calculation of the weights where possible based on the standard weighting variables of age, sex, ethnicity and DHB.

\subsection{Weighting}

For this survey 'calibrated' weighting was used to 'reflect the probabilities of selection of each respondent' and 'make use of external population benchmarks to correct for any discrepencies between the sample and the population benchmarks - this improves the precision of estimates and reduces bias due to non-response'. This was done using population counts based on age, sex, ethnicity and DHB (used as the main geographic classification during analysis), from the 2006 New Zealand Census.

Weights were 'chosen to minimise a measure of distance between the weights and the inverse selection probabilities' whilst still having low bias and improved precision of estimates (due to the weights being calibrated by age, sex, ethnicity and DHB) which also provides consistency between survey estimates and creates external benchmarks for analysis.

The inverse selection probability is referred to as the initial weight. The final calibrated weights are expressed as:

$$
\text { final weight }=\text { initial weight } \times g \text {-weight }
$$

The $g$-weight indicated the factor by which calibration had changed the initial weight.

100 replicate weights were calculated for each respondent using the GREGWT (Generalised regression estimation) package, provided by the Australian Bureau of Statistics. This jackknife method uses 100 replicate estimators for each respondent, which correspond to removing a group of meshblocks, reweighting the remaining sample and then scaling to the appropriate levels (Ministry of Health 2008). The standard errors produced for a population estimate are then based on the variation of the replicate estimates.

Table 2.6 shows the effect that the weights have on the sample, as they alter the percentages of sub populations, to mirror the New Zealand population, based on population benchmarks from the 2006 New Zealand Census. 
Table 2.6: Representativeness of the NZHS 2006/07 Adult Sample

\begin{tabular}{|c|c|c|c|c|}
\hline Subdomain & $\begin{array}{c}\text { Sample } \\
\text { Percentage }(\%)\end{array}$ & $\begin{array}{c}\text { Weighted } \\
\text { Percentage }(\%)\end{array}$ & $\begin{array}{l}\text { Sample } \\
\text { Number }\end{array}$ & $\begin{array}{l}\text { Weighted } \\
\text { Number }\end{array}$ \\
\hline Sex & & & & \\
\hline Male & 42.22 & 47.99 & 5,273 & $1,497,567$ \\
\hline Female & 57.78 & 52.01 & 7,215 & $1,623,139$ \\
\hline Age & & & & \\
\hline $15-24$ & 13.32 & 17.73 & 1,663 & 553,203 \\
\hline $25-34$ & 16.66 & 16.27 & 2,080 & 507,857 \\
\hline $35-44$ & 20.64 & 19.53 & 2,577 & 609,571 \\
\hline $45-54$ & 16.65 & 17.82 & 2,079 & 555,991 \\
\hline $55-64$ & 13.84 & 13.39 & 1,729 & 417,985 \\
\hline $65-74$ & 10.44 & 8.59 & 1,304 & 268,155 \\
\hline 75 & 8.46 & 6.66 & 1,056 & 207,944 \\
\hline Ethnicity & & & & \\
\hline European/Other & 55.63 & 74.88 & 6,947 & $2,336,893$ \\
\hline Māori & 25.30 & 11.39 & 3,160 & 355,364 \\
\hline Pacific & 7.35 & 4.98 & 918 & 155,378 \\
\hline Asian & 11.72 & 8.75 & 1,463 & 273,071 \\
\hline Deprivation Quintile & & & & \\
\hline NZDep 1 & 16.10 & 21.60 & 2,011 & 674,178 \\
\hline NZDep 2 & 16.99 & 19.51 & 2,122 & 608,808 \\
\hline NZDep 3 & 20.03 & 20.66 & 2,501 & 644,759 \\
\hline NZDep 4 & 21.87 & 20.50 & 2,731 & 639,695 \\
\hline NZDep 5 & 25.01 & 17.73 & 3,123 & 553,266 \\
\hline
\end{tabular}




\section{Chapter 3}

\section{Statistical Methods}

This chapter describes the statistical theory used for analysing the data from the New Zealand Health Survey 2006/07. A review of the theory used for simple univariate analysis of the survey data, along with point estimates and confidence intervals is presented. A description of the jackknife method follows. The jackknife method is used in all variance estimation for the NZHS 2006/07. A description of regression models is presented along with infomation on the model selection and model checking processes used in this analysis.

\subsection{General calculations and notation}

\subsubsection{Descriptive analysis}

In descriptive analysis of the NZHS and ICS II Oral Health Suvey most variables of interest are categorical, where we have a single categorical outcome and we wish to estimate the size of the population in each category and hence the proportion of the population in each category.

Population totals were calculated using

$$
\hat{Y}=\sum_{k} I_{k}^{c} w_{k}
$$

Where $I_{k}^{c}$ is the indicator variable associated with whether a person belongs to a particular class or not. $w_{k}$ is the survey estimation weight of individual $k$.

$$
I_{k}^{c}= \begin{cases}1, & \text { if individual } k \text { is in category } C \\ 0, & \text { if individual } k \text { is not in category } C\end{cases}
$$

Proportions for each category can be calculated using:

$$
\begin{aligned}
P_{c} & =\frac{\sum_{k} I_{k}^{c} w_{k}}{\sum_{k} w_{k}} \\
& =\frac{\sum_{k \in c} w_{k}}{\sum_{k} w_{k}}
\end{aligned}
$$




\subsubsection{Single-factor analysis}

For Single-factor analysis we can incorporate an explanatory variable into this analysis. We group the outcome variable into categories according to explanatory variables. Population totals are calculated using

$$
\hat{Y}=\sum_{k} I_{k}^{L c} w_{k}
$$

Where $I_{k}^{L c}$ is the indicator variable associated with whether a person belongs to a subset $(L)$ of particular category $(C)$ or not.

$$
I_{k}^{L c}= \begin{cases}1, & \text { if individual } \mathrm{k} \text { is in class } C \text { and in subset } L \\ 0, & \text { if individual } \mathrm{k} \text { is not in class } C \text { and subset } L\end{cases}
$$

Proportions for each category can be calculated using:

$$
\begin{aligned}
P_{c} & =\frac{\sum_{k} I_{k}^{L c} w_{k}}{\sum_{k} I_{k}^{C} w_{k}} \\
& =\frac{\sum_{k \in C, L} w_{k}}{\sum_{k \in C} w_{k}} \\
& =\text { proportion of people in class } C \text { who are in group } L
\end{aligned}
$$

If $\sum_{k \in C} w_{k}$ is known and has been used as a post stratification benchmark, then $P_{c}$ is a simple linear estimator. Otherwise $P_{c}$ is a ratio estimator, with both numerator and denominator being estimates.

\subsubsection{Means}

Let $w_{j}$ be the number of people in group $j, y_{k}$ is the value of the variable for individual $k$. $\widehat{w}_{k j}=$ the number of people in group $j$ and also in subgroup $k$, with variance $=\operatorname{var}\left(\widehat{w}_{k j}\right)$ The mean value of a certain characteristic $(k)$ for the people in group $j$ is $\hat{\theta}_{j}$

$$
\begin{aligned}
\theta_{j} & =\frac{\sum_{k} y_{k} w_{k j}}{w_{j}} \\
\hat{\theta}_{j} & =\frac{\sum_{k} y_{k} \widehat{w}_{k j}}{w_{j}}
\end{aligned}
$$

where $\hat{\theta}_{j}$ has variance $\operatorname{var}\left(\hat{\theta}_{j}\right)=\sum_{k} \frac{y_{k}^{2}}{w_{j}^{2}} \operatorname{var}\left(\widehat{w}_{k j}\right)$

\subsection{The jackknife method}

The jackknife method is used to calculate variances for the NZHS estimates because the survey has a complex survey design, and analytical results are not available in general. The jackknife method is also used in the regression model analysis. Health and Disability Intelligence (HDI) created a set of jackknife replicate survey weights for this dataset using the Delete-a-group jackknife method.

In using the jackknife method we are re-sampling the sample data, by taking subsets of the sample and recalculating the required statistics (estimators). We then take the variability 
between these new subset estimates and use this as the variance of our estimator $(\hat{\theta})$ which was calculated based on the whole sample.

The Delete-a-group jackknife deletes whole groups of PSUs (rather than a single PSU) to form the new subsets. The units in the remaining PSUs are reweighted so that the weights for each replicate add up to the correct population benchmarks. The NZHS data contained 100 groups $(G)$ and their replicate weights were provided by HDI with the data set. These groups were balanced across strata to represent the sample design.

The formula used to calculate the jackknife variance estimate for our estimator $(\widehat{\theta})$ for a population parameter $\theta$, where we used delete-a-group jackknifing is:

$$
\operatorname{Var}(\hat{\theta})=\frac{G-1}{G} \times \sum_{g=1}^{G}\left(\hat{\theta}_{(g)}-\hat{\theta}\right)^{2}
$$

The general method is:

1. We calculate our estimate $\hat{\theta}$ using the whole sample;

2. We drop group $g$ out, recalculate the weights (including benchmarking again, so that the new weights for the reduced sample still add up to the benchmark totals - the weights in general have to be larger). Then we create a new estimate $\hat{\theta}_{(g)}$;

3. Repeat for all $G$ groups - so we have a set of $G$ jackknife estimates $\hat{\theta}_{g}, g=1, \ldots, G$ along with the original estimate $\hat{\theta}$;

4. Calculate the variance of those $G$ estimates $V$;

5. The variance of the estimator is then $\operatorname{Var}(\hat{\theta})=\frac{(G-1)^{2}}{G} \times V$.

\section{Sampling error and confidence intervals}

For approximately normal distributions, the sampling error (SE) can be found from the jackknifed variance:

$$
\widehat{\mathrm{SE}}(\hat{\theta})=\sqrt{\widehat{\operatorname{Var}}(\hat{\theta})}
$$

and using the sampling error, $95 \%$ confidence intervals can be calculated for $\hat{\theta}$ :

$$
\hat{\theta} \pm 1.96 \times \widehat{\mathrm{SE}}(\hat{\theta})
$$

\section{Relative Sampling Error}

The Relative Sampling Error (RSE) gives an indication of the precision of the results.

$$
\operatorname{RSE}(\hat{\theta})=\frac{\widehat{\operatorname{SE}}(\hat{\theta})}{(\hat{\theta})}
$$

A large RSE of 0.3 or more, suggests an unreliable result, that should be treated with caution. An RSE of 0.5 or more is considered a very unreliable result.

\subsubsection{Significance testing for differences}

To test the significance of differences between estimates from the two separate surveys, we need to have comparable variables and corresponding estimates. Let $\widehat{\theta}_{1}$ be the estimate of some parameter $\theta$ from survey 1 , and $\widehat{\theta}_{2}$ be the corresponding estimate from survey 2 . 


$$
\begin{aligned}
& \widehat{\theta}_{1} \text { has variance } v_{1}=\operatorname{Var}\left(\widehat{\theta_{1}}\right) \\
& \widehat{\theta}_{2} \text { has variance } v_{2}=\operatorname{Var}\left(\widehat{\theta_{2}}\right)
\end{aligned}
$$

Then the estimator of the change in $\theta$ is

$$
\widehat{\delta}=\widehat{\theta_{1}}-\widehat{\theta_{2}}
$$

with

$$
\mathrm{v}_{\delta}=\operatorname{Var}(\widehat{\delta})=\operatorname{Var}\left(\widehat{\theta_{1}}\right)+\operatorname{Var}\left(\widehat{\theta_{2}}\right)-2 \operatorname{Cov}\left(\widehat{\theta_{1}}, \widehat{\theta_{2}}\right)
$$

When two surveys are independent $\operatorname{Cov}\left(\widehat{\theta_{1}}, \widehat{\theta_{2}}\right)=0$

We calculate the $\mathrm{Z}$ test statistic using:

$$
Z=\frac{\widehat{\delta}}{\operatorname{SE}(\widehat{\delta})}
$$

Where for independent surveys

$$
\mathrm{SE}(\widehat{\delta})=\sqrt{\operatorname{var}\left(\widehat{\theta_{1}}\right)+\operatorname{var}\left(\widehat{\theta_{2}}\right)}
$$

The corresponding 2 sided $\mathrm{p}$-value is calculated from the $\mathrm{Z}$ value. $\mathrm{P}$-values below 0.05 are considered significant at the $5 \%$ significance level and we conclude there is a significant difference between $\theta_{1}$ and $\theta_{2}$.

\subsection{Regression}

\subsubsection{Generalised linear models}

The Generalised Linear Model (GLM) is used to model the relationship between a dependent (response) variables $Y$ and explanatory (observed) variables $\mathbf{x}$. Here $\mathbf{x}$ is $p \times 1$ vector of explanatory variables. $\boldsymbol{\beta}$ is a $p \times 1$ vector of parameters.

The GLM has three components:

1. The Response variables $Y_{1}, \ldots, Y_{N}$, are assumed to share the same distribution which belongs to a member of the exponential family of distributions. This means that the probability distribution function of each $Y_{i}$ has the canonical form

$$
f\left(y_{i} ; \theta_{i}\right)=\exp \left[y_{i} b\left(\theta_{i}\right)+c\left(\theta_{i}\right)+d\left(y_{i}\right)\right]
$$

which depends on the parameter $\theta_{i}$.

2. A set of parameters $\boldsymbol{\beta}$ and explanatory variables $\mathbf{x}$ which combine to form the linear predictor $\mu_{i}=\mathbf{x}_{\mathbf{i}}^{\mathbf{T}} \boldsymbol{\beta}$

3. A monotone link function $g$ such that

$$
g\left(\mu_{i}\right)=\mathbf{x}_{\mathbf{i}}^{\mathbf{T}} \boldsymbol{\beta}=\mu_{\mathbf{i}}
$$

where

$$
\mu_{i}=E\left(Y_{i}\right)
$$


An example of a GLM is a Logit Model. This is used in the case where our outcome variables $Y$ are from a Bernoulli distribution (i.e.. they only have two possible values: 0 or 1).

$$
Y_{i} \sim \operatorname{Bernoulli}\left(\pi_{i}\right) \text { and } E\left(Y_{i}\right)=\mu_{i}=\pi_{i}
$$

The probability function takes the form

$$
\begin{aligned}
f\left(y_{i} ; \pi_{i}\right) & =\pi_{i}^{y_{i}}\left(1-\pi_{i}\right)^{1-y_{i}} \\
& =\left(1-\pi_{i}\right) \exp \left[y_{i} \log \left(\frac{\pi_{i}}{1-\pi_{i}}\right)\right]
\end{aligned}
$$

which is in the form

$$
f\left(y_{i} ; \theta_{i}\right)=s\left(y_{i}\right) t\left(\theta_{i}\right) \exp \left[a\left(y_{i}\right) b\left(\theta_{i}\right)\right]
$$

$a\left(y_{i}\right), s\left(y_{i}\right)$ and $t\left(\theta_{i}\right)=$ are known functions. This can be rewritten as

$$
f\left(y_{i} ; \theta_{i}\right)=\exp [a(y) b(\theta)+c(\theta)+d(y)]
$$

where $s(y)=\exp [d(y)]$ and $t(\theta)=\exp [c(\theta)]$, implying that it belongs to the exponential family (Dobson 2002)

The model has a natural parameter,

$$
b\left(\pi_{i}\right)=\log \left(\frac{\pi_{i}}{1-\pi_{i}}\right)=\operatorname{logit}\left(\pi_{i}\right)
$$

which in this case is known as a 'logit of $\pi$ '. A logit model is a GLM which has a logistic link

$$
g\left(\pi_{i}\right)=\log \left(\frac{\pi_{i}}{1-\pi_{i}}\right)=\mathbf{x}_{\mathbf{i}}^{\mathbf{T}} \boldsymbol{\beta}
$$

\subsubsection{Forms of regression models}

The null model contains only an intercept term as the single parameter giving

$$
E\left[Y_{i}\right]=\mu \text { for all } i
$$

with the corresponding equation for the null model for logistic regression being

$$
\operatorname{logit}\left(\pi_{i}\right)=\alpha
$$

A saturated or maximal model is where there is one parameter for every observation defined in the model. The set of parameters $p$ is the same size as the number of observations $n$. i.e. $p=n$. Here

$$
E\left[Y_{i}\right]=\mu_{i}
$$

Between the saturated and null models are a set of alternative models of various levels of complexity, incorporating the predictor variables $\mathbf{x}_{\mathbf{i}}$. These models have a set of parameters where $1<p<n$, and which have the form:

$$
g\left(E\left[Y_{i}\right]\right)=g\left(\mu_{i}\right)=\mathbf{x}_{\mathbf{i}}^{\mathbf{T}} \boldsymbol{\beta}
$$

A main effects model does not involve any interaction terms between explanatory variables. A logistic main effects model with two parameters looks like

$$
\operatorname{logit}\left(\pi_{i}\right)=\alpha+\beta_{1} x_{1 i}+\beta_{2} x_{2 i}
$$

where $x_{1 i}$ and $x_{2 i}$ are variables such as sex $($ Female $=1$, Male $=0)$ or a binary ethnicity variable such as Māori (Māori=1, Non-Māori=0 for individual $i$ ).

If an interaction term was to be added to the above model we would have

$$
\operatorname{logit}\left(\pi_{i}\right)=\alpha+\beta_{1} x_{1 i}+\beta_{2} x_{2 i}+\beta_{3} x_{1 i} x_{2 i}
$$




\subsubsection{Logistic regression}

The Likelihood function for the logistic regression model is

$$
\begin{aligned}
L(\mathbf{y} ; \pi(\mathbf{x})) & =\prod_{i=1}^{n} f\left(y_{i} ; \pi_{i}\right) \\
& =\prod_{i=1}^{n} \pi_{i}^{y_{i}}\left(1-\pi_{i}\right)^{1-y_{i}} \\
& =\exp \left[\sum_{i=1}^{n} y_{i} \log \left(\frac{\pi_{i}}{1-\pi_{i}}\right)+\log \left(1-\pi_{i}\right)\right]
\end{aligned}
$$

This assumes independence of the $\mathrm{Y}$ values such that $y_{i} \Perp y_{j} \mid \pi_{i}$ where $i \neq j$. This has a log-likelihood function of:

$$
\begin{aligned}
l\left(\mathbf{y} ; \pi(\mathbf{x})_{\mathbf{i}}\right) & =\log L\left(\mathbf{y} ; \pi(\mathbf{x})_{\mathbf{i}}\right) \\
& =\sum_{i=1}^{n}\left[y_{i} \log \left(\frac{\pi_{i}}{1-\pi_{i}}\right)+\log \left(1-\pi_{i}\right)\right] \\
& =\sum_{i=1}^{n}\left[y_{i} \operatorname{logit}\left(\pi_{i}\right)+\log \left(1-\pi_{i}\right)\right] \\
& =\sum_{i=1}^{n}\left[y_{i} \mathbf{x}_{\mathbf{i}}^{\mathbf{T}} \boldsymbol{\beta}+\log \left(\mathbf{1}+\mathbf{x}^{\mathbf{T}} \boldsymbol{\beta}\right)\right]
\end{aligned}
$$

The above log-likelihood equation can be maximised with respect to $\boldsymbol{\beta}$ and solved with respect to $\boldsymbol{\beta}$ to find the Maximum Likelihood (ML) estimates for $\boldsymbol{\beta}$.

Once the logistic regression model has been fitted the probability of success for individual $i$ is:

$$
\widehat{\pi}_{i}=g^{-1}\left(\mathbf{x}^{\mathbf{T}} \widehat{\boldsymbol{\beta}}\right)=\frac{\exp \left(\mathbf{x}^{\mathbf{T}} \widehat{\boldsymbol{\beta}}\right)}{\mathbf{1}+\exp \left(\mathbf{x}^{\mathbf{T}} \widehat{\boldsymbol{\beta}}\right)}
$$

The residual for observation $i$ is $e_{i}=y_{i}-\hat{\pi}_{i}$.

\subsubsection{Model interpretation}

For each explanatory variable used in the logistic regression we have an odds ratio (OR) and a confidence interval. If an explanatory variable has two values, $a$ and $b$, the general odds ratio is given by:

$$
\frac{\operatorname{Odds}(x=a)}{\operatorname{Odds}(x=b)}=\frac{\frac{P(x=a)}{1-P(x=a)}}{\frac{P(x=b)}{1-P(x=b)}}=\exp (\alpha+\beta a-\alpha-\beta b)=\exp (\beta[a-b])
$$

A $95 \%$ confidence interval for the odds ratio is calculated by forming a $95 \%$ confidence interval for $\beta(a-b)$ in the form $(L, U)$ for example using:

$$
L=\hat{\beta}(a-b)-1.96 \times(a-b) S E(\hat{\beta})
$$


where the SE is the standard error of $\hat{\beta}$ calculated using the jackknife technique. The $95 \%$ confidence interval becomes $(\exp (L), \exp (U))$

The explanatory variables used in the analyses in this thesis are all categorical variables. A reference category is selected for each variable and odds ratios are calculated with respect to this reference level. The odds ratio for each estimate simplifies to become:

$$
\frac{\operatorname{odds}(x=1)}{\operatorname{odds}(x=0)}=\exp (\beta)
$$

where $x=0$ is the reference level and the odds ratio has the $95 \%$ confidence interval:

$$
\exp (\beta \pm 1.96 \times S E(\beta))
$$

If $X_{j}$ is a binary explanatory variable then $\exp \left(\beta_{j}\right)$ is the odds ratio associated with that explanatory factor, when all other factors are fixed. When there is an interaction term in the regression model the interpretation becomes more complex as the associated odds ratio for each $i$ group depends on the category of the $j$ group to which we are assessing.

\subsubsection{Ordinal regression}

For ordinal response outcome variables, where there are 2 or more ordered categorical outcomes, we can model functions called cumulative logits by performing an ordered logistic regression, using the proportional odds model (Stokes et al. 2000).

A cumulative probability for $\mathrm{Y}$ is the probability that $\mathrm{Y}$ falls at or below a particular point. For outcome category $j$ (where $j=1 \ldots J$ ), the cumulative probability is

$$
P(Y \leq j)=\pi_{1}+\ldots+\pi_{j}
$$

These cumulative probabilities reflect the ordering of the outcome variable, with

$$
P(Y \leq 1) \leq P(Y \leq 2) \leq \ldots \leq P(Y \leq J)=1
$$

The logits of the cumulative probabilies are

$$
\begin{aligned}
\operatorname{logit}[P(Y \leq j)] & =\log \left[\frac{P(Y \leq j)}{1-P(Y \leq j)}\right] \\
& =\log \left[\frac{\pi_{1}+\ldots+\pi_{j}}{\pi_{j+1}+\ldots+\pi_{J}}\right] \\
\text { where } j & =1, \ldots J-1 .
\end{aligned}
$$

The model for the cumulative logit $j$ looks like a binary logistic regression model in which categories 1 to $j$ and $j+1$ to $J$ form the two categories (Agresti 2007). For a single explanatory variable $x$, the model is

$$
\begin{gathered}
\operatorname{logit}\left[P\left(Y_{i} \leq j\right)\right]=\alpha_{j}+\beta x_{i} \\
\text { for } j=1, \ldots J-1 .
\end{gathered}
$$

where $\alpha_{1}<\alpha_{2}<\ldots<\alpha_{J-1}<\alpha_{J}=\infty$.

The limitation with this model is that $\beta$ does not depend on $j$. 


\section{Model interpretation}

Odds ratios for the cumulative probabilities can be used to intepret the cumulative probability model. For two values $x_{1}$ and $x_{2}$ of $x$, an odds ratio comparing the cumulative probabilities is

$$
\frac{P\left(Y \leq j \mid X=x_{2}\right) / P\left(Y>j \mid X=x_{2}\right)}{P\left(Y \leq j \mid X=x_{1}\right) / P\left(Y>j \mid X=x_{1}\right)}
$$

'The log of this odds ratio is the difference between the cumulative logits at those two values of $x$. This equals $\beta\left(x_{2}-x_{1}\right)$, proportional to the distance between the $x$ values' (Agresti 2007). 'For this $\log$ odds ratio $\beta\left(x_{2}-x_{1}\right)$, the same proportionality constant $\beta$ applies for each cumulative probability' (Agresti 2007). This property is called the proportional odds assumption of the model

$$
\begin{gathered}
\operatorname{logit}[P(Y \leq j)]=\alpha_{j}+\beta x \\
\text { for } j=1, \ldots J-1 .
\end{gathered}
$$

The model expression for the cumulative probabilities is

$$
P(Y \leq j)=\frac{\exp \left(\alpha_{j}+\beta x\right)}{\left[1+\exp \left(\alpha_{j}+\beta x\right)\right]}
$$

\subsubsection{Ordinal regression model example}

To illustrate how ordinal regression works, we demonstrate the method using an example taken from Categorical Data Analysis Using the SAS System Stokes et al. (2000)(Chapter 9, Logistic Regression II: Polytomous Response).

The example uses data on arthritis patients given in Table 3.1, and the extent of their improvement (marked, some or none) based on their sex and treatment (active or placebo).

Table 3.1: Arthritis Data

\begin{tabular}{|ll|c|c|c|c|}
\hline & & \multicolumn{3}{|c|}{ Improvement } & \\
Sex & Treatment & Marked & Some & None & Total \\
\hline Female & Active & 16 & 5 & 6 & 27 \\
Female & Placebo & 6 & 7 & 19 & 32 \\
Male & Active & 5 & 2 & 7 & 14 \\
Male & Placebo & 1 & 0 & 10 & 11 \\
\hline
\end{tabular}

We use the following code to enter the data set into SAS

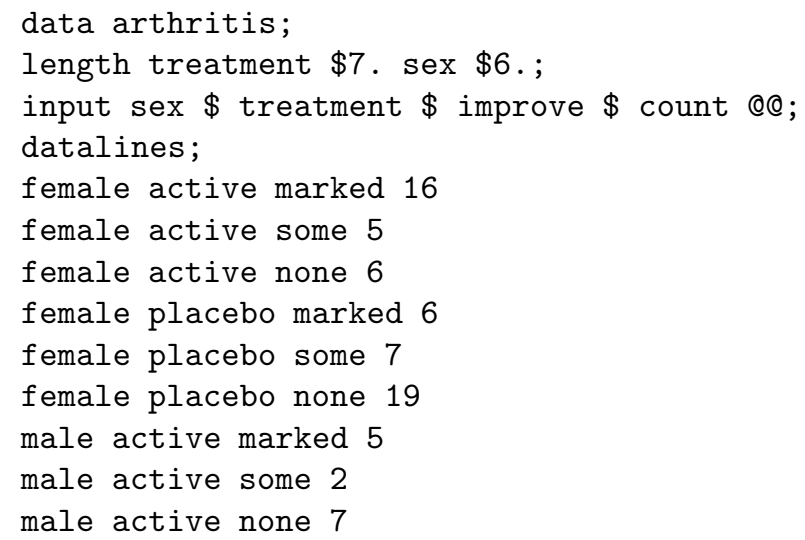


male placebo marked 1

male placebo some 0

male placebo none 10;

run;

Fitting the interaction model using proc logistic in SAS.

proc logistic order=arthritis;

freq count;

class sex treatment / param=reference;

model improve $=$ sex treatment sex*treatment / selection=forward start $=2$;

run;

SAS output gives:

The LOGISTIC Procedure

Analysis of Maximum Likelihood Estimates

\begin{tabular}{|c|c|c|c|c|c|c|c|}
\hline Parameter & & $D F$ & Fstimate & Standard & $\begin{array}{r}\text { Wald } \\
\text { Chi-Sauare }\end{array}$ & $\operatorname{Pr}$ & ChiSq \\
\hline Intercept & marked & 1 & -2.6671 & 0.5997 & 19.7800 & & $<.0001$ \\
\hline Intercept & some & 1 & -1.8127 & 0.5566 & 10.6064 & & 0.0011 \\
\hline $\operatorname{sex}$ & female & 1 & 1.3187 & 0.5292 & 6.2096 & & 0.0127 \\
\hline treatment & active & 1 & 1.7973 & 0.4728 & 14.4493 & & 0.0001 \\
\hline
\end{tabular}

Odds Ratio Estimates

Effect

sex female vs male

treatment active vs placebo

Point

Estimate
3.739
6.033
1.325
2.388

95\% Wald

Confidence Limits

Association of Predicted Probabilities and Observed Responses

$\begin{array}{llll}\text { Percent Concordant } & 58.8 & \text { Somers' D } & 0.438 \\ \text { Percent Discordant } & 15.0 & \text { Gamma } & 0.593 \\ \text { Percent Tied } & 26.2 & \text { Tau-a } & 0.271 \\ \text { Pairs } & 2156 & \text { C } & 0.719\end{array}$

Example interpretation:

The model used here is

$$
\operatorname{logit}(P(Y \leq j))=\alpha_{j}+\beta_{1}(\operatorname{sex})_{i}+\beta_{2}(\text { treatment })_{i}
$$

where

$$
(\operatorname{sex})_{i}= \begin{cases}1, & \text { if person } i \text { is female } \\ 0, & \text { if person } i \text { is male }\end{cases}
$$




$$
\text { (treatment })_{i}= \begin{cases}1, & \text { if person } i \text { has active treatment } \\ 0, & \text { if person } i \text { has placebo }\end{cases}
$$

Because forward selection has been specified in the model, the interaction term of sex $\times$ treatment was found to not be significant and was not printed with the final results as it was omitted from the final model.

$\alpha_{1}=-2.667$ with a standard error of 0.600 . This is the log odds of marked improvement versus some or no improvement for males receiving a placebo treatment. The odds ratio is $\exp (-2.667)=0.0695$.

$\alpha_{2}=-1.813$ with a standard error of 0.557 . This is the log odds of some improvement versus no improvement for males receiving a placebo treatment. The odds ratio is $\exp (-1.813)=0.1632$

$\beta_{1}=1.319$ with a standard error of 0.529 is the increment for both types of log odds due to female sex. This means that females have $\exp (1.319)=3.7$ times higher odds of showing improvement as males, both for marked improvement versus some or no improvement.

$\beta_{2}=1.797$ with a standard error of 0.473 is the increment for both types of log odds due to active drug. This means that those receiving the active drug have $\exp (1.8)=6$ times higher odds of showing improvement as those on placebo, both for marked improvement versus some or no improvement and for some or marked improvement versus no improvement.

\subsubsection{Model selection and checking}

\section{Testing individual parameters}

We define the maximal model to be that with all main effects and two-way interactions of a set of predictor variables. We then use backward stepwise regression to remove unnecessary explanatory variables from the model one at a time, based on a goodness of fit test. In the analysis in this thesis, in particular those in Chapter 6, we use Wald tests to perform model selection because deviance based tests are unavailable due to our data being weighted survey data.

The Wald test is used to test the significance of the individual parameters $\beta_{\ell}$ and their difference from zero. Our null hypothesis is $\mathrm{H}_{o}: \beta_{\ell}=0$ against the two-sided alternative that $\mathrm{H}_{a}: \beta_{\ell} \neq 0$. The test statistic is

$$
z=\frac{\beta_{\ell}}{S E\left(\beta_{\ell}\right)}
$$

and this follows a standard normal distribution. If the corresponding p-value for our test statistic $z$ is less than our specified significance level (usually $\alpha=5 \%$ ) then we reject $\mathrm{H}_{o}$ and $\beta_{\ell}$ is taken to be a significant parameter in the model (Agresti 2007).

For categorical explanations, if any level of the factor is found to be significant by the Wald test, then that factor is retained in the model even if some factor levels are not significantly different from zero.

\section{Log-likelihood and deviance}

For a logistic regression model, parameters $(\beta)$ are obtained through maximum likelihood estimation (MLE). 
For unweighted data, once the parameters $\beta$ have been found for each model, the deviance can be used to determine the best model. The deviance follows an approximated chi-squared distribution $D \sim \chi_{n-p}^{2}$ where $n$ is the number of observations and $p$ is the number of parameters.

$$
\begin{aligned}
D & =2\left[\log L_{\max }-\log L\right] \\
& =2\left[l_{\max }-l(\mu)\right]
\end{aligned}
$$

This deviance, $D$, of a candidate model is always positive.

We can compare two nested models using the change in deviance. One model must be a subset of the other. Here, $M_{1}$ is a subset of the more complex model $M_{2}$. The null hypothesis is $H_{o}: M_{1}$ holds and the alternative is $H_{A}: M_{2}$ holds.

The change in deviance is given as:

$$
\begin{aligned}
\Delta D & =D_{1}-D_{2} \\
& =2\left(l_{\max }-l_{1}\right)-2\left(l_{\max }-l_{2}\right) \\
& =2\left(l_{2}-l_{1}\right) \\
& \sim \chi_{p 2-p 1}^{2}
\end{aligned}
$$

Where $D_{i}$ are the deviances for models $i=1,2 ; p_{i}$ is the number of observations for the model $M_{i} ; l_{\max }, l_{1}$ and $l_{2}$ are the $\log$ likelihood values for the maximal model and the two models $M_{1}$ and $M_{2}$. The degrees of freedom is given by $\left(p_{2}-p_{1}\right)$.

For weighted data the log likelihood is

$$
l(\beta)=\sum_{i} w_{i}\left(y_{i} \operatorname{logit} \pi_{i}+\log \left(1-\pi_{i}\right)\right)
$$

which is maximised over $\beta$. However the deviance based tests do not apply. Instead, we use the Wald tests described above for model selection, and use residual plots for model checking.

\section{Stepwise logistic regression}

The most appropriate model can be selected using stepwise methods. Stepwise logistic regression involves moving fowards, backwards or in both directions through models, by adding and dropping explanatory variables based on the Wald Statistics results, log likelihood and deviance measures. Terms in the model are dropped during backwards regression, after they have been found to be non-significant after Wald testing.

\section{Goodness of fit}

Goodness of fit tests describe how well the model fits the data. We test the hypothesis $H_{O}$ : the model holds, against the alternative $H_{A}$ : the model does not hold.

For unweighted data we can use the deviance to compare the maximised values of the log likelihood functions for the maximal and the model we are interested in. This goodness of fit test requires categorical or grouped data. The deviance is given as:

$$
D=2\left[\log L_{\max }-\log L\right]
$$


Pearson's chi-squared test can also be used to test the goodness of fit, by comparing observed and expected values for the data. The test statistic is given by the formula:

$$
X^{2}=\sum_{i=1}^{n} \frac{\left(y_{i}-n_{i} \hat{\pi}_{i}\right)^{2}}{\operatorname{Var}\left(n_{i} \hat{\pi}_{i}\right)}
$$

where $i=1, \ldots, n$ are the cross-classified cells in the model, $y_{i}$ are the observed values in cell $i$, and $\hat{p}_{i}$ are the predicted probabilities in the model for cell $i$.

Both $D$ and $X^{2}$ follow a chi-squared distribution $\chi_{(n-p)}^{2}$, where $p$ is the number of estimated parameters and $n$ is the number of observations. However for weighted data such tests are no available, and instead we rely on analysis of residuals for model checking.

\section{Residuals}

Graphs of residuals can be checked to ensure that there are no outlier or systematic trends and thus test model fit. The residuals are calculated as the difference between the observed values and the expected values, based on our selected model and are expected to lie with in \pm 3 standard deviations of the mean.

$$
\text { Residual }=y_{i}-\hat{y}_{i}
$$

Where $y_{i}$ is the observed count in cell $i$, and

$$
\hat{y}_{i}=n_{i} \hat{\pi}_{i}
$$

where $n_{i}$ are the population counts in cell $i$ and $\hat{p}_{i}$ are the expected probabilities from the selected regression model.

We use the following formula for standardised residuals in order to take into account the different group sizes for variables, we create a standardised residual combining the estimation variance and the variance of the predicted values.

$$
\operatorname{Residual}_{S t d}=\frac{y_{i}-n_{i} \hat{p}_{i}}{\sqrt{\operatorname{Var}\left(n_{i} \hat{p}_{i}\right)+n_{i} \hat{p}_{i}\left(1-\hat{p}_{i}\right)}}
$$

The estimator variance $\operatorname{var}\left(n_{i} \hat{p}_{i}\right)$ is derived from the jackknife.

The outcome measures analysed in this thesis are all categorical and observed and fitted values, must be aggregated into larger categories before residuals can be calculated. We use age, sex and ethnicity to form cells in which we calculate residuals, and inspect plots of these residuals to test for adequate model fit. 


\section{Chapter 4}

\section{Demographic characteristics}

In this chapter we summarise the demographics characteristics of the New Zealand population as described by the New Zealand Health Survey. This helps us create an understanding of the population and its demographics and to help identify any underlying correlations in the data, which can help with our regression analysis later on. It also highlights the effect that the oversampling of the Māori, Pacific and Asian sub-populations has on the survey sample and the weightings required to balance out this effect in the final estimates presented.

Our analyses are based on weights post-stratified to population benchmarks. This effectively assumes that respondents and non-respondents do not differ within the estimation cells defined by the benchmarks (age, sex and ethnicity). This missing at random (MAR) assumption is made recognising the possibility of bias if there are systematic differences in the oral health of respondents and non-respondents.

\subsection{Adult New Zealand Health Survey 2006/07}

In Table 4.1 we show the sample and population percentages and totals for the adult NZHS 2006/07. Here we can clearly see the differences in the sample and population percentages caused by the oversampling of Māori, Pacific and Asian people. The high correlation between ethnicity and deprivation means that the higher deprivation quintiles have also been oversampled; that is the oversampling of Māori and Pacific people means that because higher proportions of them are from areas of high deprivation, those quintiles are also oversamples.

\subsubsection{Gender}

Results for sex are plotted in Figure 4.1. The higher proportion of females in the sample is a consequence of lower levels of response for males.

Males have a lower response rate, for all ethnicities, than females leading to a smaller sample size and higher weighted values, which are used to compensate for this lower response rate. The total males response rate was $66.1 \%$ compared to women who had a response rate of $69.9 \%$ as shown in Table 4.2 .

\subsubsection{Age}

Response rates were unable to be calculated by age because of the unknown ages for noninterviewed people, unlike ethnicity which was collected at the start on the household form. 
Table 4.1: Demographics of the NZHS 2006/07 Adult Sample

\begin{tabular}{|c|c|c|c|c|}
\hline Subdomain & $\begin{array}{r}\text { Sample } \\
\text { Percentage }(\%)\end{array}$ & $\begin{array}{r}\text { Weighted } \\
\text { Percentage }(\%)\end{array}$ & $\begin{array}{r}\text { Sample } \\
\text { Number }\end{array}$ & $\begin{array}{r}\text { Weighted } \\
\text { Number }\end{array}$ \\
\hline Sex & & & & \\
\hline Male & 42.22 & 47.99 & 5,273 & $1,497,567$ \\
\hline Female & 57.78 & 52.01 & 7,215 & $1,623,139$ \\
\hline Age & & & & \\
\hline $15-24$ & 13.32 & 17.73 & 1,663 & 553,203 \\
\hline $25-34$ & 16.66 & 16.27 & 2,080 & 507,857 \\
\hline $35-44$ & 20.64 & 19.53 & 2,577 & 609,571 \\
\hline $45-54$ & 16.65 & 17.82 & 2,079 & 555,991 \\
\hline $55-64$ & 13.84 & 13.39 & 1,729 & 417,985 \\
\hline $65-74$ & 10.44 & 8.59 & 1,304 & 268,155 \\
\hline $75+$ & 8.46 & 6.66 & 1,056 & 207,944 \\
\hline Ethnicity & & & & \\
\hline Māori & 25.30 & 11.39 & 3,160 & 355,364 \\
\hline Pacific & 7.35 & 4.98 & 918 & 155,378 \\
\hline Asian & 11.72 & 8.75 & 1,463 & 273,071 \\
\hline European/Other & 55.63 & 74.88 & 6,947 & $2,336,893$ \\
\hline Deprivation Quintile & & & & \\
\hline NZDep 1 & 16.10 & 21.60 & 2,011 & 674,178 \\
\hline NZDep 2 & 16.99 & 19.51 & 2,122 & 608,808 \\
\hline NZDep 3 & 20.03 & 20.66 & 2,501 & 644,759 \\
\hline NZDep 4 & 21.87 & 20.50 & 2,731 & 639,695 \\
\hline NZDep 5 & 25.01 & 17.73 & 3,123 & 553,266 \\
\hline Household Income & & & & \\
\hline$\leq \$ 10,000$ & 3.11 & 2.05 & 337 & 5,439 \\
\hline$\$ 10,001-\$ 30,000$ & 29.63 & 20.81 & 3,212 & 552,994 \\
\hline$\$ 30,001-\$ 50,000$ & 19.19 & 17.31 & 2,081 & 459,969 \\
\hline$\$ 50,001-\$ 70,000$ & 15.79 & 16.65 & 1,712 & 442,504 \\
\hline$\$ 70,001-\$ 100,000$ & 15.88 & 19.16 & 1,722 & 509,258 \\
\hline$>\$ 100000$ & 16.40 & 24.02 & 1,778 & 63,845 \\
\hline Health Insurance Status & & & & \\
\hline Health Insurance & 33.15 & 38.37 & 4,124 & $1,190,938$ \\
\hline No Health Insurance & 66.85 & 61.63 & 8,316 & $1,912,510$ \\
\hline Urban/Rural Spread & & & & \\
\hline Main Urban Area & 71.36 & 72.82 & 8,912 & $2,272,546$ \\
\hline Secondary Urban Area & 6.37 & 5.82 & 795 & 181,568 \\
\hline Minor Urban Area & 9.15 & 7.86 & 1,143 & 245,352 \\
\hline Rural Area & 13.12 & 13.50 & 1,638 & 421,240 \\
\hline
\end{tabular}




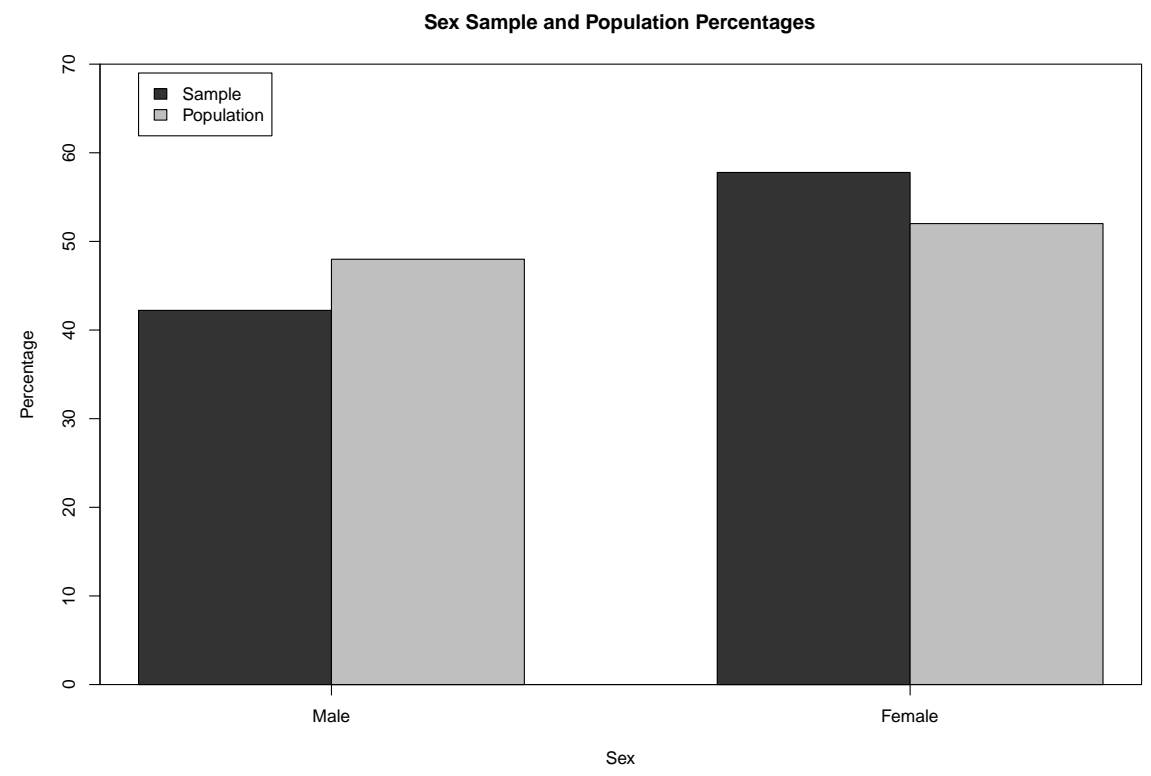

Figure 4.1: Sex distribution of sample and population for the Adult NZHS 2006/07

Table 4.2: Final adult weighted response rates (percentage), by ethnic group and gender NZHS 2006/07

\begin{tabular}{|l|c|c|c|c|c|}
\hline & \multicolumn{5}{|c|}{ Weighted Response rate (\%) } \\
\hline Ethnic group (total response) & Māori & Pacific & Asian & European/Other & Total \\
\hline Males & 62.6 & 65.5 & 79.5 & 66.4 & 66.1 \\
Females & 70.9 & 74.3 & 79.6 & 68.9 & 69.9 \\
\hline Total & 67.5 & 70.2 & 79.6 & 67.8 & 67.9 \\
\hline
\end{tabular}

From Figure 4.2 we can see that proportionally fewer 15-24 year olds were interviewed, and people in this age group will therefore have higher sample weights to compensate.

\subsubsection{Ethnicity}

Ethnicity in the New Zealand Health Survey is a self-determined identification. Participants were able to select more than one ethnicity. Four groups were selected as outputs for the prioritised Ethnicity category - with participants firstly identifying as Māori, then as Pacific, thirdly as Asian. Anyone not already identified in an ethnicity category was allocated tp the final option of European/Other.

Here, in Figure 4.3, the oversampling of Māori, Pacific and Asian populations is clear, with greater percentages of the sample being made up of these subpopulations than is the case of the true New Zealand population. This leads to a smaller sample of European/Others. Māori, Pacific and Asian populations will have smaller corresponding sample weights, whilst those in the European/Other category will have larger sample weights, to more accurately portray the New Zealand population. This inequality of sampling proportions does however 


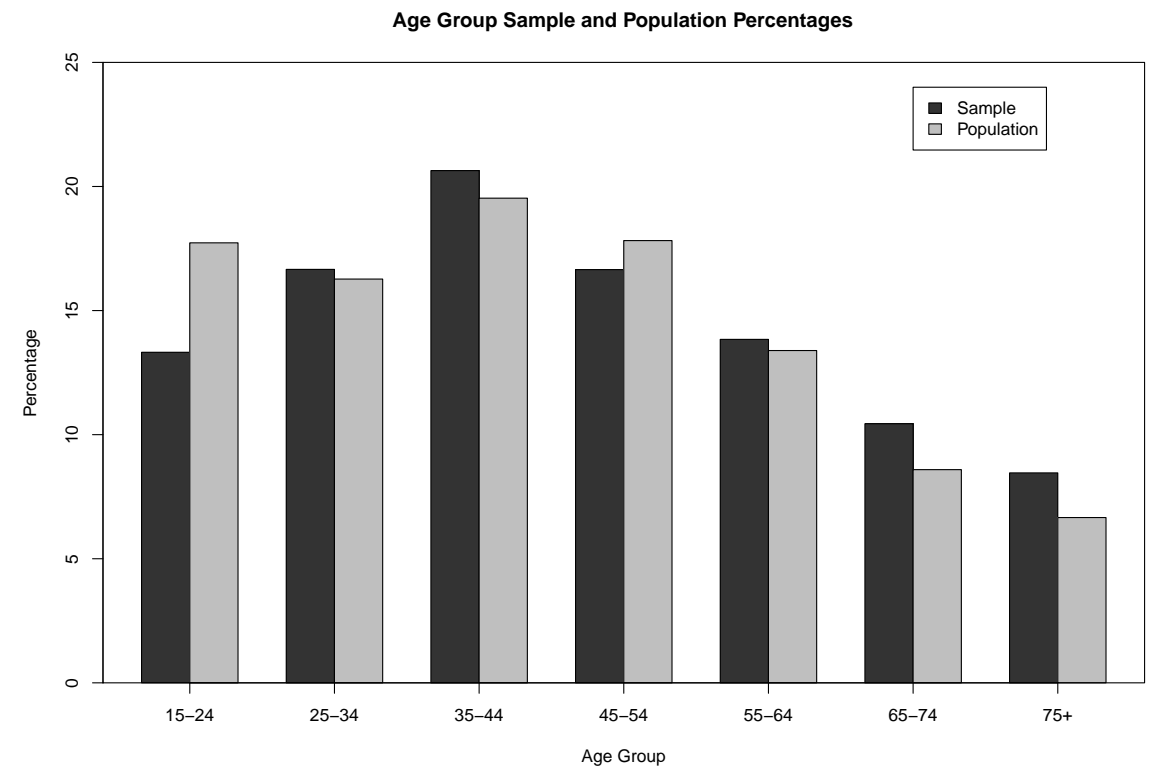

Figure 4.2: Age Group distribution of Sample and Population for the Adult NZHS $2006 / 07$

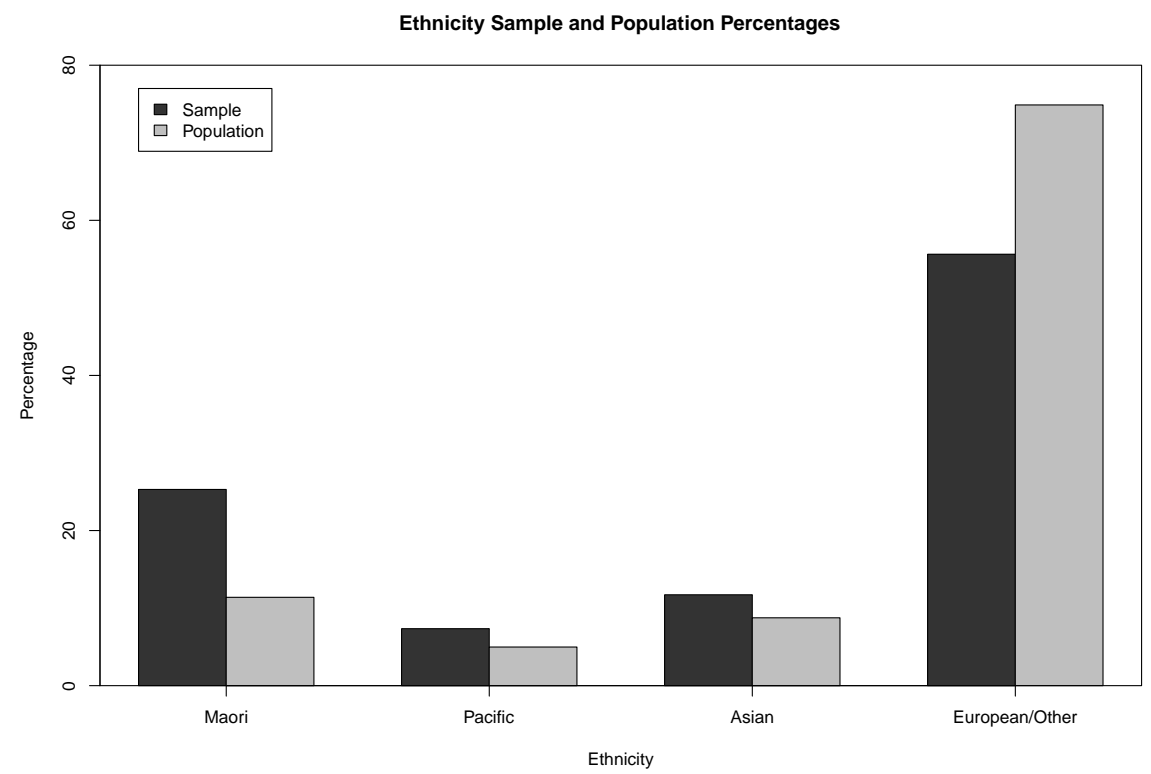

Figure 4.3: Ethnicity distribution of Sample and Population for the Adult NZHS 2006/07 
ensure that separate estimates for the Māori, Pacific and Asian ethnic groups are more precise than would have occured without oversampling.

Table 4.3: Ethnicity by Age for the Adult New Zealand Population based on the NZHS $2006 / 07$

\begin{tabular}{|c|c|c|c|c|c|}
\hline Age & Māori & Pacific & Asian & European/Other & Total \\
\hline $15-24$ & 27.24 & 28.17 & 27.18 & 14.48 & 17.73 \\
$25-34$ & 21.01 & 21.84 & 21.12 & 14.62 & 16.27 \\
$35-44$ & 20.74 & 20.76 & 21.87 & 19.00 & 19.53 \\
$45-54$ & 15.76 & 14.44 & 16.16 & 18.55 & 17.82 \\
$55-64$ & 8.85 & 8.33 & 7.83 & 15.07 & 13.39 \\
$65-74$ & 4.70 & 4.58 & 4.27 & 9.96 & 8.59 \\
$75+$ & 1.70 & 1.88 & 1.58 & 8.33 & 6.66 \\
\hline Total & 100.00 & 100.00 & 100.00 & 100.00 & 100.00 \\
\hline
\end{tabular}

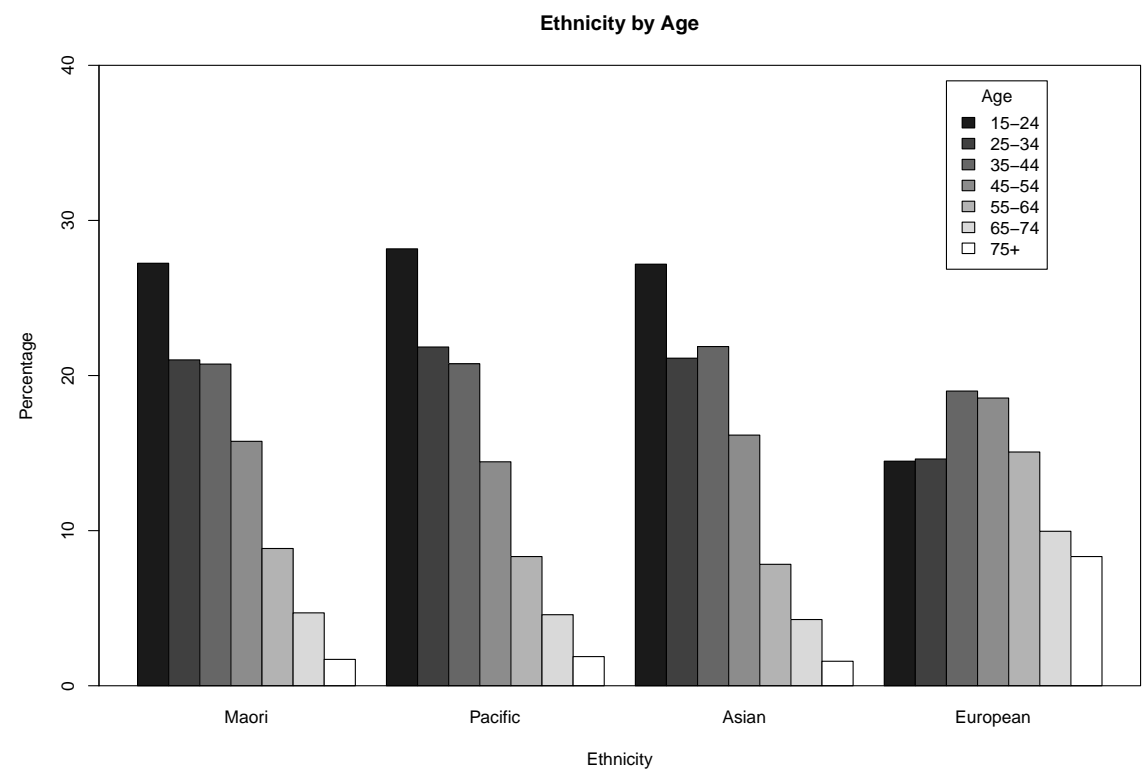

Figure 4.4: Ethnicity by Age for the New Zealand Population, based on the weighted adult NZHS 2006/07

Table 4.3 and Figure 4.4 show that Māori, Pacific and Asian populations all follow a similar distribution of age, where the percentage of people decreases as age increases. These subpopulations all have the greatest percentage of people in the lower age group of 15-24. The European/Other sub population follows a more uniform distribution, with the largest percentage of people being aged between 35 and 54 .

\subsubsection{Deprivation}

The NZHS 2006/07 used the 2006 New Zealand Index of Deprivation (NZDep2006) to measure socioeconomic status. NZDep2006 is an area based index that measures the level of 
socioeconomic deprivation for each meshblock. The socioeconomic status, using the 2006 New Zealand Index of Deprivation, of respondents was categorised using the NZDep2006. The NZDep2006 is an updated version of previous (1991, 1996 and 2001) indexes based on small areas. This specific index combines nine variables from the 2006 Census, which reflect aspects of material and social deprivation. The variables used to determine a NZDep2006 score are income, benefit status, transport access, household size, home ownership, employment status, qualifications, support and telephone access. Each meshblock in New Zealand is then assigned a deprivation score which is broken into deciles, where 1 represents those least deprived and 10 the areas with the most deprived. For some parts of this report the deciles have been grouped into pairs and are displayed as quintiles 1-5, with 1 being the least deprived and 5 being the most deprived (Salmond et al. 2007).

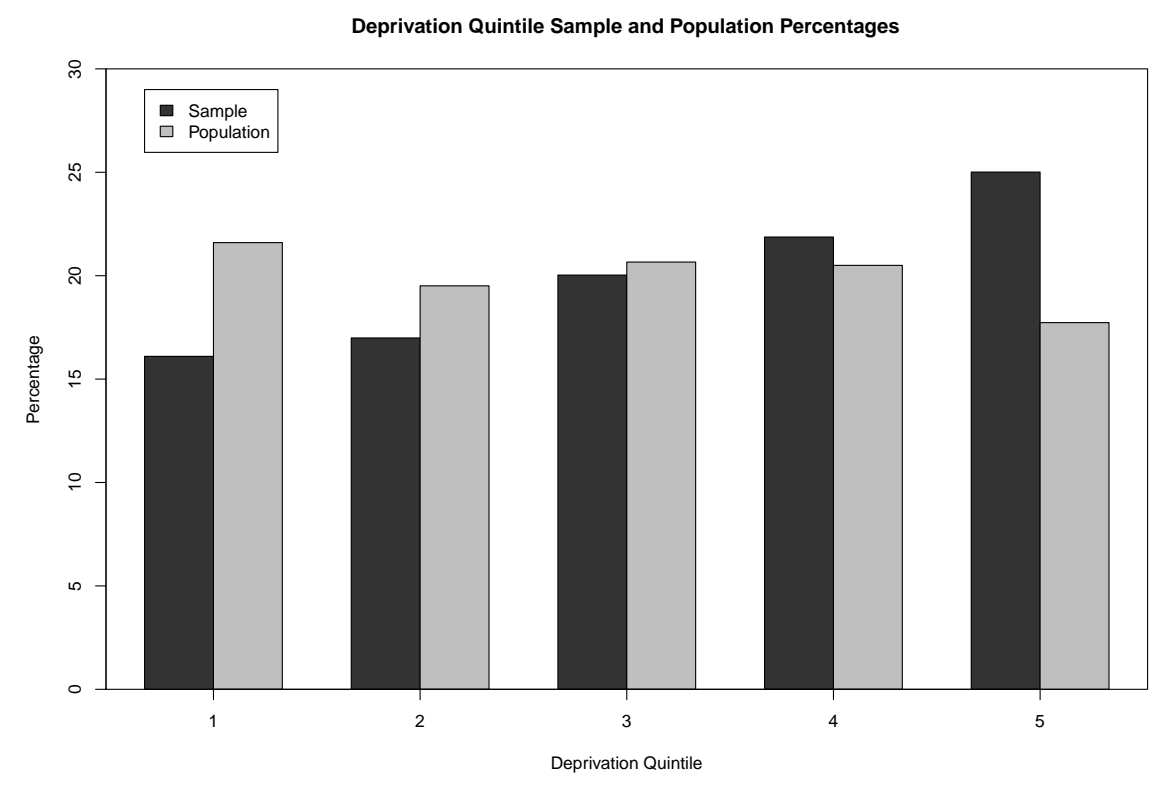

Figure 4.5: Deprivation Quintile distribution of Sample and Population, based on the Adult NZHS 2006/07 ( 1 = least deprived, 5 = most deprived $)$

In Figure 4.5 we can see how the 5th deprivation quintile appears to be oversampled. This is due to the over-sampling of the Māori and Pacific populations, which are found more in the lower deprivation quintiles with $38.36 \%$ of the Māori population and $55.75 \%$ of Pacific people being in the 5 th and most deprived quintile of the New Zealand population.

Table 4.4 and Figure 4.6 show that Māori and Pacific islanders have the largest percentage of people in the 5th deprivation quintile, which represents the most deprived people in New Zealand. Asian and European/Other Ethnicities are more evenly spread amongst the 5 deprivation quintiles.

\subsection{Child New Zealand Health Survey 2006/07}

The child sample of the NZHS 2006/07 is similar to the adult sample, with over-sampling of the Māori, Pacific and Asian subpopulations. 40.3\% of the sample were identified as Māori, compared to only $22.9 \%$ of the population. The child sample had a smaller difference in 
Table 4.4: Ethnicity by Deprivation for the New Zealand Adult Population based on the NZHS 2006/07

\begin{tabular}{|c|c|c|c|c|c|}
\hline Deprivation Quintile & Māori & Pacific & Asian & European/Other & Total \\
\hline NZDep 1 & 9.10 & 3.96 & 15.49 & 25.39 & 21.6 \\
NZDep 2 & 12.47 & 8.97 & 17.96 & 21.46 & 19.51 \\
NZDep 3 & 15.90 & 13.34 & 20.38 & 21.90 & 20.66 \\
NZDep 4 & 24.17 & 17.98 & 28.71 & 19.15 & 20.50 \\
NZDep 5 & 38.36 & 55.75 & 17.46 & 12.09 & 17.73 \\
\hline Total & 100.00 & 100.00 & 100.00 & 100.00 & 100.00 \\
\hline
\end{tabular}

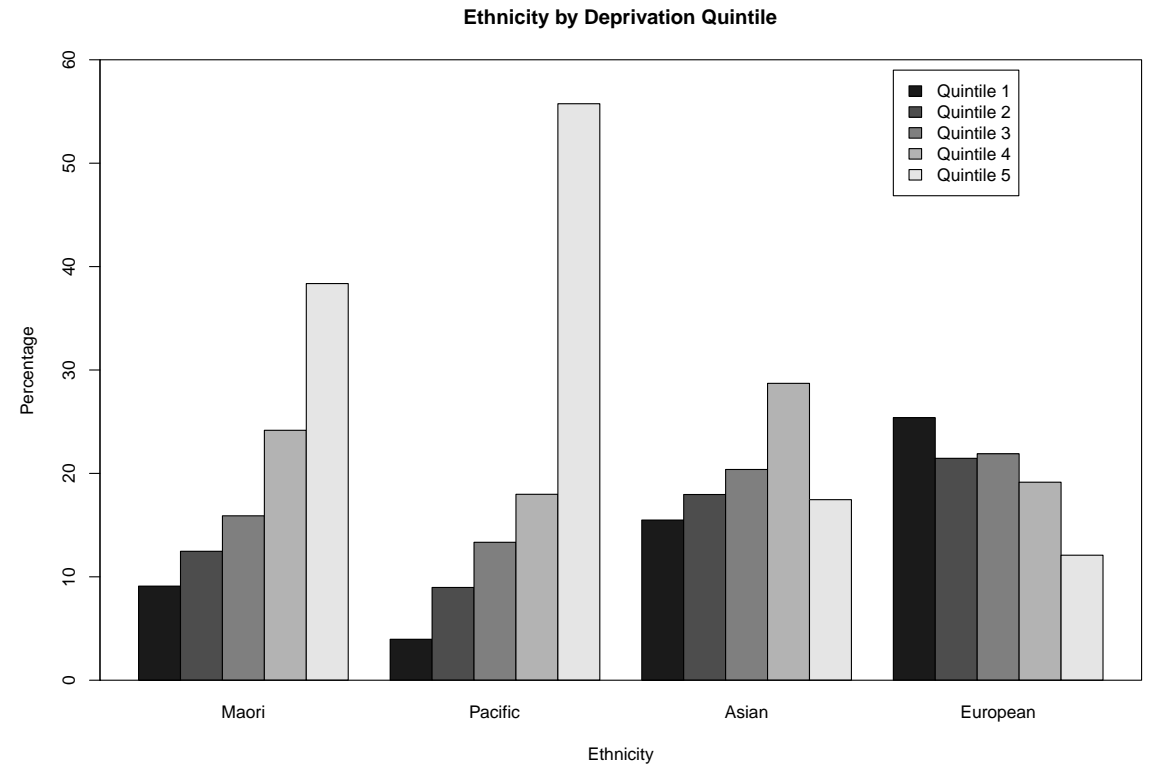

Figure 4.6: Ethnicity by Deprivation Quintile of NZ Population, based on the weighted Adult NZHS 2006/07 (1 = least deprived, 5 = most deprived $)$ 
proportions of female and males than the adult sample, and the sample and population both had a uniformly distributed population of ages, refer to Table 4.5 . 
Table 4.5: Demographic Characteristics of the NZHS 2006/07 Child Sample

\begin{tabular}{|c||c|c||c|c|}
\hline Subdomain & $\begin{array}{c}\text { Sample } \\
\text { Percentage(\%) }\end{array}$ & $\begin{array}{c}\text { Weighted } \\
\text { Percentage(\%) }\end{array}$ & $\begin{array}{c}\text { Sample } \\
\text { Number }\end{array}$ & $\begin{array}{c}\text { Weighted } \\
\text { Number }\end{array}$ \\
\hline Sex & & & & \\
Male & 52.6 & 51.2 & 2,589 & 437,215 \\
Female & 47.4 & 48.8 & 2,332 & 417,212 \\
\hline Age & 34.6 & 32.7 & 1,704 & 279,615 \\
$0-4$ & 30.0 & 33.2 & 1,476 & 28,086 \\
$5-9$ & 35.4 & 34.0 & 1,741 & 290,827 \\
10-14 & & & & \\
Ethnicity & 40.3 & 22.9 & 667 & 70,206 \\
Māori & 11.3 & 9.4 & 1,715 & 508,613 \\
Pacific & 13.6 & 8.2 & 1,983 & 195,706 \\
Asian & 34.9 & 59.5 & 556 & 79,902 \\
\hline European/Other & & & & \\
Deprivation Quintile & 14.9 & 21.4 & 733 & 183,068 \\
NZDep 1 & 15.3 & 18.1 & 755 & 154,327 \\
NZDep 2 & 18.8 & 19.4 & 926 & 165,923 \\
NZDep 3 & 21.4 & 19.2 & 1,053 & 164,502 \\
NZDep 4 & 29.5 & 21.8 & 1,454 & 186,608 \\
NZDep 5 & 100.0 & 100.0 & 4,921 & 854,427 \\
\hline Total & \multicolumn{3}{|c}{}
\end{tabular}




\section{Chapter 5}

\section{Exploratory Data Analysis}

In this chapter we carry out an anlysis of the oral health outcome variables from the New Zealand Helth Survey 2006/07. Oral health outcomes are presented with their corresponding $95 \%$ confidence intervals. Estimates are also presented for sub groups defined by variables such as sex, age and ethnicity. Unreliable estimates are identified based on large RSE values and are idicated in the appropriate data tables. This exploratory data analysis is carried out prior to full regression analysis to assist in finding significant associations between variables and aide in the selection of possible regression analysis predictor variables.

\subsection{New Zealand Health Survey 2006/07 Adult Results}

\subsubsection{Removal of teeth due to tooth decay or gum disease}

The first oral health question asked in the NZHS 2006/07 was ablout the removal of teeth. The question asked:

How many of your teeth have been removed because of tooth decay or gum disease? Do not include teeth lost for other reasons such as injury, crowded mouth or orthodontics.

0 . None of my teeth have been removed because of tooth decay or gum disease

1-35+ I have had ... of my teeth removed because of tooth decay or gum disease

99. All of my teeth have been removed because of tooth decay or gum disease

The values used here have been calculated by revaluing all values of 32 and above, as well as those who said they had lost all of their teeth as 32.32 is the standard number of teeth (including wisdom teeth) that an average adult has (The Cleveland Clinic Foundation 1995).

Table 5.1 displays the mean number of teeth lost due to tooth decay and gum disease for various sub populations. The mean number of teeth an adult New Zealander has had removed due to tooth decay or gum disease is 4.59. An estimated 1,593,676 or $51.3 \%$ adults having had no teeth removed due to tooth decay or gum disease shown in Figure 5.1.

Excluding all those adults (249,037 people or $8.02 \%$ of the adult population) who have lost all their teeth (in this case 32 or more teeth) the mean number of teeth removed in an adult due to tooth decay or gum disease is 2.19 .

Figure 5.2 shows that tooth loss due to tooth decay or gum disease is positively related to age. A consistently positive gradient suggests that tooth loss due to tooth decay or gum 
Table 5.1: Mean Number of teeth removed due to tooth decay and gum disease for the Adult NZHS 2006/07

\begin{tabular}{|c|c|}
\hline & Mean teeth lost \\
\hline Total & $\begin{array}{c}4.59 \\
(4.56,4.61)\end{array}$ \\
\hline 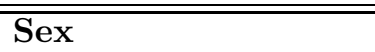 & \\
\hline Male & $\begin{array}{c}4.34 \\
(4.30,4.38)\end{array}$ \\
\hline Female & $\begin{array}{c}4.81 \\
(4.77,4.85) \\
\end{array}$ \\
\hline $\begin{array}{l}\text { Age } \\
15-24\end{array}$ & $\begin{array}{c}0.29 \\
(0.29,0.29)\end{array}$ \\
\hline $25-34$ & $\begin{array}{c}1.03 \\
(1.02,1.05)\end{array}$ \\
\hline $35-44$ & $\begin{array}{c}1.78 \\
(1.76,1.80)\end{array}$ \\
\hline $45-54$ & $\begin{array}{c}3.89 \\
(3.80,3.98)\end{array}$ \\
\hline $55-64$ & $\begin{array}{c}7.72 \\
(7.43,8.01)\end{array}$ \\
\hline $65-74$ & $\begin{array}{c}13.58 \\
(12.92,14.24)\end{array}$ \\
\hline $75+$ & $\begin{array}{c}17.27 \\
(16.08,18.46) \\
\end{array}$ \\
\hline $\begin{array}{l}\text { Ethnicity } \\
\text { Māori }\end{array}$ & $\begin{array}{c}4.93 \\
(4.84,5.01)\end{array}$ \\
\hline Pacific & $\begin{array}{c}2.89 \\
(2.74,3.03)\end{array}$ \\
\hline Asian & $\begin{array}{c}1.99 \\
(1.94,2.04)\end{array}$ \\
\hline European/Other & $\begin{array}{c}4.95 \\
(4.92,4.98) \\
\end{array}$ \\
\hline $\begin{array}{l}\text { Deprivation Quintile } \\
\text { NZDep } 1\end{array}$ & $\begin{array}{c}3.39 \\
(3.00,3.78)\end{array}$ \\
\hline NZDep 2 & $\begin{array}{c}4.16 \\
(3.67,4.64)\end{array}$ \\
\hline NZDep 3 & $\begin{array}{c}4.68 \\
(4.16,5.20)\end{array}$ \\
\hline NZDep 4 & $\begin{array}{c}5.04 \\
(4.58,5.49)\end{array}$ \\
\hline NZDep 5 & $\begin{array}{c}5.74 \\
(5.23,6.24)\end{array}$ \\
\hline
\end{tabular}




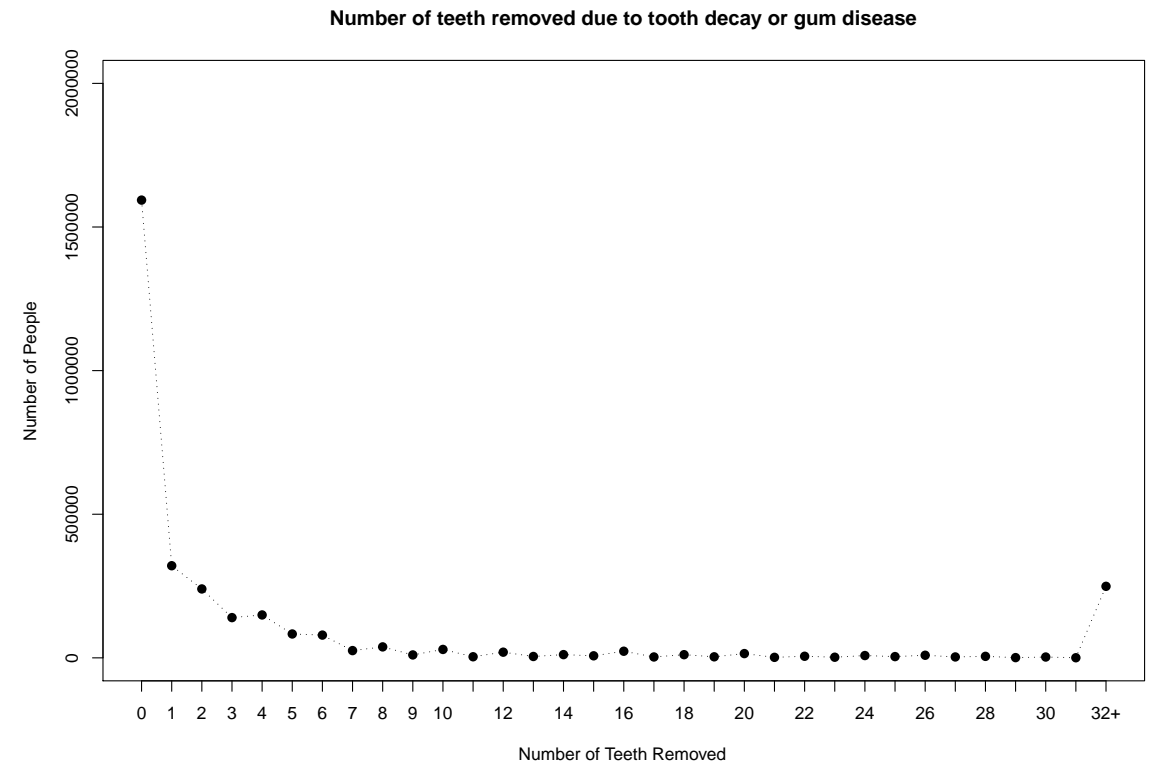

Figure 5.1: Tooth Loss due to Tooth Decay or Gum Disease for the Adult NZHS 2006/07

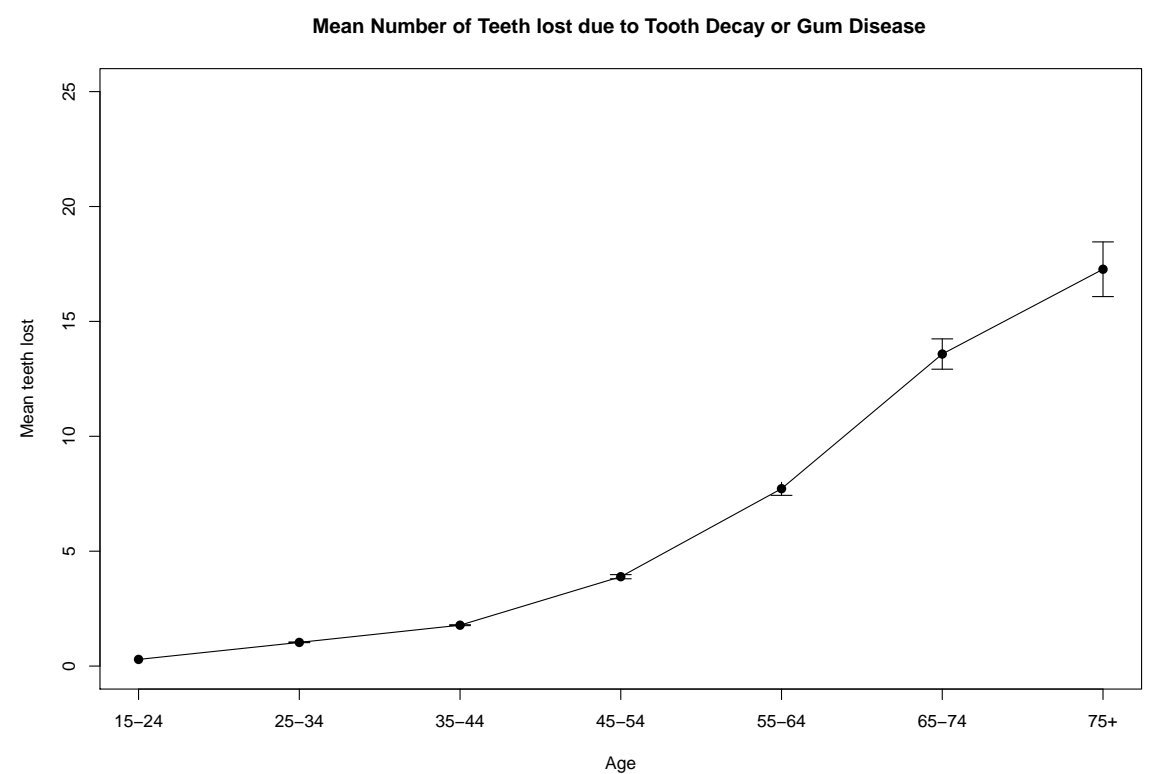

Figure 5.2: Mean Number of Teeth Lost due to Tooth Decay or Gum Disease by Age for the Adult NZHS 2006/07 


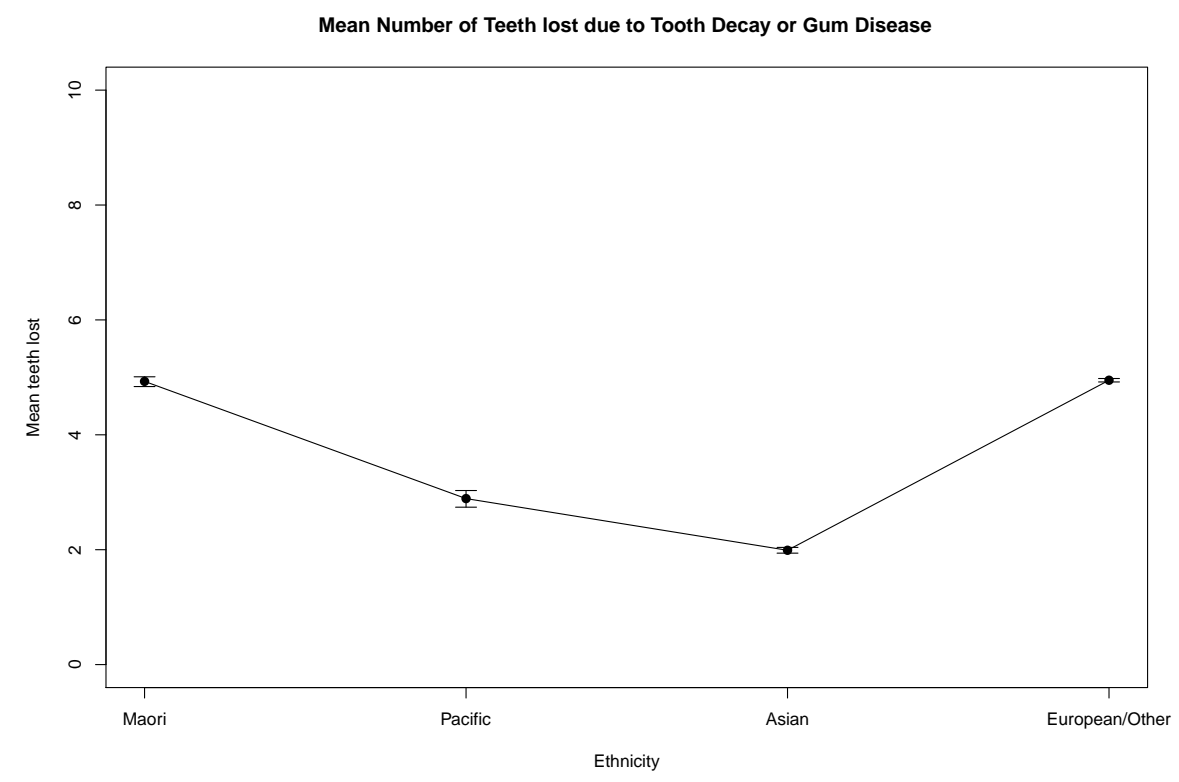

Figure 5.3: Mean Number of Teeth Lost due to Tooth Decay or Gum Disease by Ethnicity for the Adult NZHS 2006/07

disease is greater for older age groups..

From Figure 5.3 we can see that the Māori and European/Other sub-populations have the highest mean number of teeth lost due to tooth decay or gum disease, with $4.93(4.84,5.01)$ and $4.95(4.92,4.98)$ teeth lost respectively. However, these values do not include untreated teeth that may need to be extracted due to tooth decay or gum disease. Further participant questioning and/or examination would need to be carried out to get a more accurate rates of tooth decay and gum disease in New Zealand.

Before conclusions can be drawn rates of oral health care visitation would need to be taken into account, as people may need tooth extraction due to tooth decay or gum disease, but without access to an oral health care specialist, these teeth may not be extracted and this leads to an underestimation of our tooth removal estimates. Pacific people have low rates of oral health care visits with $20.0 \%$ never going to see an oral health care worker, meaning that their lower mean number of teeth lost value of $2.89(2.74,3.03)$ may be underestimated due to a lack of oral health care.

Adjustments also need to be made for differing age structures in the population, since tooth loss increases with age as shown in Figure 5.2. Māori, Pacific and Asian populations are all significantly younger than the European/other population as seen in Figure 4.4. The regression analyses in Chapter 6 make these adjustments.

\section{Tooth loss and diabetes}

From the survey we know that 5.01\% $(4.59,5.42)$ of the New Zealand population have diabetes. This includes both type I and type II diabetes. Of these $(155,365)$ people diagnosed with diabetes in New Zealand, the mean number of teeth lost to tooth decay or gum disease is $12.27(11.19,13.35)$. This is significantly higher than the mean number of teeth lost by 
those who have not been diagnosed with diabetes, who have lost a mean of $4.15(3.97,4.33)$ teeth.

\section{Tooth loss and asthma}

$17.9 \%(17.0,18.8)$ of New Zealand adults have been diagnosed with asthma. Those with asthma have a mean tooth loss of $4.50(4.10,4.91)$ teeth, which does not significantly differ from the $82.01 \%$ of New Zealanders who do not have asthma and have a mean tooth loss of $4.57(4.39,4.76)$ teeth.

\section{Tooth loss and blood pressure}

$21.4 \%(20.5,22.4)$ of New Zealand adults have been told by a doctor that they have had high blood pressure at some point (not including during pregnancy). Those with high blood pressure have a mean tooth loss of 8.99 (8.43,9.56). This is a much higher mean than the mean value of $3.35(3.20,3.51)$ teeth lost due to tooth decay or gum disease for people who do not have high blood pressure.

\section{Tooth loss and cholesterol}

$18.2 \%(17.5,18.9)$ of people have been told by their doctor that they have high levels of cholesterol in their blood. Those with high cholesterol have a mean tooth loss of $8.47(7.88,9.06)$. This is a much higher mean than the mean value of $3.68(3.50,3.86)$ teeth lost due to tooth decay or gum disease for people who do not have high cholesterol levels.

\section{Tooth loss and smoking}

Question A3-19 asked respondents 'have you ever smoked cigarettes or tobacco at all?'. Of the $64.65 \%$ of the New Zealand population who had smoked cigarettes or tobacco, the mean tooth loss due to tooth decay or gum disease is $5.02(4.79,5.24)$. Of the $35.35 \%$ of people who had never smoked the mean tooth loss due to tooth decay or gum disease was $3.73(3.52,3.94)$.

6100 respondents who had admitted to previous smoking answered the next question about how much they smoke now. Of those who do not smoke now, the mean tooth loss was 7.24 (6.80,7.69). Those who smoked at least once a month had lost a mean of $1.90(0.31,3.49)$, those who smoke at least once a week had lost a mean of $2.45(1.45,3.46)$ teeth. And those who smoke at least once a day had lost a mean of $5.46(4.74,5.57)$ teeth.

A current smoker was defined to have smoked more than 100 cigarettes in their life time and currently smokes at least once a month. The mean tooth loss for current smokers was 4.94 $(4.56,5.33)$ which was not significantly different from the mean tooth loss of $4.47(4.27,4.66)$ teeth for non current smokers (ex-smokers).

\section{Tooth loss and alcohol consumption}

Question A3-30 asked repondents if they had had a drink containing alcohol in the past 12 months. $83.7 \%$ of respondents had had an alcoholic drink in the past 12 months and those people had a mean tooth loss of $4.15(3.97,4.34)$ teeth. $16.31 \%$ of people had not had an alcoholic drink in the past 12 months, and they had a mean tooth loss of $6.65(6.20,7.10)$.

Question A3-31 asked the 9948 respondents who had answered yes to having a drink containing alcohol in the past 12 months, 'how often do you have a drink containing alcohol?'. Of the $26.08 \%$ of people that only drink monthly or less, the mean number of teeth lost due to tooth decay or gum disease is $4.64(4.27,5.00)$. Those who drink 4 times a month had lost 
$3.18(2.87,3.50)$ teeth and those who drink up to 3 times a week had lost $3.42(3.04,3.79)$ teeth. The $20.25 \%$ of the population who have at least 4 drinks a week, had lost the most teeth due to tooth decay or gum disease, with a mean tooth loss of $5.13(4.75,5.51)$.

\section{Tooth loss and diet and nutrition}

Fruit and vegetable intake is not significantly associated with tooth loss. Those who eat less than one serving of fruit a day have lost a mean of $4.73(4.26,5.20)$ teeth, those who eat 1-3 servings a day have lost a mean of $4.53(4.30,4.77)$ teeth and those who consume 4 or more servings of fruit a day have lost a mean of $4.50(3.97,5.03)$ teeth.

Those who eat less than one serving of vegetables a day have lost a mean of $5.23(4.27,6.20)$ teeth, those who eat 1-3 servings a day have lost a mean of $4.26(4.04,4.48)$ teeth and those who consume 4 or more servings of vegetables a day have lost a mean of $5.14(4.75,5.53)$ teeth.

\section{Tooth loss and Body Mass Index (BMI)}

Respondents were placed into one of four weight categories based on calculated Body Mass Index (BMI) for respondents, and aligned to meet the World Health Organization cutoffs. Those with an average weight had lost a mean of $3.07(2.82,3.32)$ teeth. Overweight people have lost a mean of $4.77(4.48,5.06)$ teeth, while obese people have lost a mean of 6.09 $(5.72,6.45)$ teeth. Underweight people have a mean tooth loss of $3.18(1.88,4.49)$.

\subsubsection{Regularity of oral health care}

'Two aspects of the time interval are important. The percentage of adults who last visited within 12 months indicates the recency of the last visit. Some of those visits will be for regular check-up; while other visits will be for dental treatment as a result of experiencing a dental problem. Visiting within the last 12 months for a check-up is widely recommended by the dental profession. Such visits provide the opportunity for provision of specific preventive services, early diagnosis and prompt treatment of dental disease' Slade et al. (2007).

Question A2-49 asked respondents:

Which of the following statements describes best the regularity of your consultations with an oral health care worker?

1. I visit an oral health care worker at least every two years for a check up

2. I visit an oral health care worker for check-ups regularly, but with intervals of more than two years

3. I only visit an oral health care worker when I have toothache or other similar trouble

4. I never visit an oral health care worker

Estimates for regularity of care are presented in Table 5.2 and are displayed with $95 \%$ confidence intervals for sex, age and ethnicity sub populations.

Figure 5.4 shows that European/Other subpopulations of people are most likely to have regular consultations with an oral health care worker, with $47.4 \%(45.8,49.1)$ visiting an oral health care worker at least every 2 years for a check up. European/Other people also have the lowest rate of $35.8 \%(34.4,37.2)$ of people only seeing an oral health care worker when they have tooth ache or similar trouble, and the lowest rate, $6.8 \%(6.2,7.5)$ of people who 
Table 5.2: Regularity of consultation with an oral health care worker for the Adult NZHS $2006 / 07$

\begin{tabular}{|c|c|c|c|c|}
\hline & $\begin{array}{l}\text { At least every } 2 \\
\text { years for a check } \\
\text { up }\end{array}$ & $\begin{array}{lr}\text { Regularly for } \\
\text { check ups but } \\
\text { more than } 2 \\
\text { years apart }\end{array}$ & $\begin{array}{l}\text { Only when have } \\
\text { toothache or } \\
\text { similar trouble }\end{array}$ & Never \\
\hline Total & $\begin{array}{c}41.0 \\
(39.7,42.4)\end{array}$ & $\begin{array}{c}9.2 \\
(8.6,9.9)\end{array}$ & $\begin{array}{c}40.3 \\
(39.0,41.5)\end{array}$ & $\begin{array}{c}9.5 \\
(8.8,10.2)\end{array}$ \\
\hline $\begin{array}{l}\text { Sex } \\
\text { Male }\end{array}$ & $\begin{array}{c}36.4 \\
(34.5,38.3) \\
\end{array}$ & $\begin{array}{c}9.4 \\
(8.3,10.5) \\
\end{array}$ & $\begin{array}{c}43.7 \\
(41.9,45.4)\end{array}$ & $\begin{array}{c}10.5 \\
(9.5,11.6)\end{array}$ \\
\hline Female & $\begin{array}{c}45.4 \\
(43.8,47.0) \\
\end{array}$ & $\begin{array}{c}9.1 \\
(8.1,10.1) \\
\end{array}$ & $\begin{array}{c}37.0 \\
(35.5,38.6) \\
\end{array}$ & $\begin{array}{c}8.5 \\
(7.7,9.3) \\
\end{array}$ \\
\hline $\begin{array}{l}\text { Age } \\
15-24\end{array}$ & $\begin{array}{c}45.3 \\
(42.1,48.5)\end{array}$ & $\begin{array}{c}8.8 \\
(6.7,11.0)\end{array}$ & $\begin{array}{c}35.8 \\
(32.3,39.2)\end{array}$ & $\begin{array}{c}10.1 \\
(8.5,11.8)\end{array}$ \\
\hline $25-34$ & $\begin{array}{c}28.0 \\
(25.1,30.9)\end{array}$ & $\begin{array}{c}10.6 \\
(9.1,12.1)\end{array}$ & $\begin{array}{c}50.3 \\
(47.6,53.0)\end{array}$ & $\begin{array}{c}11.1 \\
(9.3,12.9)\end{array}$ \\
\hline $35-44$ & $\begin{array}{c}36.5 \\
(34.0,39.1)\end{array}$ & $\begin{array}{c}9.9 \\
(8.5,11.3) \\
\end{array}$ & $\begin{array}{c}47.1 \\
(44.5,49.8)\end{array}$ & $\begin{array}{c}6.4 \\
(5.4,7.4)\end{array}$ \\
\hline $45-54$ & $\begin{array}{c}45.0 \\
(41.7,48.4)\end{array}$ & $\begin{array}{c}10.1 \\
(8.5,11.7)\end{array}$ & $\begin{array}{c}38.1 \\
(35.0,41.2)\end{array}$ & $\begin{array}{c}6.8 \\
(5.5,8.1)\end{array}$ \\
\hline $55-64$ & $\begin{array}{c}51.8 \\
(48.8,54.7)\end{array}$ & $\begin{array}{c}8.3 \\
(6.7,9.9)\end{array}$ & $\begin{array}{c}32.4 \\
(29.6,35.2)\end{array}$ & $\begin{array}{c}7.5 \\
(6.0,9.1)\end{array}$ \\
\hline $65-74$ & $\begin{array}{c}43.6 \\
(39.2,47.9)\end{array}$ & $\begin{array}{c}7.5 \\
(5.8,9.3)\end{array}$ & $\begin{array}{c}34.8 \\
(30.7,38.9)\end{array}$ & $\begin{array}{c}14.1 \\
(11.8,16.4)\end{array}$ \\
\hline $75+$ & $\begin{array}{c}43.5 \\
(38.4,48.6)\end{array}$ & $\begin{array}{c}4.5 \\
(2.7,6.3)\end{array}$ & $\begin{array}{c}29.1 \\
(24.9,33.3)\end{array}$ & $\begin{array}{c}22.9 \\
(18.9,26.9) \\
\end{array}$ \\
\hline $\begin{array}{l}\text { Ethnicity } \\
\text { Māori }\end{array}$ & $\begin{array}{c}24.3 \\
(22.1,26.5)\end{array}$ & $\begin{array}{c}5.5 \\
(4.2,6.8)\end{array}$ & $\begin{array}{c}54.2 \\
(51.9,56.5)\end{array}$ & $\begin{array}{c}16.0 \\
(14.1,17.8)\end{array}$ \\
\hline Pacific & $\begin{array}{c}16.7 \\
(13.7,19.7)\end{array}$ & $\begin{array}{c}5.8 \\
(3.9,7.7)\end{array}$ & $\begin{array}{c}57.4 \\
(52.5,62.3)\end{array}$ & $\begin{array}{c}20.0 \\
(16.9,23.2)\end{array}$ \\
\hline Asian & $\begin{array}{c}24.1 \\
(20.9,27.3)\end{array}$ & $\begin{array}{c}10.0 \\
(7.9,12.2)\end{array}$ & $\begin{array}{c}49.1 \\
(45.6,52.6)\end{array}$ & $\begin{array}{c}16.7 \\
(13.6,19.9)\end{array}$ \\
\hline European/Other & $\begin{array}{c}47.4 \\
(45.8,49.1)\end{array}$ & $\begin{array}{c}9.9 \\
(9.1,10.7)\end{array}$ & $\begin{array}{c}35.8 \\
(34.4,37.2)\end{array}$ & $\begin{array}{c}6.8 \\
(6.2,7.5)\end{array}$ \\
\hline
\end{tabular}




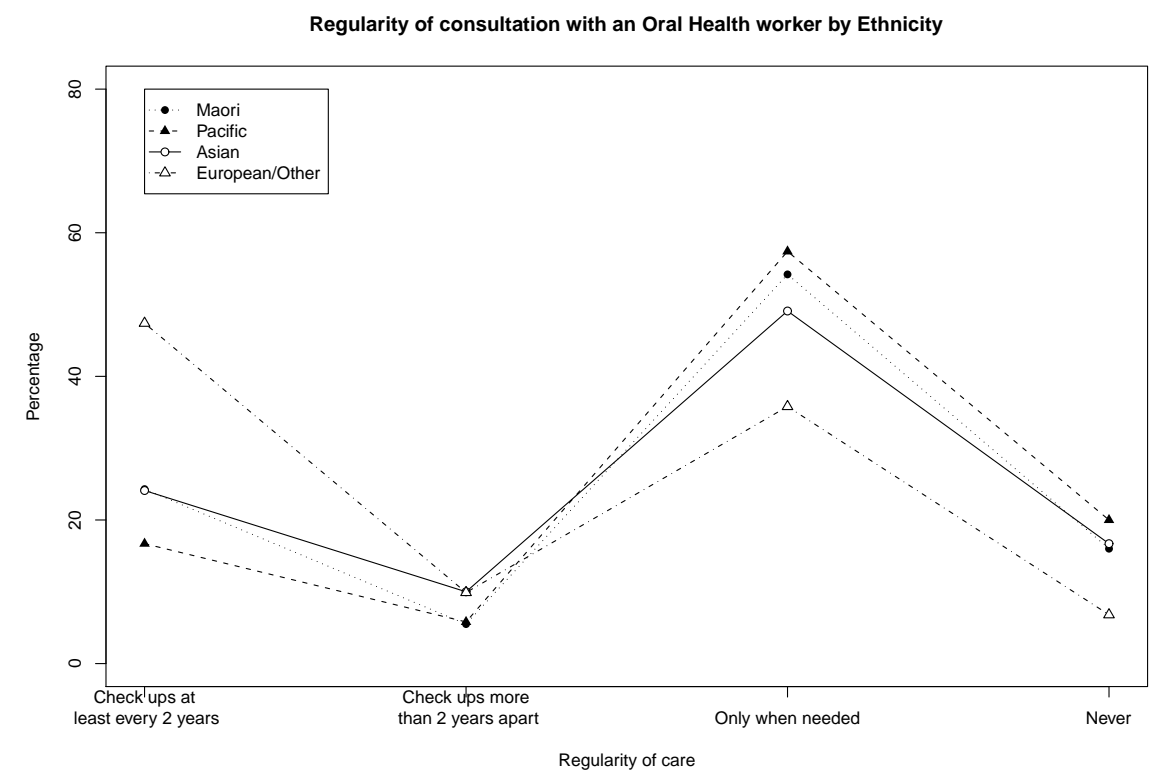

Figure 5.4: Regularity of consultations with an Oral Health care worker by Ethnicity for the Adult NZHS 2006/07

never consult with an oral health care worker. Māori, Pacific and Asian populations all follow a similar distribution with the majority of people only consulting with an oral health care worker when they have tooth ache or similar pain and consultation is deemed necessary. These three subpopulations have much lower rates of people consulting with oral health care workers for regular check ups every two years.

Figure 5.5 shows that people aged 25-44 are most liklely to only consult with an oral health care worker when needed, due to tooth ache or other trouble, whereas 15-24 year olds and people over the age of 45 are more likely to be consulting regularly with an oral health care worker for check ups. People over the age of 65 are much more likely to never consult an oral health care worker than younger people, with $22.9 \%(18.9,26.9)$ of people aged 75 and over never consulting with an oral health care worker.

\subsubsection{Time since last visit to an oral health care worker}

Time since last visiting a dentist is a key indicator of access to dental care and is an important measure of the populations access abilities to oral health care.

Question A2-45 asked respondents:

How long has it been since you last visited an oral health care worker about your own oral health, for any reason?

1. Within the past year (anytime less than 12 months age)

2. Within the past two years (more than 1 year but less than 2 years ago)

3. Within the past five years (more than 2 years but less than 5 years ago)

4. Five or more years ago 


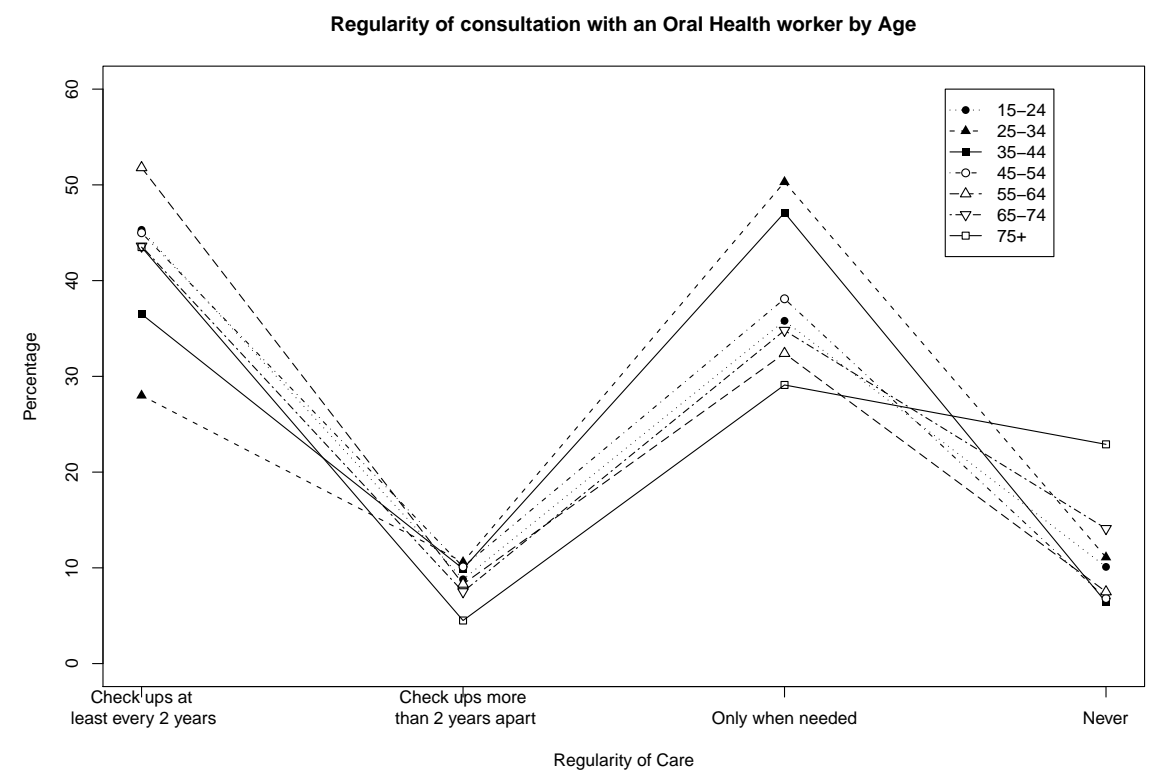

Figure 5.5: Regularity of consultations with an Oral Health care worker by Age for the Adult NZHS 2006/07

5. Have never seen an oral health care worker

Estimates for regularity of care are presented in Table 5.3 and are displayed with $95 \%$ confidence intervals for sex, age and ethnicity sub populations.

Figure 5.6 shows that most people of any age have visited an oral health care worker in the past 12 months. People over the age of 65 are more likely to not have been to an oral health care worker for more than 5 years.

Figure 5.7 shows that European/Others have the highest rates of people who have visited and oral health care worker in the past 12 months, with $56.2 \%(54.4,57.9)$ of people having done so, compared to $38.2 \%(35.6,40.7)$ for Māori, 34.0\% (30.4,37.7) for Pacific people and $35.3 \%(32.5,38.2)$ for Asians. European/Other people have the lowest rates for never seeing an oral health care worker, with a rate of $0.9 \%(0.7,1.1)$ whilst Asians have the highest rate of $11.1 \%$ (9.1,13.1). These results are consistant with those for regular check ups with an oral health care worker, with European/Others having shorter recency of their previous visit.

\subsubsection{Unmet oral health care need in the past 12 months}

Question A2-46 asked respondents:

In the last 12 months, has there been any time when you needed to see an oral health care worker about your own oral health, but then didn't get to see an oral health care worker at all?

1. Yes

2. No 
Table 5.3: Time since last visit to oral health care worker for Adult NZHS 2006/07

\begin{tabular}{|l|c|c|c|c|c|}
\hline & $<12$ months & 1 -2years & $2-5$ years & $5+$ years & never \\
\hline Total & 51.0 & 17.8 & 13.7 & 15.1 & 2.3 \\
& $(49.6,52.4)$ & $(16.8,18.8)$ & $(13.0,14.5)$ & $(14.3,15.9)$ & $(2.0,2.6)$ \\
\hline \hline Sex & & & & & \\
Male & 47.4 & 18.9 & 14.0 & 17.4 & 2.4 \\
& $(45.4,49.3)$ & $(17.4,20.3)$ & $(12.7,15.3)$ & $(16.1,18.6)$ & $(1.9,2.8)$ \\
\hline Female & 54.5 & 16.8 & 13.5 & 12.9 & 2.3 \\
& $(52.8,56.1)$ & $(15.6,18.0)$ & $(12.5,14.5)$ & $(12.0,13.9)$ & $(1.9,2.7)$ \\
\hline \hline Age & & & & & \\
$15-24$ & 51.7 & 19.6 & 15.1 & 11.3 & 2.3 \\
& $(48.5,54.9)$ & $(17.0,22.2)$ & $(12.7,17.5)$ & $(9.6,12.9)$ & $(1.6,3.0)$ \\
\hline $25-34$ & 39.5 & 20.9 & 17.7 & 18.9 & 3.0 \\
& $(36.6,42.3)$ & $(18.8,22.9)$ & $(15.9,19.4)$ & $(16.8,21.1)$ & $(2.3,3.7)$ \\
\hline $35-44$ & 46.2 & 20.3 & 16.6 & 14.8 & 2.0 \\
& $(43.5,49.0)$ & $(18.3,22.3)$ & $(14.7,18.6)$ & $(13.3,16.3)$ & $(1.4,2.6)$ \\
\hline $45-54$ & 57.5 & 16.1 & 12.0 & 12.8 & 1.6 \\
& $(54.7,60.2)$ & $(13.9,18.4)$ & $(10.3,13.6)$ & $(10.9,14.7)$ & $(1.1,2.1)$ \\
\hline $55-64$ & 61.4 & 14.4 & 10.1 & 12.5 & 1.6 \\
& $(58.3,64.6)$ & $(12.2,16.5)$ & $(8.3,11.9)$ & $(10.4,14.7)$ & $(0.8,2.3)$ \\
\hline $65-74$ & 55.8 & 13.6 & 7.2 & 19.9 & 3.4 \\
& $(51.4,60.2)$ & $(11.2,16.0)$ & $(5.5,8.9)$ & $(16.9,22.9)$ & $(2.1,4.8)$ \\
\hline $75+$ & 51.7 & 10.3 & 7.7 & 26.0 & 4.3 \\
& $(46.5,56.9)$ & $(7.7,12.8)$ & $(5.6,9.8)$ & $(21.9,30.4)$ & $(2.4,6.2)$ \\
\hline \hline Ethnicity & 38.2 & 16.6 & 17.4 & 25.6 & 2.2 \\
Māori & $(35.6,40.7)$ & $(14.8,18.4)$ & $(15.6,19.2)$ & $(23.7,27.4)$ & $(1.4,3.0)$ \\
\hline Pacific & 34.0 & 19.8 & 13.0 & 25.8 & 7.4 \\
& $(30.4,37.7)$ & $(16.8,22.8)$ & $(10.8,15.3)$ & $(22.2,29.3)$ & $(5.0,9.7)$ \\
\hline Asian & 35.3 & 18.9 & 17.8 & 16.9 & 11.1 \\
& $(32.5,38.2)$ & $(16.6,21.2)$ & $(15.4,20.2)$ & $(14.5,19.4)$ & $(9.1,13.1)$ \\
\hline European/Other & 56.2 & 17.7 & 12.7 & 12.5 & 0.9 \\
& $(54.4,57.9)$ & $(16.5,18.8)$ & $(11.8,13.7)$ & $(11.5,13.5)$ & $(0.7,1.1)$ \\
\hline
\end{tabular}




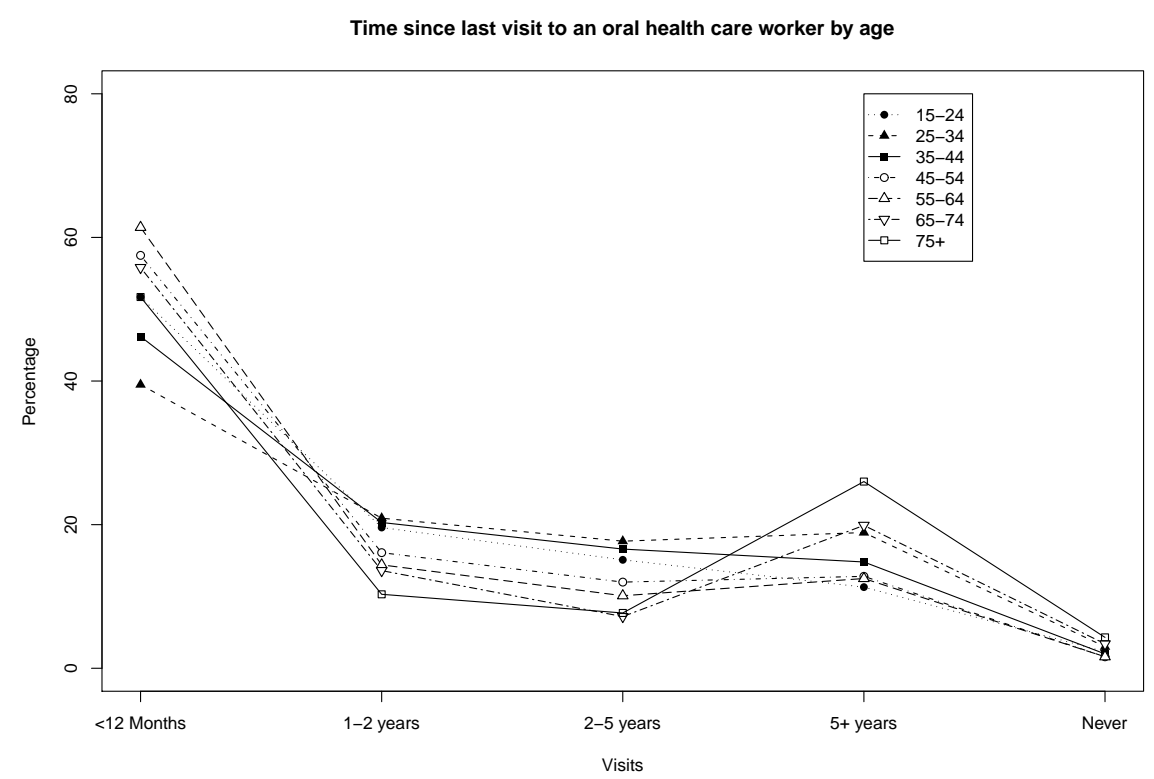

Figure 5.6: Time since last visit to an oral health care worker by age for the Adult NZHS 2006/07

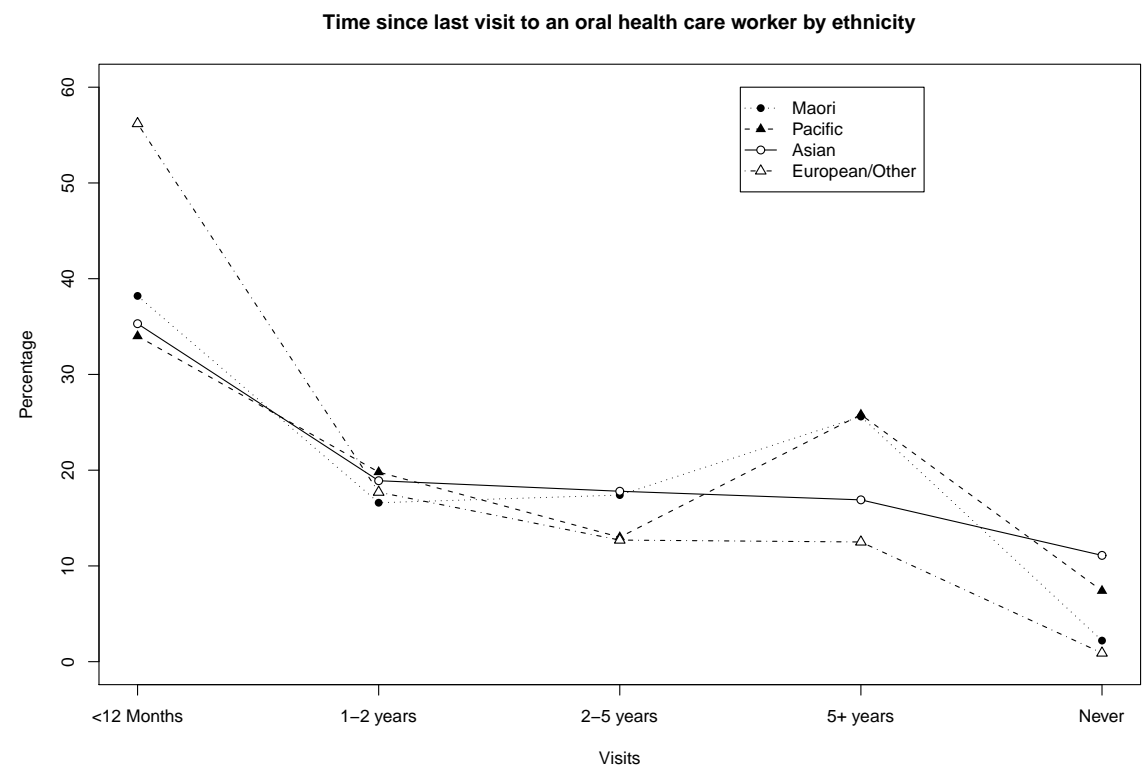

Figure 5.7: Time since last visit to an oral health care worker by ethnicity for the Adult NZHS 2006/07 
Table 5.4: Prevalence of unmet oral health care needs in the past 12 months for Adults in the NZHS 2006/07

\begin{tabular}{|c|c|c|}
\hline & Yes & No \\
\hline Total & $\begin{array}{c}10.0 \\
(9.3,10.7)\end{array}$ & $\begin{array}{c}90.0 \\
(89.1,90.9)\end{array}$ \\
\hline $\begin{array}{l}\text { Sex } \\
\text { Male }\end{array}$ & $\begin{array}{c}9.3 \\
(8.2,10.3)\end{array}$ & $\begin{array}{c}90.7 \\
(89.6,91.9)\end{array}$ \\
\hline Female & $\begin{array}{c}10.7 \\
(9.7,11.8)\end{array}$ & $\begin{array}{c}89.3 \\
(87.9,90.6)\end{array}$ \\
\hline $\begin{array}{l}\text { Age } \\
15-24\end{array}$ & $\begin{array}{c}10.6 \\
(8.9,12.4)\end{array}$ & $\begin{array}{c}89.4 \\
(87.6,91.1)\end{array}$ \\
\hline $25-34$ & $\begin{array}{c}14.5 \\
(12.5,16.5)\end{array}$ & $\begin{array}{c}85.5 \\
(83.4,87.5)\end{array}$ \\
\hline $35-44$ & $\begin{array}{c}12.9 \\
(11.5,14.3)\end{array}$ & $\begin{array}{c}87.1 \\
(85.7,88.5)\end{array}$ \\
\hline $45-54$ & $\begin{array}{c}9.1 \\
(7.6,10.6)\end{array}$ & $\begin{array}{c}90.9 \\
(89.2,92.6)\end{array}$ \\
\hline $55-64$ & $\begin{array}{c}5.7 \\
(4.4,7.0)\end{array}$ & $\begin{array}{c}94.3 \\
(91.8,96.7)\end{array}$ \\
\hline $65-74$ & $\begin{array}{c}3.5 \\
(2.4,4.6)\end{array}$ & $\begin{array}{c}96.5 \\
(92.7,100.0)\end{array}$ \\
\hline $75+$ & $\begin{array}{c}3.3 \\
(1.9,4.8)\end{array}$ & $\begin{array}{c}96.7 \\
(91.1,100.0)\end{array}$ \\
\hline $\begin{array}{l}\text { Ethnicity } \\
\text { Māori }\end{array}$ & $\begin{array}{c}18.1 \\
(16.4,19.8)\end{array}$ & $\begin{array}{c}81.9 \\
(79.9,83.8)\end{array}$ \\
\hline Pacific & $\begin{array}{c}13.1 \\
(10.4,15.7)\end{array}$ & $\begin{array}{c}86.9 \\
(83.2,90.7)\end{array}$ \\
\hline Asian & $\begin{array}{c}8.3 \\
(6.4,10.1)\end{array}$ & $\begin{array}{c}91.7 \\
(89.8,93.6)\end{array}$ \\
\hline European/Other & $\begin{array}{c}8.8 \\
(7.9,9.6)\end{array}$ & $\begin{array}{c}91.2 \\
(90.1,92.4)\end{array}$ \\
\hline $\begin{array}{c}\text { Deprivation Quintile } \\
\text { NZDep } 1\end{array}$ & $\begin{array}{c}6.5 \\
(4.5,8.4)\end{array}$ & $\begin{array}{c}93.5 \\
(82.4,100.0)\end{array}$ \\
\hline NZDep 2 & $\begin{array}{c}8.9 \\
(7.1,10.7)\end{array}$ & $\begin{array}{c}10.7 \\
(80.2,100.0)\end{array}$ \\
\hline NZDep 3 & $\begin{array}{c}10.2 \\
(8.4 .12 .0)\end{array}$ & $\begin{array}{c}89.8 \\
(80.0 .99 .6)\end{array}$ \\
\hline NZDep 4 & $\begin{array}{c}12.1 \\
(10.0,14.3)\end{array}$ & $\begin{array}{c}87.9 \\
(78.2,97.5)\end{array}$ \\
\hline NZDep 5 & $\begin{array}{c}13.0 \\
(11.0,15.1)\end{array}$ & $\begin{array}{c}87.0 \\
(75.6,98.3)\end{array}$ \\
\hline
\end{tabular}


Table 5.4 shows that Māori people have the highest rates of unmet need with $18.1 \%(16.4,19.8)$ of people being unable to consult with an oral health care worker when they needed to in the last 12 months. Deprivation also plays a part in unmet need, with those in a higher deprivation decile being more likely to have had unmet oral health needs in the past 12 months. We established in the Demographics of the NZHS that deprivation was associated with ethnicity, with $38.36 \%$ of Māori belonging to the highest deprivation quintile, meaning that we can expect to see both ethnicity and deprivation correlated with unmet need.

\subsubsection{Reasons for unmet oral health care need}

Question A2-47 asked respondents:

The last time you were not able to see an oral health care worker when you needed to, what was the reason you weren't able to? (More than one answer is allowed)

1. Cost too much

2. Had no transport to get there

3. Lack of childcare

4. Couldn't get an appointment soon enough/at a suitable time

5. It was after hours

6. Couldn't get in touch with the oral health care worker

7. Couldn't spare the time

8. Didn't want to make a fuss

9. Anxiety or fear of dental treatment

Respondents were able to select more than one answer as a reason for their unmet need, therefore totals in Table 5.5 add to more than 100\%. For 1,368 people 1,625 answers were selected, with 6 answers being the maximum amount selected by one person. 208 people selected 2 reasons, 44 people selected 3 reasons and 3 people selected 4 reasons for their unmet need.

Table 5.5 shows that the main reason for unmet need was cost, with $52.9 \%(47.3,58.8)$ of people who had had unmet need selecting this as a reason for their unmet need. 'Could not get an appointment soon enough or at a suitable time' and 'could not spare the time' were the next to most popular reasons for unmet need with $18.7 \%$ and $13.0 \%$ respectively. Anxiety and fear of dental treatement was selected as a reason for unmet need by $10.5 \%$ of people, and not wanting to make a fuss was selected by $8.3 \%$ of people. All other reasons only featured minorly with $2.5 \%$ of people or less selecting them as reasons for unmet need.

\subsubsection{Urgent unmet oral health care need}

Those who had had unmet needs in the last 12 months then answered the question about whether they considered their unmet need to be of an urgent matter.

Did you consider that this last time you were not able to see an oral health care worker, was an urgent need?

1. Yes 
Table 5.5: Reasons for unmet oral health care needs in the past 12 months for Adult NZHS $2006 / 07$

\begin{tabular}{|l|c|}
\hline Costs too much & 52.9 \\
& $(47.3,58.8)$ \\
\hline Could not get an appointment soon enough or at a suitable time & 18.7 \\
& $(15.0,22.4)$ \\
\hline Could not spare the time & 13.0 \\
& $(9.8,18.5)$ \\
\hline Anxiety or fear of dental treatment & 10.5 \\
& $(6.5,14.4)$ \\
\hline Did not want to make a fuss & 8.3 \\
& $(4.9,12.1)$ \\
\hline Could not be bothered/too lazy/kept putting it off & 2.5 \\
& $(0.7,4.6)$ \\
\hline Could not get in touch with an oral health care worker & 2.2 \\
& $(0.5,4.0)$ \\
\hline Did not have own dentist/ did not know who to go to/ old dentist has left & 2.1 \\
& $(0.6,3.7)$ \\
\hline Other & 2.1 \\
& $(0.1,3.7)$ \\
\hline Had no transport to get there & 1.7 \\
& $(0.5,2.9)$ \\
\hline It was after hours & 1.7 \\
& $(0.6,2.9)$ \\
\hline Pain went away/Condition improved & 1.4 \\
& $(0.1,2.8)$ \\
\hline Lack of childcare & 0.8 \\
& $(0.0,1.7)$ \\
\hline Away from usual dentist at time & 0.7 \\
& $(0.0,1.6)$ \\
\hline Too sick to go & 0.5 \\
& $(0.1,0.9)$ \\
\hline Pregnant and unable to take treatment & 0.3 \\
& $(0.0,0.8)$ \\
\hline
\end{tabular}




\section{No}

Respondents who had said that they had had unmet need in the past 12 months then answered the question about whether it was urgent unmet need or not. Estimates of urgent unmet need are displayed in Table 5.6. 44.77\% $(40.38,49.17)$ of people said that their unmet oral health needs in the past 12 months had been urgent, whilst $55.23 \%(49.87,60.58)$ said that their unmet oral health needs in the past 12 months were not of an urgent nature. This equates to 130,398 cases with at least one instance of urgent unmet oral health care needs in the past 12 months.

$63.5 \%(58.6,66.7)$ of Pacific people's unmet oral health care needs were urgent in the past 12 months. $57.5 \%(55.6,59.1)$ of Māori unmet oral health care needs were also urgent, whilst Asians and European/Others had urgent unmet oral health need rates lower than the population average of $44.8 \%$.

35-44 year olds with a rate of $50.9 \%(48.3,53.0)$ and $45-54$ year olds with a rate of $50.2 \%$ $(46.5,52.9)$ had the highest rates of unmet oral health care needs, whilst $15-24$ year olds with a rate of $30.6 \%(27.7,32.6)$ and people aged over 75 years with a rate of $30.6 \%(13.7,37.2)$ had the lowest rates of urgent unmet oral health care needs.

\subsection{New Zealand Health Survey 2006/07 Child Results}

The Child section of the NZHS 2006/07 asked different oral health questions from the Adult section of the NZHS 2006/07. Children were asked about their tooth brushing habits and about fillings, pain and tooth removal. However quantitative answers to these questions were not recorded, with children only answering with a yes or no to the oral health questions.

Table 5.7 displays the rates of children aged 0-14 years old, who have had at least one tooth filled, tooth pain that has kept them awake at night and the percentage of children who have had at least one tooth removed due to tooth decay, abcess or infection.

\subsubsection{Fillings}

The child section of the survey asked about fillings in childrens teeth. The question asked:

Have any of your child's teeth ever had a filling?

1. Yes

2. No

Almost half (45.5\%) of New Zealand children aged 0-14 have at least one filling in their teeth. $70.4 \%(67.4,73.4)$ of children aged 10-14 having at least one tooth filling. Whether a child has a filling depended on age, with only $5.7 \%(3.7,7.6)$ of $0-4$ year olds having had a filling. This is not suprising as children do not generally develop a full set of teeth until the age of two and a half or three years of age (Colgate 2002).

Figure 5.8 shows that Māori children are most likely to have had fillings with 51.1\% $(48.7,53.5)$ having had a filling, compared to Asians with only $37.2 \%(31.6,42.8)$ of children having had at least one tooth filled.

\subsubsection{Tooth pain}

The child section of the survey asked about pain in childrens teeth and mouth. The question asked: 
Table 5.6: Urgent unmet oral health care needs in the past 12 months for Adult NZHS 2006/07

\begin{tabular}{|c|c|c|}
\hline & Yes & $\mathrm{No}$ \\
\hline Total & $\begin{array}{c}44.8 \\
(40.4,49.2)\end{array}$ & $\begin{array}{c}55.3 \\
(49.9,60.6)\end{array}$ \\
\hline $\begin{array}{l}\text { Sex } \\
\text { Male }\end{array}$ & $\begin{array}{c}42.0 \\
(39.3,44.1)\end{array}$ & $\begin{array}{c}58.0 \\
(55.0,60.4)\end{array}$ \\
\hline Female & $\begin{array}{c}47.01 \\
(45.5,48.3)\end{array}$ & $\begin{array}{c}52.9 \\
(50.4,55.0)\end{array}$ \\
\hline $\begin{array}{l}\text { Age } \\
15-24\end{array}$ & $\begin{array}{c}30.6 \\
(27.7,32.6)\end{array}$ & $\begin{array}{c}69.4 \\
(64.9,72.7)\end{array}$ \\
\hline $25-34$ & $\begin{array}{c}48.5 \\
(44.4,51.5)\end{array}$ & $\begin{array}{c}51.5 \\
(48.6,53.8)\end{array}$ \\
\hline $35-44$ & $\begin{array}{c}50.9 \\
(48.3,53.0)\end{array}$ & $\begin{array}{c}49.1 \\
(45.6,51.9)\end{array}$ \\
\hline $45-54$ & $\begin{array}{c}50.2 \\
(46.5,52.9)\end{array}$ & $\begin{array}{c}49.8 \\
(44.1,53.8)\end{array}$ \\
\hline $55-64$ & $\begin{array}{c}43.9 \\
(36.1,48.8)\end{array}$ & $\begin{array}{c}56.1 \\
(48.2,61.1)\end{array}$ \\
\hline $65-74$ & $\begin{array}{c}32.2 \\
(22.4,37.4)\end{array}$ & $\begin{array}{c}67.8 \\
(56.7,73.5)\end{array}$ \\
\hline $75+$ & $\begin{array}{c}30.6 \\
(13.7,37.2) \\
\end{array}$ & $\begin{array}{c}69.4 \\
(53.7,75.5) \\
\end{array}$ \\
\hline $\begin{array}{l}\text { Ethnicity } \\
\text { Māori }\end{array}$ & $\begin{array}{c}57.5 \\
(55.6,59.1)\end{array}$ & $\begin{array}{c}42.5 \\
(39.5,45.1)\end{array}$ \\
\hline Pacific & $\begin{array}{c}63.5 \\
(58.6,66.7)\end{array}$ & $\begin{array}{c}36.5 \\
(31.8,39.7)\end{array}$ \\
\hline Asian & $\begin{array}{c}44.6 \\
(38.6,48.4)\end{array}$ & $\begin{array}{c}55.4 \\
(50.1,58.8)\end{array}$ \\
\hline European/Other & $\begin{array}{c}38.8 \\
(36.8,40.5)\end{array}$ & $\begin{array}{c}61.2 \\
(59.2,62.8)\end{array}$ \\
\hline $\begin{array}{c}\text { Deprivation Quintile } \\
\text { NZDep } 1\end{array}$ & $\begin{array}{c}37.9 \\
(35.0,39.4)\end{array}$ & $\begin{array}{c}62.1 \\
(54.6,66.2)\end{array}$ \\
\hline NZDep 2 & $\begin{array}{c}35.8 \\
(30.0,39.7)\end{array}$ & $\begin{array}{c}64.2 \\
(61.9,65.7)\end{array}$ \\
\hline NZDep 3 & $\begin{array}{c}42.6 \\
(39.2,45.0)\end{array}$ & $\begin{array}{c}57.4 \\
(54.7,59.3)\end{array}$ \\
\hline NZDep 4 & $\begin{array}{c}44.2 \\
(42.1,45.6)\end{array}$ & $\begin{array}{c}55.8 \\
(52.5,58.2)\end{array}$ \\
\hline NZDep 5 & $\begin{array}{c}58.8 \\
(56.0,60.9)\end{array}$ & $\begin{array}{c}41.2 \\
(37.8,43.6)\end{array}$ \\
\hline
\end{tabular}


Table 5.7: Rates of children with specific oral health characteristics NZHS 2006/07

\begin{tabular}{|c|c|c|c|}
\hline & $\begin{array}{l}\text { At least one } \\
\text { Filling }\end{array}$ & $\begin{array}{l}\text { Tooth Pain } \\
\text { at night }\end{array}$ & $\begin{array}{c}\text { At least one } \\
\text { Tooth Removed }\end{array}$ \\
\hline Total & $\begin{array}{c}45.5 \\
(43.7,47.2)\end{array}$ & $\begin{array}{c}18.0 \\
(16.3,19.8)\end{array}$ & $\begin{array}{c}10.5 \\
(9.4,11.6)\end{array}$ \\
\hline $\begin{array}{l}\text { Sex } \\
\text { Male }\end{array}$ & $\begin{array}{c}45.1 \\
(42.6,50.5)\end{array}$ & $\begin{array}{c}17.9 \\
(15.8,19.9)\end{array}$ & $\begin{array}{c}11.4 \\
(9.8,13.0)\end{array}$ \\
\hline Female & $\begin{array}{c}45.8 \\
(43.6,48.0)\end{array}$ & $\begin{array}{c}18.2 \\
(15.9,20.6)\end{array}$ & $\begin{array}{c}9.5 \\
(7.8,11.2)\end{array}$ \\
\hline $\begin{array}{c}\text { Age } \\
0-4\end{array}$ & $\begin{array}{c}5.7 \\
(3.7,7.6)\end{array}$ & $\begin{array}{c}23.1 \\
(19.8,26.5)\end{array}$ & $\begin{array}{c}1.5 \\
(0.2,2.7)\end{array}$ \\
\hline $5-9$ & $\begin{array}{c}51.8 \\
(48.2,55.4)\end{array}$ & $\begin{array}{c}15.9 \\
(13.4,18.3)\end{array}$ & $\begin{array}{c}14.6 \\
(12.4,16.8)\end{array}$ \\
\hline $10-14$ & $\begin{array}{c}70.4 \\
(67.4,73.4) \\
\end{array}$ & $\begin{array}{c}16.2 \\
(13.8,18.6) \\
\end{array}$ & $\begin{array}{c}13.5 \\
(11.4,15.6) \\
\end{array}$ \\
\hline $\begin{array}{c}\text { Ethnicity } \\
\text { Māori }\end{array}$ & $\begin{array}{c}51.1 \\
(48.7,53.5)\end{array}$ & $\begin{array}{c}19.9 \\
(18.0,21.8)\end{array}$ & $\begin{array}{c}13.3 \\
(11.5,15.2)\end{array}$ \\
\hline Pacific & $\begin{array}{c}41.3 \\
(35.1,47.6)\end{array}$ & $\begin{array}{c}14.4 \\
(11.0,17.7)\end{array}$ & $\begin{array}{c}13.9 \\
(10.2,17.7)\end{array}$ \\
\hline Asian & $\begin{array}{c}37.2 \\
(31.6,42.8)\end{array}$ & $\begin{array}{c}8.8 \\
(6.1,11.6)\end{array}$ & $\begin{array}{c}10.2 \\
(6.9,13.4)\end{array}$ \\
\hline European/Other & $\begin{array}{c}45.1 \\
(42.7,47.5) \\
\end{array}$ & $\begin{array}{c}19.2 \\
(16.7,21.6) \\
\end{array}$ & $\begin{array}{c}8.9 \\
(7.4,10.4) \\
\end{array}$ \\
\hline $\begin{array}{c}\text { Deprivation Quintile } \\
\text { NZDep } 1\end{array}$ & $\begin{array}{c}41.3 \\
(34.1,48.4)\end{array}$ & $\begin{array}{c}17.7 \\
(13.2,22.2)\end{array}$ & $\begin{array}{c}7.6 \\
(5.0,10.3)\end{array}$ \\
\hline NZDep 2 & $\begin{array}{c}48.2 \\
(40.5,56.0)\end{array}$ & $\begin{array}{c}18.6 \\
(13.7,23.5)\end{array}$ & $\begin{array}{c}9.3 \\
(6.4,12.2)\end{array}$ \\
\hline NZDep 3 & $\begin{array}{c}45.2 \\
(38.1,52.4)\end{array}$ & $\begin{array}{c}17.1 \\
(13.0,21.2)\end{array}$ & $\begin{array}{c}10.2 \\
(7.0,13.3)\end{array}$ \\
\hline NZDep 4 & $\begin{array}{c}46.0 \\
(38.9,53.2)\end{array}$ & $\begin{array}{c}18.3 \\
(13.9,22.7)\end{array}$ & $\begin{array}{c}10.2 \\
(7.8,12.5)\end{array}$ \\
\hline NZDep 5 & $\begin{array}{c}46.9 \\
(40.2,53.5)\end{array}$ & $\begin{array}{c}18.5 \\
(14.9,22.0)\end{array}$ & $\begin{array}{c}14.8 \\
(11.3,18.3)\end{array}$ \\
\hline
\end{tabular}




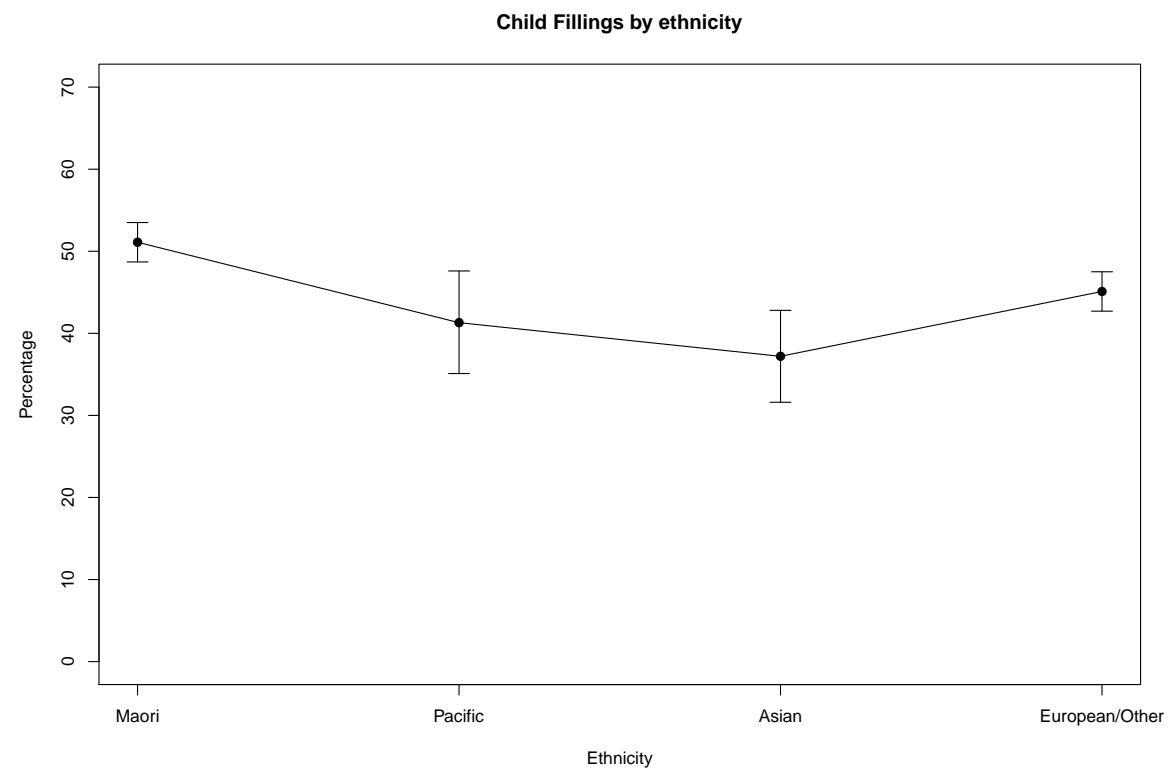

Figure 5.8: Rates of Children with Fillings by ethnicity for the Child NZHS 2006/07

Has pain in your child's teeth or mouth ever kept him/her awake at night?

1. Yes

2. No

0-4 year olds experience the most tooth and mouth pain, $23.1 \%(19.8,26.5)$ being kept awake at night. This may be due to teething, which usually begins around 3-9 months of age. Teething may make a child 'irritable or fussy and may cause restlessness, drooling or loss of appetite' (Colgate 2002) . Sex and deprivation do not appear to be associated with tooth and mouth pain among $0-14$ year olds.

Displayed in Figure 5.9 we can see that Asians have reported less pain with only $8.8 \%$ $(6.1,11.6)$ having reported pain at night, whilst 19.9\% (18.0,21.8) of Māori and 19.2\% (16.7,21.6) of European/Others experience pain at night, keeping the child awake.

\subsubsection{Tooth removal}

The child section of the survey also asked about tooth removal due to tooth decay, abcess and infection. The question asked:

Have any of your child's teeth been removed because of tooth decay or 'gum boil' (abscess) or infection? Do not include teeth lost for other reasons such as injury or orthodontics.

1. Yes

2. No

Children aged 0-4 are unlikely to have had teeth removed due to tooth decay, abscess or infection, with only $1.5 \%(0.2,2.7)$ of children in this age category having had teeth removed. 


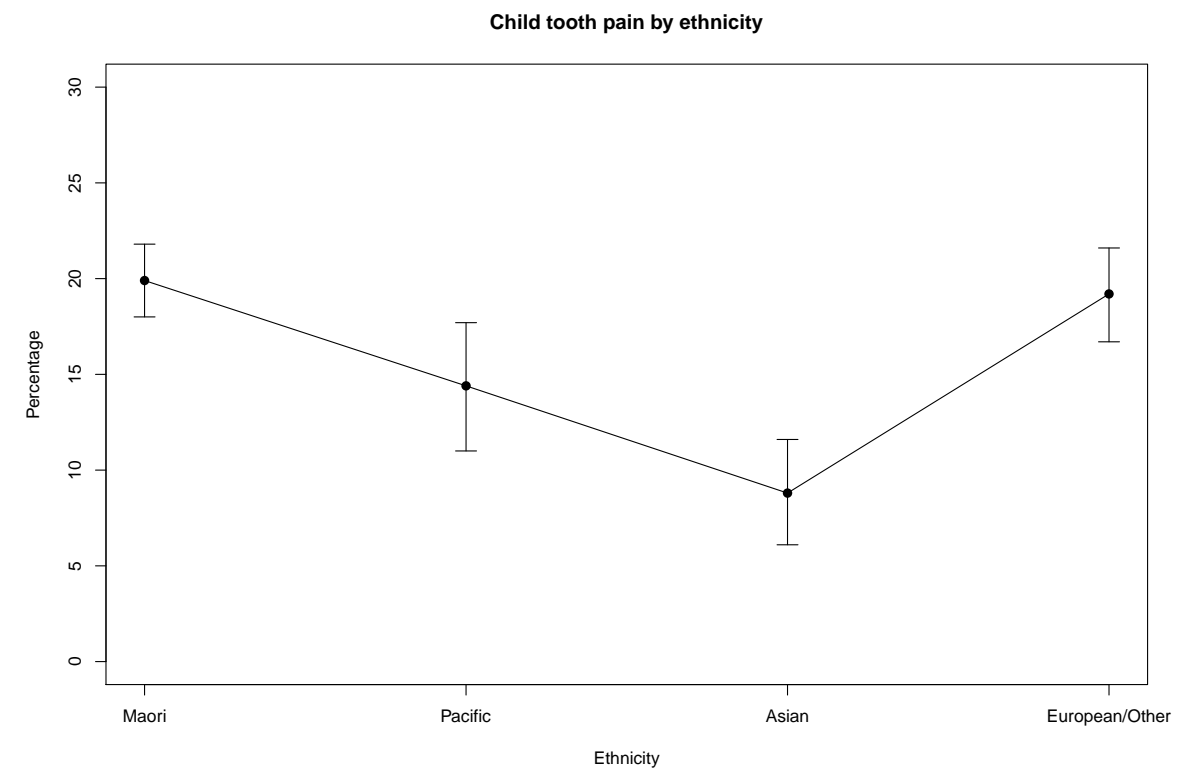

Figure 5.9: Rates of Children who are kept awake at night due to tooth or mouth pain, by ethnicity, for the Child NZHS 2006/07

$14.6 \%(12.4,16.8)$ of $5-9$ year olds and $13.5 \%(11.4,15.6)$ of $10-14$ year olds have had at least one tooth removed due to tooth decay, abscess or infection.

There is a significant difference in rates of tooth loss among children by deprivation category, with children in the least deprived deciles being less likely to lose teeth, with only $7.6 \%$ $(5.0,10.3)$ of children in the least deprived quintile having lost at least one tooth compared to the most deprived children, with $14.8 \%(11.3,18.3)$ having lost at least one tooth due to tooth decay, abscess or infection.

Figure 5.10 shows child tooth removal due to tooth decay, abscess and infection in children aged 0-14 by ethnicity. Māori and Pacific children have the highest rates of tooth removal with 13.3\% (11.5,15.2) of Māori and 13.9\% (10.2,17.7) of Pacific children having had at least one tooth removed compared to European/Other children with the lowest rate, with only $8.9 \%(1.4,10.4)$ having had at least one tooth removed due to tooth decay, abscess or infection.

\subsubsection{Tooth brushing}

Respondents were asked about their childs tooth brushing habits for the previous day.

How many times did your child brush his/her teeth yesterday?
0 . None
1. One time
2. Two times
3. Three times or more 


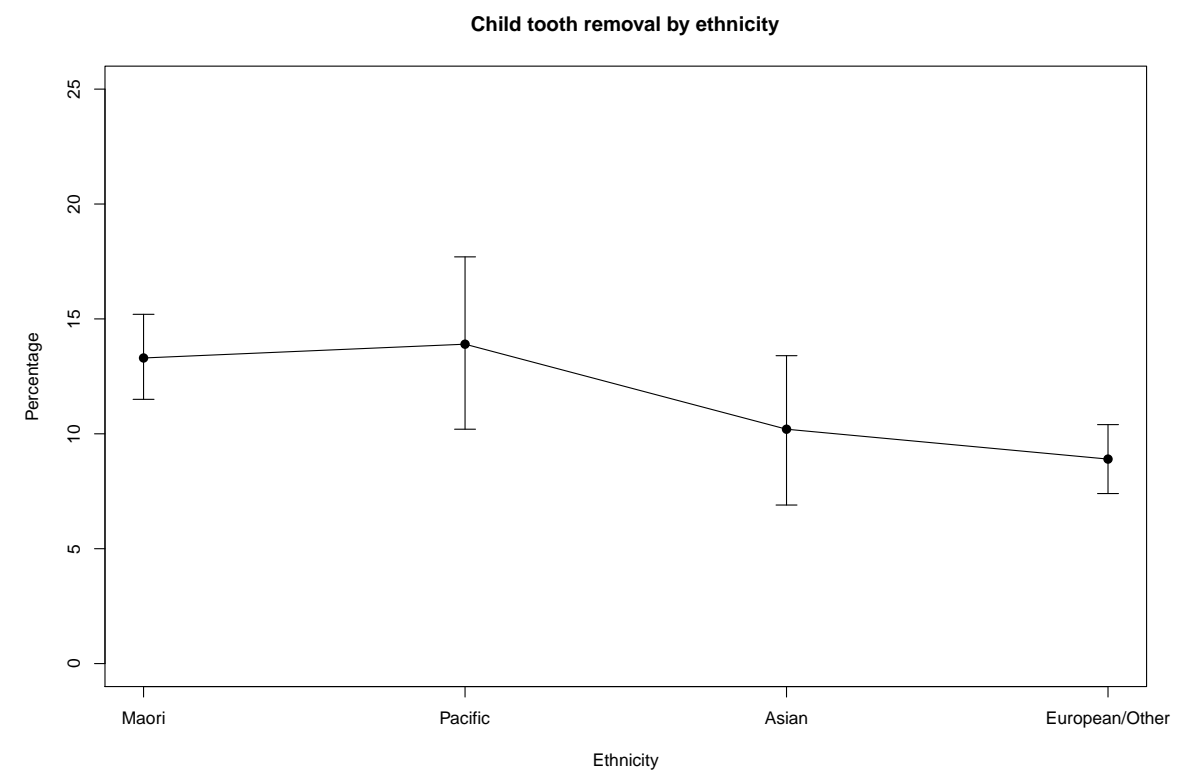

Figure 5.10: Rates of Children who have had at least one tooth removed due to tooth decay, abscess or infection by ethnicity, for the Child NZHS 2006/07

The results from this question are presented in Table 5.8 and have been used to draw conclusions about general tooth brushing habits for children.

It is recommended that children and adults brush their teeth twice a day, once in the morning and once at night (Colgate 2001). 56.9\% (54.9,58.9) of children aged 0-14 brush their teeth twice a day in New Zealand. There was a small difference in the rates of tooth brushing between males and females. with females brushing more than males.

Rates of tooth brushing were clearly associated with deprivation status. The most deprived people had the highest rates of non tooth brushing with $15.7 \%(12.7,18.7)$ not brushing their teeth at all, while only $4.3 \%(1.9,6.6)$ of the least deprived children did not brush their teeth. The least deprived children, those in quintile 1 , were most likely to brush their teeth the recommended twice a day, with $66.6 \%(55.8,77.3)$ brushing twice a day. This rate decreases as deprivation increases, with $45.8 \%(39.3,52.4)$ of the most deprived children brushing twice a day.

The rates of children brushing their teeth 3 or more times a day does not appear to be associated with sex or deprivation. 0 - 4 year olds have the highest rate of $6.8 \%(4.8,8.8)$ brushing their teeth three or more times a day, compared to only $1.5 \%(0.9,2.1)$ of $10-14$ year olds with the lowest rate for brushing three or more times a day.

Figure 5.11 shows the rates of all 4 levels of tooth brushing by ethnicity. Māori children have the highest rates of not brushing teeth at all, with $15.3 \%(13.0,17.6)$ not brushing their teeth compared to Asians with the lowest rate, with $4.7 \%(2.9,6.5)$ of Asian children not brushing their teeth.

Asians and European/Others have the highest rates of children brushing their teeth twice a day, with $62.4 \%(57.7,67.2)$ and $61.7 \%(58.7,64.7)$ respectively, whilst Māori children have 
Table 5.8: Frequency of tooth brushing by children, based on the NZHS 2006/07

\begin{tabular}{|c|c|c|c|c|}
\hline & None & One time & Two times & Three times or more \\
\hline Total & $\begin{array}{c}8.4 \\
(7.2,9.6)\end{array}$ & $\begin{array}{c}31.3 \\
(29.7,32.9)\end{array}$ & $\begin{array}{c}56.9 \\
(54.9,58.9)\end{array}$ & $\begin{array}{c}3.4 \\
(2.8,4.0)\end{array}$ \\
\hline $\begin{array}{l}\text { Sex } \\
\text { Male }\end{array}$ & $\begin{array}{c}10.0 \\
(8.2,11.8)\end{array}$ & $\begin{array}{c}34.3 \\
(31.9,36.6)\end{array}$ & $\begin{array}{c}53.0 \\
(50.2,55.8)\end{array}$ & $\begin{array}{c}2.8 \\
(1.9,3.6)\end{array}$ \\
\hline Female & $\begin{array}{c}6.7 \\
(5.4,8.0) \\
\end{array}$ & $\begin{array}{c}28.2 \\
(25.7,30.7) \\
\end{array}$ & $\begin{array}{c}61.1 \\
(58.2,64.0) \\
\end{array}$ & $\begin{array}{c}4.0 \\
(3.0,5.1) \\
\end{array}$ \\
\hline $\begin{array}{c}\text { Age } \\
0-4\end{array}$ & $\begin{array}{c}10.0 \\
(7.8,12.2)\end{array}$ & $\begin{array}{c}32.3 \\
(28.8,35.7)\end{array}$ & $\begin{array}{c}50.9 \\
(47.5,54.3)\end{array}$ & $\begin{array}{c}6.8 \\
(4.8,8.8)\end{array}$ \\
\hline $5-9$ & $\begin{array}{c}7.1 \\
(5.3,8.8)\end{array}$ & $\begin{array}{c}28.4 \\
(25.4,31.4)\end{array}$ & $\begin{array}{c}62.0 \\
(58.7,65.2)\end{array}$ & $\begin{array}{c}2.6 \\
(1.7,3.5)\end{array}$ \\
\hline $10-14$ & $\begin{array}{c}8.4 \\
(6.5,10.3) \\
\end{array}$ & $\begin{array}{c}33.4 \\
(30.6,36.2) \\
\end{array}$ & $\begin{array}{c}56.7 \\
(53.5,59.9) \\
\end{array}$ & $\begin{array}{c}1.5 \\
(0.9,2.1) \\
\end{array}$ \\
\hline $\begin{array}{l}\text { Ethnicity } \\
\text { Māori }\end{array}$ & $\begin{array}{c}15.3 \\
(13.0,17.6)\end{array}$ & $\begin{array}{c}36.8 \\
(33.9,39.6)\end{array}$ & $\begin{array}{c}43.5 \\
(40.3,46.6)\end{array}$ & $\begin{array}{c}4.5 \\
(3.3,5.7)\end{array}$ \\
\hline Pacific & $\begin{array}{c}9.9 \\
(6.9,13.0)\end{array}$ & $\begin{array}{c}30.2 \\
(24.2,36.1)\end{array}$ & $\begin{array}{c}53.9 \\
(47.1,60.7)\end{array}$ & $\begin{array}{c}6.0 \\
(3.4,8.6)\end{array}$ \\
\hline Asian & $\begin{array}{c}4.7 \\
(2.9,6.5)\end{array}$ & $\begin{array}{c}28.7 \\
(24.1,33.4) \\
\end{array}$ & $\begin{array}{c}62.4 \\
(57.7,67.2) \\
\end{array}$ & $\begin{array}{c}4.2 \\
(2.4,5.9)\end{array}$ \\
\hline European/Other & $\begin{array}{c}6.0 \\
(4.5,7.6) \\
\end{array}$ & $\begin{array}{c}29.8 \\
(27.3,32.3) \\
\end{array}$ & $\begin{array}{c}61.7 \\
(58.7,64.7) \\
\end{array}$ & $\begin{array}{c}2.5 \\
(1.6,3.4) \\
\end{array}$ \\
\hline $\begin{array}{c}\text { Deprivation Quintile } \\
\text { NZDep } 1\end{array}$ & $\begin{array}{c}4.3 \\
(1.9,6.6)\end{array}$ & $\begin{array}{c}26.0 \\
(20.8,31.3)\end{array}$ & $\begin{array}{c}66.6 \\
(55.8,77.3)\end{array}$ & $\begin{array}{c}3.1 \\
(1.3,4.9)\end{array}$ \\
\hline NZDep 2 & $\begin{array}{c}5.2 \\
(2.7,7.8)\end{array}$ & $\begin{array}{c}32.0 \\
(15.9,38.0)\end{array}$ & $\begin{array}{c}60.3 \\
(50.5,70.0)\end{array}$ & $\begin{array}{c}2.5 \\
(0.8,4.2)\end{array}$ \\
\hline NZDep 3 & $\begin{array}{c}6.1 \\
(3.8,8.3)\end{array}$ & $\begin{array}{c}31.0 \\
(25.4,36.7)\end{array}$ & $\begin{array}{c}59.7 \\
(51.6,67.9)\end{array}$ & $\begin{array}{c}3.2 \\
(1.6,4.8)\end{array}$ \\
\hline NZDep 4 & $\begin{array}{c}10.1 \\
(6.9,13.3)\end{array}$ & $\begin{array}{c}34.0 \\
(28.9,39.2)\end{array}$ & $\begin{array}{c}52.6 \\
(44.3,61.0)\end{array}$ & $\begin{array}{c}3.3 \\
(1.8,4.7)\end{array}$ \\
\hline NZDep 5 & $\begin{array}{c}15.7 \\
(12.7,18.7)\end{array}$ & $\begin{array}{c}33.8 \\
(28.2,39.4)\end{array}$ & $\begin{array}{c}45.8 \\
(39.3,52.4)\end{array}$ & $\begin{array}{c}4.7 \\
(3.0,6.3)\end{array}$ \\
\hline
\end{tabular}




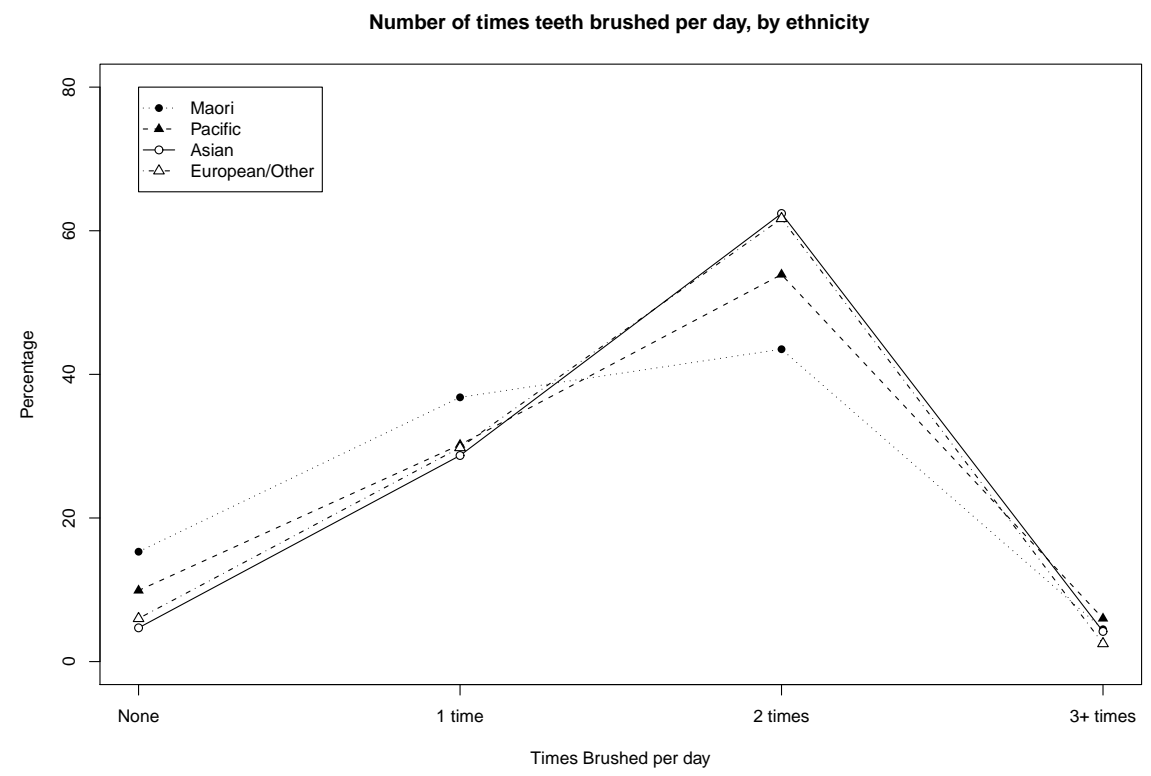

Figure 5.11: Rates of daily tooth brushing by ethnicity for the Child NZHS 2006/07

the lowest rate with $43.5 \%(40.3,46.6)$ brushing their teeth the recommended twice a day.

Rates for children who brush once a day or three or more times a day were not greatly different between ethnic groups. However, Pacific children have the highest rate, with $6.0 \%$ $(3.4,8.6)$ brushing three or more times a day, and European/Others had the lowest rate, with $2.5 \%(1.6,3.4)$ brushing three or more times a day.

Table 5.9 shows that rates of children with fillings, tooth pain and tooth removal are significantly associated with the number of times a child brushes their teeth each day.

Over half, $55.1 \%(51.0,58.2)$ of children who did not brush their teeth had at least one tooth filled, whilst only a quarter, $25.0 \%(21.0,27.8)$ of those who brush their teeth three or more

Table 5.9: Frequency of tooth brushing and relationship with oral health outcomes, Child NZHS 2006/07

\begin{tabular}{|c|c|c|c|c|c|c|}
\hline $\begin{array}{c}\text { Number of } \\
\text { Times Brushed }\end{array}$ & Yes & Nollings & \multicolumn{2}{c|}{ Pain } & \multicolumn{2}{c|}{ Tooth Removal } \\
\hline 0 & 55.1 & 44.9 & 31.0 & 69.0 & Yes & No \\
\hline & $(51.0,58.2)$ & $(42.4,46.7)$ & $(26.7,34.2)$ & $(65.4,71.7)$ & $(12.4,17.4)$ & 84.7 \\
& 45.2 & 54.8 & 18.3 & 81.7 & 10.5 & $89.86 .1)$ \\
\hline 1 & $(43.0,47.1)$ & $(53.5,56.1)$ & $(16.1,20.2)$ & $(80.9,82.5)$ & $(8.6,12.2)$ & $(89.5,89.5)$ \\
\hline 2 & 45.3 & 54.7 & 16.5 & 83.5 & 10.0 & 90.0 \\
& $(43.7,46.8)$ & $(53.5,55.8)$ & $(15.0,17.9)$ & $(83.0,84.0)$ & $(8.8,11.1)$ & $(89.7,90.3)$ \\
\hline $3+$ & 25.0 & 75.0 & 9.8 & 90.2 & 6.9 & 93.1 \\
& $(21.0,27.8)$ & $(72.0,77.0)$ & $(5.8,12.5)$ & $(88.5,91.4)$ & $(3.4,9.3)$ & $(91.8,94.0)$ \\
\hline
\end{tabular}




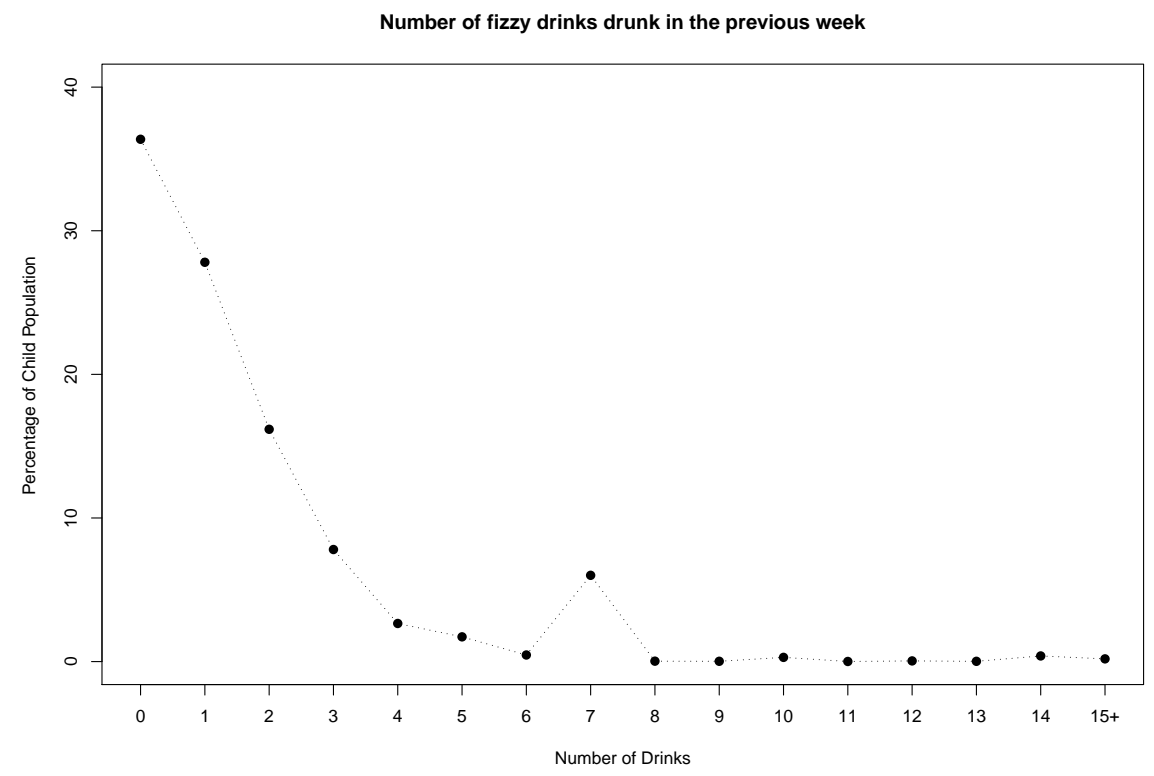

Figure 5.12: Fizzy drink intake for the previous week for the Child NZHS 2006/07

times a day have had a tooth filled.

The rate of tooth or mouth pain that keeps a child awake at night increases from $9.8 \%$ $(5.8,12.5)$ for those who brush three or more times a day to $31.0 \%(26.7,34.2)$ for those who do not brush their teeth at all.

Rates of tooth removal due to tooth decay, abscess or infection also increase as tooth brushing frequency decreases. Only $6.9 \%(3.4,9.3)$ of children who brush three or more times a day had had a tooth removed, whilst $15.3 \%(12.4,17.4)$ of children who do not brush their teeth had had at least one tooth removed for these reasons.

\subsubsection{Fizzy drink}

The number of fizzy drinks a child drank in the previous week was recorded for all children aged 0-14. The mean number of fizzy drinks drunk are presented by sub-populations in Table 5.10. These results have also been extrapolated to give a general number of fizzy drinks drunk in any given week by children.

The average number of fizzy drinks drunk in the last week by children aged 0-14 was 1.39 $(1.32,1.47)$ drinks per week. This is based on those who had the number of drinks drunk as $15+$, treated as 15 to calculate the mean.

Estimates for some subpopulations may be unreliable, as some of the cross-tabulations for different category levels had very few (or no) sample members in them at all.

Figure 5.12 shows the number of fizzy drinks drunk in the week prior to the respondent answering the survey. There is a clear spike in the data at 7 drinks per week. This may be a slight reporting bias, due to the nature of the recall-and-count question. 'This recall-and- 
Table 5.10: Child fizzy drink intake for the previous week, NZHS 2006/07

\begin{tabular}{|c|c|}
\hline Total & $\begin{array}{c}1.39 \\
(1.32,1.47) \\
\end{array}$ \\
\hline $\begin{array}{l}\text { Sex } \\
\text { Male }\end{array}$ & $\begin{array}{c}1.29 \\
(1.17,1.40)\end{array}$ \\
\hline Female & $\begin{array}{c}1.49 \\
(1.40,1.59)\end{array}$ \\
\hline $\begin{array}{c}\text { Age } \\
0-4\end{array}$ & $\begin{array}{c}0.74 \\
(0.62,0.86)\end{array}$ \\
\hline $5-9$ & $\begin{array}{c}1.41 \\
(1.29,1.52)\end{array}$ \\
\hline $10-14$ & $\begin{array}{c}2.01 \\
(1.88,2.14)\end{array}$ \\
\hline $\begin{array}{c}\text { Ethnicity } \\
\text { Māori }\end{array}$ & $\begin{array}{c}1.66 \\
(1.51,1.82)\end{array}$ \\
\hline Pacific & $\begin{array}{c}1.64 \\
(1.41,1.87)\end{array}$ \\
\hline Asian & $\begin{array}{c}1.43 \\
(1.17,1.70)\end{array}$ \\
\hline European/Other & $\begin{array}{c}1.24 \\
(1.15,1.34)\end{array}$ \\
\hline $\begin{array}{c}\text { Deprivation Quintile } \\
\text { NZDep } 1\end{array}$ & $\begin{array}{c}1.16 \\
(1.00,1.31)\end{array}$ \\
\hline NZDep 2 & $\begin{array}{c}1.28 \\
(1.10,1.46)\end{array}$ \\
\hline NZDep 3 & $\begin{array}{c}1.29 \\
(1.13,1.46)\end{array}$ \\
\hline NZDep 4 & $\begin{array}{c}1.48 \\
(1.30,1.65)\end{array}$ \\
\hline NZDep 5 & $\begin{array}{c}1.73 \\
(1.56,1.90)\end{array}$ \\
\hline
\end{tabular}




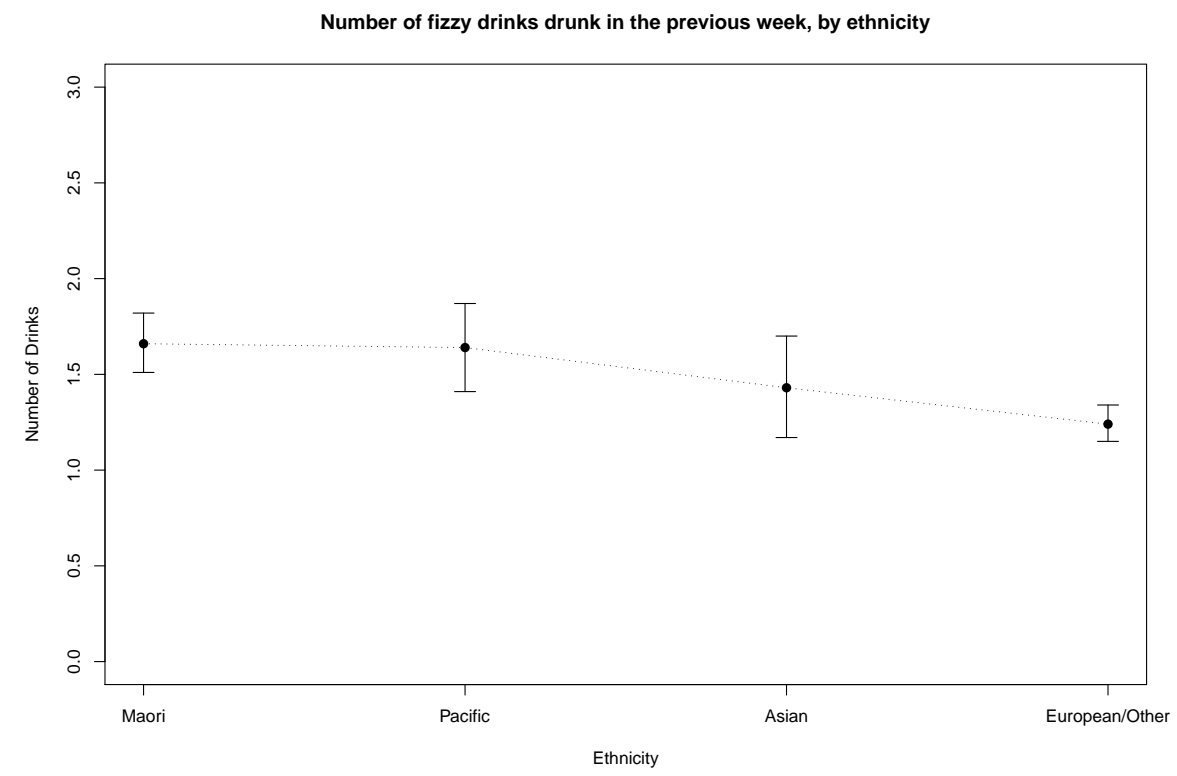

Figure 5.13: Fizzy drink intake for the previous week, by ethnicity for the Child NZHS 2006/07

count strategy is prone to omissions due to forgetting and false reports due to telescoping' (Groves et al. 2004). This could explain the high rates of respondents reporting 7 drinks per week as it corresponds to one fizzy drink a day. Respondents who selected a larger number of drinks per week may be over reporting or underreporting as 'generally, the more events there are to report, the lower the accuracy of answers based on the recall-and-count strategy' as people find it harder to accurately remember the number of fizzy drinks their child has consumed in the previous week (Groves et al. 2004). The peak of 7 drinks was visible in all subpopulations based on sex, age, ethnicity and deprivation.

Figure 5.13 shows that Māori with a mean number of $1.66(1.51,1.82)$ and Pacific people with a mean of $1.64(1.41,1.87)$, drink the most fizzy drinks a week.

Table 5.11 shows that children who drank no fizzy drinks in the previous week were less likely to have at least one tooth filling, but there did not seem to be any differences in rates of tooth fillings for children based on drinking only 1 fizzy drink and having 9 or more in a week.

\subsubsection{Take-away meals}

The number of takeaway meals a child ate in the previous week was recorded for all children aged $0-14$. The mean number of take away meals eeaten by sub populations are presented in Table 5.12. These results have also been extrapolated to give a general number of take away meals in any given week by children.

Repondents who had eaten $8+$ takeaway meals in the previous week, were recoded as the value 8 for the purposes of mean calculations.

Figure 5.14 shows that $50.1 \%$ of children have 1 take away meal a week, with $79.2 \%$ having one or less take away meals in a week. The mean number of take away meals eaten in the 
Table 5.11: Fizzy drink consumption and relationships to Fillings, Pain and Tooth Removal amoungst Children, from the NZHS 2006/07

\begin{tabular}{|c|c|c|c|c|c|c|}
\hline \multirow{2}{*}{$\begin{array}{c}\text { Number of } \\
\text { Drinks a week }\end{array}$} & Yes & No & Tooth Removal & \multicolumn{2}{c|}{ Pain } \\
& 39.1 & 60.9 & 8.5 & 91.5 & 16.3 & No \\
\hline 0 & $(36.9,41.1)$ & $(59.4,62.2)$ & $(6.8,10.0)$ & $(91.5,91.6)$ & $(14.6,17.8)$ & $(83.1,84.3)$ \\
\hline 1 & 51.2 & 48.8 & 11.4 & 88.6 & 12.0 & 88.0 \\
& $(48.9,53.2)$ & $(46.9,50.5)$ & $(9.8,12.8)$ & $(87.9,89.2)$ & $(10.2,13.6)$ & $(87.1,88.7)$ \\
\hline $2-5$ & 57.1 & 42.9 & 14.5 & 85.5 & 17.5 & 82.5 \\
& $(54.3,59.3)$ & $(39.7,45.4)$ & $(10.6,17.5)$ & $(84.7,86.2)$ & $(13.4,20.6)$ & $(80.7,84.0)$ \\
\hline $6-8$ & 60.0 & 40.0 & 13.8 & 86.2 & 21.0 & 79.0 \\
& $(55.0,63.4)$ & $(35.2,43.3)$ & $(9.7,16.8)$ & $(84.2,87.6)$ & $(15.6,25.1)$ & $(75.6,81.3)$ \\
\hline $9+$ & 52.3 & 47.7 & 5.1 & 94.9 & 12.8 & 87.2 \\
& $(19.3,55.9)$ & $(21.0,55.1)$ & $(0,6.6)$ & $(87.7,96.5)$ & $(3.8,14.0)$ & $(66.7,91.7)$ \\
\hline
\end{tabular}

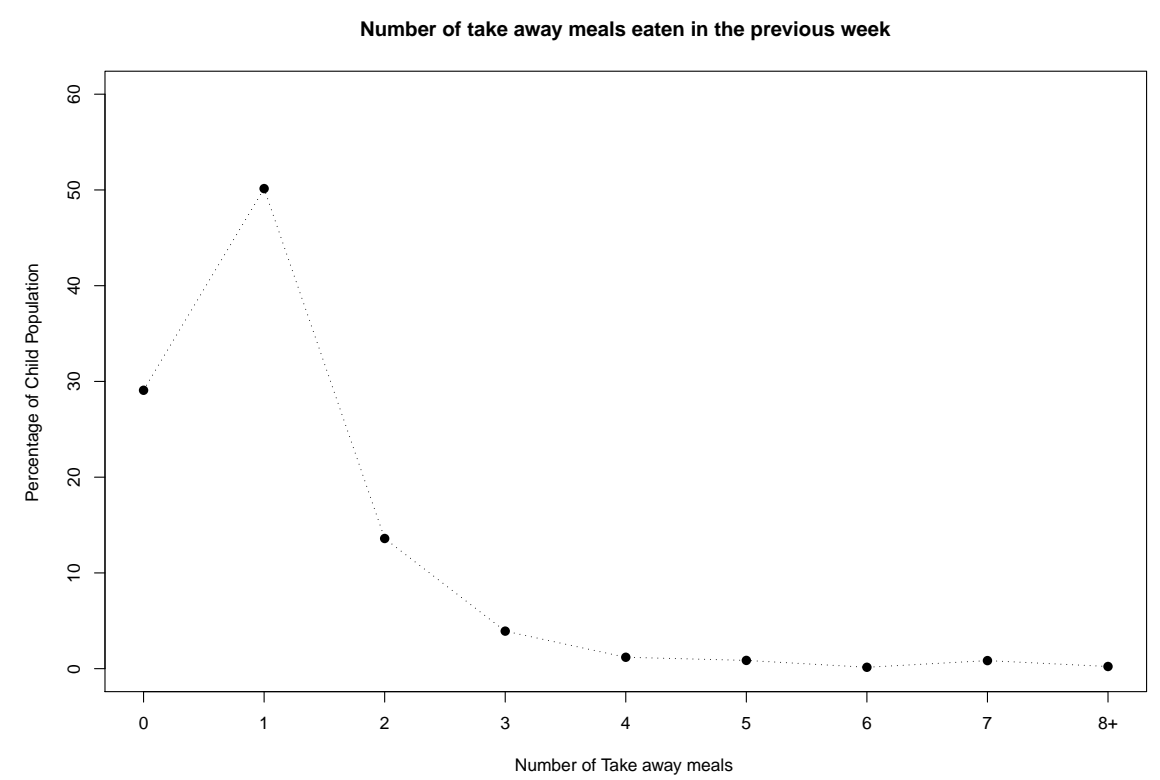

Figure 5.14: Take away meal intake for the previous week for the Child NZHS 2006/07 
Table 5.12: Mean number of take away meals eaten in the previous week, for children, NZHS $2006 / 07$

\begin{tabular}{|c|c|}
\hline Total & $\begin{array}{c}0.91 \\
(0.88,0.95)\end{array}$ \\
\hline $\begin{array}{l}\text { Sex } \\
\text { Male }\end{array}$ & $\begin{array}{c}0.96 \\
(0.90,1.02)\end{array}$ \\
\hline Female & $\begin{array}{c}0.86 \\
(0.82,0.91)\end{array}$ \\
\hline $\begin{array}{c}\text { Age } \\
0-4\end{array}$ & $\begin{array}{c}0.57 \\
(0.52,0.62)\end{array}$ \\
\hline $5-9$ & $\begin{array}{c}1.02 \\
(0.93,1.10)\end{array}$ \\
\hline $10-14$ & $\begin{array}{c}1.14 \\
(1.07,1.21) \\
\end{array}$ \\
\hline $\begin{array}{l}\text { Ethnicity } \\
\text { Māori }\end{array}$ & $\begin{array}{c}1.09 \\
(1.03,1.16)\end{array}$ \\
\hline Pacific & $\begin{array}{c}1.11 \\
(1.00,1.23)\end{array}$ \\
\hline Asian & $\begin{array}{c}0.77 \\
(0.66,0.87)\end{array}$ \\
\hline European/Other & $\begin{array}{c}0.83 \\
(0.77,0.89) \\
\end{array}$ \\
\hline $\begin{array}{c}\text { Deprivation Quintile } \\
\text { NZDep } 1\end{array}$ & $\begin{array}{c}0.74 \\
(0.68,0.80)\end{array}$ \\
\hline NZDep 2 & $\begin{array}{c}0.84 \\
(0.75,0.94)\end{array}$ \\
\hline NZDep 3 & $\begin{array}{c}0.93 \\
(0.85,1.02)\end{array}$ \\
\hline NZDep 4 & $\begin{array}{c}0.89 \\
(0.81,0.97)\end{array}$ \\
\hline NZDep 5 & $\begin{array}{c}1.14 \\
(1.03,1.26)\end{array}$ \\
\hline
\end{tabular}




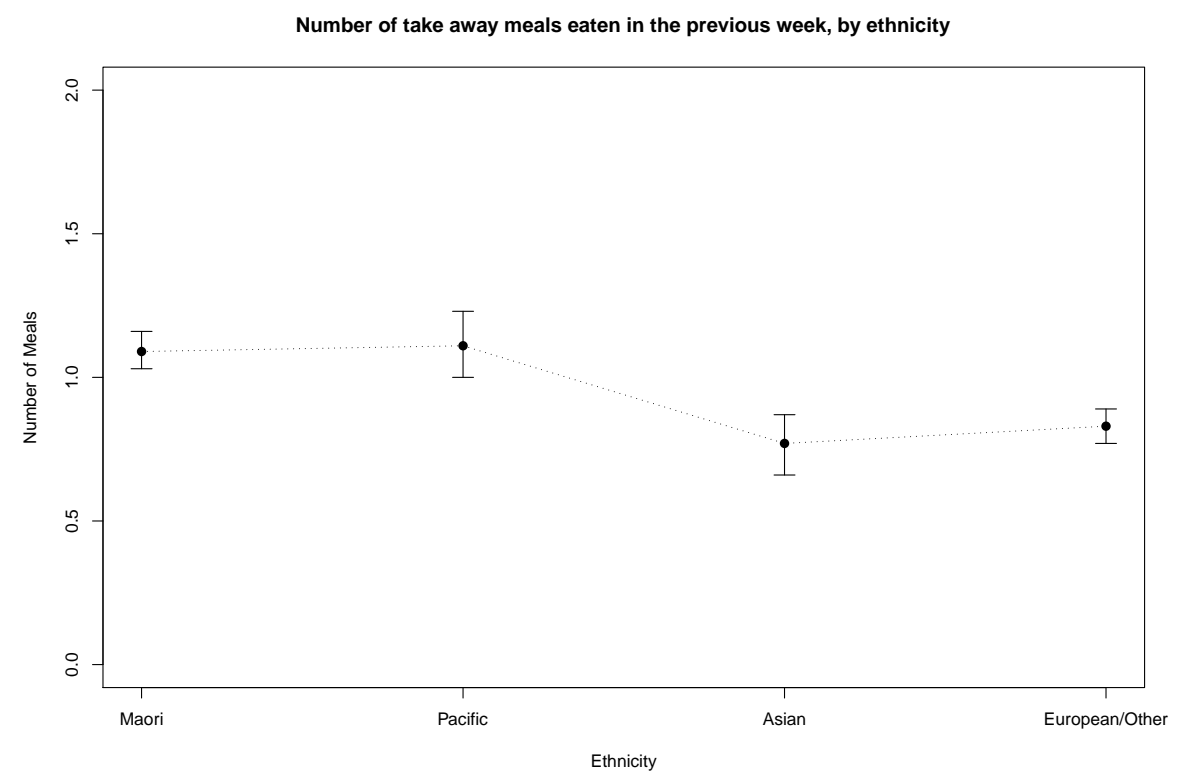

Figure 5.15: Take away meal intake for the previous week, by ethnicity for the Child NZHS 2006/07

previous week for all children aged 0-14 years old was $0.91(0.88,0.95)$.

The mean number of take away meals eaten increases as deprivation increases, with the least deprived children eating $0.74(0.68,0.87)$ take away meals a week and the most deprived children eating $1.14(1.03,1.26)$ take away meals a week.

Figure 5.15 shows how ethnicity and number of take away meals eaten a week are associated. Asian children eat the least amount of take away meals a week with a mean on 0.77 $(0.66,0.87)$, whilst Pacific children eat $1.11(1.00,1.23)$ take away meals per week.

Table 5.13 shows that rates of fillings, tooth and mouth pain and tooth removal are associated with the number of take away meals eaten by children each week.

Table 5.13: Take away meal intake and relationships to Fillngs, Pain and Tooth Removal amoungst Children, from the NZHS 2006/07

\begin{tabular}{|c|c|c|c|c|c|c|}
\hline Number of & \multicolumn{2}{|c|}{ Fillings } & \multicolumn{2}{|c|}{ Pain } & \multicolumn{2}{|c|}{ Tooth Removal } \\
\hline Takeaway meals a week & Yes & No & Yes & No & Yes & No \\
\hline 0 & $\begin{array}{c}44.0 \\
(42.2,45.6)\end{array}$ & $\begin{array}{c}56.0 \\
(54.3,57.5)\end{array}$ & $\begin{array}{c}15.0 \\
(12.8,16.8)\end{array}$ & $\begin{array}{c}85.0 \\
(84.2,85.7)\end{array}$ & $\begin{array}{c}9.5 \\
(7.8,11.0)\end{array}$ & $\begin{array}{c}90.5 \\
(88.7,89.1)\end{array}$ \\
\hline 1 & $\begin{array}{c}48.6 \\
(47.4,49.7)\end{array}$ & $\begin{array}{c}51.4 \\
(49.7,53.1)\end{array}$ & $\begin{array}{c}14.6 \\
(12.9,16.1)\end{array}$ & $\begin{array}{c}85.4 \\
(84.7,86.1)\end{array}$ & $\begin{array}{c}11.1 \\
(9.8,12.3)\end{array}$ & $\begin{array}{c}88.9 \\
(88.7,89.1)\end{array}$ \\
\hline $2-5$ & $\begin{array}{c}56.4 \\
(52.8,59.1)\end{array}$ & $\begin{array}{c}43.6 \\
(40.8,45.8)\end{array}$ & $\begin{array}{c}18.3 \\
(14.2,21.6)\end{array}$ & $\begin{array}{c}81.7 \\
(80.1,83.0)\end{array}$ & $\begin{array}{c}14.0 \\
(9.9,17.1)\end{array}$ & $\begin{array}{c}86.0 \\
(84.9,86.9)\end{array}$ \\
\hline $6+$ & $\begin{array}{c}66.4 \\
(47.5,71.7)\end{array}$ & $\begin{array}{c}33.6 \\
(18.9,40.6)\end{array}$ & $\begin{array}{c}40.2 \\
(7.5,48.2)\end{array}$ & $\begin{array}{c}59.8 \\
(45.3,65.4)\end{array}$ & $\begin{array}{c}20.5 \\
(0,26.5)\end{array}$ & $\begin{array}{c}79.5 \\
(62.1,84.6)\end{array}$ \\
\hline
\end{tabular}


$44.0 \%(12.2,45.6)$ of children who do not eat any take away meals have fillings compared to $66.4 \%(47.5,71.7)$ of children who eat 6 or more take away meals a week having at least one tooth filled.

Rates of mouth and tooth pain that keep children awake at night are lower for those who eat 5 or less take away meals a week, but this increases to $40.2 \%(7.5,48.2)$ of children who eat 6 or more take away meals a week suffering from tooth or mouth pain at night (caution needs to be taken with this large confidence interval).

Rates of tooth removal due to tooth pain, abscess and infection also increase as the number of take away meals eaten each week increases. $9.5 \%(7.8,11.0)$ of children who do not eat any take away meals have had at least one tooth removed, compared to $20.5 \%(0,26.5)$ of children who eat 6 or more take away meals a week having had at least one tooth removed.

\subsubsection{Unmet need}

Respondents were asked if there was a time in the past 12 months in which their child had had unmet oral health needs. Results for this question are presented in Table 5.14 by sub population.

Children have much less unmet need than adults with only $3.2 \%(2.7,3.8)$ of children having had an unmet oral health care need in the previous 12 months, compared to adults, with $10.0 \%(9.3,10.7)$ having had an unmet oral health care need.

0-4 year olds have the least unmet need with only $1.8 \%(0.8,2.7)$ having unmet need, whilst Māori children, of all ages have the most unmet need with 4.3\% (3.2,5.3) of Māori children having had an unmet oral health care need in the past 12 months.

\subsubsection{Time since last visit to an oral health care worker}

The time since children last visited an oral health care worker was recorded for all children aged $0-14$. Results are presented in Table 5.15, with sub population estimates.

It is important to note that in New Zealand the government employes dental therapist in schools and provides this service free of charge for children aged 0 to 8 . The dental therapist carries out routine procedures on a childs teeth and serves as an oral health educator to children (Puder 1970).

$75.8 \%(74.8,76.8)$ of children aged $0-14$ have seen an oral health care worker in the past 12 months, whereas only $51.0 \%(49.6,52.4)$ of adults have seen an oral health care worker in the past 12 months.

$45.4 \%(42.9,47.8)$ of younger children aged 0 - 4 have never seen an oral health care worker. This is likely because of a lack of teeth and need for oral health care with children usually only developing a full set of teeth at age 2 and a half to 3 years of age (Colgate 2002)

As deprivation increases, time since last visit increases with $80.5 \%(79.9,80.9)$ of the least deprived children (deprivation quintile 1) seeing an oral health care worker in the past 12 months compared to $71.6 \%(70.7,72.2)$ of the most deprived children who have seen an oral health care worker in the past 12 months. 
Table 5.14: Child unmet need in previous 12 months, from the NZHS 2006/07

\begin{tabular}{|c|c|c|}
\hline & Yes & No \\
\hline Total & $\begin{array}{c}3.2 \\
(2.7,3.8) \\
\end{array}$ & $\begin{array}{c}96.8 \\
(96.6,96.9) \\
\end{array}$ \\
\hline $\begin{array}{l}\text { Sex } \\
\text { Male }\end{array}$ & $\begin{array}{c}3.1 \\
(2.3,3.9) \\
\end{array}$ & $\begin{array}{c}96.9 \\
(96.5,97.2) \\
\end{array}$ \\
\hline Female & $\begin{array}{c}3.3 \\
(2.4,4.2)\end{array}$ & $\begin{array}{c}96.7 \\
(96.4,96.9)\end{array}$ \\
\hline $\begin{array}{c}\text { Age } \\
0-4\end{array}$ & $\begin{array}{c}1.8 \\
(0.8,2.7)\end{array}$ & $\begin{array}{c}98.2 \\
(98.1,98.4)\end{array}$ \\
\hline $5-9$ & $\begin{array}{c}3.8 \\
(2.6,5.1)\end{array}$ & $\begin{array}{c}96.2 \\
(95.0,97.3)\end{array}$ \\
\hline $10-14$ & $\begin{array}{c}3.8 \\
(2.8,4.8) \\
\end{array}$ & $\begin{array}{c}96.2 \\
(95.2,97.2) \\
\end{array}$ \\
\hline $\begin{array}{c}\text { Ethnicity } \\
\text { Māori }\end{array}$ & $\begin{array}{c}4.3 \\
(3.2,5.3)\end{array}$ & $\begin{array}{c}95.7 \\
(95.3,96.1)\end{array}$ \\
\hline Pacific & $\begin{array}{c}2.2 \dagger \\
(0.9,3.3)\end{array}$ & $\begin{array}{c}97.8 \\
(97.7,97.9) \\
\end{array}$ \\
\hline Asian & $\begin{array}{c}2.3 \dagger \\
(1.0,3.5)\end{array}$ & $\begin{array}{c}97.7 \\
(97.6,97.9) \\
\end{array}$ \\
\hline European/Other & $\begin{array}{c}3.1 \\
(2.3,4.0) \\
\end{array}$ & $\begin{array}{c}96.9 \\
(96.5,97.2) \\
\end{array}$ \\
\hline $\begin{array}{c}\text { Deprivation Quintile } \\
\text { NZDep } 1\end{array}$ & $\begin{array}{c}2.7 \dagger \\
(1.1,4.0)\end{array}$ & $\begin{array}{c}97.3 \\
(97.2,97.3) \\
\end{array}$ \\
\hline NZDep 2 & $\begin{array}{c}3.9 \\
(2.6,4.9) \\
\end{array}$ & $\begin{array}{c}96.1 \\
(95.7,96.3) \\
\end{array}$ \\
\hline NZDep 3 & $\begin{array}{c}3.7 \\
(2.1,4.9)\end{array}$ & $\begin{array}{c}96.3 \\
(95.8,96.7)\end{array}$ \\
\hline NZDep 4 & $\begin{array}{c}2.6 \\
(1.5,3.5) \\
\end{array}$ & $\begin{array}{c}97.4 \\
(97.2,97.5) \\
\end{array}$ \\
\hline NZDep 5 & $\begin{array}{c}3.2 \\
(2.2,4.1)\end{array}$ & $\begin{array}{c}96.8 \\
(96.8,96.8)\end{array}$ \\
\hline
\end{tabular}

$\dagger$ means unreliable estimate with an RSE of 0.3-0.5 
Table 5.15: Child time since last oral health care worker visitation, from the NZHS 2006/07

\begin{tabular}{|c|c|c|c|c|c|}
\hline & $<12$ months & $1-2$ years & $2-5$ years & $5+$ years & Never \\
\hline Total & $\begin{array}{c}75.8 \\
(74.8,76.8) \\
\end{array}$ & $\begin{array}{c}8.8 \\
(7.6,10.0) \\
\end{array}$ & $\begin{array}{c}0.8 \\
(0.5,1.2) \\
\end{array}$ & $\begin{array}{c}0.3 \dagger \\
(0.0,0.6)\end{array}$ & $\begin{array}{c}14.2 \\
(13.1,15.3) \\
\end{array}$ \\
\hline $\begin{array}{l}\text { Sex } \\
\text { Male }\end{array}$ & $\begin{array}{c}76.5 \\
(75.3,77.7) \\
\end{array}$ & $\begin{array}{c}8.9 \\
(7.4,10.3) \\
\end{array}$ & $\begin{array}{c}1.0 \\
(0.5,1.5)\end{array}$ & $\begin{array}{c}0.2 \dagger \\
(0.0,0.4)\end{array}$ & $\begin{array}{c}13.4 \\
(12.0,14.8) \\
\end{array}$ \\
\hline Female & $\begin{array}{c}75.1 \\
(73.7,76.4) \\
\end{array}$ & $\begin{array}{c}8.7 \\
(7.0,10.4) \\
\end{array}$ & $\begin{array}{c}0.7 \\
(0.3,1.0) \\
\end{array}$ & $\begin{array}{c}0.5 \dagger \dagger \\
(0.0,1.0) \\
\end{array}$ & $\begin{array}{c}15.0 \\
(13.4,16.6) \\
\end{array}$ \\
\hline $\begin{array}{c}\text { Age } \\
0-4\end{array}$ & $\begin{array}{c}47.1 \\
(44.7,49.4)\end{array}$ & $\begin{array}{c}7.0 \\
(5.1,8.8)\end{array}$ & $\begin{array}{c}0.4 \dagger \\
(0.0,0.8)\end{array}$ & - & $\begin{array}{c}45.4 \\
(42.9,47.8)\end{array}$ \\
\hline $5-9$ & $\begin{array}{c}89.2 \\
(87.3,91.2)\end{array}$ & $\begin{array}{c}7.3 \\
(5.6,9.1)\end{array}$ & $\begin{array}{c}0.5 \dagger \dagger \\
(0.1,1.0)\end{array}$ & $\begin{array}{c}0.2 \dagger \\
(0.0,0.7)\end{array}$ & $\begin{array}{c}2.6 \\
(1.7,3.6)\end{array}$ \\
\hline $10-14$ & $\begin{array}{c}85.0 \\
(83.1,87.0) \\
\end{array}$ & $\begin{array}{c}11.6 \\
(9.5,13.7) \\
\end{array}$ & $\begin{array}{c}1.5 \\
(0.8,2.2) \\
\end{array}$ & $\begin{array}{c}0.7 \dagger \dagger \\
(0.0,1.4)\end{array}$ & $\begin{array}{c}1.2 \\
(0.6,1.7) \\
\end{array}$ \\
\hline $\begin{array}{c}\text { Ethnicity } \\
\text { Māori }\end{array}$ & $\begin{array}{c}74.6 \\
(72.5,76.6)\end{array}$ & $\begin{array}{c}8.6 \\
(6.7,10.6)\end{array}$ & $\begin{array}{c}1.2 \dagger \\
(0.5,1.9)\end{array}$ & - & $\begin{array}{c}15.5 \\
(13.9,17.2)\end{array}$ \\
\hline Pacific & $\begin{array}{c}67.3 \\
(66.1,68.5)\end{array}$ & $\begin{array}{c}9.3 \\
(7.1,11.2)\end{array}$ & $\begin{array}{c}1.7 \dagger \\
(0.3,2.8)\end{array}$ & $\begin{array}{c}1.2 \dagger \dagger \\
(0.0,2.5)\end{array}$ & $\begin{array}{c}20.5 \\
(17.7,22.9)\end{array}$ \\
\hline Asian & $\begin{array}{c}66.1 \\
(62.7,69.2) \\
\end{array}$ & $\begin{array}{c}13.2 \\
(9.0,17.1) \\
\end{array}$ & $\begin{array}{c}1.2 \dagger \\
(0.4,2.0) \\
\end{array}$ & $\begin{array}{c}0.8 \dagger \\
(0.1,1.4) \\
\end{array}$ & $\begin{array}{c}18.8 \\
(16.0,21.4) \\
\end{array}$ \\
\hline European/Other & $\begin{array}{c}78.9 \\
(77.8,80.0) \\
\end{array}$ & $\begin{array}{c}8.2 \\
(6.5,9.8) \\
\end{array}$ & $\begin{array}{c}0.5 \dagger \\
(0.2,0.9)\end{array}$ & $\begin{array}{c}0.3 \dagger \dagger \\
(0,0.6) \\
\end{array}$ & $\begin{array}{c}12.1 \\
(10.6,13.5) \\
\end{array}$ \\
\hline $\begin{array}{c}\text { Deprivation Quintile } \\
\text { NZDep } 1\end{array}$ & $\begin{array}{c}80.5 \\
(79.9,80.9)\end{array}$ & $\begin{array}{c}6.9 \\
(5.1,8.3)\end{array}$ & $\begin{array}{c}0.5 \dagger \dagger \\
(0.0,0.9)\end{array}$ & $\begin{array}{c}0.8+\dagger \\
(0.0,1.5)\end{array}$ & $\begin{array}{c}11.3 \\
(9.5,12.7)\end{array}$ \\
\hline NZDep 2 & $\begin{array}{c}79.6 \\
(79.3,80.0) \\
\end{array}$ & $\begin{array}{c}7.8 \\
(5.5,9.6) \\
\end{array}$ & $\begin{array}{c}0.4 \dagger \dagger \\
(0.0,0.7)\end{array}$ & - & $\begin{array}{c}12.2 \\
(10.0,13.8) \\
\end{array}$ \\
\hline NZDep 3 & $\begin{array}{c}74.8 \\
(74.2,75.4)\end{array}$ & $\begin{array}{c}10.2 \\
(8.0,12.0)\end{array}$ & $\begin{array}{c}1.7 \dagger \\
(0.6,2.6)\end{array}$ & $\begin{array}{c}0.1 \dagger \dagger \\
(0.0,0.2)\end{array}$ & $\begin{array}{c}13.1 \\
(11.1,14.7)\end{array}$ \\
\hline NZDep 4 & $\begin{array}{c}72.8 \\
(72.0,73.4)\end{array}$ & $\begin{array}{c}10.3 \\
(8.4,11.8)\end{array}$ & $\begin{array}{c}0.6 \dagger \\
(0.1,0.9)\end{array}$ & $\begin{array}{c}0.3 \dagger \dagger \\
(0.0,0.7)\end{array}$ & $\begin{array}{c}16.0 \\
(14.3,17.4)\end{array}$ \\
\hline NZDep 5 & $\begin{array}{c}71.6 \\
(70.7,72.2) \\
\end{array}$ & $\begin{array}{c}8.9 \\
(6.9,10.4) \\
\end{array}$ & $\begin{array}{c}1.0 \\
(0.5,1.5) \\
\end{array}$ & $\begin{array}{c}0.4 \dagger \dagger \\
(0.0,0.7)\end{array}$ & $\begin{array}{c}18.2 \\
(17.1,19.1) \\
\end{array}$ \\
\hline
\end{tabular}

$\dagger$ means unreliable estimate with an RSE of 0.3-0.5

$\dagger \dagger$ means a very unreliable estimate with an $\mathrm{RSE}>0.5$ 


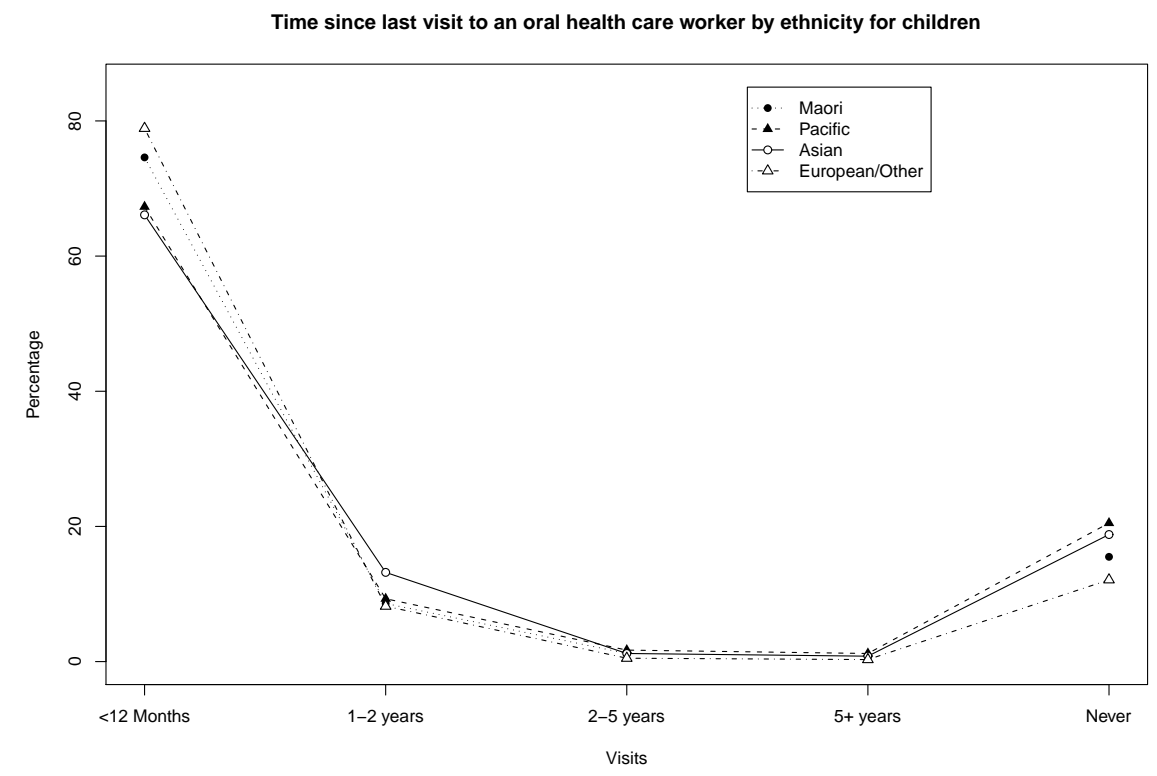

Figure 5.16: Time since last visit to an oral health care worker for children, NZHS $2006 / 07$

Figure 5.16 shows that Pacific and Asian children are least likely to have seen an oral health care worker in the past 12 months, compared to Māori and European/Others. Asians have the highest rate of children who have seen an oral health care worker in the last 1-2 years. Pacific children are least likely to have seen and oral health care worker with $20.5 \%(17.7,22.9)$ having never seen an oral health care worker. This is in contrast to the adult results in which the differences in times by ethnicity are more visible, as seen in Figure 5.7 


\section{Chapter 6}

\section{Regression models for oral health outcomes}

In this chapter, we use ordinal regression to investigate socio-demographic and behavioural risk factors associated with regularity of oral health care and tooth loss due to tooth decay and gum disease among New Zealand adults.

The stepwise method is used for model selection. In this case, because of a large number of significant main effects variables, interaction terms were added and assessed in the model in batches so that the model still converged and could be handled by the SAS system.

Since deviance-based tests are not available, Wald tests were used to assess levels of individual explanatory variables and interaction terms. The significance of these terms were tested at the $5 \%$ level.

Two outcomes were investigated. These outcomes were regularity of oral health care, tooth loss due to tooth decay and gum disease.

Low regularity of care can lead to poor oral health, and in turn tooth loss due to this poor oral health.

Tooth loss may be a proxy for a set of (possibly unmeasured) predisposing and behavioural factors affecting oral health. These may include aversion to visiting oral health care professionals and in the extreme case people who lose all their teeth may stop seeking oral health care altogether.

It is arguable that there is reverse causation between tooth loss and regularity of care, as each can cause the other in certain circumstances. Therefore models were carried out with and without the other variables involved in the model.

Selected explanatory variables were tested using the Wald test for significance in the regression models, with non-significant variables being removed from the model. Interaction terms were introduced into the model in batches, as the SAS system was unable to handle the required number of interaction terms that needed to be tested in the model and convergence of the model no longer happened with such a large number of terms in the model.

Reference categories for explanatory variables were selected based on the size of the subpopulations for that variable. Binary explanatory variables used the respondents without the wanted characteristic as the base level for analysis, to investigate what effect that characteristic had on regularity of care or tooth loss. For example not having health insurance 
was selected as the reference category so that the effect that having health insurance had in the model could easily be identified and interpreted.

\subsection{Regularity of oral health care}

The first regression analysis used regularity of care as the outcome variable. Regularity of care had four outcome levels:

1. I visit an oral health care worker at least every two years for a check up,

2. I visit an oral health care worker for check-ups regularly, but with intervals of more than two years,

3. I only visit an oral health care worker when I have toothache or other similar trouble,

4. I never visit an oral health care worker.

\subsubsection{Model 1}

Based on the literature review, risk factors for regularity of care were identified. The following explanatory variables were selected: sex, age (in 10 year age groups) prioritised ethnicity, socio-economic deprivation (NZ deprivation at the quintile level), household income, highest qualification, urban/rural residency, health insurance status and diabetes. All explanatory variables were converted into categorical variables, with appropriate levels.

Also selected as explanatory variables were the number of teeth lost due to tooth decay and gum disease and whether a person has had unmet oral health care needs in the past 12 months. Time since last visit to an oral health care worker was originally in the model, but after further analysis was taken out due to the strong relationship between regularity of care and time since last visit.

From this ordinal regression analysis, most of the above risk factors were found to be significant risk factors for regularity of oral health care at the $5 \%$ level and were included in the ordinal regression model. Diabetes and urban/rural residency were not found to be significant and were removed.

Interaction terms were then tested for significance, also using the Wald test at the $5 \%$ significance level. In this case four interactions were found to be significant and were kept in the final model.

We refer to this model as Model 1. The results of this ordinal regression analysis are presented in Tables 6.1 and 6.2, separated into main effects and interaction terms. In these tables the baseline category variables have an odds ratio of 1 . This is the reference category used in the development and interpretation of the ordinal model.

\section{Model Interpretation}

This analysis found that significant factors for greater regularity of oral health care were:

- Being female,

- Being of European/Other ethnicity,

- Being a non current smoker, 
Table 6.1: Model 1: Regularity of oral health care, main effects including unmet need and toothloss, from the NZHS

\begin{tabular}{|c|c|c|c|}
\hline Explanatory Variable & \multicolumn{2}{|c|}{ Odds Ratio } & p-value \\
\hline Check ups $<2$ years apart vs Non regular check ups (Intercept 1) & 0.35 & $(0.23,0.53)$ & $<0.001$ \\
\hline Regular check ups vs No check ups (Intercept 2) & 0.56 & $(0.37,0.85)$ & 0.006 \\
\hline Visiting vs Never visiting (Intercept 3) & 9.38 & $(5.96,14.77)$ & $<0.001$ \\
\hline $\begin{array}{c}\text { Female } \\
\end{array}$ & 1.76 & $(1.57,1.97)$ & $<0.001$ \\
\hline Male & 1.00 & & \\
\hline Asian & 0.38 & $(0.28,0.54)$ & $<0.001$ \\
\hline Māori & 0.56 & $(0.46,0.68)$ & $<0.001$ \\
\hline Pacific & 0.55 & $(0.42,0.71)$ & $<0.001$ \\
\hline European/Other & 1.00 & & \\
\hline $15-24$ & 1.41 & $(0.97,2.05)$ & 0.076 \\
\hline $25-34$ & 0.53 & $(0.38,0.75)$ & $<0.001$ \\
\hline $35-44$ & 0.64 & $(0.46,0.90)$ & 0.010 \\
\hline $45-54$ & 0.96 & $(0.68,1.34)$ & 0.792 \\
\hline $55-64$ & 1.23 & $(0.88,1.72)$ & 0.235 \\
\hline $65-74$ & 1.04 & $(0.75,1.45)$ & 0.802 \\
\hline $75+$ & 1.00 & & \\
\hline Current smoker & 0.16 & $(0.03,0.83)$ & 0.029 \\
\hline Non-current smoker & 1.00 & & \\
\hline$<\$ 20,000$ & 0.61 & $(0.47,0.79)$ & $<0.001$ \\
\hline$\$ 20,001-\$ 50,000$ & 0.77 & $(0.64,0.92)$ & 0.004 \\
\hline$\$ 50,001-\$ 100,000$ & 0.84 & $(0.72,0.99)$ & 0.042 \\
\hline$>\$ 100,001$ & 1.00 & & \\
\hline No qualification & 1.00 & & \\
\hline School qualification & 1.38 & $(1.17,1.62)$ & $<0.001$ \\
\hline Vocational/Trade qualification & 1.59 & $(1.37,1.86)$ & $<0.001$ \\
\hline Degree or higher & 2.11 & $(1.77,2.52)$ & $<0.001$ \\
\hline No Health Insurance & 1.00 & & \\
\hline Health Insurance & 4.33 & $(2.66,7.07)$ & $<0.001$ \\
\hline Unmet need in past 12 months & 0.50 & $(0.42,0.58)$ & $<0.001$ \\
\hline No Unmet need in past 12 months & 1.00 & & \\
\hline NZDep Quintile 1 & 2.18 & $(1.68,2.82)$ & $<0.001$ \\
\hline NZDep Quintile 2 & 1.92 & $(1.51,2.43)$ & $<0.001$ \\
\hline NZDep Quintile 3 & 1.67 & $(1.35,2.07)$ & $<0.001$ \\
\hline NZDep Quintile 4 & 1.32 & $(1.07,1.63)$ & 0.009 \\
\hline NZDep Quintile 5 & 1.00 & & \\
\hline 0 teeth lost & 1.00 & & \\
\hline $1-10$ teeth lost & 1.03 & $(0.91,1.17)$ & 0.640 \\
\hline 11-20 teeth lost & 0.49 & $(0.38,0.63)$ & $<0.001$ \\
\hline 21-30 teeth lost & 0.20 & $(0.14,0.30)$ & $<0.001$ \\
\hline $31+$ teeth lost & 0.02 & $(0.01,0.04)$ & $<0.001$ \\
\hline
\end{tabular}


Table 6.2: Model 1: Regularity of oral health care, including unmet need and toothloss, interaction terms, from the NZHS

\begin{tabular}{|ll|cc|c|}
\hline \multicolumn{2}{|c|}{ Explanatory Variables } & \multicolumn{2}{|c|}{ Odds Ratios } & $\mathrm{p}$-value \\
\hline $15-24$ & Insurance & 0.34 & $(0.19,0.60)$ & $<0.001$ \\
$25-34$ & Insurance & 0.45 & $(0.28,0.72)$ & 0.001 \\
$35-44$ & Insurance & 0.51 & $(0.33,0.79)$ & 0.002 \\
$45-54$ & Insurance & 0.51 & $(0.32,0.82)$ & 0.006 \\
$55-64$ & Insurance & 0.47 & $(0.29,0.78)$ & 0.003 \\
$65-74$ & Insurance & 0.64 & $(0.35,1.17)$ & 0.149 \\
$75+$ & & 1.00 & & \\
& No Insurance & 1.00 & & \\
\hline $15-24$ & Smoker & 4.36 & $(0.86,22.2)$ & 0.076 \\
$25-34$ & Smoker & 6.96 & $(1.40,34.44)$ & 0.017 \\
$35-44$ & Smoker & 9.03 & $(1.84,44.37)$ & 0.007 \\
$45-54$ & Smoker & 6.47 & $(1.23,34.18)$ & 0.278 \\
$55-64$ & Smoker & 6.64 & $(1.31,33.80)$ & 0.022 \\
$65-74$ & Smoker & 5.69 & $(1.03,31.40)$ & 0.046 \\
$75+$ & & 1.00 & & \\
& Non Smoker & 1.00 & & \\
\hline Asian & Female & 0.80 & $(0.55,1.18)$ & 0.259 \\
Māori & Female & 1.00 & $(0.77,1.29)$ & 0.999 \\
Pacific & Female & 0.52 & $(0.36,0.74)$ & $<0.001$ \\
European/Other & & 1.00 & & \\
& Male & 1.00 & & \\
\hline$<\$ 20,000$ & Smoker & 0.80 & $(0.53,1.22)$ & 0.306 \\
$\$ 20,001-\$ 50,000$ & Smoker & 0.56 & $(0.37,0.85)$ & 0.006 \\
$\$ 50,001-\$ 100,000$ & Smoker & 0.83 & $(0.55,1.26)$ & 0.381 \\
$>\$ 100,001$ & & 1.00 & & \\
& Non Smoker & 1.00 & & \\
\hline
\end{tabular}


- Having a household income of more than $\$ 100,000$,

- Having a Degree or higher qualification,

- Having health insurance,

- Having had no unmet oral health care needs in the past 12 months,

- Being in deprivation quintile 1 (Least deprived)

Age $\times$ health insurance, age $\times$ smoking status, ethnicity $\times$ sex and household income $\times$ smoking status were the interaction terms found to be significant in the model.

The odds ratios for the variables which were also involved in an interaction term were altered by the odds of the interaction values for each specific level.

The first intercept for this model is $0.35(0.23,0.53)$ which is the odds of visiting an oral health care professional for a check up at least every 2 years compared to visiting every at intervals longer than 2 years for a check up for a person in all reference categories.

The second intercept for this model is $0.56(0.37,0.85)$ which are the odds for a person in all categories visiting an oral health care worker for regular check ups at least every 5 years as opposed not visiting an oral health care professional on a regular basis for check ups.

The third intercept for this model is $9.38(5.96,14.77)$ which are the odds of visiting an oral health care worker for regular check ups of only when needed compared to never visiting an oral health care worker, suggesting that people are much more likely to visit an oral health care worker than not.

Females have 1.76 times higher odds of seeing an oral health care worker more regularly than males for each of the four levels of regularity. However these odds are altered due to the significant interaction found between ethnicity and sex in the model.

European/Others have higher odds of seeing oral health care workers regularly, with Asians having the lowest odds of visiting regularly. These odds are altered based on sex due to the significant interaction found between sex and ethnicity. We find that for Asian and Pacific women, the odds are reduced even more due to the interaction, with Asian females odds becoming $1.76 \times 0.80=1.408$ the odds of visiting oral health care workers regularly compared to Asian males.

Regularity of care is significantly associated with tooth loss, with those who have lost fewer teeth having more regular oral health care. The odds of having regular care reduce by (100$2)=98 \%$ for those who have lost 31 or more teeth than those who have lost no teeth due to tooth decay or gum disease.

Those who have a degree or higher education have the highest odds of seeing an oral health care worker regularly. There is a positive association with qualification, as qualification increases so do the odds of regularity of care.

Having unmet need in the previous 12 months have reduced odds by $50 \%$ of having regular oral health care compared to those who did not have unmet need in the previous 12 months for all four levels of regularity.

Having health insurance odds are dependent on age and the odds decrease as age decreases, due to the significant interaction between age and health insurance status. However in general people with health insurance visit an oral health care worker more regularly than those 


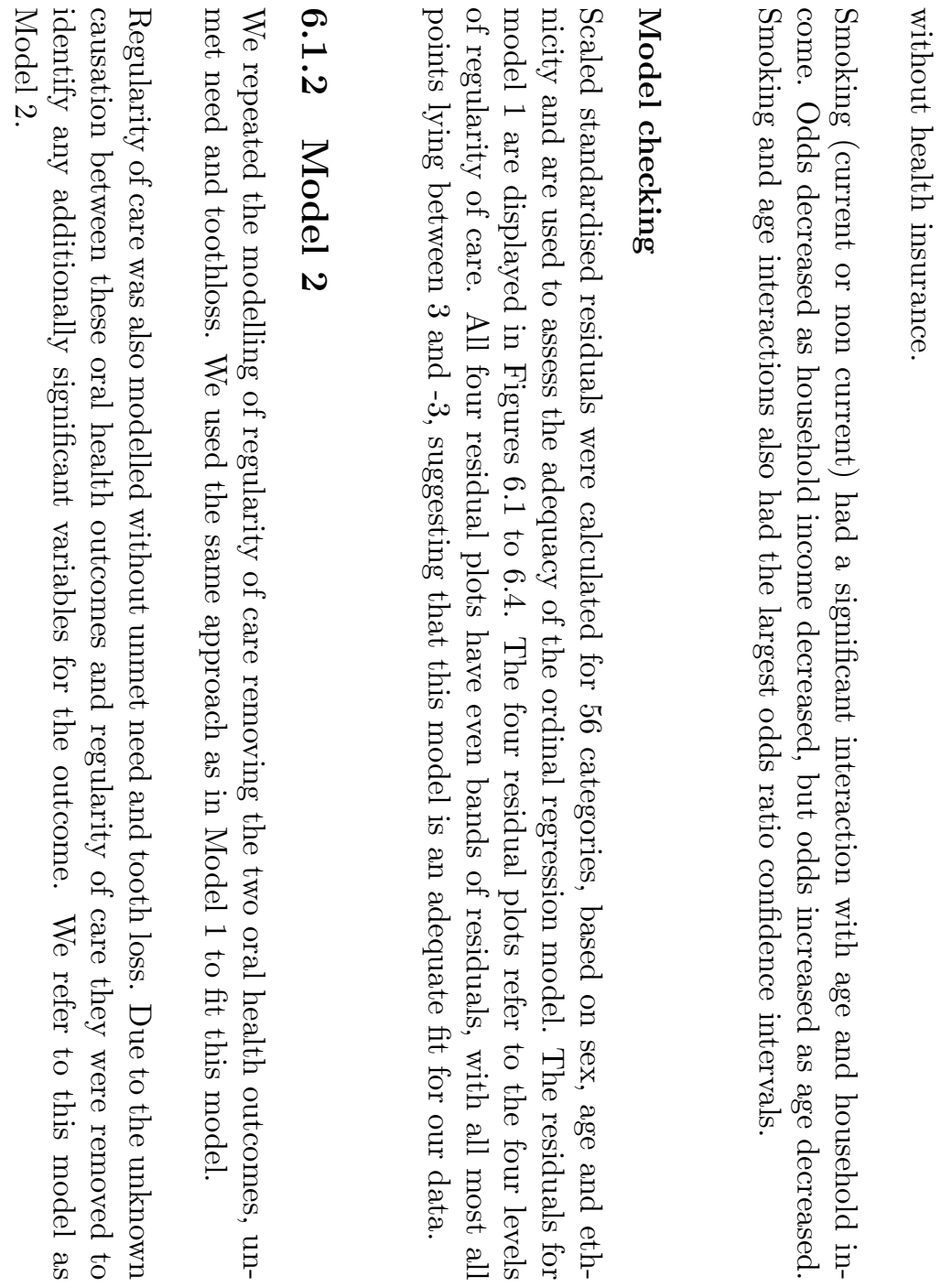

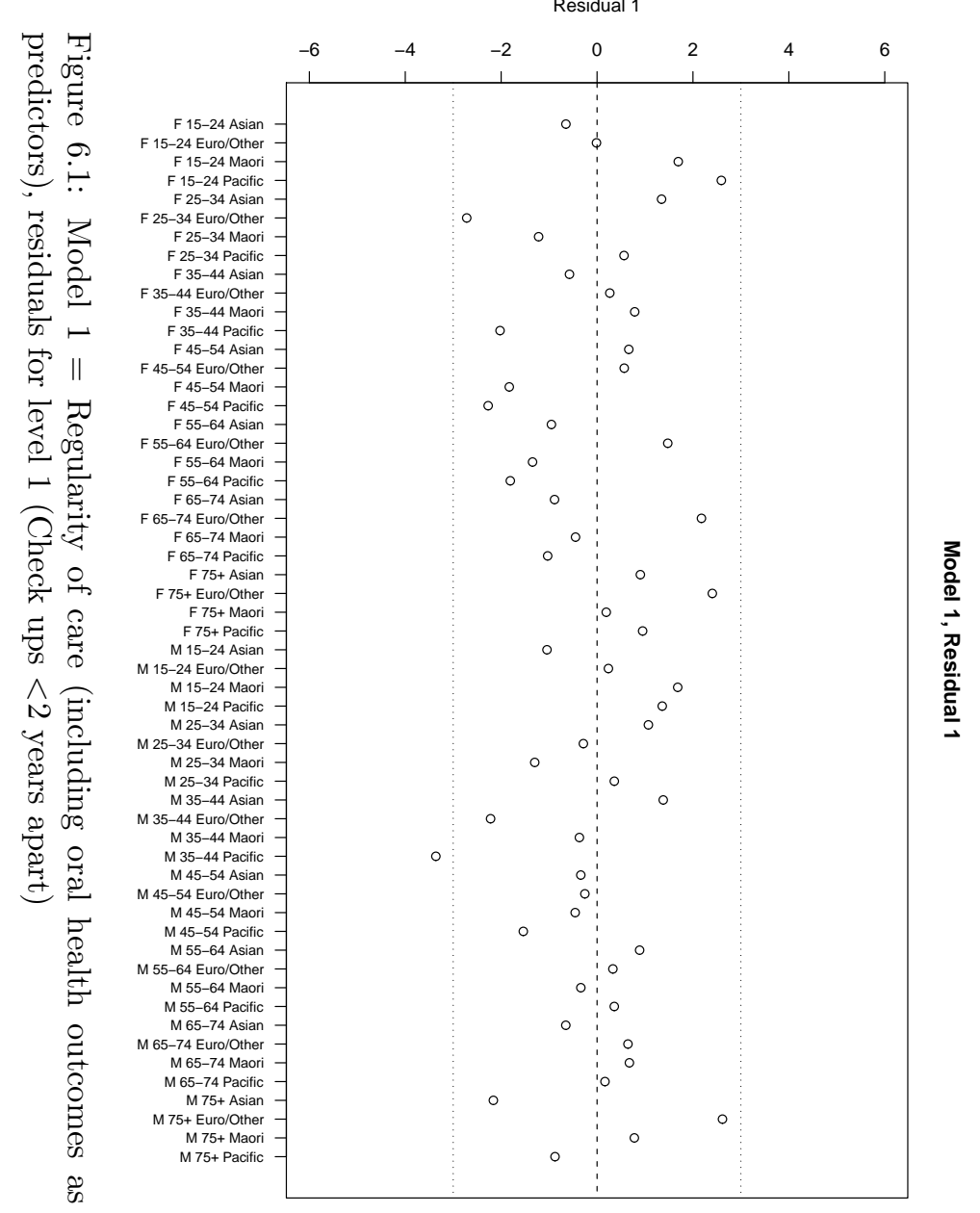



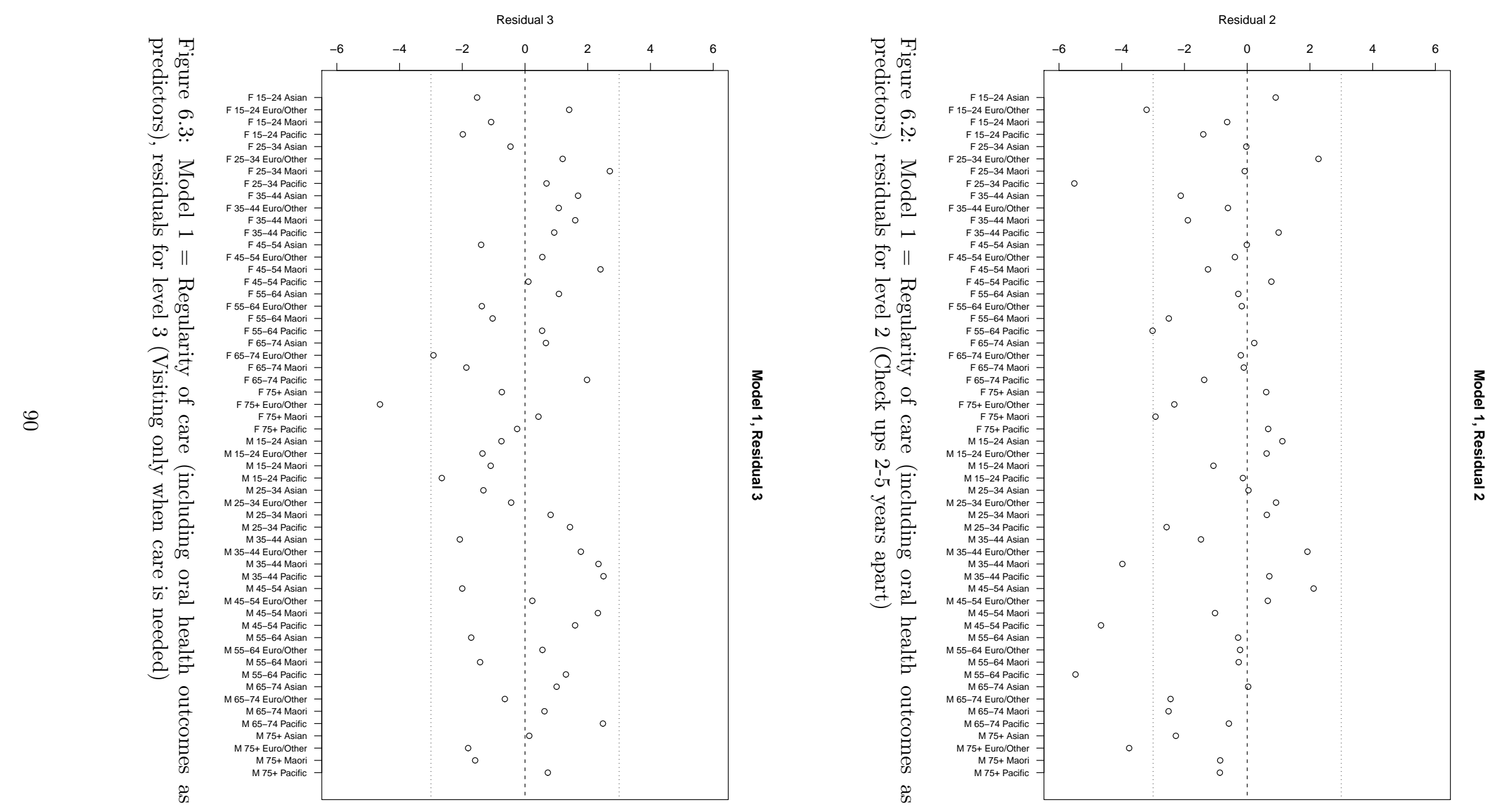

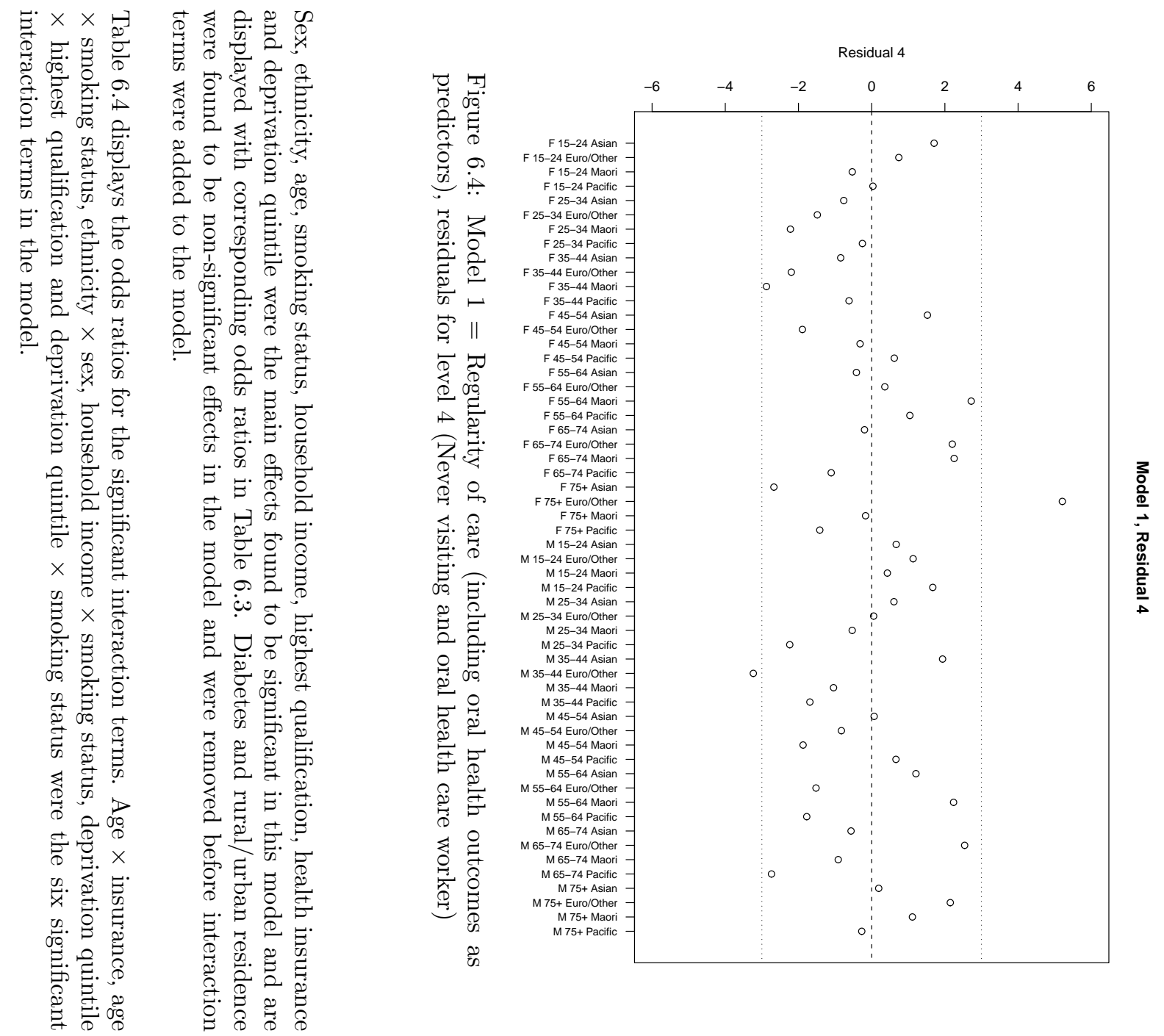
Table 6.3: Model 2: Regularity of oral health care, excluding unmet need and toothloss, main effect terms

\begin{tabular}{|c|c|c|c|}
\hline Explanatory Variable & \multicolumn{2}{|c|}{ Odds Ratio } & p-value \\
\hline Check ups $<2$ years apart vs Non regular check ups (Intercept 1 ) & 0.18 & $(0.12,0.28)$ & $<0.001$ \\
\hline Regular check ups vs No check ups (Intercept 2) & 0.29 & $(0.19,0.44)$ & $<0.001$ \\
\hline Visiting vs Never visiting (Intercept 3) & 4.13 & $(2.64,6.45)$ & $<0.001$ \\
\hline Female & 1.70 & $(1.52,1.89)$ & $<0.001$ \\
\hline Male & 1.00 & & \\
\hline Asian & 0.41 & $(0.30,0.56)$ & $<0.001$ \\
\hline Māori & 0.54 & $(0.44,0.66)$ & $<0.001$ \\
\hline Pacific & 0.53 & $(0.41,0.69)$ & $<0.001$ \\
\hline European/Other & 1.00 & & \\
\hline $15-24$ & 2.56 & $(1.80,3.65)$ & $<0.001$ \\
\hline $25-34$ & 0.95 & $(0.70,1.29)$ & 0.744 \\
\hline $35-44$ & 1.16 & $(0.83,1.63)$ & 0.373 \\
\hline $45-54$ & 1.66 & $(1.21,2.28)$ & 0.002 \\
\hline $55-64$ & 1.87 & $(1.33,2.64)$ & $<0.001$ \\
\hline $65-74$ & 1.35 & $(0.94,1.93)$ & 0.105 \\
\hline $75+$ & 1.00 & & \\
\hline Current smoker & 0.20 & $(0.06,0.69)$ & 0.011 \\
\hline Non-current smoker & 1.00 & & \\
\hline$<\$ 20,000$ & 0.58 & $\overline{(0.44,0.75)}$ & $<0.001$ \\
\hline$\$ 20,001-\$ 50,000$ & 0.73 & $(0.60,0.88)$ & $<0.001$ \\
\hline$\$ 50,001-\$ 100,000$ & 0.84 & $(0.72,0.99)$ & 0.039 \\
\hline$>\$ 100,000$ & 1.00 & & \\
\hline No qualification & 1.00 & & \\
\hline School qualification & 1.63 & $(1.27,2.09)$ & $<0.001$ \\
\hline Vocational/Trade qualification & 1.84 & $(1.40,2.43)$ & $<0.001$ \\
\hline Degree or higher & 2.58 & $(1.65,4.03)$ & $<0.001$ \\
\hline No Health Insurance & 1.00 & & \\
\hline Health Insurance & 3.88 & $(2.36,6.37)$ & $<0.001$ \\
\hline NZDep Quintile 1 & 2.07 & $(1.48,2.88)$ & $<0.001$ \\
\hline NZDep Quintile 2 & 2.43 & $(1.73,3.40)$ & $<0.001$ \\
\hline NZDep Quintile 3 & 1.52 & $(1.13,2.04)$ & 0.006 \\
\hline NZDep Quintile 4 & 1.14 & $(0.86,1.53)$ & 0.359 \\
\hline NZDep Quintile 5 & 1.00 & & \\
\hline
\end{tabular}




\section{Model Interpretation}

For this model the significant factors found for greater regularity of oral health care were:

- Being Female,

- Being of European/Other ethnicity,

- Being a non-current smoker,

- Having a household income greater than $\$ 100,000$ per year,

- Having a degree or higher qualification,

- Having health insurance

The first intercept for this model is $0.18(0.12,0.28)$ which is the odds of visiting an oral health care professional for a check up at least every 2 years compared to not visiting every 2 years for a check up for a person in all reference categories.

The second intercept for this model is $0.29(0.19,0.44)$ which is the odds for a person in all categories visiting an oral health care worker for regular check ups at least every 5 years as opposed not visiting an oral health care professional on a regular basis for check ups.

The third intercept for this model is $4.13(2.64,6.45)$ which are the odds of visiting an oral health care worker for regular check ups of only when needed compared to never visiting an oral health care worker.

Females have 1.70 times higher odds of seeing an oral health care worker more regularly than their male equivalents. However these odds for females are slightly lower when taking into account the interaction between sex and ethnicity, especially for Pacific females, whose odds become $1.70 \times 0.58=0.986$ times the odds of Pacific males.

Smoking status was a significant term in the model, by itself and interacting with age, household income and deprivation. The main effect of being a current smoker gives reduced odds by $80 \%$ of the odds for those who are non-current smokers. The interactions with deprivation and household income decrease these odds again. However the age $\times$ smoker interaction terms increases the odds of regular care and cancels out some of the decreases made through the interaction between smoking $\times$ deprivation and smoking $\times$ household income.

As deprivation decreases the odds of seeing an oral health care worker regularly increase based on the main effect of deprivation in the model. However odds decrease due to the deprivation $\times$ smoking interaction in the model. Odds are also slightly altered by qualification status, with the deprivation odds generally increasing slightly for those who have a higher level of education such as a degree or higher.

\section{Model Checking}

Scaled standardised residuals were calculated for 56 categories, based on sex, age and ethnicity and are used to assess the adequacy of the ordinal regression model. The residuals for model 2 are displayed in Figures 6.5 to 6.8. The four residual plots refer to the four levels of regularity of care. Model 2 residual plots have less even bands of residuals than Model 1. Residual plots 2 and 3 have a greated variation in residuals, with a greater number of residuals lying below -3 , some as far as away as -12 . This suggests that Model 1 is a better model for the regularity of oral health care, as the residuals are more normally distributed around a mean of 0 , with a variance of 1 . This is to be expected because adding more predictors into the model means that the model can fit the data better, based on the greater number of 
Table 6.4: Model 2: Regularity of oral health care, excluding unmet need and toothloss, interaction terms

\begin{tabular}{|c|c|c|c|c|}
\hline \multicolumn{2}{|c|}{ Explanatory Variable } & \multicolumn{2}{|c|}{ Odds Ratio } & \multirow{2}{*}{$\frac{p \text {-value }}{<0.001}$} \\
\hline $15-24$ & Insurance & 0.30 & $(0.16,0.55)$ & \\
\hline $25-34$ & Insurance & 0.38 & $(0.22,0.67)$ & $<0.001$ \\
\hline $35-44$ & Insurance & 0.42 & $(0.25,0.70)$ & $<0.001$ \\
\hline $45-54$ & Insurance & 0.43 & $(0.25,0.74)$ & $<0.001$ \\
\hline $55-64$ & Insurance & 0.45 & $(0.26,0.80)$ & 0.006 \\
\hline $65-74$ & Insurance & 0.69 & $(0.37,1.30)$ & 0.253 \\
\hline \multirow{2}{*}{$75+$} & & 1.00 & & \\
\hline & No Insurance & 1.00 & & \\
\hline $15-24$ & Smoker & 3.55 & $(1.01,12.48)$ & 0.048 \\
\hline $25-34$ & Smoker & 5.66 & $(1.73,18.54)$ & 0.004 \\
\hline $35-44$ & Smoker & 6.73 & $(2.09,21.60)$ & 0.001 \\
\hline $45-54$ & Smoker & 5.01 & $(1.44,17.45)$ & 0.011 \\
\hline $55-64$ & Smoker & 4.46 & $(1.28,15.52)$ & 0.019 \\
\hline $65-74$ & Smoker & 3.26 & $(0.93,11.39)$ & 0.065 \\
\hline \multirow[t]{2}{*}{$75+$} & & 1.00 & & \\
\hline & Non Smoker & 1.00 & & \\
\hline Asian & Female & 0.80 & $(0.56,1.16)$ & 0.239 \\
\hline Māori & Female & 1.01 & $(0.79,1.30)$ & 0.942 \\
\hline Pacific & Female & 0.58 & $(0.40,0.84)$ & 0.004 \\
\hline \multirow[t]{2}{*}{ European/Other } & & 1.00 & & \\
\hline & Male & 1.00 & & \\
\hline$<\$ 20,000$ & Smoker & 0.78 & $(0.51,1.18)$ & 0.232 \\
\hline$\$ 20,001-\$ 50,000$ & Smoker & 0.59 & $(0.39,0.88)$ & 0.011 \\
\hline$\$ 50,001-\$ 100,000$ & Smoker & 0.86 & $(0.58,1.29)$ & 0.468 \\
\hline \multirow[t]{2}{*}{$>\$ 100,000$} & & 1.00 & & \\
\hline & Non Smoker & 1.00 & & \\
\hline NZDep Quintile 1 & School Qualification & 1.02 & $(0.69,1.51)$ & 0.901 \\
\hline NZDep Quintile 1 & Vocational/Trade & 0.99 & $(0.63,1.56)$ & 0.964 \\
\hline NZDep Quintile 1 & Degree & 1.05 & $(0.62,1.77)$ & 0.849 \\
\hline NZDep Quintile 2 & School Qualification & 0.56 & $(0.37,0.86)$ & 0.008 \\
\hline NZDep Quintile 2 & Vocational/Trade & 0.70 & $(0.45,1.10)$ & 0.703 \\
\hline NZDep Quintile 2 & Degree & 0.58 & $(0.33,0.12)$ & 0.059 \\
\hline NZDep Quintile 3 & School Qualification & 0.93 & $(0.61,1.42)$ & 0.744 \\
\hline NZDep Quintile 3 & Vocational/Trade & 1.02 & $(0.69,1.51)$ & 0.927 \\
\hline NZDep Quintile 3 & Degree & 0.85 & $(0.53,1.36)$ & 0.502 \\
\hline NZDep Quintile 4 & School Qualification & 1.09 & $(0.76,1.57)$ & 0.639 \\
\hline NZDep Quintile 4 & Vocational/Trade & 1.03 & $(0.73,1.46)$ & 0.869 \\
\hline NZDep Quintile 4 & Degree & 1.06 & $(0.61,1.87)$ & 0.830 \\
\hline NZDep Quintile 5 & School Qualification & 1.00 & & \\
\hline NZDep Quintile 5 & Vocational/Trade & 1.00 & & \\
\hline \multirow{2}{*}{ NZDep Quintile 5} & & 1.00 & & \\
\hline & No qualificiation & 1.00 & & \\
\hline NZDep Quintile 1 & Smoker & 0.57 & $(0.33,0.99)$ & 0.045 \\
\hline NZDep Quintile 2 & Smoker & 0.73 & $(0.53,1.02)$ & 0.062 \\
\hline NZDep Quintile 3 & Smoker & 0.70 & $(0.51,0.96)$ & 0.028 \\
\hline NZDep Quintile 4 & Smoker & 0.92 & $(0.65,1.31)$ & 0.643 \\
\hline \multirow[t]{2}{*}{ NZDep Quintile 5} & & 1.00 & & \\
\hline & Non Smoker & 1.00 & & \\
\hline
\end{tabular}



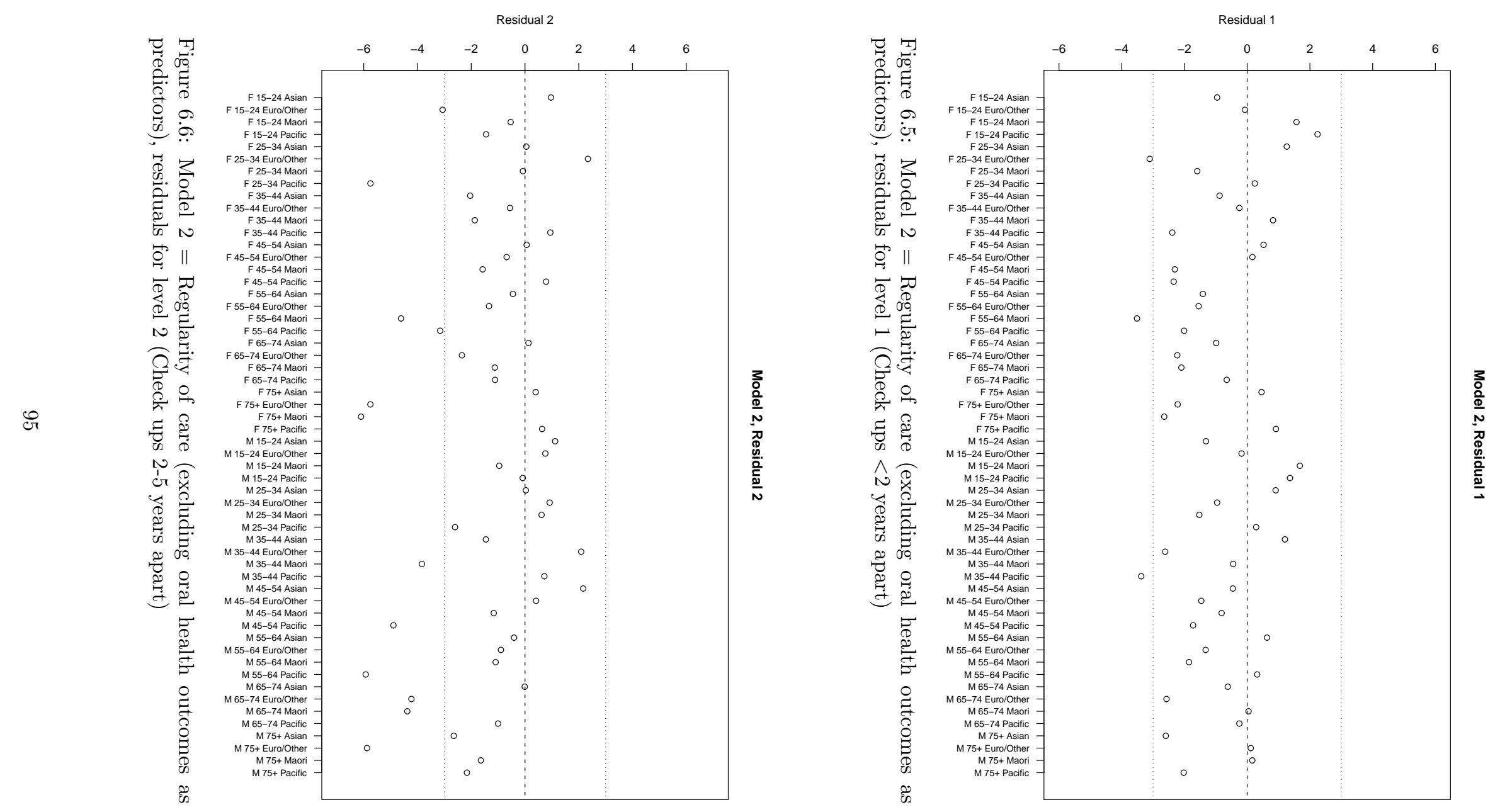

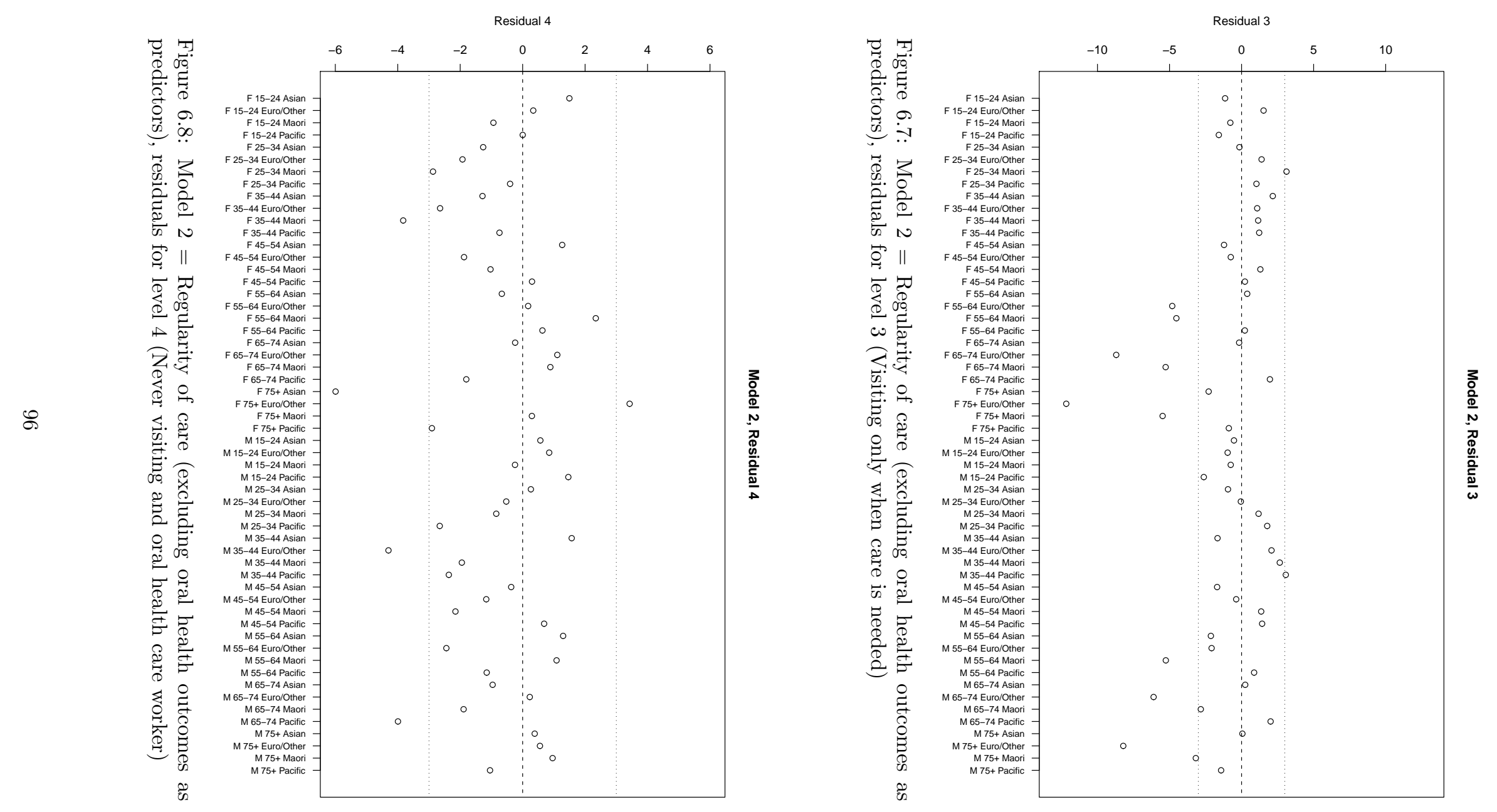
predictors. Model 1 includes tooth loss, and this variable may have underlying, unidentified factors in common with regularity of care, meaning that they have many of the same predictors, and even those that are unmeasured and unused in our model appear through the tooth loss predictor.

\subsection{Toothloss}

In this section we model tooth loss as the oral health outcome. Tooth loss due to tooth decay and gum disease was split into three categories for ordinal regression analysis. 0 teeth lost, 1-10 teeth lost and 11+ teeth lost were the three tooth loss categories selected to represent no tooth loss, some tooth loss and major tooth loss.

Explanatory variables selected were based on the literature associated with dentition and dental caries, which can lead to the extraction of decayed teeth. The following explanatory variables were selected to use in the initial stages of model selection: sex, age (in 10 year age groups), prioritised ethnicity, socio-economic deprivation (NZ Deprivation at the quintile level), household income, highest qualification, urban/rural residency, health insurance status and diabetes. All explanatory variables were converted into categorical variables with appropriate levels.

\subsubsection{Model 3}

The first model using tooth loss as the outcome variable was carried out without using other oral health outcomes as predictors in the model. This model we refer to as Model 3.

In this ordinal regression analysis all of the selected explanatory variables were significant at the $5 \%$ significance level in the main effects model. These main effects interaction terms and confidence intervals are presented in Table 6.5 Interaction terms were then tested for significance with the use of the Wald test at the $5 \%$ significance level. Ten interaction terms were found to be significant in the model. The odds ratios and confidence intervals for the ten interaction terms are presented in Table 6.6. 
Table 6.5: Model 3: Tooth loss, excluding regularity of care and unmet need, main effects

\begin{tabular}{|c|c|c|c|}
\hline Explanatory Variable & \multicolumn{2}{|c|}{ Odds Ratio } & p-value \\
\hline $11+$ vs $0-10$ teeth lost (Intercept 1$)$ & 1.25 & $(0.90,1.72)$ & 0.185 \\
\hline $1+$ vs 0 teeth lost (Intercept 2 ) & 18.74 & $(13.35,26.30)$ & $<0.001$ \\
\hline Female & 1.18 & $(0.91,1.54)$ & 0.211 \\
\hline Male & 1.00 & & \\
\hline Asian & 1.08 & $(0.26,4.55)$ & 0.915 \\
\hline Māori & 2.16 & $(0.97,4.81)$ & 0.059 \\
\hline Pacific & 0.94 & $(0.21,4.17)$ & 0.936 \\
\hline European/Other & 1.00 & & \\
\hline $15-24$ & 0.01 & $(0.00,0.01)$ & $<0.001$ \\
\hline $25-34$ & 0.03 & $(0.02,0.05)$ & $<0.001$ \\
\hline $35-44$ & 0.07 & $(0.05,0.09)$ & $<0.001$ \\
\hline $45-54$ & 0.13 & $(0.10,0.17)$ & $<0.001$ \\
\hline $55-64$ & 0.26 & $(0.20,0.33)$ & $<0.001$ \\
\hline $65-74$ & 0.56 & $(0.43,0.74)$ & $<0.001$ \\
\hline $75+$ & 1.00 & & \\
\hline Current smoker & 1.69 & $(1.48,1.94)$ & $<0.001$ \\
\hline Non-current smoker & 1.00 & & \\
\hline$<\$ 20,000$ & 1.54 & $(1.24,1.91)$ & $<0.001$ \\
\hline$\$ 20,001-\$ 50,000$ & 1.44 & $(1.23,1.68)$ & $<0.001$ \\
\hline$\$ 50,001-\$ 100,000$ & 1.25 & $(1.07,1.45)$ & 0.005 \\
\hline$>\$ 100,000$ & 1.00 & & \\
\hline No qualification & 1.00 & & \\
\hline School qualification & 0.61 & $(0.48,0.78)$ & $<0.001$ \\
\hline Vocational/Trade qualification & 0.52 & $(0.42,0.63)$ & $<0.001$ \\
\hline Degree or higher & 0.30 & $(0.23,0.39)$ & $<0.001$ \\
\hline No Health Insurance & 1.00 & & \\
\hline Health Insurance & 0.89 & $(0.70,1.14)$ & 0.366 \\
\hline NZDep Quintile 1 & 0.80 & $(0.62,1.04)$ & 0.094 \\
\hline NZDep Quintile 2 & 0.73 & $(0.57,0.92)$ & 0.009 \\
\hline NZDep Quintile 3 & 0.88 & $(0.70,1.12)$ & 0.315 \\
\hline NZDep Quintile 4 & 0.95 & $(0.74,1.24)$ & 0.722 \\
\hline NZDep Quintile 5 & 1.00 & & \\
\hline Diabetic & 1.52 & $(0.93,2.47)$ & 0.094 \\
\hline Non Diabetic & 1.00 & & \\
\hline Urban & 1.00 & & \\
\hline Rural & 1.88 & $(1.28,2.76)$ & 0.001 \\
\hline
\end{tabular}


Table 6.6: Model 3: Tooth loss, excluding regularity of care and unmet need, interaction terms

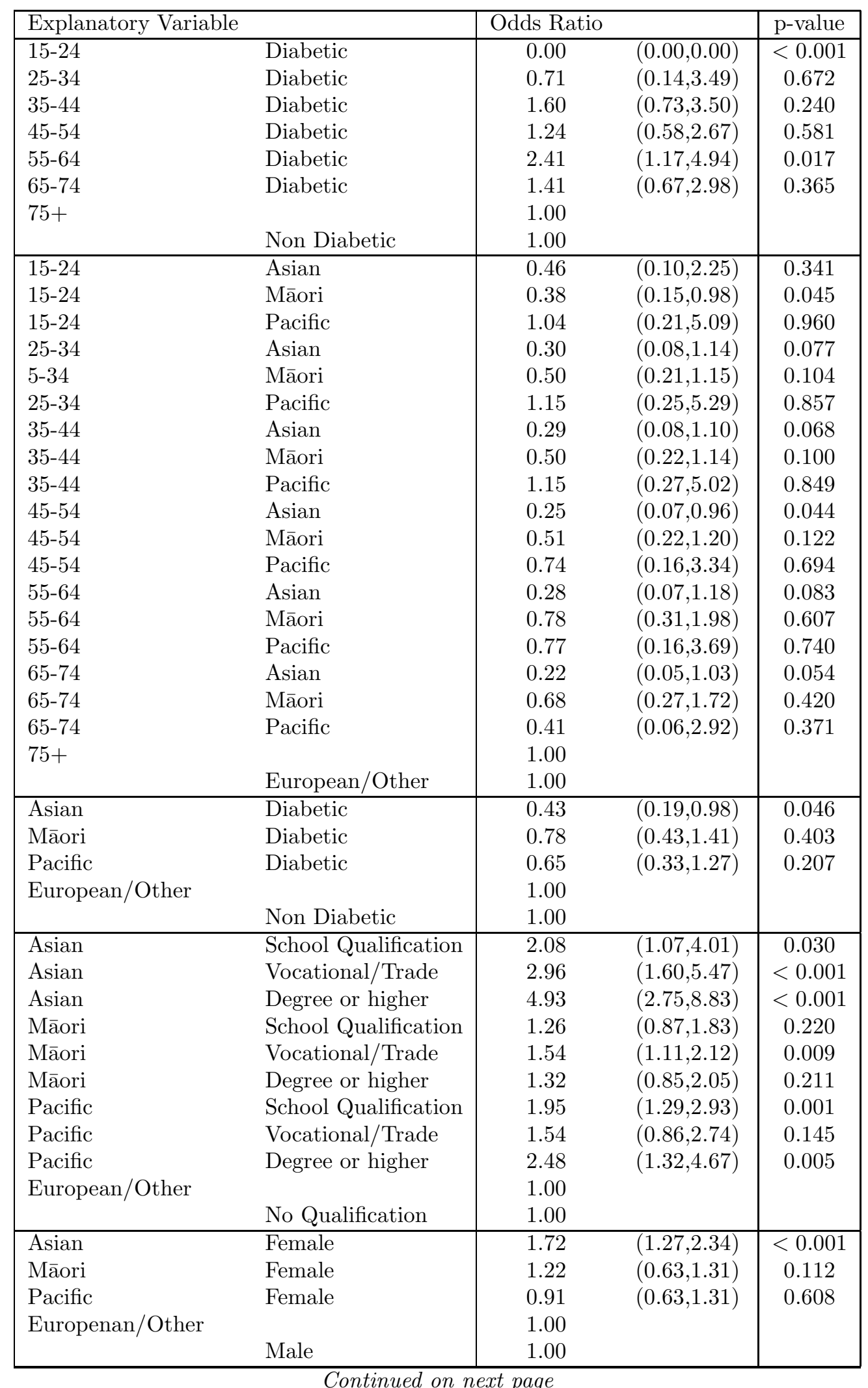


Continued from previous page

\begin{tabular}{|c|c|c|c|c|}
\hline \multicolumn{2}{|l|}{ Explanatory Variable } & \multicolumn{2}{|c|}{ Odds Ratio } & \multirow{2}{*}{$\frac{\mathrm{p} \text {-value }}{0.030}$} \\
\hline Asian & Rural & 0.26 & $(0.07,0.88)$ & \\
\hline Māori & Rural & 0.77 & $(0.57,1.05)$ & 0.102 \\
\hline Pacific & Rural & 2.34 & $(0.42,13.11)$ & 0.335 \\
\hline \multirow{2}{*}{ European } & & 1.00 & & \\
\hline & urban & 1.00 & & \\
\hline$<\$ 20,000$ & Rural & 0.82 & $(0.48,1.43)$ & 0.492 \\
\hline$\$ 20,001-\$ 50,000$ & Rural & 0.66 & $(0.42,1.02)$ & 0.062 \\
\hline$\$ 50,001-\$ 100,000$ & Rural & 0.63 & $(0.43,0.93)$ & 0.019 \\
\hline \multirow[t]{2}{*}{$>\$ 100,000$} & & 1.00 & & \\
\hline & Urban & 1.00 & & \\
\hline NZDep Quintile 1 & Insurance & 0.67 & $(0.48,0.93)$ & 0.018 \\
\hline NZDep Quintile 2 & Insurance & 0.81 & $(0.56,1.13)$ & 0.208 \\
\hline NZDep Quintile 3 & Insurance & 1.07 & $(0.77,1.49)$ & 0.695 \\
\hline NZDep Quintile 4 & Insurance & 0.78 & $(0.56,1.11)$ & 0.166 \\
\hline \multirow[t]{2}{*}{ NZDep Quintile 5} & & 1.00 & & \\
\hline & Insurance & 1.00 & & \\
\hline NZDep Quintile 1 & Female & 0.96 & $(0.68,1.36)$ & 0.827 \\
\hline NZDep Quintile 2 & Female & 0.84 & $(0.61,1.17)$ & 0.303 \\
\hline NZDep Quintile 3 & Female & 0.72 & $(0.52,1.00)$ & 0.050 \\
\hline NZDep Quintile 4 & Female & 0.96 & $(0.71,1.30)$ & 0.792 \\
\hline \multirow[t]{2}{*}{ NZDep Quintile 5} & & 1.00 & & \\
\hline & Male & 1.00 & & \\
\hline School Qualification & Female & 0.75 & $(0.56,0.99)$ & 0.045 \\
\hline Vocational/Trade & Female & 0.71 & $(0.54,0.92)$ & 0.009 \\
\hline Degree or Higher & Female & 0.80 & $(0.59,1.09)$ & 0.166 \\
\hline \multirow[t]{2}{*}{ No Qualification } & & 1.00 & & \\
\hline & Male & 1.00 & & \\
\hline
\end{tabular}

\section{Model interpretation}

The analysis found that the significant factors for greater tooth loss (that is 11 of more teeth lost) were:

- Being 75 years of age or older,

- Having a low household income,

- Having no qualification,

- Being a current smoker,

- Being from a rural area

Interaction terms were found to be significant for age $\times$ diabetes, age $\times$ ethnicity, ethnicity $\times$ diabetes, ethnicity $\times$ qualification, ethnicity $\times$ sex, ethnicity $\times$ urban/rural residency, household income $\times$ urban/rural residency, deprivation $\times$ health insurance, deprivation $\times$ sex and qualification $\times$ sex.

These interaction terms alter the odds ratios for each specific level of those terms involved in the interaction term. 
The first intercept for this model is $1.25(0.90,1.72)$ which is the odds of having lost 11 or more teeth compared to having lost 0 or 1-10 teeth for a person in all reference categories.

The second intercept for this model is $18.74(13.35,26.30)$ which are the odds for a person in all categories having lost 1 or more teeth due to tooth decay or gum disease as opposed to having lost no teeth. This intercept means that some tooth loss is highly likely and is not what we expected. These large intercepts, suggesting people are much more likely to have lost some teeth as opposed to no teeth, suggests the model may be inadequate.

Age was significantly associated with tooth loss, with all levels of age having significant effects. As age increases the odds of having lost more teeth due to tooth decay or gum disease increase.

Age $\times$ diabetes and age $\times$ ethnicity interactions also existed in the model, with these odds ratios decreasing the age odds ratios even more based on ethnicity (except for younger Pacific people). The age $\times$ diabetes interaction is extremely significant in the model, especially for 15-24 year olds, with the odds ratio for 15-24 year olds with diabetes interaction term being 0.00003 .

Having a lower level of qualification, having a higher household income and being from a less socioeconomically deprived decile decreased a person's odds of having lost more teeth, while being diabetic and living in a rural area increased the odds of having lost more teeth due to tooth decay or gum disease.

\section{Model checking}

Scaled standardised residuals were calculated for 56 categories based on sex, age and ethnicity and were used to assess the adequacy of the model selected. There are three graphs of residuals presented in Figures 6.9, 6.10 and 6.11, representing each of the three levels of tooth loss used in the ordinal model. We can clearly see that the residuals behave systematically with age, rather than randomly. The residuals are systematically low for younger age groups and high for older age groups. The model is over-estimating the tooth loss for these younger age groups, meaning that age is not adequately accounted for in the model, especially for the residuals calculated for 11 or more teeth lost in Figure 6.9 and 1-10 teeth lost in Figure 6.10.

\subsubsection{Model 4}

We now add the two oral health variables, regularity of care and unmet need in the previous 12 months into the tooth loss model. Adding more predictors to the model can create a more adequate, or better fitting model, due to having more explanatory variables attempting to explain the outcomes as well as more possible underlying associations with the new oral health predictors added to the model. This was seen in the models for regularity of care, where underlying associations between tooth loss and regularity of care meant that having tooth loss in Model 1 made the model a better predictor for regularity of care. Here were are trying the reverse, by seeing whether including regularity of care helps make the tooth loss model a better fit, due to some underlying associations between the two variables including possible shared unmeasured confounders and/or reverse causation.

This new model we refer to as Model 4. All 12 variables tested in the model were found to have significant main effects. These are displayed in Table 6.7. 12 interaction terms were also found to be significant in the model and these are displayed in Table 6.8. 

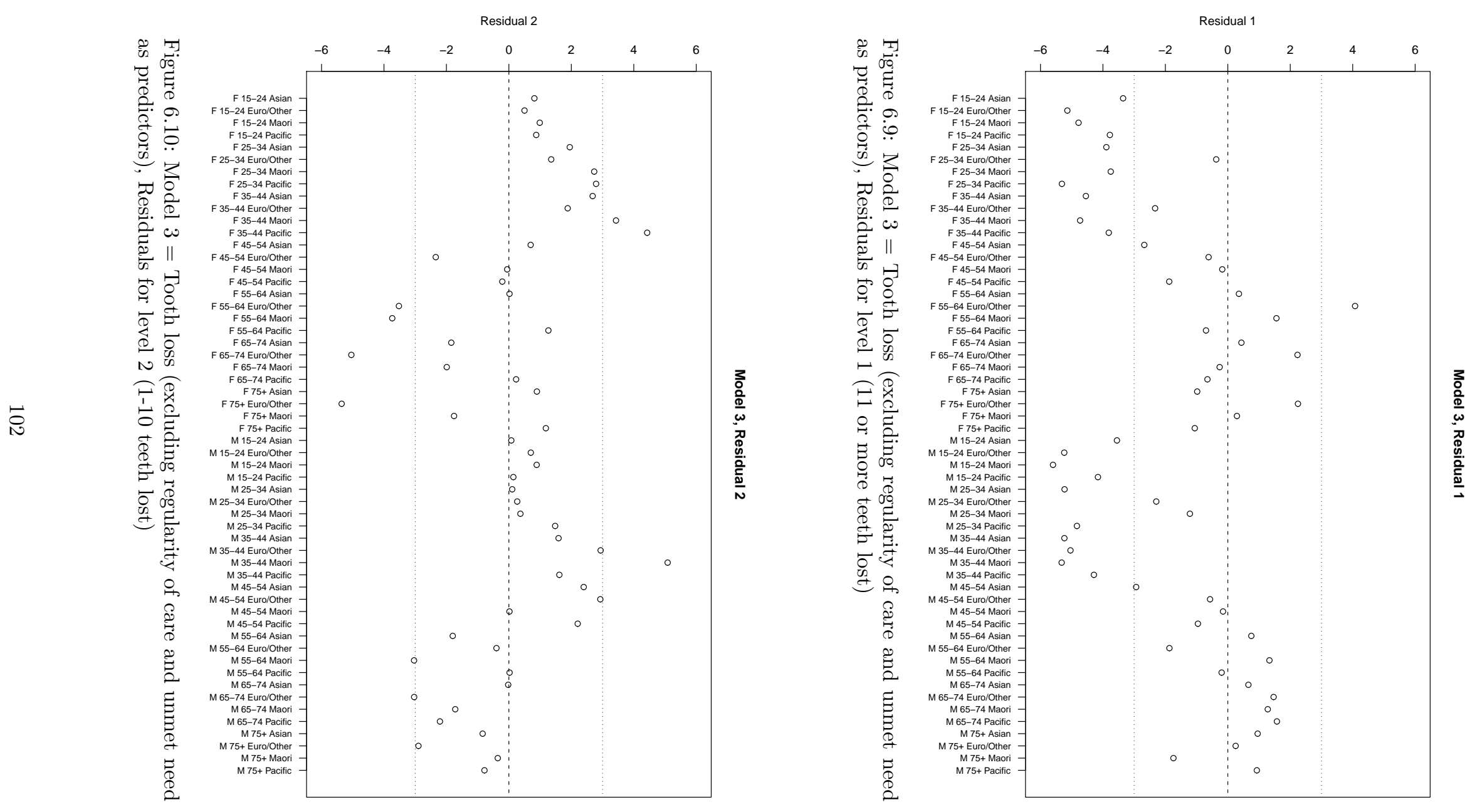

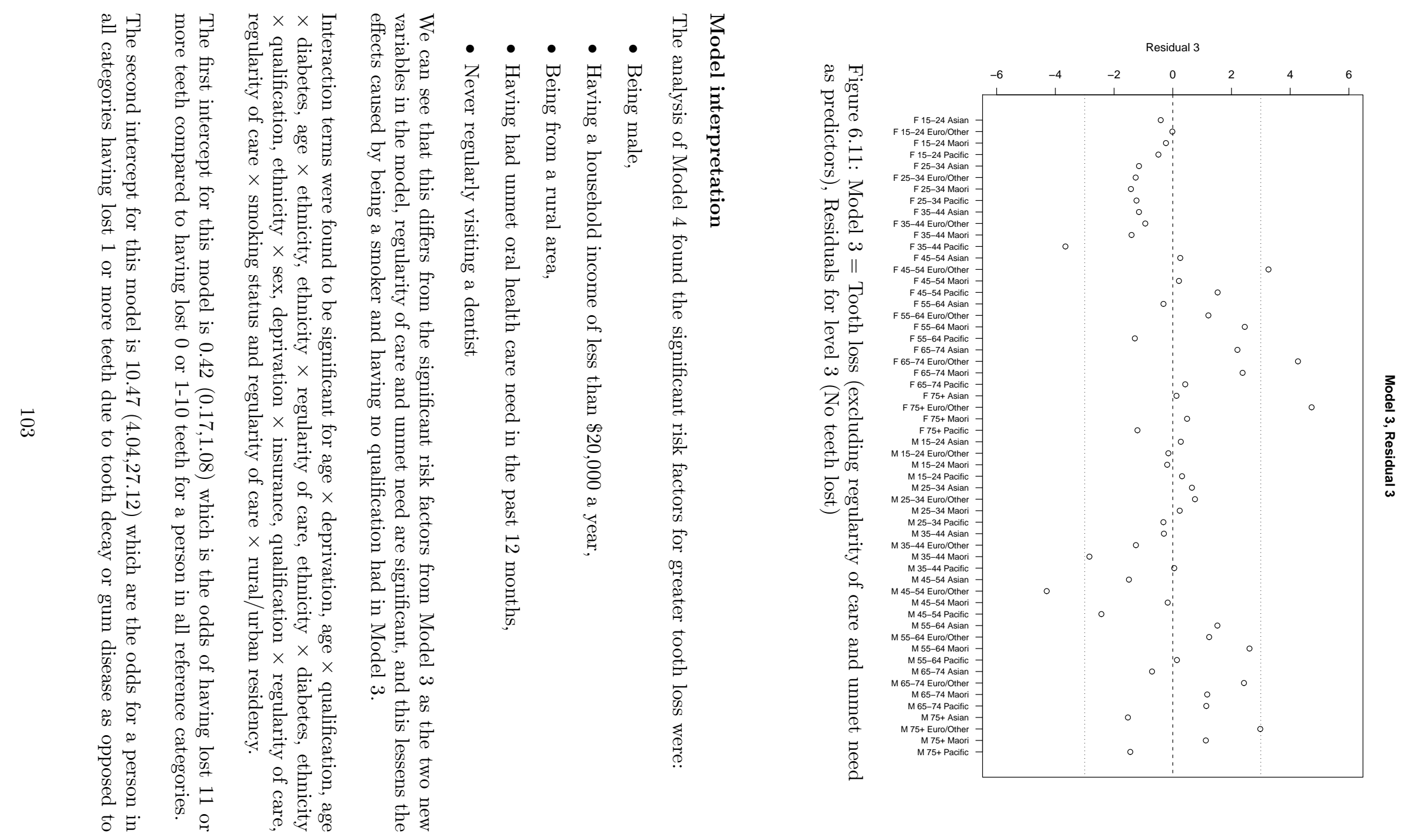
having lost no teeth.

Age was significantly associated with tooth loss, with all levels of age having significant effects. As age increases the odds of having lost more teeth due to tooth decay or gum disease increase. These odds are however altered due to all the interaction terms involving age. Age $\times$ deprivation, age $\times$ qualification, age $\times$ diabetes, age $\times$ ethnicity interaction terms are all lpresent in the model. All four interaction terms in general decreased the odds based on age alone, so that younger people had even lower odds for having lost more teeth based on their qualification status, ethnicity, and deprivation. The interaction odds for diabetic 15-24 year olds is almost zero, but is extremely significant in the model.

Having more regular oral health care visits decreased the odds of having lost more teeth; however, interaction terms which involving qualification, being a current smoker and ethnicity increased these odds.

The odds of having more tooth loss increase as houshold income decreases. Those who have a household income of less than $\$ 20,000$ a year have 1.38 times higher odds of tooth loss than those who earn more than $\$ 100,0000$ a year. Household income was not found to significantly interact with any other predictors in the model. 
Table 6.7: Model 4: Tooth loss, including regularity of care and unmet need, main effects

\begin{tabular}{|c|c|c|c|}
\hline Explanatory Variable & \multicolumn{2}{|c|}{ Odds Ratio } & p-value \\
\hline Intercept1 & 0.42 & $(0.17,1.08)$ & 0.072 \\
\hline Intercept2 & 10.47 & $(4.04,27.12)$ & $<0.001$ \\
\hline Female & 0.82 & $(0.72,0.95)$ & 0.006 \\
\hline Male & 1.00 & & \\
\hline $15-24$ & 0.05 & $(0.02,0.13)$ & $<0.001$ \\
\hline $25-34$ & 0.08 & $(0.03,0.21)$ & $<0.001$ \\
\hline $35-44$ & 0.16 & $(0.06,0.40)$ & $<0.001$ \\
\hline $45-54$ & 0.39 & $(0.17,0.93)$ & 0.033 \\
\hline $55-64$ & 0.60 & $(0.24,1.46)$ & 0.258 \\
\hline $64-74$ & 0.78 & $(0.30,2.05)$ & 0.617 \\
\hline $75+$ & 1.00 & & \\
\hline Diabetic & 1.52 & $(0.76,3.07)$ & 0.239 \\
\hline Non diabetic & 1.00 & & \\
\hline Asian & 1.26 & $(0.15,10.30)$ & 0.828 \\
\hline Māori & 2.78 & $(0.85,9.07)$ & 0.091 \\
\hline Pacific & 0.91 & $(0.13,6.39)$ & 0.922 \\
\hline European/other & 1.00 & & \\
\hline$<\$ 20,000$ & 1.38 & $(1.09,1.75)$ & 0.007 \\
\hline$\$ 20,001-\$ 50,000$ & 1.23 & $(1.06,1.47)$ & 0.008 \\
\hline$\$ 50,001-\$ 100,000$ & 1.15 & $(0.99,1.33)$ & 0.067 \\
\hline$>\$ 100,000$ & 1.00 & & \\
\hline Health insurance & 1.05 & $(0.79,1.39)$ & 0.743 \\
\hline No health insurance & 1.00 & & \\
\hline NZdep Quintile 1 & 0.95 & $(0.30,3.08)$ & 0.938 \\
\hline NZDep Quintile 2 & 1.27 & $(0.49,3.30)$ & 0.622 \\
\hline NZDep Quintile 3 & 1.30 & $(0.53,3.18)$ & 0.563 \\
\hline NZDep Quintile 4 & 1.21 & $(0.42,3.48)$ & 0.717 \\
\hline NZDep Quintile 5 & 1.00 & & \\
\hline No qualification & 1.00 & & \\
\hline School Qualification & 0.44 & $(0.20,0.97)$ & 0.041 \\
\hline Vocational/Trade & 0.85 & $(0.37,1.97)$ & 0.710 \\
\hline Degree or Higher & 0.27 & $(0.09,0.83)$ & 0.023 \\
\hline Smoker & 0.58 & $(0.32,1.06)$ & 0.076 \\
\hline Non smoker & 1.00 & & \\
\hline Rural & 2.78 & $(1.48,5.23)$ & 0.001 \\
\hline Urban & 1.00 & & \\
\hline Unmet need past 12 months & 1.28 & $(1.07,1.53)$ & 0.008 \\
\hline No unmet need & 1.00 & & \\
\hline Check ups $<2$ years apart & 0.39 & $(0.21,0.73)$ & 0.003 \\
\hline Check ups 2-5 years apart & 0.48 & $(0.23,1.00)$ & 0.050 \\
\hline Only when needed & 0.86 & $(0.49,1.51)$ & 0.604 \\
\hline Never & 1.00 & & \\
\hline
\end{tabular}


Table 6.8: Model 4: Tooth loss, including regularity of care and unmet need, interaction terms

\begin{tabular}{|c|c|c|c|c|}
\hline \multicolumn{2}{|c|}{ Explanatory Variable } & \multicolumn{2}{|c|}{ Odds Ratio } & p-value \\
\hline $15-24$ & NZDep Quintile 1 & 0.61 & $(0.16,2.35)$ & 0.477 \\
\hline $15-24$ & NZDep Quintile 2 & 0.15 & $(0.04,0.58)$ & 0.006 \\
\hline $15-24$ & NZDep Quintile 3 & 0.56 & $(0.18,1.72)$ & 0.312 \\
\hline $15-24$ & NZDep Quintile 4 & 0.54 & $(0.15,1.94)$ & 0.348 \\
\hline $25-34$ & NZDep Quintile 1 & 1.16 & $(0.31,4.39)$ & 0.828 \\
\hline $25-34$ & NZDep Quintile 2 & 0.50 & $(0.19,1.34)$ & 0.169 \\
\hline $25-34$ & NZDep Quintile 3 & 0.53 & $(0.20,1.37)$ & 0.190 \\
\hline $25-34$ & NZDep Quintile 4 & 0.82 & $(0.27,2.48)$ & 0.720 \\
\hline $35-44$ & NZDep Quintile 1 & 0.96 & $(0.29,3.12)$ & 0.939 \\
\hline $35-44$ & NZDep Quintile 2 & 0.57 & $(0.19,1.66)$ & 0.301 \\
\hline $35-44$ & NZDep Quintile 3 & 0.58 & $(0.23,1.48)$ & 0.256 \\
\hline $35-44$ & NZDep Quintile 4 & 0.78 & $(0.26,2.29)$ & 0.645 \\
\hline $45-54$ & NZDep Quintile 1 & 0.98 & $(0.32,3.02)$ & 0.965 \\
\hline $45-54$ & NZDep Quintile 2 & 0.68 & $(0.25,1.88)$ & 0.460 \\
\hline $45-54$ & NZDep Quintile 3 & 0.86 & $(0.34,2.18)$ & 0.747 \\
\hline $45-54$ & NZDep Quintile 4 & 1.03 & $(0.34,3.14)$ & 0.955 \\
\hline $55-64$ & NZDep Quintile 1 & 1.04 & $(0.35,3.10)$ & 0.945 \\
\hline $55-64$ & NZDep Quintile 2 & 0.77 & $(0.28,2.13)$ & 0.612 \\
\hline $55-64$ & NZDep Quintile 3 & 0.68 & $(0.26,1.78)$ & 0.436 \\
\hline $55-64$ & NZDep Quintile 4 & 1.03 & $(0.36,2.94)$ & 0.953 \\
\hline $65-74$ & NZDep Quintile 1 & 1.16 & $(0.35,3.84)$ & 0.802 \\
\hline $65-74$ & NZDep Quintile 2 & 1.12 & $(0.35,3.59)$ & 0.845 \\
\hline $65-74$ & NZDep Quintile 3 & 0.77 & $(0.28,2.11)$ & 0.617 \\
\hline $65-74$ & NZDep Quintile 4 & 1.04 & $(0.31,3.56)$ & 0.946 \\
\hline \multirow{2}{*}{$75+$} & & 1.00 & & \\
\hline & NZDep Quintile 5 & 1.00 & & \\
\hline $15-24$ & Degree or higher & 0.67 & $(0.10,4.53)$ & 0.681 \\
\hline $15-24$ & Vocational/Trade & 0.40 & $(0.17,0.91)$ & 0.028 \\
\hline $15-24$ & School qualification & 0.51 & $(0.22,1.15)$ & 0.104 \\
\hline $25-34$ & Degree or higher & 0.80 & $(0.30,2.13)$ & 0.657 \\
\hline $25-34$ & Vocational/Trade & 0.33 & $(0.16,0.68)$ & 0.003 \\
\hline $25-34$ & School qualification & 0.77 & $(0.38,1.56)$ & 0.475 \\
\hline $35-44$ & Degree or higher & 0.74 & $(0.31,1.79)$ & 0.502 \\
\hline $35-44$ & Vocational/Trade & 0.48 & $(0.26,0.85)$ & 0.130 \\
\hline $35-44$ & School qualification & 0.72 & $(0.36,1.46)$ & 0.366 \\
\hline $45-54$ & Degree or higher & 0.64 & $(0.24,1.66)$ & 0.354 \\
\hline $45-54$ & Vocational/Trade & 0.26 & $(0.13,0.50)$ & $<0.001$ \\
\hline $45-54$ & School qualification & 0.50 & $(0.23,1.09)$ & 0.081 \\
\hline $55-64$ & Degree or higher & 0.64 & $(0.25,1.68)$ & 0.367 \\
\hline $55-64$ & Vocational/Trade & 0.34 & $(0.19,0.62)$ & $<0.001$ \\
\hline $55-64$ & School qualification & 0.63 & $(0.29,1.40)$ & 0.259 \\
\hline $65-74$ & Degree or higher & 0.93 & $(0.35,2.50)$ & 0.888 \\
\hline $65-74$ & Vocational/Trade & 0.42 & $(0.19,0.92)$ & 0.030 \\
\hline $65-74$ & School qualification & 1.04 & $(0.49,2.23)$ & 0.916 \\
\hline \multirow[t]{2}{*}{$75+$} & & 1.00 & & \\
\hline & No qualification & 1.00 & & \\
\hline $15-24$ & Diabetic & 0.00 & $(0.00,0.00)$ & $<0.001$ \\
\hline $25-34$ & Diabetic & 0.54 & $(0.11,2.76)$ & 0.459 \\
\hline $35-44$ & Diabetic & 1.72 & $(0.63,4.71)$ & 0.294 \\
\hline
\end{tabular}

Continued on next page 
Continued from previous page

\begin{tabular}{|c|c|c|c|c|}
\hline \multicolumn{2}{|c|}{ Explanatory Variable } & \multicolumn{2}{|c|}{ Odds Ratio } & \multirow{2}{*}{$\frac{\mathrm{p} \text {-value }}{0.996}$} \\
\hline $45-54$ & Diabetic & 1.00 & $(0.42,2.40)$ & \\
\hline $55-64$ & Diabetic & 2.35 & $(0.96,5.77)$ & 0.062 \\
\hline $65-74$ & Diabetic & 0.92 & $(0.36,2.37)$ & 0.863 \\
\hline \multirow[t]{2}{*}{$75+$} & & 1.00 & & \\
\hline & Non Diabetic & 1.00 & & \\
\hline $15-24$ & Asian & 0.23 & $(0.03,2.02)$ & 0.185 \\
\hline $15-24$ & Māori & 0.23 & $(0.07,0.83)$ & 0.024 \\
\hline $15-24$ & Pacific & 0.83 & $(0.11,6.24)$ & 0.855 \\
\hline $25-34$ & Asian & 0.19 & $(0.03,1.24)$ & 0.082 \\
\hline $25-34$ & Māori & 0.43 & $(0.13,1.38)$ & 0.154 \\
\hline $25-34$ & Pacific & 1.21 & $(0.16,9.00)$ & 0.849 \\
\hline $35-44$ & Asian & 0.18 & $(0.03,1.12)$ & 0.066 \\
\hline $35-44$ & Māori & 0.41 & $(0.13,1.27)$ & 0.123 \\
\hline $35-44$ & Pacific & 1.13 & $(0.17,7.34)$ & 0.901 \\
\hline $45-54$ & Asian & 0.14 & $(0.02,0.92)$ & 0.041 \\
\hline $45-54$ & Māori & 0.34 & $(0.10,1.08)$ & 0.068 \\
\hline $45-54$ & Pacific & 0.71 & $(0.10,5.23)$ & 0.737 \\
\hline $55-64$ & Asian & 0.15 & $(0.02,1.05)$ & 0.056 \\
\hline $55-64$ & Māori & 0.33 & $(0.10,1.10)$ & 0.072 \\
\hline $55-64$ & Pacific & 0.81 & $(0.12,5.37)$ & 0.827 \\
\hline $65-74$ & Asian & 0.14 & $(0.02,1.21)$ & 0.074 \\
\hline $65-74$ & Māori & 0.52 & $(0.14,1.94)$ & 0.328 \\
\hline $65-74$ & Pacific & 0.53 & $(0.05,6.12)$ & 0.610 \\
\hline \multirow[t]{2}{*}{$75+$} & & 1.00 & & \\
\hline & European/Other & 1.00 & & \\
\hline Asian & Check ups $<2$ years apart & 2.91 & $(1.31,6.48)$ & 0.009 \\
\hline Asian & Check ups 2-5 years apart & 2.29 & $(0.89,5.90)$ & 0.085 \\
\hline Asian & Only when needed & 1.78 & $(0.80,3.95)$ & 0.155 \\
\hline Māori & Check ups $<2$ years apart & 1.12 & $(0.64,1.95)$ & 0.702 \\
\hline Māori & Check ups 2-5 years apart & 1.19 & $(0.62,2.29)$ & 0.606 \\
\hline Māori & Only when needed & 0.93 & $(0.57,1.52)$ & 0.776 \\
\hline Pacific & Check ups $<2$ years apart & 0.99 & $(0.47,2.06)$ & 0.974 \\
\hline Pacific & Check ups $2-5$ years apart & 2.13 & $(0.70,6.49)$ & 0.186 \\
\hline Pacific & Only when needed & 1.15 & $(0.61,2.17)$ & 0.675 \\
\hline \multirow[t]{2}{*}{ European/Other } & & 1.00 & & \\
\hline & Never & 1.00 & & \\
\hline Asian & Diabetic & 0.34 & $(0.14,0.79)$ & 0.013 \\
\hline Māori & Diabatic & 0.71 & $(0.34,1.48)$ & 0.362 \\
\hline Pacific & Diabetic & 0.94 & $(0.48,1.87)$ & 0.870 \\
\hline \multirow[t]{2}{*}{ European/Other } & & 1.00 & & \\
\hline & Non diabetic & 1.00 & & \\
\hline Asian & Degree or higher & 3.78 & $(1.90,7.51)$ & $<0.001$ \\
\hline Asian & Vocational/Trade & 2.32 & $(1.19,4.53)$ & 0.013 \\
\hline Asian & School qualification & 1.90 & $(0.92,3.91)$ & 0.081 \\
\hline Māori & Degree or higher & 1.06 & $(0.63,1.78)$ & 0.832 \\
\hline Māori & Vocational/Trade & 1.32 & $(0.88,1.97)$ & 0.183 \\
\hline Māori & Vocational/Trade & 1.16 & $(0.75,1.80)$ & 0.507 \\
\hline Pacific & Degree or higher & 1.70 & $(0.80,3.61)$ & 0.169 \\
\hline Pacific & Vocational/Trade & 1.22 & $(0.64,2.35)$ & 0.548 \\
\hline Pacific & Vocational/Trade & 1.85 & $(1.12,3.03)$ & 0.015 \\
\hline European/Other & & 1.00 & & \\
\hline
\end{tabular}

Continued on next page 
Continued from previous page

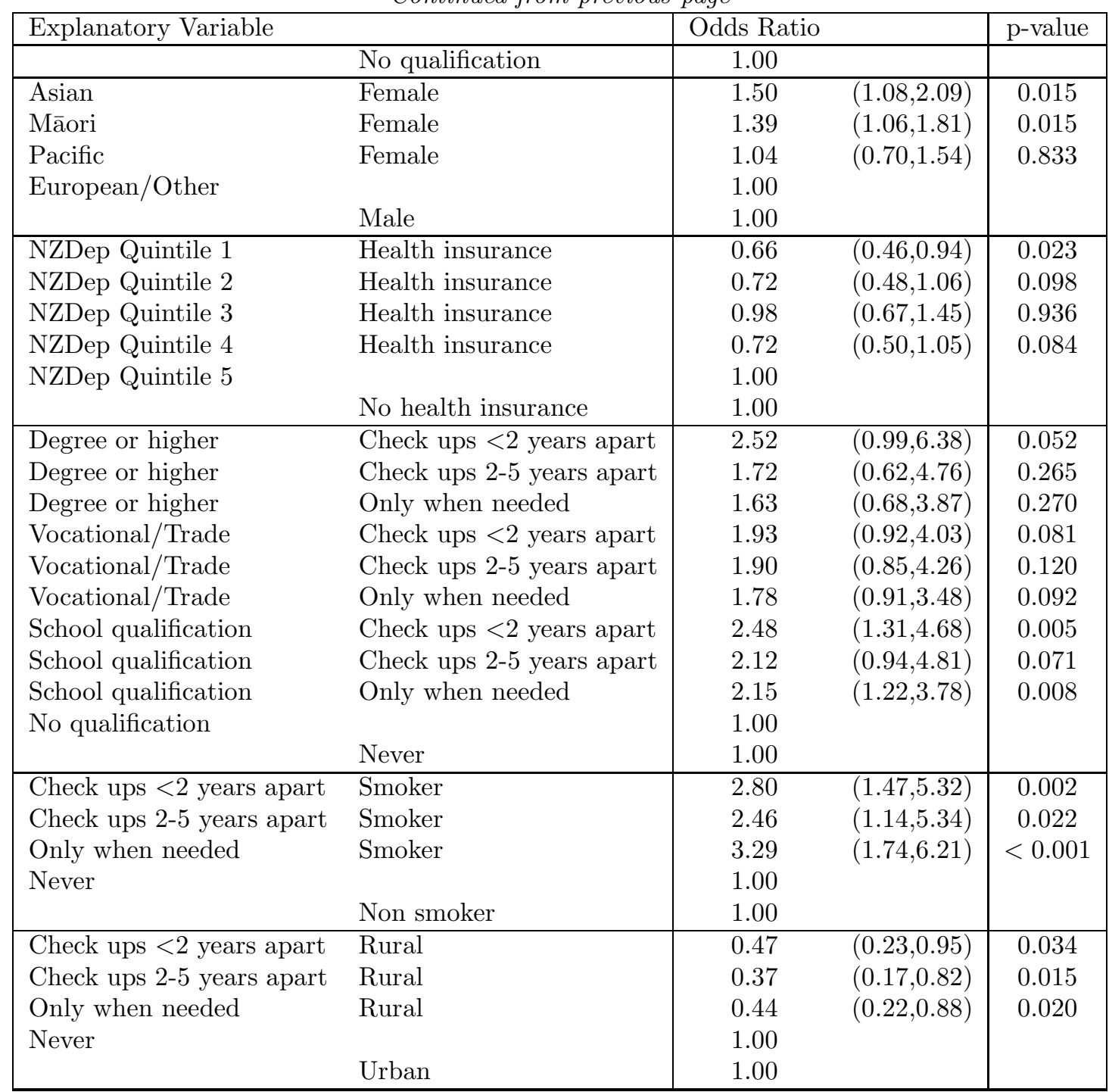

\section{Model checking}

Once again, the residuals for this model are not randomly distributed, and in fact are dependent on age. This means that even with the added oral health outcomes in the model, we are unable to adequately model tooth loss for the three selected levels, as these three levels do not have a uniform effect based on age.

The cumulative logit model does not capture the structure of the data sufficiently well. Tooth loss is not a uniform profile for our three categories of tooth loss across all ages and the model does not take this into account. A multinomial logistic model could be used to account for this age association, and produce different $\beta$ values in 3 separate models for each specific tooth loss level.

The proportional odds assumption is that $\beta_{j}=\beta$ for all $j$, and simplifies the model to

$$
\operatorname{logit}=\alpha_{j}+\beta x_{i j}
$$



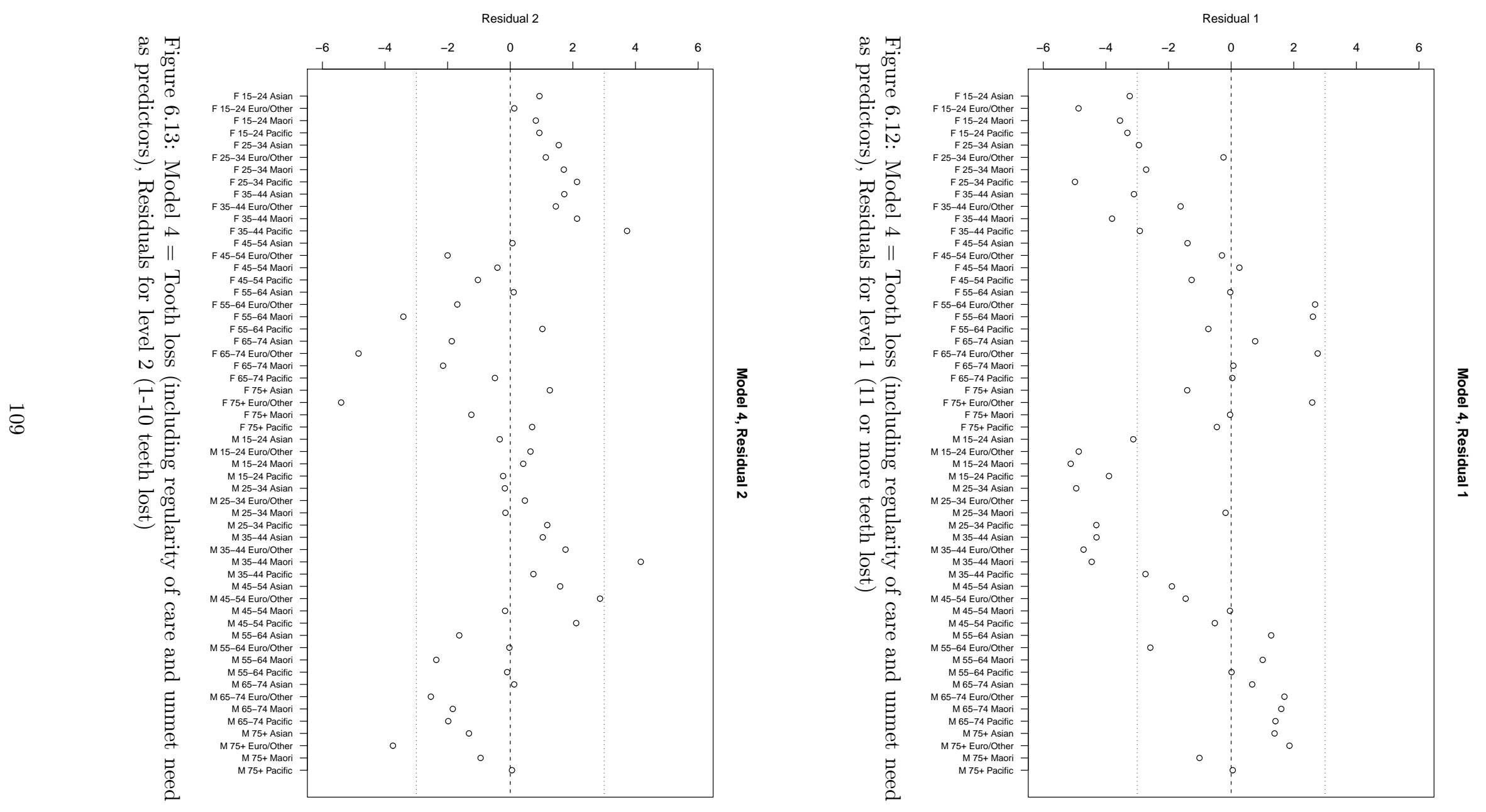

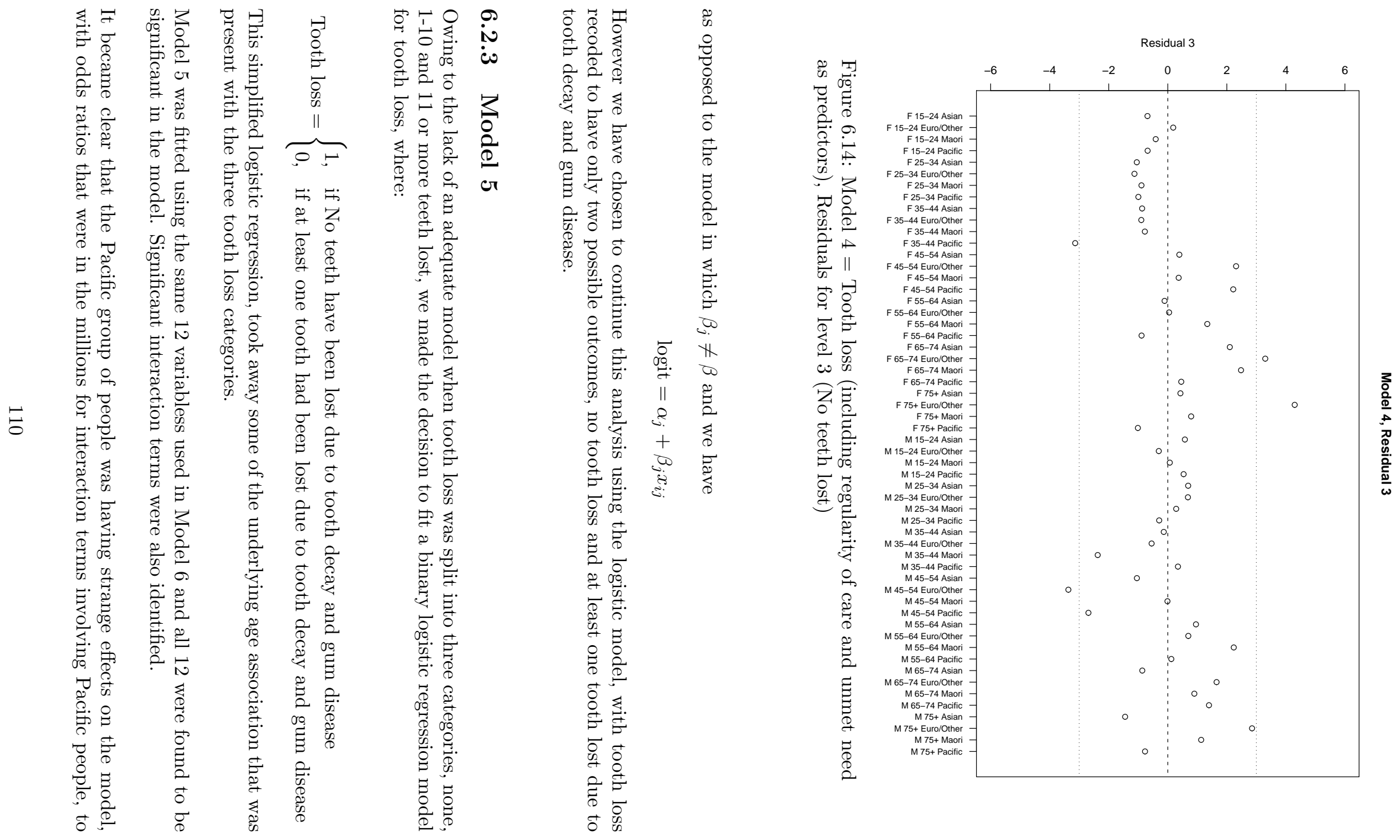
cancel out the extremely small odds ratio from the Pacific people main effect. The Pacific people sample was the smallest of the 4 ethnicity categories, and therefore had a greater chance of specific cells not containing anyone and leading to odd estimates in our model. It was decided to merge Pacific people into the European/Other category and re-run the model.

\subsubsection{Model 6}

Model 6 used the logistic regression to model tooth loss, with ethnicity set at three levels, Asian, Māori and European/Other.

Again all 12 predictor variables were found to be significant in the logistic regression model and are displayed with corresponding odds ratios in Table 6.9. The following interaction terms were also found to be significant in the model: age $\times$ deprivation, age $\times$ qualification, age $\times$ diabetes, age $\times$ smoking status, ethnicity $\times$ qualification, ethnicity $\times$ diabetes, ethnicity $\times$ sex, ethnicity $\times$ rural/urban residency, deprivation $\times$ health insurance, deprivation $\times$ rural/urban residency and regularity of care $\times$ smoking status and the corresponding odds ratios are displayed in Table 6.10 .

\section{Model interpretation}

The analysis of Model 6 found the significant risk factors for any tooth loss were:

- Being male,

- Being from a rural area,

- Having had unmet oral health care need in the past 12 months,

- Only visiting a dentist when needed

The intercept for the model gives a value of $1.76(0.92,3.38)$ times the odds of having lost some teeth compared to no tooth loss. It is important to note that this intercept confidence interval does include the value 1 and that there is no significant difference in the odds of having lost or not lost any teeth due to tooth decay and gum disease.

AS age decreases so do the odds of having tooth loss. Having a higher level of qualification and being less deprived interact with age and decrease the odds of tooth loss based on age more due to these interaction terms.

Females have 0.76 times the odds of lossing teeth compared to males, however these odds become larger than the odds of males for Asian and Māori populations once the interaction for ethnicity and sex is accounted for.

The main effect of smoking status indicated that those who are current smokers are less likely to have lost teeth due to tooth decay and gum disease. However once interaction terms for age and regularity of care are included these odds increase and reverse the main effects results, such that those who do currently smoke are more likely to have lost teeth due to tooth decay and gum disease than those who do not currently smoke. 
Table 6.9: Model 6: Tooth loss, including regularity of care and unmet need, main effects

\begin{tabular}{|c|c|c|c|}
\hline Explanatory Variable & \multicolumn{2}{|c|}{ Odds Ratio } & p-value \\
\hline Intercept & 1.76 & $(0.92,3.38)$ & 0.088 \\
\hline Female & 0.76 & $(0.66,0.88)$ & $<0.001$ \\
\hline Male & 1.00 & & \\
\hline Asian & 0.42 & $(0.21,0.82)$ & 0.011 \\
\hline Māori & 1.01 & $(0.71,1.45)$ & 0.948 \\
\hline European/Other & 1.00 & & \\
\hline $15-24$ & 0.11 & $(0.05,0.24)$ & $<0.001$ \\
\hline $25-34$ & 0.27 & $(0.14,0.54)$ & $<0.001$ \\
\hline $35-44$ & 0.45 & $(0.22,0.92)$ & 0.029 \\
\hline $45-54$ & 0.79 & $(0.41,1.51)$ & 0.477 \\
\hline $55-64$ & 0.98 & $(0.49,1.98)$ & 0.964 \\
\hline $65-74$ & 1.25 & $(0.58,2.69)$ & 0.568 \\
\hline $75+$ & 1.00 & & \\
\hline Current smoker & 0.27 & $(0.09,0.78)$ & 0.016 \\
\hline Non-current smoker & 1.00 & & \\
\hline$<\$ 20,000$ & 1.18 & $(0.93,1.49)$ & 0.170 \\
\hline$\$ 20,001-\$ 50,000$ & 1.20 & $(1.00,1.42)$ & 0.042 \\
\hline$\$ 50,001-\$ 100,000$ & 1.16 & $(0.99,1.35)$ & 0.073 \\
\hline$>\$ 100,000$ & 1.00 & & \\
\hline No qualification & 1.00 & & \\
\hline School qualification & 1.12 & $(0.62,2.01)$ & 0.713 \\
\hline Vocational/Trade qualification & 1.81 & $(0.99,3.29)$ & 0.053 \\
\hline Degree or higher & 0.79 & $(0.36,1.72)$ & 0.555 \\
\hline No Health Insurance & 1.00 & & \\
\hline Health Insurance & 0.98 & $(0.74,1.31)$ & 0.906 \\
\hline NZDep Quintile 1 & 1.42 & $(0.54,3.72)$ & 0.471 \\
\hline NZDep Quintile 2 & 1.43 & $(0.67,3.08)$ & 0.357 \\
\hline NZDep Quintile 3 & 1.64 & $(0.77,3.49)$ & 0.198 \\
\hline NZDep Quintile 4 & 1.53 & $(0.69,3.42)$ & 0.299 \\
\hline NZDep Quintile 5 & 1.00 & & \\
\hline Diabetic & 1.49 & $(0.70,3.21)$ & 0.314 \\
\hline Non Diabetic & 1.00 & & \\
\hline Urban & 1.00 & & \\
\hline Rural & 2.03 & $(1.10,3.76)$ & 0.024 \\
\hline Unmet need in past 12 months & 1.44 & $(1.17,1.77)$ & $<0.001$ \\
\hline No unmet need & 1.00 & & \\
\hline Check ups $<2$ years apart & 1.52 & $(1.16,1.98)$ & 0.002 \\
\hline Check ups 2-5 years apart & 1.54 & $(1.16,2.06)$ & 0.003 \\
\hline When needed & 2.34 & $(1.79,3.05)$ & $<0.001$ \\
\hline Never & 1.00 & & \\
\hline
\end{tabular}


Table 6.10: Model 6: Tooth loss, including regularity of care and unmet need, interaction terms

\begin{tabular}{|c|c|c|c|c|}
\hline \multicolumn{2}{|c|}{ Explanatory Variable } & \multicolumn{2}{|c|}{ Odds Ratio } & \multirow{2}{*}{$\frac{\mathrm{p} \text {-value }}{0.371}$} \\
\hline $15-24$ & NZDep Quintile 1 & 0.37 & $(0.11,1.25)$ & \\
\hline $15-24$ & NZDep Quintile 2 & 0.13 & $(0.04,0.42)$ & $<0.001$ \\
\hline $15-24$ & NZDep Quintile 3 & 0.45 & $(0.16,1.28)$ & 0.136 \\
\hline $15-24$ & NZDep Quintile 4 & 0.45 & $(0.16,1.26)$ & 0.127 \\
\hline $25-34$ & NZDep Quintile 1 & 0.60 & $(0.19,1.94)$ & 0.396 \\
\hline $25-34$ & NZDep Quintile 2 & 0.38 & $(0.16,0.88)$ & 0.024 \\
\hline $25-34$ & NZDep Quintile 3 & 0.37 & $(0.15,0.88)$ & 0.024 \\
\hline $25-34$ & NZDep Quintile 4 & 0.57 & $(0.23,1.41)$ & 0.228 \\
\hline $35-44$ & NZDep Quintile 1 & 0.51 & $(0.18,1.44)$ & 0.201 \\
\hline $35-44$ & NZDep Quintile 2 & 0.40 & $(0.16,1.02)$ & 0.055 \\
\hline $35-44$ & NZDep Quintile 3 & 0.39 & $(0.17,0.90)$ & 0.028 \\
\hline $35-44$ & NZDep Quintile 4 & 0.54 & $(0.21,1.37)$ & 0.193 \\
\hline $45-54$ & NZDep Quintile 1 & 0.61 & $(0.23,1.61)$ & 0.318 \\
\hline $45-54$ & NZDep Quintile 2 & 0.59 & $(0.25,1.38)$ & 0.225 \\
\hline $45-54$ & NZDep Quintile 3 & 0.68 & $(0.29,1.58)$ & 0.373 \\
\hline $45-54$ & NZDep Quintile 4 & 0.89 & $(0.37,2.18)$ & 0.804 \\
\hline $55-64$ & NZDep Quintile 1 & 0.74 & $(0.27,2.04)$ & 0.554 \\
\hline $55-64$ & NZDep Quintile 2 & 0.73 & $(0.33,1.61)$ & 0.435 \\
\hline $55-64$ & NZDep Quintile 3 & 0.67 & $(0.27,1.65)$ & 0.381 \\
\hline $55-64$ & NZDep Quintile 4 & 0.83 & $(0.35,1.99)$ & 0.678 \\
\hline $65-74$ & NZDep Quintile 1 & 0.76 & $(0.25,2.30)$ & 0.628 \\
\hline $65-74$ & NZDep Quintile 2 & 0.82 & $(0.29,2.32)$ & 0.708 \\
\hline $65-74$ & NZDep Quintile 3 & 0.47 & $(0.21,1.03)$ & 0.058 \\
\hline $65-74$ & NZDep Quintile 4 & 0.69 & $(0.24,1.97)$ & 0.492 \\
\hline \multirow[t]{2}{*}{$75+$} & & 1.00 & & \\
\hline & NZDep Quintile 5 & 1.00 & & \\
\hline $15-24$ & School qualification & 0.45 & $(0.21,0.95)$ & 0.037 \\
\hline $15-24$ & Vocational/Trade & 0.35 & $(0.16,0.74)$ & 0.006 \\
\hline $15-24$ & Degree or higher & 0.43 & $(0.07,2.51)$ & 0.0346 \\
\hline $25-34$ & School qualification & 0.60 & $(0.32,1.12)$ & 0.106 \\
\hline $25-34$ & Vocational/Trade & 0.22 & $(0.11,0.45)$ & $<0.001$ \\
\hline $25-34$ & Degree or higher & 0.38 & $(0.15,0.97)$ & 0.044 \\
\hline $35-44$ & School qualification & 0.62 & $(0.32,1.23)$ & 0.172 \\
\hline $35-44$ & Vocational/Trade & 0.35 & $(0.19,0.66)$ & 0.001 \\
\hline $35-44$ & Degree or higher & 0.41 & $(0.18,0.91)$ & 0.028 \\
\hline $45-54$ & School qualification & 0.45 & $(0.21,0.97)$ & 0.041 \\
\hline $45-54$ & Vocational/Trade & 0.21 & $(0.11,0.41)$ & $<0.001$ \\
\hline $45-54$ & Degree or higher & 0.41 & $(0.21,0.97)$ & 0.041 \\
\hline $55-64$ & School qualification & 0.55 & $(0.25,1.23)$ & 0.145 \\
\hline $55-64$ & Vocational/Trade & 0.33 & $(0.16,0.67)$ & 0.002 \\
\hline $55-64$ & Degree or higher & 0.50 & $(0.19,1.27)$ & 0.0142 \\
\hline $65-74$ & School qualification & 1.12 & $(0.50,2.49)$ & 0.789 \\
\hline $65-74$ & Vocational/Trade & 0.42 & $(0.18,0.95)$ & 0.037 \\
\hline $65-74$ & Degree or higher & 0.89 & $(0.31,2.56)$ & 0.830 \\
\hline \multirow[t]{2}{*}{$75+$} & & 1.00 & & \\
\hline & No qualificiation & 1.00 & & \\
\hline $15-24$ & Diabetic & 0.00 & $(0.00,0.00)$ & $<0.001$ \\
\hline $25-34$ & Diabetic & 0.52 & $(0.10,2.76)$ & 0.441 \\
\hline $35-44$ & Diabetic & 2.12 & $(0.73,6.18)$ & 0.168 \\
\hline
\end{tabular}

Continued on next page 
Continued from previous page

\begin{tabular}{|c|c|c|c|c|}
\hline \multicolumn{2}{|l|}{ Explanatory Variable } & \multicolumn{2}{|c|}{ Odds Ratio } & $\mathrm{p}$-value \\
\hline $45-54$ & Diabetic & 1.20 & $(0.48,2.98)$ & 0.692 \\
\hline $55-64$ & Diabetic & 2.64 & $(0.99,7.09)$ & 0.053 \\
\hline $65-74$ & Diabetic & 0.83 & $(0.29,2.37)$ & 0.722 \\
\hline \multirow[t]{2}{*}{$75+$} & & 1.00 & & \\
\hline & Non Diabetic & 1.00 & & \\
\hline $15-24$ & Smoker & 2.06 & $(0.69,6.19)$ & 0.197 \\
\hline $25-34$ & Smoker & 3.02 & $(1.11,8.20)$ & 0.030 \\
\hline $35-44$ & Smoker & 4.44 & $(1.60,12.31)$ & 0.004 \\
\hline $45-54$ & Smoker & 4.01 & $(1.48,10.88)$ & 0.006 \\
\hline $55-64$ & Smoker & 2.76 & $(0.93,8.23)$ & 0.068 \\
\hline $65-74$ & Smoker & 2.35 & $(0.68,8.10)$ & 0.178 \\
\hline \multirow{2}{*}{$75+$} & & 1.00 & & \\
\hline & Non Smoker & 1.00 & & \\
\hline Asian & School qualification & 1.95 & $(0.93,4.10)$ & 0.079 \\
\hline Asian & Vocational/Trade & 2.34 & $(1.13,4.84)$ & 0.023 \\
\hline Asian & Degree or higher & 3.88 & $(1.97,7.63)$ & $<0.001$ \\
\hline Māori & School qualification & 1.12 & $(0.64,1.97)$ & 0.694 \\
\hline Māori & Vocational/Trade & 1.47 & $(0.95,2.27)$ & 0.087 \\
\hline Māori & Degree or higher & 1.00 & $(0.64,1.56)$ & 0.993 \\
\hline \multirow[t]{2}{*}{ European/Other } & & 1.00 & & \\
\hline & No qualification & 1.00 & & \\
\hline Asian & Diabetic & 0.29 & $(0.13,0.62)$ & 0.001 \\
\hline Māori & Diabetic & 0.67 & $(0.30,1.50)$ & 0.326 \\
\hline \multirow[t]{2}{*}{ European/Other } & & 1.00 & & \\
\hline & Non Diabetic & 1.00 & & \\
\hline Asian & Female & 1.76 & $(1.26,2.46)$ & $<0.001$ \\
\hline Māori & Female & 1.47 & $(1.09,1.96)$ & 0.010 \\
\hline \multirow[t]{2}{*}{ European/Other } & & 1.00 & & \\
\hline & Male & 1.00 & & \\
\hline Asian & Rural & 0.24 & $(0.06,0.95)$ & 0.043 \\
\hline Māori & Rural & 0.80 & $(0.55,1.16)$ & 0.236 \\
\hline \multirow[t]{2}{*}{ European/Other } & & 1.00 & & \\
\hline & Urban & 1.00 & & \\
\hline NZDep Quintile 1 & health insurance & 0.69 & $(0.48,1.00)$ & 0.048 \\
\hline NZDep Quintile 2 & health insurance & 0.75 & $(0.51,1.12)$ & 0.166 \\
\hline NZDep Quintile 3 & health insurance & 0.98 & $(0.66,1.45)$ & 0.906 \\
\hline NZDep Quintile 4 & health insurance & 0.77 & $(0.52,1.14)$ & 0.188 \\
\hline \multirow[t]{2}{*}{ NZDep Quintile 5} & & 1.00 & & \\
\hline & No health insurance & 1.00 & & \\
\hline NZDep Quintile 1 & Rural & 0.79 & $\overline{(0.37,1.70)}$ & 0.551 \\
\hline NZDep Quintile 2 & Rural & 0.61 & $(0.32,1.15)$ & 0.124 \\
\hline NZDep Quintile 3 & Rural & 0.63 & $(0.32,1.24)$ & 0.177 \\
\hline NZDep Quintile 4 & Rural & 0.47 & $(0.23,0.98)$ & 0.043 \\
\hline \multirow[t]{2}{*}{ NZDep Quintile 5} & & 1.00 & & \\
\hline & Urban & 1.00 & & \\
\hline Check ups $<2$ years apart & Smoker & 1.52 & $(0.90,2.55)$ & 0.118 \\
\hline Check ups 2-5 years apart & Smoker & 1.56 & $(0.81,2.99)$ & 0.180 \\
\hline When needed & Smoker & 2.12 & $(1.36,3.60)$ & 0.001 \\
\hline \multirow[t]{2}{*}{ Never } & & 1.00 & & \\
\hline & Non smoker & 1.00 & & \\
\hline
\end{tabular}



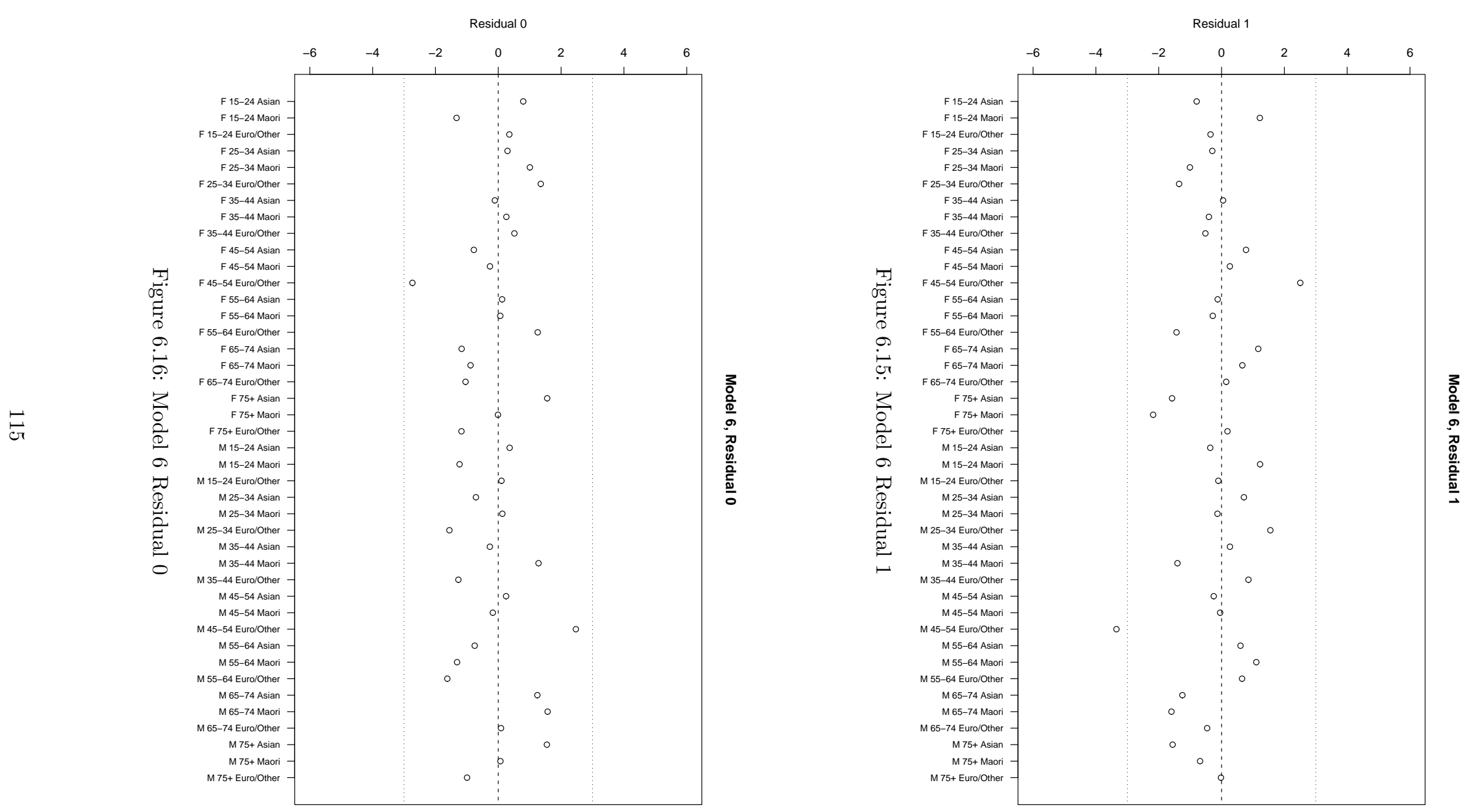


\section{Model checking}

Scaled standardised residuals were produced for Model 6 based on sex, age and ethnicity (at the new 3 levels). All but one residual for both levels of tooth loss lay between the desired values of -3 and +3 and were evenly spread, with no visible trends and our model is a good fit for the data. 


\section{Chapter 7}

\section{Survey Comparison}

In this chapter an overview of the World Health Organisation (WHO) International Collaborative Study of Oral Health Outcomes (ICS II) is provided, including survey design and strategy. A section on the demographic variables in this survey is given, along with a section exploring some of the oral health outcomes from this study. Finally, a comparison is done with the NZHS 2006/07 for specific oral health outcomes that were common to both surveys, to measure changes over time in New Zealanders oral health status.

\subsection{ICS II Survey Design}

\subsubsection{Survey Background}

In 1973 the World Health Organization (WHO) International Collaborative Study of Dental Manpower Systems in Relation to Oral Health Status (ICS I) study was conducted, with 10 countries participating, including New Zealand (Hunter et al. 1992). The New Zealand section of ICS I took place in the province of Canterbury and New Zealanders showed high levels of decayed, missing and filled teeth for teenagers as well as a significant proportion of adults, aged 35-44, with tooth loss or complete tooth loss. In 1978 a national workshop was held in New Zealand to review oral health in New Zealand. Specific goals were set for reducing rates of oral disease among New Zealanders over the following 10 year period.

New Zealand then agreed to participate in the second ICS study, the International Collaborative Study of Oral Health Outcomes (ICS II). ICS II built on ICS I and attempted to examine the relationships between environmental, personal factors and oral health delivery systems with oral health outcomes and expenditure, within and between the seven participating countries. The final results were published in The Study of Oral Health Ouctomes: The 1988 New Zealand Section of the WHO Second International Collaborative study and this section is drawn from this literature.

The specific objectives of the New Zealand section of the ICS II study were to:

- assess, for specific age groups, oral health and oral disease and to document any changes since previous surveys;

- examine the sociodemographic characteristics, oral health beliefs, attitudes, knowledge and self-care practices of the general public and to document any changes since the previous surveys; 
- describe the oral health care system and the sociodemographic and behavioural factors relevant to oral health and the oral health care system;

- identify the factors that best explain the variations in oral health, the use of the oral health care system and the quality of care;

- asses the relative effects of sociodemographic and personal factors on oral health status;

- provide policy makers with information that can be used to improve oral health and the efficiency of the oral health care system.

This study was administered by the Dental Health Programme of the Department of Health and its Research Services Section.

\subsubsection{Population and frame}

The target population for the 1988 ICS II was the national New Zealand population in 4 specified age groups, 12-13 years, 20-24 years, 35-44 years and 65-74 years. The adult groups of the survey included people on the two main islands of New Zealand (North and South Islands). Excluded were people not on these two main islands, and those not in private dwellings such as motels, hospitals and prisons and those not in the specified age groups.

The child population aimed to sample 12-13 year olds in Form 2 (the final year in which students received free school dental care) from the North and South Islands of New Zealand.

\subsubsection{Sample design and strategy}

\section{Adult survey}

The sampling frame for the adult sections of the ICS II was developed by the Department of Statistics (now Statistics New Zealand). The sampling frame was a modified version of that used for the Household Labour Force Survey and the New Zealand Household Expenditure and Income Survey.

Meshblocks obtained from the 1986 Census were the Primary Sampling Units (PSU) for the ICS II. These meshblocks were divided into 94 strata based on geography, age, ethnicity, family type, education and employment status. Three PSU's were randomly selected from each of the 94 strata, two urban and one rural.

The second stage of sampling used a list of dwelling units based on the 1986 Census. $56 \%$ of the dwelling units in the urban PSU's and $100 \%$ of those in the rural PSU's were randomly selected for screening for the 65-74 year age group. Of those dwellings screened for the 65-74 year age group, $57 \%$ were then randomly selected to be screened for the 35-44 year age group, with the final random selection done to $87.5 \%$ of the last group for the $20-24$ year old group. All adults in the 3 age categories were eligible for interview. This sampling method aimed to sample 500 20-24 year olds, 1000 35-44 year olds and 750 65-74 year olds.

\section{Child survey}

Stratified multistage random sampling was used to obtain the child sample for ICS II. Schools containing Form 2 students close to the selected PSU's from the adult sample were identified. In rural areas any schools in the PSU were selected and in the urban areas 'area units' were created consisting of around 12 meshblocks and all schools in these 'area units' were used. 
50 schools were then selected from the above frame of eligible schools using probability proportional to the number of eligible students. One or two classes of Form 2 students were selected from the 50 chosen schools, this meant a total of 1480 classes were selected. 1074 students were then randomly selected with each student having equal probability of selection.

\subsubsection{Data Collection and response rate}

AGB McNair was contracted to locate and interview the adults for the 1988 ICS II sample. 30 teams of two experienced interviewers were trained extensively to carry out the interview process, with 8 dentists used for the oral examination part of ICS II.

An initial letter informing selected dwellings of the survey and asking for their permission was sent out a few days before the survey started. Eligible adults were questioned as soon as contact was made, with non-contacts being given up to 3 callbacks in urban areas and only one call back in rural areas. The oral examinations were conducted at a later date in the respondents own dwelling with the interviewer recording the data from this examination conducted by the dentist. The final response for $20-24$ year olds was $71 \%$, for $35-44$ year olds was $78 \%$ and for $65-74$ year olds was $80 \%$ when the number of people identified using the screening questionnaire is used to calculate these rates.

Extensive quality control was used to ensure high standards of data quality. Interviewers were observed, assessed and audited and response analysis was completed on a weekly basis along with two-stage checks on coded data forms.

For the child part of the survey permission was obtained from the parents. An hour was spent filling in the questionnaire, followed by the oral exam where the questionnaires were examined and corrected for obvious mistakes. This child data were collected at the same time as when the dental examiners were in the same area, with assistance from the local school Dental nurses. The response rate for both the questionnaire and the oral examination for the child sample was $96 \%$.

\subsubsection{The questionnaire}

Blum's model of the determinants of health status states that four major factors, environment, lifestyle, the health care system and human biology, determine an individual's health status (Blum 1973). The first three of these factors were used to develop the questionnaire for the New Zealand ICS II. The study involved the collection of basic descriptive information on oral health and the factors that influence it. Respondent's views on oral health outcomes and oral health practices were also investigated.

Basic sociodemographic variables and perceived general health questions were asked. These were followed by questions about enabling factors for oral health and oral health, usage, care costs, insurance and questions about specific appointments with oral health services and respondent satisfaction levels for oral health services used. The next group of variables covered aspects of oral health behavior. The final set of questions covered perceived oral health status.

The oral examination method and criteria were a modification of the basic methods developed for oral health surveys by the World Health Organization (WHO). Dentition status and the condition was recorded for both primary and permanent teeth, along with tooth treatment needs for survey participants. 


\subsubsection{Weighting}

Sampling weights were used to ensure unbiased national estimates of population parameters, to account for the selection probability used for each sampling unit. The sampling weights differentially weight the sample data to reflect the level of disproportionality in the sample relative to the population.

The student sample of the ICS II survey, has corresponding weights associated with each respondent based on the selection probabilities at each of the sampling stages, and nonresponse rates. 'The final weights were constructed by multiplying the selection probability weight by the non-response weight and then adjusting these weights to a mean of one'.

The adult weights were calculated using the selection probability using the Primary Sampling Unit (PSU), Dwelling Unit (DW), indivdual respondent levels and non-response rates. 'Poststratification was also conducted by age group and sex to reflect the national distribution'. This weighting ensures that the survey weights add up to the sample size.

Note that due to the complex design appropriate software need to be used to calculate weighted estimates and variances. Unlike the NZHS 2006/07, where jackknife weights had been calculated we use the Taylor seies linearisation method as implemented in the SAS SURVEY function, especially through the use of SURVEYFREQ. Stratum identities were not provided in the data, but PSU's were, and so we treated the datasets as a 2 stage cluster sample.

\subsection{ICS II Demographics}

Here we summarise the demographics for the adult and child sections of the ICS II.

\subsubsection{Adults}

Table 7.1 shows the age distribution of the ICS II sample with $19.62 \%$ of the adult sample aged $20-24,47.86 \%$ aged $35-44$, and $32.53 \%$ aged $65-74.47 .95 \%(45.9,50.1)$ of the adult population were male, while $52.05 \%(49.9,54.1)$ were female.

First ethnicity (ETHNIC1) was recorded as a varible in the data set, where respondents selected their main ethnicity (Separate questions were asked where respondents were able to identify with each specific ethnicity). 1558 respondents selected European/Pakeha as their main ethnicity, 113 selected Māori, 55 selected Pacific Islander and 40 selected Other. Using the sample weights, and taking into account of the PSU clustering we get the following percentages of ethnicities for the New Zealand adult population in 1988: 89.06\% (86.1,92.0) selected European/Pakeha as their priority ethnicity, 5.65\% (4.2,7.1) selected Māori, 3.05\% $(1.3,4.8)$ selected Pacific Islander, and $2.24 \%$ (1.4,3.1) selected Other as their main ethnicity.

Based on results from the New Zealand 1991 Census, 83.2\% of New Zealanders identified themselves as European, $13.0 \%$ identified as Māori, 5.0\% as Pacific Islander and 3.2\% as Other, with $4.1 \%$ of the population identifing with more than one ethnicity group (Statistics New Zealand 2002). We can compare this with the results states above and which are visible in Table 7.1, where 3 years later in 1991, a greater percentage of people identified as Māori, than those who did in the ICS II. 


\subsubsection{Students}

1024 students aged between 12 and 13 answered the student survey section of the ICS II. 549 were male, which equates to $51.1 \%(46.3,56.0)$ of the population and 475 were female, equating to $48.9 \%(44.0,53.7)$ of the population for this age category.

$207(15.3 \%)$ Students identified themselves as being a Māori, 157 (12.5\%) as a Pacific Islander, $744(77.9 \%)$ as European/Pakeha and 51 (5.3\%) as being from an Other Ethnicity. This is a total of $1159(111 \%)$, as students were allowed to identify with more than one ethnicity. This is the non prioritised from of this question.

\subsection{Data Exploration}

Published results found in The Study of Oral Health Outcomes, The 1988 New Zealand section of the WHO second International Collaborative Study (Hunter et al. 1992) indicated that:

- Greater availability of access to dental services did not appear to be directly related to oral health status;

- School-based delivery systems were very effective in treating the oral diseases of childhood but may not have had a long term impact on adult oral health;

- The primary barrier to receiving oral health care appeared to be the perceived acceptability of services;

- The oral health care delivery system may not have been the primary determinant of oral health status, as other factors such as the value the population places on oral health and how determined the professionals are at preventive activities associated with oral health status (Hunter et al. 1992).

\subsubsection{Adults}

The ICS II data set had a much larger set of oral health variables, and also consisted of results from individual dental examinations. For this analysis we focus on the results from the ICS II that were also present in the NZHS 2006/07 data set, so that comparisons can be made over time.

\section{Time since last oral health specialist care}

Table 7.2 shows that $46.82 \%(43.4,50.3)$ had seen an oral health care worker in the past year, $13.12 \%(11.2,15.1)$ had been in the last $1-2$ years, $15.93 \%(14.0,17.8)$ had been to an oral health worker in the last $2-5$ years, $23.13 \%(20.4,25.9)$ had not seen an oral health care worker for the last five years and $0.99 \%(0.3,1.6)$ had never seen an oral health care worker. Figure 7.1 displays the time since last visit to an oral health care worker by ethnicity. Pacific Islanders have the highest rates of people never seeing an oral health care worker. It is also important to note that because of the small sample size, many of the estimates for Pacific Islanders and those in the Other ethnicity category are unreliable due to large RSE values.

\section{Reasons for no oral health care in the past 2 years}

The main reason a respondent had not seen an oral health care worker in the past 2 years was reported. $38.59 \%(32.51,44.68)$ of people had not seen an oral health care worker in the past 2 years as there was 'nothing wrong' with them, so they had had no need to. $32.20 \%$ $(26.88,37.52)$ of people had not seen an oral health care worker in the past 2 years due to having false teeth or having no teeth. $12.50 \%(9.67,15.25)$ could not afford the cost of care 
Table 7.1: Demographics of the ICS II Adult Sample

\begin{tabular}{|l||r|r|r|}
\hline Subdomain & $\begin{array}{r}\text { Sample } \\
\text { Percentage(\%) }\end{array}$ & $\begin{array}{r}\text { Weighted } \\
\text { Percentage(\%) }\end{array}$ & $\begin{array}{r}\text { Sample } \\
\text { Number }\end{array}$ \\
\hline Sex & & & \\
Male & 45.8 & 48.0 & 812 \\
Female & 54.2 & 52.0 & 962 \\
\hline Age & & & \\
$20-24$ & 19.6 & 19.6 & 849 \\
$35-44$ & 37.9 & 47.9 & 849 \\
$65-74$ & & 32.5 & 577 \\
\hline Ethnicity & 6.4 & & \\
Māori & 3.1 & 5.6 & 113 \\
Pacific & 88.2 & 3.1 & 55 \\
European & 2.3 & 89.1 & 1,558 \\
Other & 100.0 & 100.2 & 40 \\
\hline Total & & & \\
\hline
\end{tabular}

Table 7.2: Time since last visit to oral health care worker for Adult ICS II

\begin{tabular}{|l|c|c|c|c|c|}
\hline & $<12$ months & $1-2$ years & $2-5$ years & $5+$ years & never \\
\hline Total & 46.8 & 13.1 & 15.9 & 23.1 & $1.0 \dagger$ \\
& $(43.4,50.3)$ & $(11.2,15.1)$ & $(14.0,17.8)$ & $(20.4,25.9)$ & $(0.3,1.6)$ \\
\hline \hline Male & 453 & 13.1 & 18.2 & 22.1 & $1.3 \dagger \dagger$ \\
& $(41.0,49.5)$ & $(10.5,15.8)$ & $(15.0,21.5)$ & $(18.8,25.3)$ & $(0.3,2.3)$ \\
\hline Female & 48.2 & 13.1 & 13.8 & 22.1 & $0.7 \dagger \dagger$ \\
& $(43.7,52.8)$ & $(10.8,15.4)$ & $(11.4,16.3)$ & $(20.6,27.6)$ & $(0.1,1.3)$ \\
\hline \hline $20-24$ & 54.7 & 19.6 & 20.1 & 5.2 & $0.4 \dagger \dagger$ \\
& $(48.1,61.4)$ & $(15.4,23.8)$ & $(14.5,25.7)$ & $(2.6,7.8)$ & $(0,1.3)$ \\
\hline $35-44$ & 55.8 & 14.0 & 14.9 & 15.6 & $0.7 \dagger \dagger$ \\
& $(51.0,60.6)$ & $(11.4,16.6)$ & $(12.3,17.6)$ & $(11.4,17.8)$ & $(0,1.5)$ \\
\hline $65-74$ & 28.8 & 7.9 & 14.9 & 46.7 & $1.7 \dagger$ \\
& $(24.9,32.7)$ & $(15.4,23.8)$ & $(14.5,25.7)$ & $(2.6,7.8)$ & $(0,1.3)$ \\
\hline \hline Māori & 34.1 & 15.0 & 24.4 & 24.6 & $1.9 \dagger \dagger$ \\
& $(24.5,43.7)$ & $(7.9,22.2)$ & $(17.2,31.7)$ & $(16.1,33.0)$ & $(0,4.9)$ \\
\hline Pacific & 26.0 & $18.1 \dagger$ & 19.5 & 24.3 & $12.1 \dagger \dagger$ \\
& $(11.5,40.6)$ & $(7.1,29.1)$ & $(9.9,29.0)$ & $(12.1,36.4)$ & $(0,24.9)$ \\
\hline European & 48.5 & 12.6 & 15.4 & 23.0 & $0.5 \dagger \dagger$ \\
& $(45.0,52.0)$ & $(10.5,14.6)$ & $(13.4,17.5)$ & $(20.0,26.0)$ & $(0.1,0.8)$ \\
\hline Other & 40.3 & $18.3 \dagger$ & $12.3 \dagger \dagger$ & $24.7 \dagger$ & $4.3 \dagger \dagger$ \\
& $(23.9,56.8)$ & $(7.0,29.7)$ & $(0,25.2)$ & $(8.9,40.6)$ & $(0,12.7)$ \\
\hline
\end{tabular}

$\dagger$ means unreliable estimate with an RSE of 0.3-0.5

$\dagger \dagger$ means a very unreliable estimate with an RSE $>0.5$ 
which had prevented them from seeing an oral health care worker in the past 2 years. $4.04 \%$ $(2.31,5.78)$ were afraid of dental treatment or did not like dentists, and this had prevented them going to see one in the past 2 years.

\section{Tooth Brushing}

Tooth brushing frequency was recorded for adults in the survey, with $66.42 \%(63.49,69.35)$ of adults in the three specified age categories brushing their teeth two or more times a day. $25.86 \%(23.16,28.57)$ brushed their teeth once a day, with the remaining $7.72 \%$ of adults brushing their teeth less than once a day.

\subsubsection{Students}

\section{Tooth Brushing}

$45.83 \%(39.93,51.73)$ of students aged $12-13$ brush their teeth two or more times a day, $34.69 \%$ $(30.30,39.08)$ of students brush their teeth once a day, while $19.48 \%(15.08,23.88)$ of children brush their teeth less than once a day.

\section{Oral health specialist care}

$50.1 \%(44.69,55.50)$ of children aged $12-13$ have visited a dentist, while $99.04 \%(98.25,99.83)$ of children aged 12-13 had visited a school dental nurse.

\subsection{Comparison with NZHS 2006/07}

Few variables are present in both the ICS II and NZHS 2006/07 and have adequate response categories to be able to do a meaningful comparison. Comparisons were only carried out for the age groups specified in the ICS II data set, so that results are comparable.

\section{Tooth Brushing}

Tooth brushing for students aged 12 and 13 can be compared for both surveys. A reclassification of the response categories was carried out to get equivalent responses for both surveys. Table 7.3 shows the changes in time from 1988 to 2006/07 using the results from the two surveys.

The rates of children aged 12-13 brushing their teeth once a day has not significantly changed over time. However the rates of children brushing twice or more a day has significantly increased over the 18 year time period. $45.8 \%$ of 12-13 year old children in 1988 were brushing their teeth twice or more times a day, compared to $59.0 \%$ of $12-13$ year old children brushing their teeth twice or more times a day in 2006/07.

The rate of children who brush their teeth less than once a day has decreased over the 18 year period. $19.5 \%$ of children aged 12-13 in 1988 brushed their teeth less than once a day, compared to only $7.9 \%$ of $12-13$ year old children only brushing their teeth once a day in 2006/07.

The overall increase in child tooth brushing has been to a positive effect, with more 12-13 year olds now taking better care of their teeth through tooth brushing in 2006/07 than they did in 1988. 


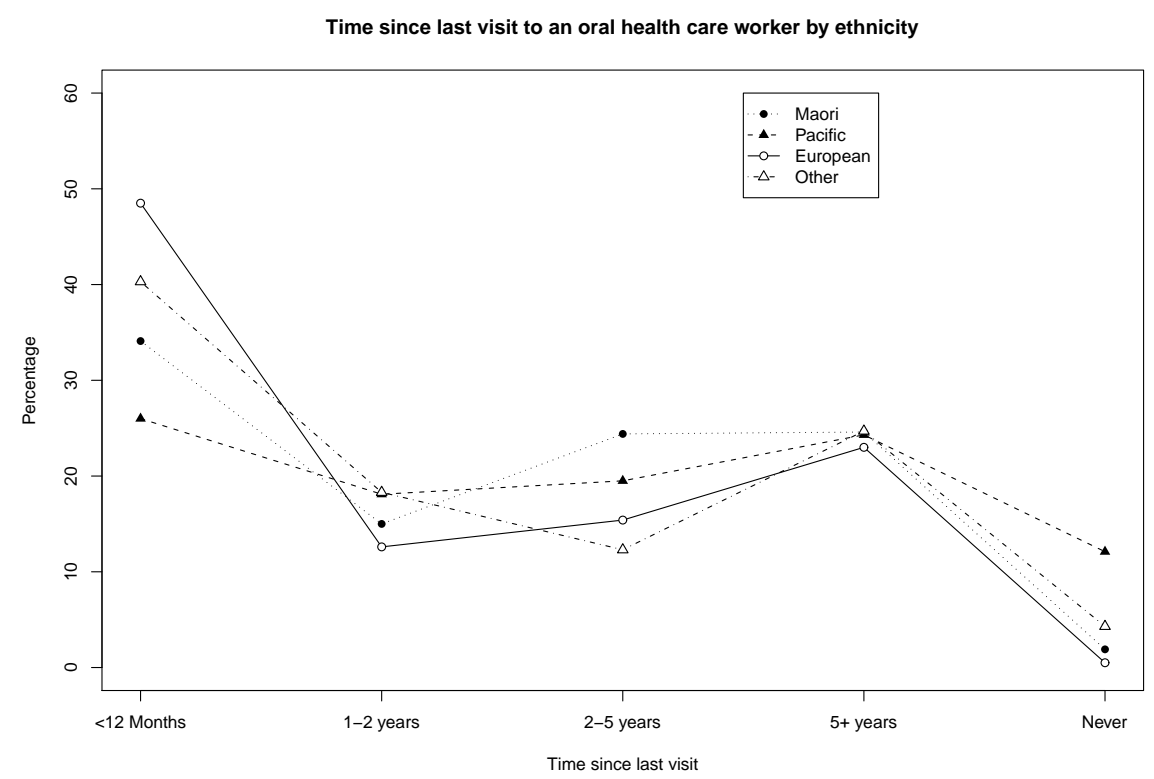

Figure 7.1: Time since last visit to an oral health worker for adults aged 20-24, 35-44 and 65-74 ICS II 1988

Table 7.3: Tooth brushing frequency for children aged 12-13

\begin{tabular}{|l|c|c|c|c|}
\hline Frequency of & ICS II & NZHS & & \\
Tooth Brushing & 1988 & $2006 / 07$ & Difference & P-value \\
\hline Twice or more times a day & 45.83 & 59.0 & 13.12 & 0.002 \\
& $(39.93,51.73)$ & $(53.24,64.66)$ & $(4.91,21.33)$ & \\
Once a day & 34.69 & 33.1 & -1.54 & 0.644 \\
& $(30.30,39.08)$ & $(28.32,37.98)$ & $(-8.07,4.99)$ & \\
Less than once a day & 19.48 & 7.9 & -11.59 & $<0.001$ \\
& $(15.08,23.88)$ & $(5.11,10.67)$ & $(-16.79,-6.39)$ & \\
\hline
\end{tabular}


Figure 7.2 displays the confidence intervals for tooth brushing frequency for 1988 and 2006/07. We can see that there is a greater percentage of 12-13 year olds brushing their teeth twice or more times a day in 2006/07 than there was in 1988. Rates of children brushing less than once a day have decreased over time, as displayed in the graph by a lower confidence interval for the years 2006/07 for those who brush less than once a week.

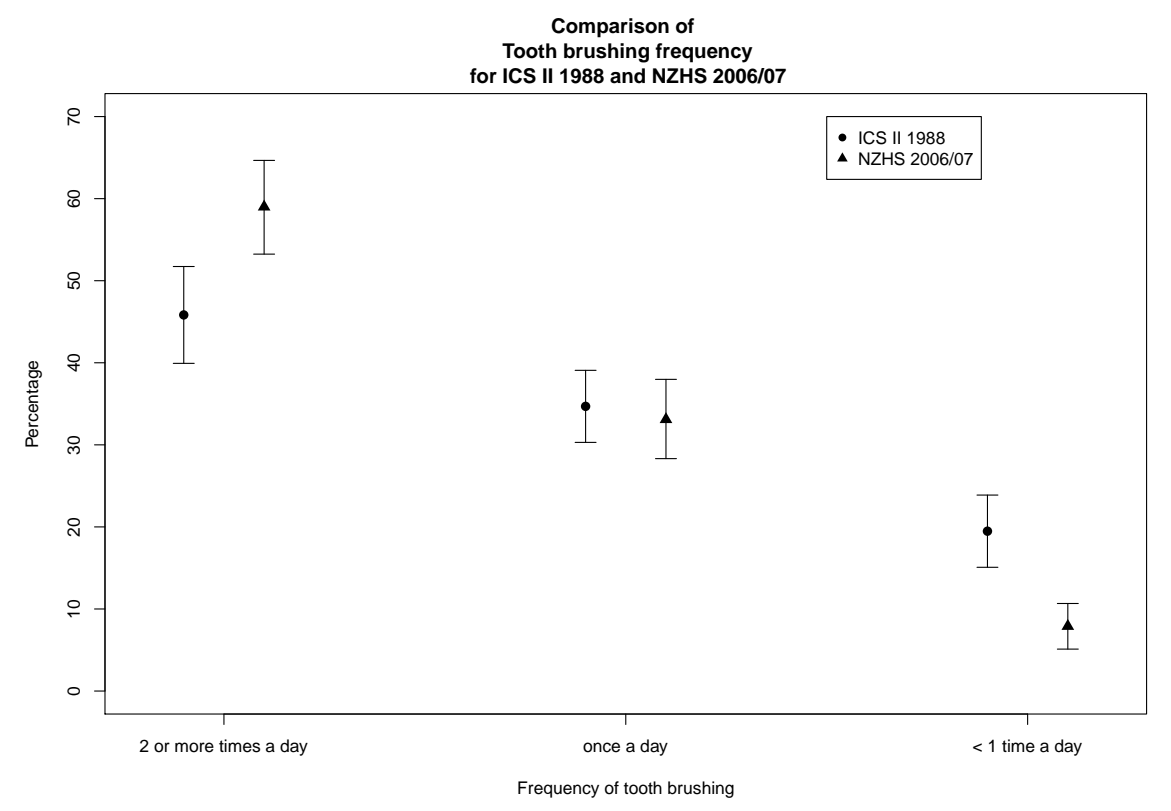

Figure 7.2: Comparison of tooth brushing frequency for children aged 12-13, ICS II 1988 and NZHS 2006/07

\section{Oral health visits}

The time since last visit to an oral health worker was recorded in both the ICS II and the NZHS 2006/07. An aggregation of categories in the ICS II data set can provide an equivalent set of outcomes to that in the NZHS 2006/07 data set. Comparisons are made for those in the age categories specified in the ICS II data set, that is people aged 20-24, 35-44 and 65-74. Table 7.4 details the differences in the two surveys for the outcome variable, time since last visit to an oral helath care worker and using significane testing provides estimates in the differences over time from 1988 to 2006/07.

Figure 7.3 is a graphical display of the time since last visit to an oral health care worker for the years 1988 and 2006/07. This figure displays the $95 \%$ confidence intervals based on the data from the ICS II and the NZHS 2006/07 surveys. We can see the biggest differences over time for the number of people visiting an oral health care worker in the last 1-2 years and those who have not visited an oral health care worker for more than five years.

The rates of people who have visited an oral health care worker in the past 12 months or in the past 2-5 years have not significantly changed over time.

The rates of people who have visited an oral health care in the preious 1-2 years has increased significantly over time. $19.55 \%$ of people in 2006/07 had previouslt seen an oral health care worker in the past 1-2 years, compared to $13.12 \%$ of people in 1988 . The difference over time 
Table 7.4: Time since last visit to an oral health care worker (for people aged 20-24, 35-44, $65-74)$

\begin{tabular}{|l|c|c|c|c|}
\hline $\begin{array}{l}\text { Time since } \\
\text { last visit }\end{array}$ & ICS II & NZHS & & \\
\hline$<12$ months & 46.82 & $2006 / 07$ & Difference & P-value \\
& $(43.4,50.3)$ & $(42.8,47.3)$ & $(-5.86,2.36)$ & 0.404 \\
$1-2$ years & 13.12 & 19.55 & 6.43 & $<0.001$ \\
& $(11.2,15.1)$ & $(18.0,21.1)$ & $(3.96,8.90)$ & \\
$2-5$ years & 15.93 & 16.01 & 0.08 & 0.947 \\
& $(14.0,17.8)$ & $(14.6,17.4)$ & $(-2.29,2.45)$ & \\
$5+$ years & 23.13 & 16.77 & -6.36 & $<0.001$ \\
& $(20.4,25.9)$ & $(15.5,18.1)$ & $(-9.44,-3.28)$ & \\
Never & 0.99 & 2.60 & 1.61 & $<0.001$ \\
& $(0.3,1.6)$ & $(2.1,3.1)$ & $(0.79,2.43)$ & \\
\hline
\end{tabular}

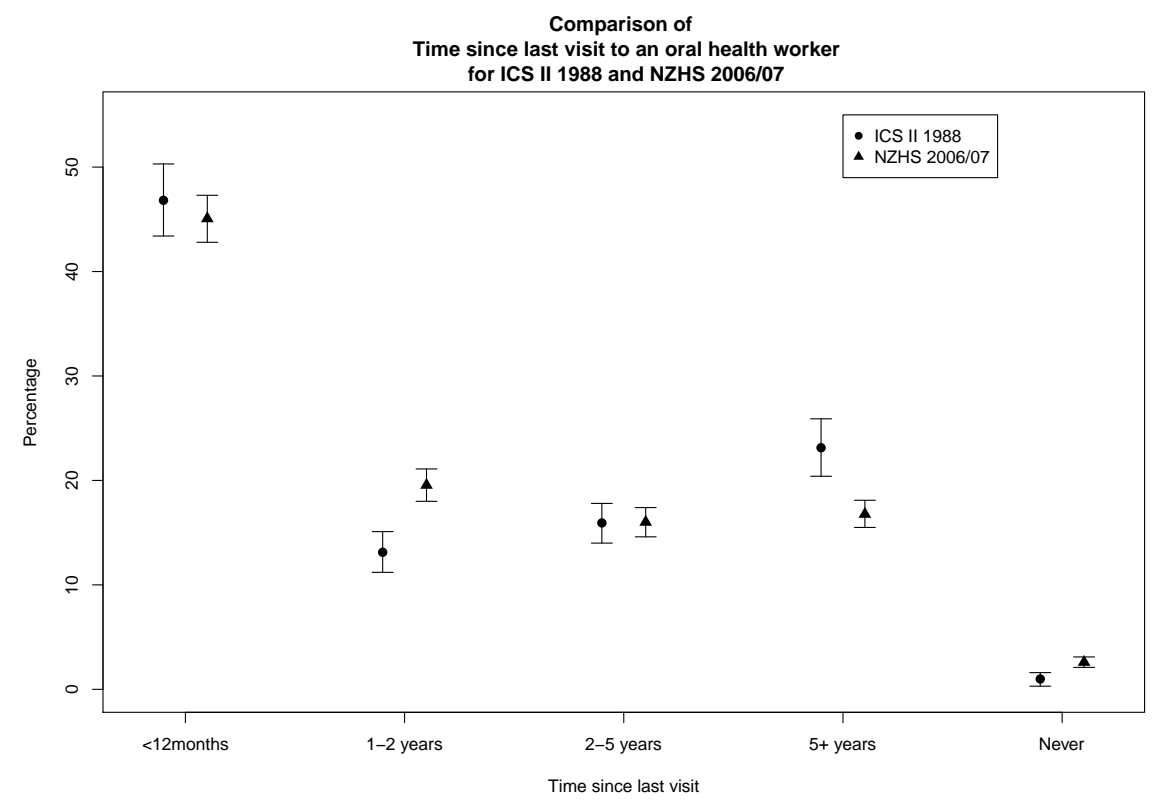

Figure 7.3: Comparison of time since last visit to an oral health worker for adults aged 20-24, 35-44 and 65-74 ICS II 1988 and NZHS 2006/07 
is shown by a positive confidence interval and a significantly small p-value associated with the test for the difference in two means, for the independent surveys.

Rates of people who have not visitied an oral health care worker in the past 5 years, but still do visit one occasionally, have decreased over time. $23.23 \%$ of people in 1988 had waited over 5 years since they last saw in oral health worker, compared to $16.77 \%$ of people in $2006 / 07$ who had waited this long since last seeing an oral health care worker. This decrease those waiting longer over time is a positive effect as in 2006/07 more people had seen an oral health care worker in the past 1-2 years as opposed to waiting longer.

The estimates produced for those who have never seen an oral health care worker in 1988 are unreliable as the estimate had a large RSE value. This means that our comparison with the rates from 2006/07 are also unreliable due to this estimate. It appears that rates of people never seeing an oral health care worker have not significantly changed over time, however we are unable to draw solid conclusions on this due to the unreliable estimate.

Overall, people have a shorter time since last visit to an oral health care worker in 2006/07 than they did in 1988. 


\section{Chapter 8}

\section{Discussion}

In this chapter we review the findings from the analysis carried out on the NZHS 2006/07, through exploratory data analysis and through the use of the ordinal regression models. Limitations of the survey are detailed along with the main findings from the exploratory data analysis, the regression analysis and the comparison done over time using the ICS II data from 1988. Final conclusions are drawn and suggestions for future work are given.

\subsection{Methods}

\subsubsection{Survey Limitations}

The results in this study were based on survey data, which means that the results are subject to sampling errors. Because of cost, time and other limitations, not all people in the sampling frame were measured. This is the error created by conducting a sample survey as opposed to a census.

As stated before the target population was the usually resident civilian population of all ages living in permanent private dwellings in New Zealand. This target population excluded residents in New Zealand living in non-permanent private dwellings such as holiday accomodation and institutions, this included $30.6 \%$ of people aged 75 , who were not covered by this target population. We assume that those people who are not covered by the sample frame have the same rates of tooth loss and regularity of care based on their demographics, but are aware that some findings may be subject to unqualified biases, for example people living in aged care facilities may have easier acess to oral health workers than those living separately.

98.9\% of the 1.4 million permanent private dwellings in New Zealand were eligible for participation in the survey. Those excluded were excluded due to location (for example those not on one of New Zealand's 3 main islands) or being in meshblocks that were too small; however, the people residing in these excluded dwellings were accounted for in the final survey weights. We can only assume that those situated in these more remote comunitites have the same rates of tooth loss and regularity of care; however, due to access difficulties, the regularity of dental or specialist care may be lower due to this location barrier.

The final weighted response rate for the adult NZHS 2006/07 was $67.9 \%$, and was $71.2 \%$ for the child section of the survey. Up to 10 calls over a three month period were made to selected dwellings before a dwelling was labelled as a non-contact. Calls were made at different times of the week to try and capture all possible respondents and increase the survey response rate. Guidelines were established to minimise respondent burden and maximise response rates. These guidelines included the culture and language pairing of respondents 
Table 8.1: Item non response for oral health questions

\begin{tabular}{|ll|r|r|r|r|r|}
\hline Variable & Missing & $\begin{array}{r}\text { Don't } \\
\text { Know }\end{array}$ & Refused & $\begin{array}{r}\text { Total } \\
\text { Missing }\end{array}$ & $\begin{array}{r}\text { Percentage } \\
\text { of sample }\end{array}$ \\
\hline A2-44 & Number of teeth lost & 80 & & & 80 & 0.64 \\
A2-45 & Time since last visit & 1096 & 9 & 2 & 1107 & 8.86 \\
A2-46 & Unmet need in past 12 months & 1096 & 1 & 2 & 1099 & 8.80 \\
A2-49 & Regularity of care & 1096 & 3 & 2 & 1101 & 8.82 \\
\hline
\end{tabular}

and interviewers and using a proxy respondent when a respondent was unable to complete the survey due to health or disability.

Item non-response can cause biases in analysis results. It is assumed that item non-response for demographic and oral health variables were missing at random (MAR) and that no imputation was carried out for these missing items.

$11.12 \%$ (1389) of respondents did not know their household income and $2.06 \%$ (257) refused to answer this question. For this report these people were excluded from the regression model analysis.

There may also be inaccuracies in the oral health outcome responses due to recall difficulties and 'positivity bias' for questions asked about specific oral health behaviours and the sensitive nature of the questions asked in a health survey.

Recall difficulties arise when a question requires a respondent to recall and count a number of events, such as the child survey questions about the number of fizzy drinks and take away meals consumed in the past 7 days. 'This recall-and-count strategy is prone to omissions due to forgetting and false reports due to telescoping' (Groves et al. 2004). As the number of events to report increases, the accuracy of those reports decreases as it becomes more difficult to accurately recall each specific event. This may go some way to explaining the peaks at 7 fizzy drinks per week found for all sub-populations in the child survey.

One of the 'most error prone strategies for behavioural frequency questions are those based on impressions' (Groves et al. 2004). The response categories offered can affect impressionbased estimates. This combined with the 'positivity bias' can lead to inaccurate estimates. For example most people know that they and their children should be brushing their teeth twice a day, and may select this answer when asked about their brushing habits, even if it is incorrect so that they appear to themselves and the interviewer to be doing the correct positive thing. People also tend to avoid the negative end of the scale when selecting answersto questions, for example brushing their teeth 0 times the previous day as 'respondents also tend to avoid the most extreme answer categories' (Groves et al. 2004).

Sampling errors were accounted for by calculating 95\% confidence intervals for estimates presented in this study. These confidence intervals show the range of values in which the true population value lies.

For this survey, weighting was used to 'reflect the probabilities of selection of each respondent' and 'make use to external population benchmarks to correct for any discrepancies between the sample and the population benchmarks, this improves the precision of estimates and reduces bias due to non-response' (Ministry of Health 2008). This was done using population counts based on age, sex, ethnicity and DHB, from the 2006 New Zealand Census. The weights were 'chosen to minimise a measure of distance between the weights and the inverse selection 
probabilities' whilst still having low bias and improved precision of estimates, which also provides consistency between survey estimates and creates external benchmarks for analysis.

\subsubsection{Statistical Analysis}

The statistical analysis of the NZHS 2006/07 included descriptive results for the sample and New Zealand population and oral health outcomes, along with the corresponding $95 \%$ confidence intervals. The jackknife method was used for variance estimation, which was needed for the calculation of the confidence intervals.

For the adult survey estimates were reported separately for different sub-populations based on age, sex, ethnicity and deprivation quintile. Because of a low level of item non-response and adequate reporting categories, all cell counts and RSEs were of an acceptable level, leading to relatively reliable estimates.

The child survey had a much smaller sample size and, in many cases, this led to small cell counts for various sub-populations and high RSE values. These high RSE values meant that the estimates for certain factors were unreliable because of these small cell counts. Unreliable estimates were marked with $\dagger$ or $\dagger \dagger$ depending on the severity of the RSE value. These estimates are to be treated with caution when interpreting results. In some cases a cell count of zero was found and estimates are unable to be obtained for these categories.

Formal comparisons between population mean and rates were carried out through the use of estimates and confidence intervals, with an overlap in confidence intervals suggesting no significant difference in values between two sub populations. However testing like this does not take into account other factors that may be influencing outcomes. For example the correlation between ethnicity and deprivation is not accounted for when only sub populations for one variable (either deprivation or ethnicity) are compared as done in the exploratory data analysis in Chapter 6.

\subsection{Main findings}

\subsubsection{Adults}

Tooth loss and regularity of care were the two main oral health outcomes of interest from the adult NZHS 2006/07.

Section 5.1.1 detailed tooth loss from the NZHS 2006/07. Tooth loss was defined to be the number of teeth a person has lost due to tooth decay or gum disease and did not include tooth loss due to orthodontics or injury. As rates of tooth decay were not explicitly recorded this is the best variable from the NZHS 2006/07 to help gauge the status of oral health in New Zealand.

The mean tooth loss due to tooth decay and gum disease was calculated in groups for the standard demographics of age, sex, ethnicity and deprivation. The average number of teeth a New Zealand adult has removed due to tooth decay or gum disease is 4.6, with $51.3 \%$ of the population having had no teeth removed. Age was found to be strongly associated with tooth loss with older people having lost more teeth due to tooth decay and gum disease. Deprivation was also positively associated with tooth loss; as deprivation increased so did the mean number of teeth lost. Tooth loss was greatest for Māori and European/Other ethnic groups, with Asian people having had the least amount of teeth removed due to tooth decay 
or gum disease as shown in Figure 5.3.

Inequalities in rates of dental caries and tooth loss based on ethnicity and socio-economic status are reviewed in Chapter 1. Our findings here in which deprivation and ethnicity are strongly associated with tooth loss are consistant with previous findings outlined in the literature review.

The number of teeth lost due to tooth decay or gum disease was associated with whether a person had diabetes or not. Those with diabetes had lost almost 3 times as many teeth as those how did not have diabetes. Those with high blood pressure and high levels of cholesterol also had significantly higher rates of tooth loss due to tooth decay or gum disease.

Tooth loss was not associated with being a current smoker. Those who had never smoked a cigarette in their life had lower rates of tooth loss due to tooth decay and gum disease than those who had smoked at least once.

Fruit and vegetable intake was not associated with tooth loss and is consistent with a lack of association between these variables and oral health outcomes, as specified in the literature review in Chapter 1. Alcohol intake was also not found to be associated with rates of tooth loss.

Regularity of oral health care was recorded at four levels, check ups at least every 2 years, check ups more than 2 years apart, only when oral health care is needed and never. $50.2 \%$ of people had check-ups with oral health care workers, while $40.3 \%$ saw an oral health care worker only when needed. Females tended to see oral health care workers more regularly than males. 25-34 year olds saw oral health care workers the least often, with those aged 55-64 having the most regular check ups. Ethnicity was strongly associated with regularity of care, with European/Others seeing oral health care workers for check ups more often than Māori, Pacific and Asian people. Pacific people had the highest proportions of people who had never seen an oral health care worker. Regularity of oral health care was displayed in Table 5.2 for different sub-populations.

As well as general regularity of oral health care, questions were asked about the time since a respondent's last visit to an oral health care worker. $51.0 \%$ of the New Zealand population had seen an oral health care worker in the past 12 months. This includes dentists and oral hygienists. European/Others were most likely to have seen an oral health care worker in the past 12 months, while Asian, Māori and Pacific people all had similar patterns of previous oral health care visitations as shown in Figure 5.7.

Unmet need is described as a time when a person needed to see an oral health care worker but was not able to for any reason. $10.0 \%$ of New Zealanders had experienced unmet oral health care needs in the previous 12 months. Māori people had the most unmet oral health care needs, while Asians had the least. Unmet need was positively correlated with deprivation. As deprivation increased so did the rates of unmet need. Age was negatively associated with rates of unmet need, with older people having much less unmet need than their younger counterparts.

$44.8 \%$ of people reported that their unmet need in the previous 12 months had been of an urgent nature, with Pacific people having the highest percentage of unmet need being classed as urgent as seen in Table 5.6.

The main reason specified for unmet oral health care needs was cost, with $52.9 \%$ of people citing this as one of the reasons for their previous unmet need. $33.4 \%$ of people had issues with time, such as no spare time or couldn't get an appointment at a suitable time, preventing them from having their oral health care needs met. $10.5 \%$ of people cited fear or anxiety 
of dental treatment as a reason for their unmet need.

\subsubsection{Children}

The child section of the NZHS 2006/07 had more oral health outcome questions to analyse than the adult section. Whether a child had had any teeth filled, had lost any teeth due to tooth decay, abscess or infection or whether they suffer from tooth or mouth pain that keeps them awake at night were all asked. However quantitative data for the number of teeth filled or removed were not available.

Almost half (45.5\%) of New Zealand children had at least one filling. Whether a child had had any teeth filled was associated with ethnicity, with Māori children having the highest amount of children with filled teeth, and Asians having the lowest. As age increased so did the percentage of children who had had at least one tooth filled.

The number of times a child brushes their teeth was significantly associated with whether a child had had a tooth filled or not. As the number of times a child brushes their teeth increases, the percentage of children with tooth fillings decreased as shown on page 72 .

Children who did not drink fizzy drinks had the lowest rates of children with tooth fillings. However the number of fizzy drinks drunk did not have a significant association with rates of tooth fillings amongst children. The number of takeaway meals eaten each week was significantly associated with the rates of children with fillings. As the number of take away meals eaten a week increases, the percentage of children with filled teeth increases.

Child tooth pain was recorded when tooth pain kept a child awake at night. Almost 1 in 5 children have experienced tooth pain that kept them awake at night. 0-4 year olds had the highest rates of tooth pain. Asian children had significantly lower rates of reported tooth pain.

Tooth pain keeping children awake at night was negatively associated with tooth brushing, with those who brush their teeth the least having higher rates of tooth pain. The number of fizzy drinks drunk each week was not significantly associated with rates of tooth pain experienced by children. Children who ate 6 or more take away meals each week had the highest number of children reporting tooth pain, keeping them awake at night.

$10.5 \%$ of children have had at least one tooth removed due to tooth decay, abscess or infection. Rates of tooth removal were significantly lower for children aged 0-4, compared to children in the 5-9 and 10-14 age brackets. Deprivation was positively associated with tooth removal, with tooth removal increasing as deprivation increases.

Tooth removal was negatively associated with tooth brushing, with lower rates of tooth brushing leading to more children having had teeth removed. The number of take away meals eaten each week was associated with tooth removal, with those who eat 6 or more take away meals a week having a higher percentage of children having had teeth removed.

Children had lower rates of unmet oral health care needs than adults, with only $3.2 \%$ of children having had unmet need in the previous year. There was no significant associations found between child unmet need and sex, age, ethnicity or deprivation.

Children were more likely to have seen an oral health care worker in the previous 12 months than adults, with over $75 \%$ of children doing so, which in some part is due to the School Dental Service in New Zealand. Young children aged 0-4 had the highest rates of children who had never visited an oral health care worker. AS with the adult results, Pacific children 
had the highest rates of children never visiting an oral health care worker.

\subsubsection{Regression}

Regression analysis can be used to estimate the significance of an explanatory variable, while controlling for all other factors. With the use of regression analysis we can distinguish the differences between risk factors and confounding factors.

Ordinal regression analysis was carried out for regularity of care with an oral health care worker and for the number of teeth a person has lost due to tooth decay or gum disease in adults. Explanatory variables were selected for the regression models by analysis of the literature in Chapter 1, to see what risk factors had previously been identified as significant factors for oral health outcomes in previous studies.

As the regression was performed on a sample that came from a complex design, the method selected to assess the goodness of fit for the explanatory variables was the Wald test. Because weights were used in the regression analysis we are unable to use techniques such as the deviance to check the overall fit of the model and instead we assessed residuals to determine the selected model adequacy.

Regularity of oral health care was modeled with and without other oral health outcomes included in the model using the cumulative logit model for ordinal regression analysis. It was found that the model that included these extra oral health outcomes was a better fit for the data, than the model with out them. Toothloss was sinificantly associated with regularity of care and may have some unmeasured factors that are significantly associated with regularity of care, meaning that having tooth loss in the model created a better fit.

The cumulative logit model was a poor model for tooth loss, as tooth loss is significantly associated with age and the model did not take into account the underlying interaction between tooth loss and age that causes tooth loss to have a non-uniform profile based on age. The residual plots for these cumulative logit models showed an underlying age trend amoung the residuals and this systematic pattern of the residuals suggested that the model was a poor fit for the data.

We chose to continue this analysis using the binary logistic model, with tooth loss recoded to only have two possible outcomes, no tooth loss and at least one tooth lost due to tooth decay and gum disease. Residual plots showed that the chosen logistic model was a much better fit.

Although many terms in the model are significant individually in the regression model, interaction terms need to be taken into account when interpreting the model.

\subsubsection{Comparison of NZHS 2006/07 with ICS II 1988}

2006/07 was the first time that the Ministry of Health has included questions on oral health in its National Health Survey. This survey extends beyond the previous 1988 survey on oral health in a number of ways as associations between oral health and general health variables can be made, as well as associations between oral health outcomes and a much larger set of demographic variables that are collected in the NZHS.

Comparisons over time were made for the specific oral health outcomes that were present in the ICS II 1988 WHO study, which only included survey participants from four select age brackets. It was found that rates of tooth brushing for children aged 12-13 have positively 
increased over time, with more children brushing their teeth the recommended two or more times a day in 2006/07 than in 1988 as presented on page 124 .

Adults' time since last visit to an oral health care has in general decreased over the period from 1988 to 2006/07, with more people visiting an oral health care worker in the previous 1-2 years in 2006/07 than in 1988. Fewer people in 2006/07 have not been to an oral health care worker in the past 5 years than in 1988 .

\subsubsection{Conclusions and future work}

The work carried out in this thesis is useful as a description of oral health and oral health behaviours in 2006/07. We have established a picture of oral health in New Zealand and provided estimates for the oral health outcomes collected in the NZHS 2006/07. We established and identified associations between behavioural and demographic variables with oral health outcomes. We investigated the key predictors of oral health status with tooth loss due to tooth decay and regularity of oral health care through the use of ordinal and logistic regression. Comparisons made on specific oral health outcomes, using ICS II data from 1988 and the NZHS 2006/07 data are useful for further work done on oral health time related comparisons

An overall picture of poor oral health behaviours (tooth brushing), outcomes (tooth loss) and care (oral health care visits) emerges for those with access to fewer material rescources, such as those in the most deprived socio-economic deciles and in the Māori and Pacific ethnic groups. Age was a significant factor in oral health, with adult tooth loss, number of childhood fillings and tooth removal, all being associated with age, and suggests oral health decreases as age increases.

Future work based on this research could involve comparisons with the New Zealand Oral Health Survey (NZOHS) which was carried out in 2009 by the Ministry of Health, Defence Dental of the New Zealand Armed Forces and the New Zealand Dental Association. As mentioned in Chapter 1, the NZOHS was an extension of the NZHS 2006/07 in which nearly 5000 respondents completed an oral health survey and underwent a simple dental examination. Results on oral health from the NZOHS will create a much richer set of oral health outcomes than that gained from the NZHS 2006/07 and the technical report from this survey is due to be published at the end of 2010 .

Future comparisons could also be carried out with the use of oral health outcomes in future New Zealand Health Surveys. The NZHS 2006/07 was the first to have an expanded oral health care section and it is hoped that future NZHS will also have this expanded section on oral health so that comparisons can be made with future NZHS.

Expansions of the oral health section could be made to provide a more extensive set of oral health outcomes. Questions about oral health behaviour, such as frequency of tooth brushing of flossing could be expanded into the Adult section of the New Zealand Health Survey, as well as questions about tooth and mouth pain. Questions could also be asked about the number and quality of false teeth and/or crowns in adults' mouths, to help give a clearer overview of the status of respondents' teeth and their oral health care needs based on this status. Questions on regularity of care could also be expanded to ask questions about why the respondent only visits an oral health care worker as regularly as they do.

Questions of fillings and tooth removal in the child section could be altered to be of a quantitative nature, as opposed to a dichotomous yes or no answer, so that a clearer picture of child oral health could be gained and comparisons could be made between the data collected 
by the Ministry of Health for children aged 5 and in Year 8 from the School Dental Service. 


\section{Bibliography}

Agresti, A. (2007), An Introduction to Categorical Data Analysis, Wiley series in Probability and Statistics, second edn, John Wiley \& Sons, Inc.

Albandar, J. (2002), 'Global risk factors and risk indicators for periodontal diseases', Periodontology 2000 pp. 177-206.

Allukian, M. (2002), 'Oral Health'.

URL: http://www.enotes.com/public-health-encyclopedia/oral-health

Bloom, B., Gift, H. \& Jack, S. (1992), 'Dental Services and Oral Health, united States, 1989', Vital and Health Statistics (183).

Blum, H. (1973), Planning for Health, Development and Application of Social Change Theory, Human Science Press.

Brennan, D., Singh, K., Liu, P. \& Spencer, A. (2010), 'Fruit and vegetable consumption among older adults by tooth loss and socio-economic status', Australian Dental Journal (55), 143-149.

Chen, M. \& Hunter, P. (1996), 'Oral Health and Quality of Life in New Zealand: A Social Perspective', Social Science \&3 Medicine 43, 1213-1222.

Colgate (2001), 'Your Child's Mouth'.

URL: http://www.colgate.com/app/Colgate/US/OC/HomePage.cvsp

Colgate (2002), 'Your Infant's Mouth'.

URL: http://www.colgate.com/app/Colgate/US/OC/HomePage.cvsp

Colgate (2006), 'Press Release'.

URL: $h t t p: / / w w w . s c o o p . c o . n z /$ stories/GE0608/S00010.htm

Crocombe, L., Stewart, J., Barnard, P., Slade, G., Roberts-Thomson, K. \& Spencer, A. (2010), 'Relative oral health outcome trends between people inside and outside capital city areas of Australia', Australian Dental Journal (55), 280-284.

Dobson, A. (2002), An Introduction to Generalized Linear Models, Texts in Statistical Science, second edn.

Fawell, J., Bailey, K., Chilton, J., Dahi, E., Fewtrell, L. \& Magara, Y. (2006), Fluoride in Drinking-water, IWA Publishing, London, UK.

Gilbert, G., Duncan, R. \& Shelton, B. (2003), 'Social Determinants of Tooth Loss', Health Services Research (38:6 Part II).

Government Statistical Service (1999), Adult Dental Health Survey: Oral Health in the United Kingdom 1998.

Green, L. \& Mercer, S. (2002), 'Predisposing Factors'.

URL: http://www.enotes.com/public-health-encyclopedia/predisposing-factors 
Groves, R., Fowler, F., Couper, M., Lepkowski, J., Singer, E. \& Tourangeau, R. (2004), Survey Methodology, Wiley Series in Survey Methodology, John Wiley \& Sons, Inc., Hoboken, New Jersey.

Hunter, P., Kirk, R. \& de Liefde, B. (1992), The study of Oral Health Outcomes: The 1988 New Zealand section of the WHO Second International Collaborative Study, Department of Health, Wellington.

Marshall, G. (1998), 'Kish grid'.

URL: http://www.encyclopedia.com

Ministry of Health (2006), Good Oral Health for all, for life: The strategic vision for Oral Health in New Zealand, Ministry of Health, Wellington.

Ministry of Health (2008), Methodology Report for the 2006/07 New Zealand Health Survey, Wellington.

Moynihan, P. (2005), 'The role of diet and nutrition in the etiology and prevention of oral diseases', Bulletin of the World Health Organization 83(9), 694-699.

National Advisory Committee on Health and Disability (2003), Improving Child Oral Health and Reducing Child Oral Health Inequalities: Report to the Minister of Health from the Public Health Advisory Committee, National Health Committee, Wellington.

Petersen, P. (2003a), The World Oral Health Report 2003. Continuous improvement of oral health in the 21st century - the approach of the WHO Global Oral Health Programme.

Petersen, P. (2003b), 'Tobacco and Oral Health - the Role of the World Health Organization', Oral Health $\&$ Preventative Dentistry 1(4), 309-315.

Phipps, K. \& Stevens, V. (1995), 'Relative Contribution of Caries and Periodontal Disease in Adult Tooth Loss for an HMO Dental Population', Journal of Public Health Dentistry (55), 250-252.

Puder, E. (1970), 'The New Zealand Dental Nurse', American Journal of Public Health pp. 1259-1263.

Reibel, J. (2005), 'Tobacco or oral health', Bulletin of the World Health Organization 83(9), 643-644.

Roberts-Thomson, K. \& Do, L. (2007), Oral health status, Australian Institute of Health and Welfare, Canberra, pp. 81-142.

Salmond, C., Crampton, P. \& Atkinson, J. (2007), NZDep2006 Index of Deprivation User's Manual, Wellington.

Slade, G., Spencer, A. \& Roberts-Thomson, K. (2007), Australia's Dental Generations: The National Suvey of Adult Oral Health 2004-06, Technical Report 34, Australian Institute of Health and Welfare.

Statistics New Zealand (2002), '2001 Census: Ethnic Groups - Refernce Report'.

URL: http://www.stats.govt.nz/census/2001-census-data/2001-census-ethnic-groups.aspx

Stokes, M., Davis, C. \& Koch, G. (2000), Categaorical Data Analysis Using The SAS System, second edn, SAS Institute and John Wiley \& Sons.

The Cleveland Clinic Foundation (1995), 'Teeth Eruption Timetable'.

URL: http://my.clevelandclinic.org

The National Institute of Dental and Craniofacial Research (NIDCR) (2007), Oral Health in America: A Report of the Surgeon General, Department of Health and Human Services.

URL: http://www.nidcr.nih.gov/DataStatistics/SurgeonGeneral/sgr 
Thomson, W., Ayers, K. \& Broughton, J. (2003), Child Oral Health Inequalities in New Zealand: A Background Paper to the Public Health Advisory Committee, National Health Committee. 


\title{
Appendix A
}

\section{Definitions}

\begin{abstract}
Abscess - An abscess is a limited area of pus formed as a result of a bacterial infection. The body's immune system reacts to the infection, and sends white blood cells to the area to try to get rid of the bacteria. Pus is a mixture of live and dead white blood cells, enzymes and parts of destroyed cells and tissues. When there is no way for pus to drain, it forms an abscess.
\end{abstract}

Canines - sometimes called cuspids, these teeth are shaped like points (cusps) and are used for tearing food.

Crown - the top part of the tooth, and the only part you can normally see. The shape of the crown determines the tooth's function. For example, front teeth are sharp and chisel-shaped for cutting, while molars have flat surfaces for grinding.

Dental Decay/Caries - Dental decay is a process in which the hard mineral structure of teeth is dissolved by acids produced by bacteria. The process produces a cavity on the crown of the tooth or a softening of the root surface.

Dentate - People who have more than 1 natural tooth left.

Dentine - the layer of the tooth under the enamel. If decay is able to progress its way through the enamel, it next attacks the dentine where millions of tiny tubes lead directly to the dental pulp.

Dentition - The set of teeth. A complete dentition comprises 32 adult teeth.

Enamel - Hard white mineralised tissue covering the crown of the tooth. This is the outermost layer of the tooth. Enamel is the hardest, most mineralized tissue in the body, yet it can be damaged by decay if teeth are not cared for properly.

Fluoride - A naturally occurring mineral that helps reduce tooth decay.

Fluorosis - Discolouration or pitting of enamel caused by excessive amounts of fluoride.

Gum disease - Gingivitis or periodontitis.

Gumline - where the tooth and the gums meet. Without proper brushing and flossing, plaque and tartar can build up at the gumline, leading to gingivitis and gum disease.

Gingivitis - Inflammation of the gums. 


\section{Tooth Development: Permanent Teeth}

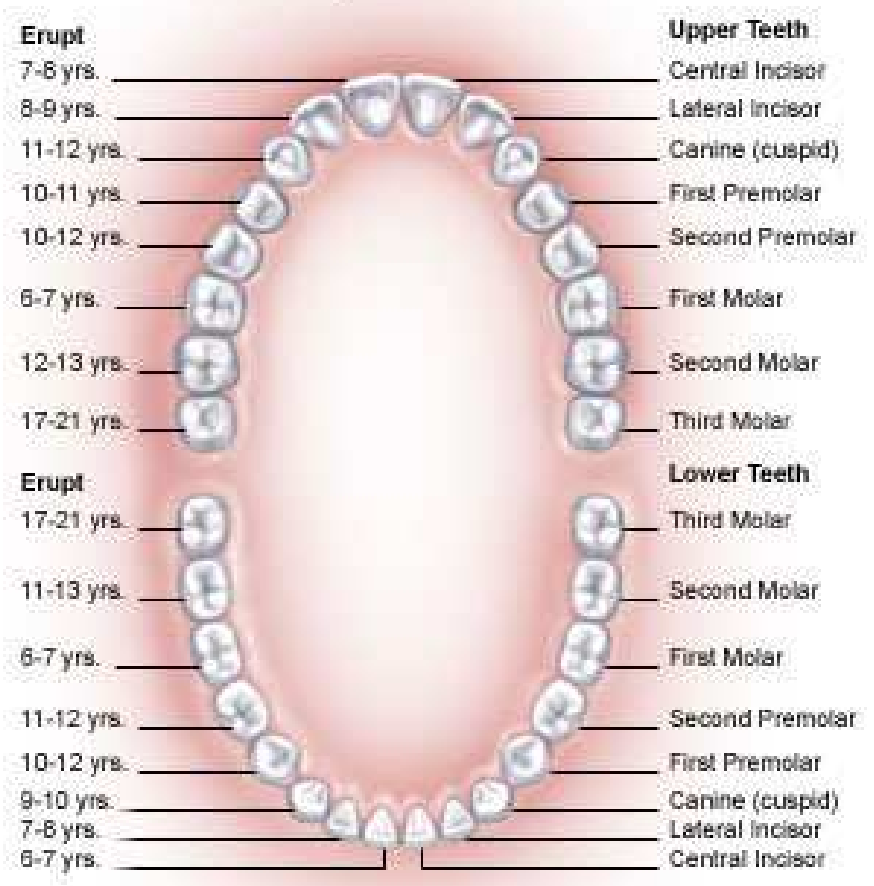

Figure A.1: Adult teeth. source: http://www.colgate.com

Inadequate natural dentition - Fewer than 21 teeth.

Incisors - the sharp, chisel-shaped front teeth (four upper, four lower) used for cutting food.

Molars - used for grinding, these teeth have several cusps on the biting surface

Periodontitis - inflammation or infection of the gums and the surrounding bone.

Premolars - these teeth have two pointed cusps on their biting surface and are sometimes referred to as bicuspids. The premolars are for crushing and tearing.

Pulp - the soft tissue found in the center of all teeth, where the nerve tissue and blood vessels are. If tooth decay reaches the pulp, you usually feel pain.

Root - the part of the tooth that is embedded in bone. The root makes up about two-thirds of the tooth and holds the tooth in place. 


\title{
Appendix B
}

\section{Derived Variables}

\begin{abstract}
Age
Respondents were asked what year they were born in and from this their age was derived based on the year of the interview. Age was grouped into the following ten year age groups: 15-24, 25-34, 35-44, 45-54, 55-64, 65-74, 75+ for the adult survey and five year age bands of 0-4, 5-9 and 10-14 for the child survey.
\end{abstract}

\section{Ethnicity}

Ethnicity in the New Zealand Health Survey is a self-determined affiliation. The ethnicity reported in this research refers to the respondents prioritised ethnicity. Participants were able to select more than one Ethnicity to be classed as. Four groups were selected as outputs for the Prioritised Ethnicity category - with participants firstly identifing as Māori, then as Pacific, thirdly as Asian, and any one not already identified in an ethnicity category was prioritised as the final option of European/Other.

\section{Deprivation Quintile}

The New Zealand Health Survey 06/07 used the 2006 New Zealand Index of Deprivation (NZDep2006) to measure socioeconomic status. NZDep2006 is an area based index that measures the level of socioeconomic deprivation for each meshblock. The variables used to determine a NZDep2006 score are income, benefit status, transport access, household size, home ownership, employment status, qualifications, support and telephone access. Each meshblock in New Zealand is then assigned a deprivation score which is broken into deciles, where 1 represents those least deprived and 10 the areas with the most deprived. For some parts of this report the deciles have been grouped into pairs and are displayed as quintiles 1-5, with 1 (NZDep deciles 1 and 2) being the least deprived and 5 (NZDep deciles 9 and 10) being the most deprived (Salmond et al. 2007).

\section{Education}

Highest Qualification was created from two survey questions to record a respondent's highest qualification.

The respondent was recorded as having a highest qualification of degree if they had a qualification which included:

- Bachelor's degree, with or without honours 
- Masters degree

- $\mathrm{PhD}$

- Post Graduate diploma

Their highest qualification was recorded as Vocational or Professional qualfication if their highest qualification was from the following:

- Diploma (not post graduate)

- Trade or technical certificate that took more than 3 months full time study

- Professional qualifications like CA, teachers, nurses

The respondents highest qualification was a school qualification if their highest qualification was:

- a New Zealand school qualification such as NZ School Certificate, NCEA levels 1-3, Bursary, Higher School Certificate, Sixth form Certificate

- Overseas secondary school qualification

The highest qualification was recorded as 'None' if the respondent had none of the above qualifications.

\section{Household Income}

Household income was simplified into 4 brackets for this analysis.

1. was based on a household income of less than or equal to $\$ 20,000$ a year

2. was based on a household income of $\$ 20,001$ to $\$ 50,000$ a year

3. was based on a household income of $\$ 50,001$ to $\$ 100,000$ a year

4. those who had a household income of more than or equal to $\$ 100,001$ a year

\section{Health Insurance}

This variable indicated whether a person was covered by a health or medical insurance scheme.

\section{Smoking}

A current smoker was defined to have smoked more than 100 cigarettes in a life time and currently smokes at least once a month. 